\title{
Technical and Non-Technical Issues towards the Commercialisation of Wave Energy Converters
}





\section{Technical and Non-Technical Issues towards the Commercialisation of Wave Energy Converters}

Revised Version

PhD Thesis Defended in public at Aalborg University March 15, 2013

Julia Fernández Chozas

Department of Civil Engineering, The Faculty of Engineering and Science, Aalborg University, Aalborg, Denmark

River Publishers

Aalborg 
ISBN 978-87-93102-53-8 (e-book)

Published, sold and distributed by:

River Publishers

Niels Jernes Vej 10

9220 Aalborg Ø

Denmark

Tel.: +45369953197

www.riverpublishers.com

Copyright for this work belongs to the author, River Publishers have the sole right to distribute this work commercially.

All rights reserved (c) 2013 Julia Fernández Chozas.

No part of this work may be reproduced, stored in a retrieval system, or transmitted in any form or by any means, electronic, mechanical, photocopying, microfilming, recording or otherwise, without prior written permission from the Publisher. 


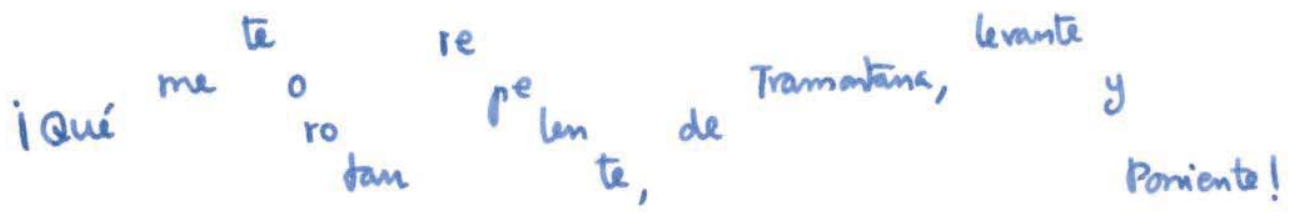

Cachivactres de la abuela, historias y hazañas de Pío, Conde Duque, las bateas; inupiración y wijo.

Sueños de norias de agua, fantanias de mononín, ¡un fenómeno literata!

pluma, cunderno y atîl.

Hijóteris fileróficas

escrutar la realidad

al son de notras banoces

- viajar ,o no viajar-

Cometas y predicción,

CTO y excelente ingeniero, optimista, $y$ a veves zol,

zalta ks refes in miedo.

olar de Santoña y mutrico, Sugres, Azenhes do mas, Buraco do Inferno, Dico, ondiñas que verren e vans.

Copenhague,

Primavera 2013. 

"Se queres aprender a rezar, entra no mar" ("If you want to learn how to pray, go to sea") Portuguese proverb

“La mobilité et l'inégalité successive des vagues, après s’être élevées comme des montagnes, s'affaissent l'instant après, entraînant dans leurs mouvements tous les corps qui surnagent, quels que soient leur poids et leur volume. La masse énorme d'un vaisseau de ligne, qu'aucune puissance connue ne serait capable de soulever, obéit cependant au moindre mouvement de l'onde"

("The motion and successive inequality of waves, which after having been elevated like mountains fall away in the following instant, take into their motion all bodies which float on them, regardless their weight or volume. The imposing mass of a vessel, which no other known force is capable of lifting, responds to the slightest wave motions")

Girard father and son, Paris, 1799

"Glendenning ... said that much of it would be inaccessible for economic exploitation, as the line extended well north of the Hebrides and transmission became difficult, if not impossible. But that was said in 1977. No one would say it today (1992), when the oil industry has shown that inaccessible areas suddenly become reachable when there is energy to be won"

David Ross, Energy from Ocean Waves, 1992 



\section{Table of Contents}

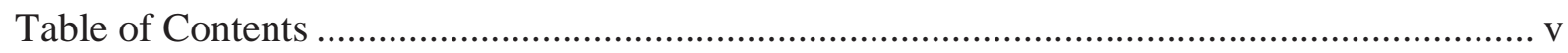

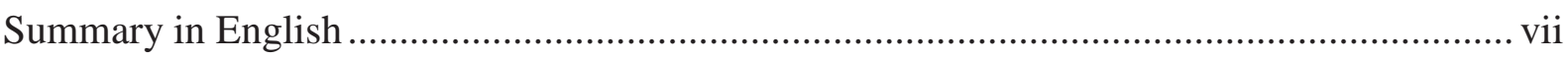

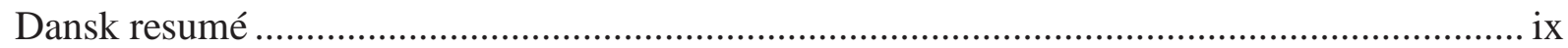

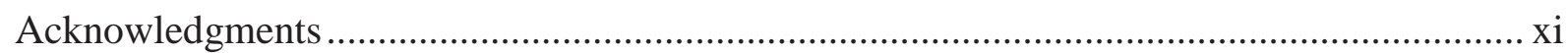

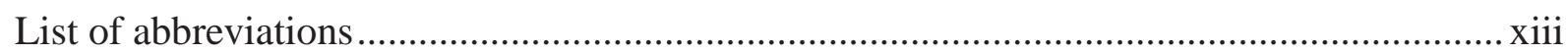

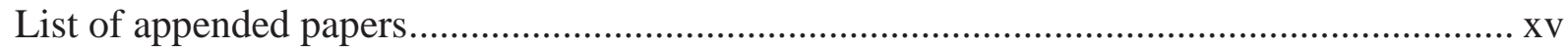

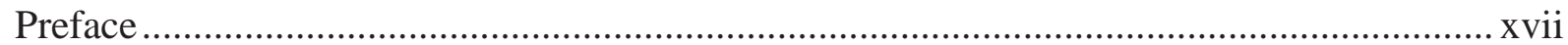

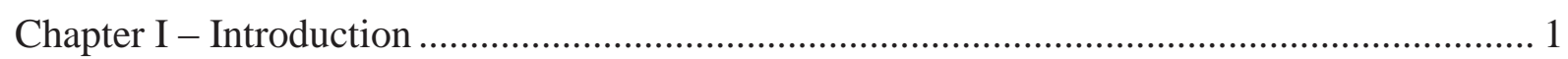

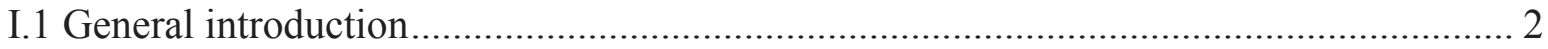

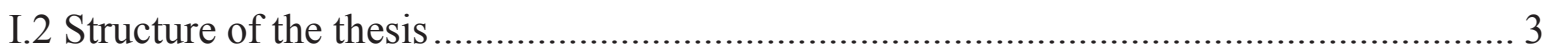

Chapter II - History and prospects of wave energy …............................................................ 5

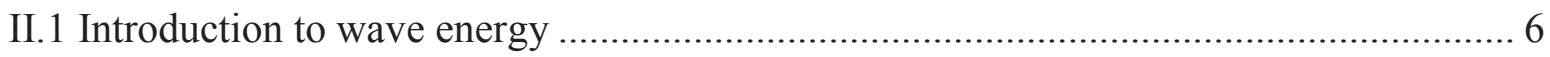

II.2 Advantages and disadvantages of wave energy ................................................... 7

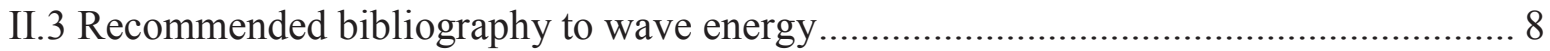

II.3.1 European projects relevant to the thesis …......................................................... 9

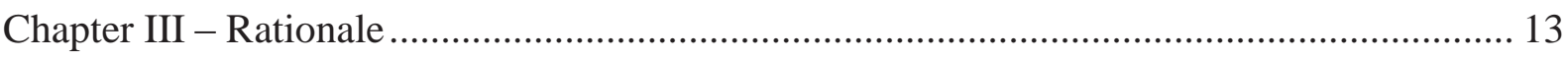

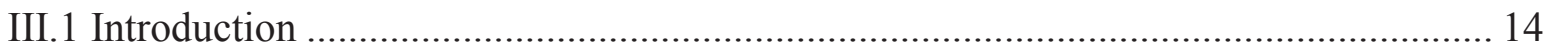

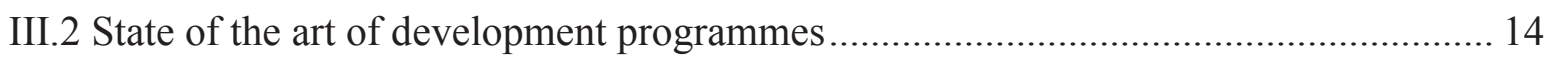

III.2.1 Examples of development programmes ....................................................... 17

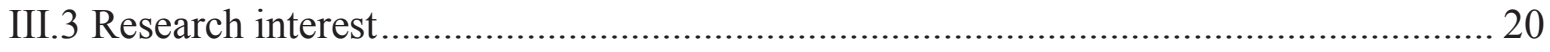

III.3.1 Overview of a proposed wave energy converter development ............................. 21

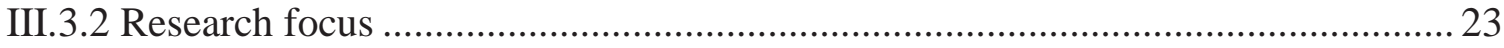

Chapter IV - Review of identified issues towards wave energy commercialisation ............... 27

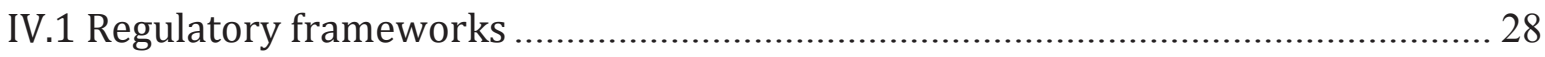

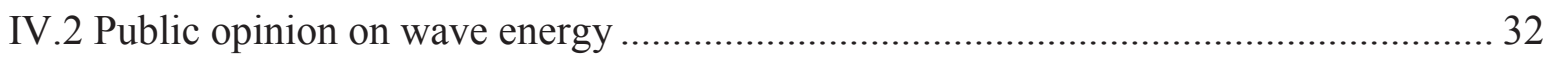

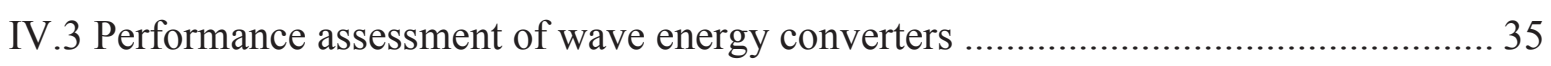

IV.4 Grid connection and integration of wave energy in European offshore grids............. 39

IV.5 Diversified renewable systems with wave and offshore wind production .................. 41

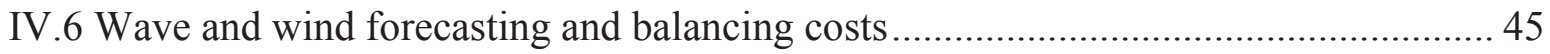

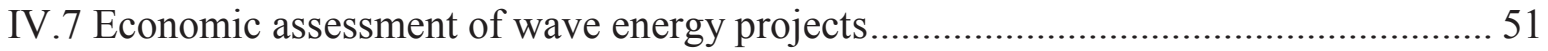




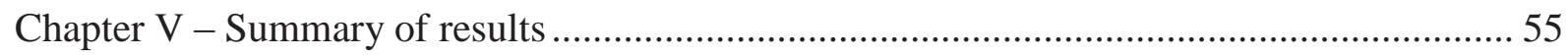

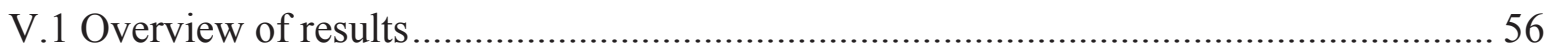

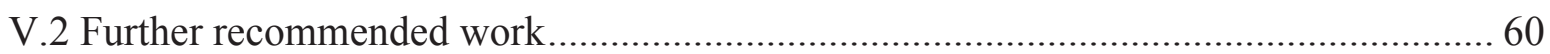

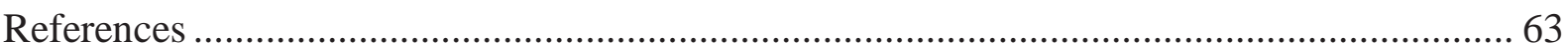

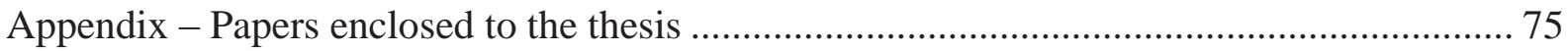

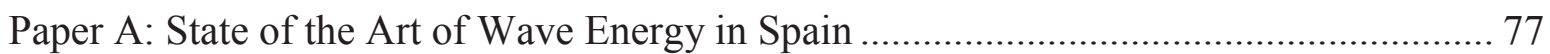

Paper B: Toward Best Practices for Public Acceptability in Wave Energy: Whom, How and

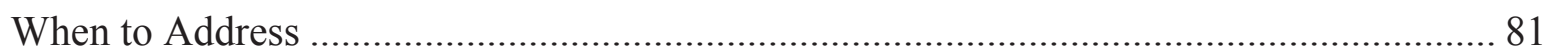

Paper C: Toward Best Practices for Public Acceptability in Wave Energy: Issues

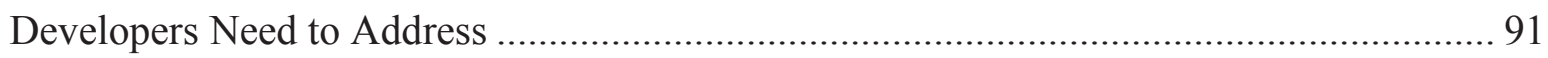

Paper D: Performance Assessment of the Wave Dragon Wave Energy Converter Based on

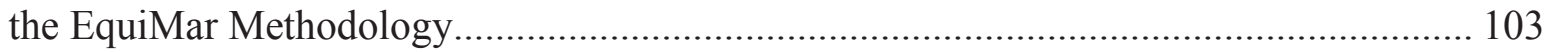

Paper E: Integration of Wave and Offshore Wind Energy in a European Offshore Grid .. 115

Paper F: Combined Production of a full-scale Wave Converter and a full-scale Wind

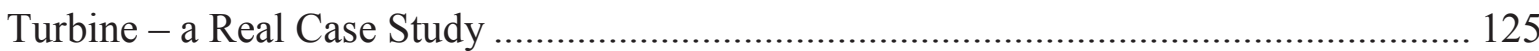

Paper G: Predictability of the Power Output of Three Wave Energy Technologies in the

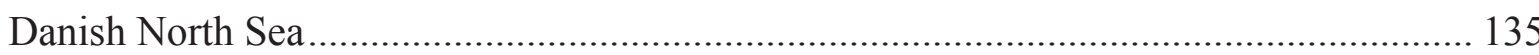

Paper H: Economic Benefit of Combining Wave and Wind Power Productions in DayAhead Electricity Markets 


\section{Summary in English}

The thesis "Technical and non-technical issues towards the commercialisation of wave energy converters" elaborates on the necessary steps and on the different difficulties that appear during the development of a wave energy converter (WEC). It focuses on seven key areas which appear when a WEC is going through sea trials. As examined throughout the thesis, all these subjects are of relevance to successfully reach the commercialisation of WECs and need attention from the sector as such, not least from device developers.

The thesis is presented in two parts: a main introduction and a collection of papers. The first part provides a brief history of wave energy, introduces the research topic, describes the different disciplines addressed in the thesis and relates them. The eight papers comprise the core part of the work. The papers address the research topic in different ways: from a legal, social, technical and economic viewpoint, and from various WEC development stages. All the analyses are carried out from the perspective of device developers.

The understanding of WEC developments has been central to the outline of the thesis, as it has formed the framework of the work. Therefore, the rationale behind the thesis has been firstly, to identify the primary phases that generally appear within the development of a WEC, until it becomes a commercial reality; secondly, within that development, to determine the issues or phases where there is a gap in research, and thirdly, to examine the identified key subjects. These seven areas are:

i. Regulatory frameworks for wave energy developments and how they affect project execution.

ii. The role of stakeholder's and of the public's opinion on project's implementation.

iii. Evaluation of the power performance of WECs in sea trials, accordingly to a recently-developed methodology.

iv. Opportunities to grid-connect offshore wave energy projects and the synergies in this area with offshore wind energy projects.

v. Benefits of including wave energy in diversified renewable energy systems, chiefly with respect to power output variability and availability.

vi. Predictability of waves, and assessment of the value of wave forecasting in electricity markets.

vii. Economic assessment of wave energy projects.

The scope of the thesis is broad and embraces subjects that can be categorised within technical and non-technical disciplines. This combination of findings leads to an overview of the wave energy field and of WEC developments.

Overall, the thesis underlines hindrances that can affect developments when WECs are commissioned and the benefits wave energy brings to energy systems, especially when wave and wind generation are combined. 



\section{Dansk resumé}

Denne $\mathrm{PhD}$ afhandling "Tekniske og ikke tekniske udfordringer på vejen mod kommercialisering af bølgeenergimaskiner" omhandler de nødvendige tiltag og vanskeligheder forbundet med den kommercielle udvikling af bølgeenergi. Den fokuserer på syv nøgleområder, der skal overvindes, når man vil gennemføre afprøvning af et prototype bølgeenergianlæg. Afhandlingen belyser de forhold, der er af betydning for en succesfuld kommercialisering af bølgeenergi, og som enhver udvikler inden for området skal have for øje.

Afhandlingen er opdelt i to dele, en introduktion til området samt en samling af otte artikler. Den første del giver en kort historisk gennemgang af bølgeenergiområdet og præsenterer forskningsområdet og sammenhængen mellem de enkelte områder, der behandles i afhandlingen. Afhandlingens anden halvdel - de otte artikler - udgør dens hoveddel. Artiklerne behandler de enkelte forskningsområder ud fra et lovgivningsmæssigt, socialt, teknisk og økonomisk udgangspunkt samt sætter problemstillingerne i perspektiv i forhold til de forskellige udviklingstrin en prototype må gennemgå. Alle undersøgelser tager primært udgangspunkt i udviklerens situation.

Forståelsen af hvilke udviklingstrin en prototype bør gennemgå fra konceptstadiet til en egentlig prototype danner skelettet i arbejdet. Afhandlingen starter derfor med at identificere de forskellige udviklingstrin; herefter belyses hvor der er huller i den eksisterende forskningsviden; slutteligt analyseres de udpegede syv nøgleområder:

i. Rammebetingelserne for etablering af bølgeenergi og deres betydning for etablering af en prototype.

ii. Interessenternes rollefordeling herunder det offentliges mening om bølgeenergi.

iii. Behovet for at opstille en troværdig power matrix for et bølgeenergianlæg samt metoder hertil.

iv. Mulighederne for nettilslutning af offshore bølgekraftanlæg samt synergien med offshore vind.

v. Fordelene ved bølgeenergi set i relation til et energimix af forskellige vedvarende energikilder specielt med fokus på fluktuerende energikilder og stabiliteten af elforsyningen.

vi. Belysning og dokumentation af en af de oftest citerede fordele ved bølgeenergi: dens forudsigelighed, og herunder også værdien på en elbørs af, hvordan bølgeenergi kan forudsiges timer før produktionen finder sted.

vii. Modeller for den økonomiske vurdering af et bølgeenergiprojekt.

Afhandlingen er bredt dækkende inden for bølgeenergiens mange faglige og ikke-faglige discipliner. Konklusionerne belyser de forhold, der kan blokere for udviklingen af bølgeenergi, men også de fordele, som sektoren kan bibringe el-systemer, specielt i forhold til kombinationen af offshore vind og bølgeenergi. 



\section{Acknowledgments}

I would like to gratefully acknowledge the invaluable help from the following people and research groups throughout these years of knowledge, experiences and learning.

To Spok ApS, especially to Hans and to Lise, for trusting me, for their warm welcome in Denmark, for their help and for their continuous support; my most sincere thank you to Hans for his commitment, his fruitful comments and advices, his mentorship and his diligent guide during these years.

To the Wave Energy Research Group at Aalborg University for providing the opportunity of teaching and sharing my enthusiasm for wave energy with a wide variety of students, for their approach of learning by experience and for having an open-used wave tank. I would like to personally thank Jens Peter for his wise observations, constructive discussions, guidance and support in the PhD; and John for his helpful corrections and precious time.

To the Wave Dragon team, particularly to Erik, for his moral of company openness and sincerity, for sharing his priceless knowledge, for his valuable remarks, for his guidance throughout the wave energy world, and for making the dark Danish winters a bit brighter and colourful.

My thankful acknowledge to Energinet.dk and PSO project 10791, and to Niels Ejner for his continuous support and collaboration.

To the Wavetrain2 family: Frank, Miguel, fellows, partners, teachers and course organisers for the project realisation, the lectures, the active participation, the enthusiasm, the discussions and the time shared in Pico, Orkney, Cork, Trondheim, Islay, Portaferry, Nantes, Gran Canaria, and many more exotic places. An especial thank to the European Commission (grant agreement 215414), whose funding has been essential for the project success.

To INORE and the INOREans, with whom I have gained a global and multidisciplinary understanding of wave energy, and to its sponsors. My special thanks to INORE Steering Committee 2011-2012 (Kate, Davide, Joao and Sam), for their enthusiasm, creativity and excellent group work, and for the overwhelming experiences, stress, uncertainties and the final great success shared.

To Wave Star, for their openness, trust and information exchange, to Dong Energy for the constructive discussions and to the Nordisk Folkecenter for Renewable Energy for their data sharing. To Sascha, Elena, Yago, Alina, the people I have been drowning with emails and the rest of people I have collaborated with, for their help and advices, and for keeping me updated with the development stage of projects. To Marco, for the exchange of opinions on the sector and for the learning through experience; and to Miguel, whose enthusiasm for new developments and his will to explain in common words 'Our energy problem' have inspired me. 
To my dear Danish family, the liveliest people I have ever met in spite of the weather, with who I have always felt at home.

Finally, to the whole wave energy community, for their tireless efforts in bringing wave energy forward.

"Audentes fortuna iuvat"

(Translation: fortune favors the bold) Verse 284, Book X, Aeneid, Virg 


\section{List of abbreviations}

\begin{tabular}{|c|c|}
\hline AWS & Archimedes Wave Swing \\
\hline EC & European Commission \\
\hline EIA & Environmental Impact Assessment \\
\hline EMEC & European Marine Energy Centre \\
\hline ENTSO-E & European Network on Transmission System Operators for Electricity \\
\hline EU-OEA & European Ocean Energy Association \\
\hline FIT & Feed-in Tariff \\
\hline FP & Framework Programme (of the EC) \\
\hline HMRC & Hydraulics and Maritime Research Centre \\
\hline HVAC & High Voltage Alternating Current \\
\hline HVDC & High Voltage Direct Current \\
\hline IEC & International Electrotechnical Commission \\
\hline LCC & Line Commutated Converter \\
\hline LCOE & Levelised Cost of Energy \\
\hline MAE & Mean Absolute Error \\
\hline MOWC & Mutriku Oscillating Water Column \\
\hline MSP & Maritime Spatial Planning \\
\hline NIMBY & Not In My Back Yard \\
\hline NMAE & Normalised Mean Absolute Error \\
\hline NREAP & National Renewable Energy Action Plan \\
\hline NUIM & National University of Maynooth \\
\hline O\&M & Operation and Maintenance \\
\hline OES & Ocean Energy Systems \\
\hline OPEX & Operational Expenditures \\
\hline OWC & Oscillating Water Column \\
\hline OWEC & Offshore Wave Energy Converter \\
\hline PTO & Power Take-Off \\
\hline R\&D & Research and Development \\
\hline RMSE & Root Mean Square of the Error \\
\hline SME & Small and Medium Enterprise \\
\hline SSG & Seawave Slot-cone Generator \\
\hline TPL & Technology Performance Level \\
\hline TRL & Technology Readiness Level \\
\hline TSO & Transmission System Operator \\
\hline UCTE & Union for the Co-ordination of Transmission of Electricity \\
\hline VSC & Voltage Source Converter \\
\hline WEC & Wave Energy Converter \\
\hline
\end{tabular}





\section{List of appended papers}

This thesis is presented as a collection of eight papers included in the Appendix:

Paper A: J. Fernández-Chozas and H. C. Soerensen, "State of the Art of Wave Energy in Spain", in Proceedings of IEEE 3rd Annual Electrical Power and Energy Conference (EPEC), Montreal, Canada, 2009.

Paper B: J. Fernández-Chozas, M. Stefanovich and H. C. Soerensen, "Toward Best Practices for Public Acceptability in Wave Energy: Whom, How and When to Address", in Proceedings of the $3^{\text {rd }}$ International Conference on Ocean Energy (ICOE), Bilbao, Spain, 2010.

Paper C: $\quad$ M. Stefanovich and J. Fernández-Chozas, "Toward Best Practices for Public Acceptability in Wave Energy: Issues Developers Need to Address", in Proceedings of the 3rd International Conference on Ocean Energy (ICOE), Bilbao, Spain, 2010.

Paper D: $\quad$ S. Parmeggiani, J. Fernández-Chozas, A. Pecher, E. Friis-Madsen, H. C. Soerensen and J. P. Kofoed, "Performance Assessment of the Wave Dragon Wave Energy Converter Based on the EquiMar Methodology", in Proceedings of the 9th European Wave and Tidal Energy Conference (EWTEC), Southampton, United Kingdom, 2011.

Paper E: J. Fernández-Chozas, H. C. Soerensen and M. Korpås, "Integration of Wave and Offshore Wind Energy in a European Offshore Grid", in Proceedings of the $20^{\text {th }}$ International Symposium of Offshore and Polar Engineering (ISOPE), Beijing, China, 2010.

Paper F: J. Fernández-Chozas, J. P. Kofoed, M. M. Kramer and H. C. Soerensen, "Combined Production of a full-scale Wave Converter and a full-scale Wind Turbine - a Real Case Study", in Proceedings of the 4th International Conference on Ocean Energy (ICOE), Dublin, Ireland, 2012.

Paper G: J. Fernández-Chozas, N. E. Helstrup Jensen, H. C. Soerensen, J. P. Kofoed and A. Kabuth, "Predictability of the Power Output of Three Wave Energy Technologies in the Danish North Sea", in Proceedings of the 9th European Wave and Tidal Energy Conference (EWTEC), Southampton, United Kingdom, 2011.

Paper H: J. Fernández-Chozas, N. E. Helstrup Jensen and H. C. Soerensen, "Economic Benefit of Combining Wave and Wind Power Productions in Day-Ahead Electricity Markets", in Proceedings of the 4th International Conference on Ocean Energy (ICOE), Dublin, Ireland, 2012. 
Other relevant publications to the thesis, including articles, reports and a book, which have not been included in the Appendix are:

H. C. Soerensen and J. Fernández-Chozas, "The Potential of Wave Energy in the North Sea”, Proceeding of the $3^{\text {rd }}$ International Conference on Ocean Energy (ICOE), Bilbao, Spain, 2010.

J. Fernández-Chozas, "Public Perception of Wave Energy", Newsletter of the Waveplam Project, Issue 6, 2010.

H. C. Soerensen, E. Friis-Madsen, N. Rousseau and J. Fernández-Chozas, "Pre-feasibility Studies. Case studies: Horns Rev and North Sea, Denmark, and Wales, United Kingdom”, Deliverables to the Waveplam project, 2011.

A. Raventos and J. Fernández-Chozas, "Tools and database development. Public policies and socio-economic and environmental impacts", Deliverable 19 of Wavetrain2 project, 2011.

J. Fernández-Chozas, "Predictability of wave energy and electricity markets", Modern Energy Review, Vol. 4 (1), pp. 59-61, 2012.

J. Fernández-Chozas, "Energía undimotriz", Editorial Académica Española, ISBN 978-3659-02998-1, 2012.

I. Le Crom, A. Pecher, S. Parmeggiani and J. Fernández-Chozas, "Performance characterisation. Full-scale and prototype plants", Deliverable 29 of Wavetrain2 Project, Case studies development of Work Package 5, 2012.

A. Raventos and J. Fernández-Chozas, "Public policies and socio-economic and environmental impacts", Deliverable 28 of Wavetrain2 project, Case studies development of Work Package 9, 2012.

J. Fernández-Chozas, "Predictability of wave parameters at Hanstholm, Denmark. Wave resource and forecast", Deliverable 26 of Wavetrain2 Project, Case studies development of Work Package 7, 2012.

L. Marquis, M. M. Kramer, J. V. Kringelum, J. Fernández-Chozas and N. E. Helstrup Jensen, "Introduction of Wavestar wave energy converters at the Danish offshore wind power plant Horns Rev 2", in Proceedings of the $4^{\text {th }}$ International Conference on Ocean Energy (ICOE), Dublin, Ireland, 2012.

Fernández-Chozas J., Soerensen H.C. and Kofoed J.P. "Final project report: Analysis of Power Output Predictability of Wave and Wind”, Energinet.dk, PSO project 10791, 2013. 


\section{Preface}

This thesis reflects the major research findings of a $\mathrm{PhD}$ carried out in close collaboration between academia and industry, through the Department of Civil Engineering of Aalborg University and Spok ApS. Aalborg University has a long record of participation in the development of wave energy in Denmark during the last 15 years. More than fifty projects have been carried out on approximately thirty different devices, which have been tested and assessed. Spok ApS is a Danish consultancy firm on offshore and onshore wind, wave and tidal energy, specialised on environmental impact assessments, public consultation processes, regulations and project execution. It is also partner of Wave Dragon ApS, which is a Small and Medium Enterprise (SME) behind the development of the Wave Energy Converter (WEC) under the same name, with whom the author has had continuous collaboration. Consequently, the thesis has been supervised by Jens Peter Kofoed, Head of the Wave Energy Research Group of Aalborg University, and by Hans Christian Soerensen, Director of Spok ApS and chairman of Wave Dragon ApS. The last part of the PhD has also been done in partnership with Energinet.dk, the Danish transmission system operator in charge of security of supply of electricity and gas.

The PhD has been mostly supported by the Wavetrain2 project, funded under the Marie Curie Initial Training Actions and the 7th Framework Programme (FP7) of the European Commission (EC). The project encompasses the EC's efforts on creating a research community specialised on wave energy - hence the name Wavetrain. The research and training programme has supported twenty research positions, at different university groups and companies, and eight one-week-long courses on various topics of wave energy.

The author first studied wave energy during Electrical Engineering studies in Spain. The first research on wave energy technologies, conversion mechanisms and the state of the art of the sector in Europe and in Spain took the form of a master thesis on 2008, which has been published in the book "Energía Undimotriz" (Fernández-Chozas, 2012a). The author has then pursued the $\mathrm{PhD}$ in Denmark, which has been the focus of most of the subsequent research. Danish and Spanish centred research occur frequently in this thesis due to the good resources and interesting projects both countries have, along with their different approaches to renewable energy projects.

The close collaborative work with academia and industry has allowed the author to gain a broad perspective of the wave energy sector, alone and in comparison with other renewables, to become familiarised with actual industry challenges and to observe, face and deal with daily issues behind WECs' developments. Consequently, the thesis covers several areas within the wave energy field and of the interactions of the sector with other marine industries. It aims at providing a broad overview of the road towards commercialisation of WECs, as it elaborates on the challenges, problems and best practices to reach the commercial stage. Above all, the thesis should provide new insights on wave energy developments. 

(Azenhas do Mar, Sintra, Portugal)

\section{Chapter I - Introduction}

This chapter provides a general introduction to the thesis, where the title, the objectives and the outreach of thesis are commented.

This is followed by an overview of the thesis structure that outlines the chapters and sections in which it is divided. 


\section{I.1 General introduction}

The title of the thesis is broad: Technical and non-technical issues towards the commercialisation of wave energy converters. Indeed, it has been chosen to encompass many of the disciplines found in the wave energy sector, with the intention to remind the reader at a first glance about the large number of stages and efforts behind the development of a wave energy technology.

The title speaks about technical and non-technical issues. They refer to technological, socio-economic, financial, environmental and regulatory obstacles. Experience shows it is difficult to draw a line between the two categories, since they generally exist simultaneously in time and space. For instance, it is an arduous task to define which of the two first affects a development. Also, some elements could be considered in close relationship with socioeconomics and with engineering. For example, a promising technology facing a complex regulatory system may never obtain the permission to deploy in the water; whereas a committed renewable energy plan along with inefficient technologies will not do any better. Precisely the same could happen with the public opinion. It will be hard to bring forward a new energy source if public opinion is considerably against the new technologies, even if the proper testing facilities and programmes are made available. As a result, the thesis takes into account both subjects.

Commercialisation refers to the development stage where wave technologies have been tested thoroughly in real sea conditions - including arrays sea trials -, have proved reliable and have demonstrated their working capabilities. Therefore, the commercial stage is understood from a performance point of view, which might not necessarily imply economic competitiveness with other industries.

The expression wave energy converters (WECs) denotes the technologies developed to extract the energy from ocean waves and transform it to useful energy - electricity for example. In a fruitful dinner with Professor H. Lund we discussed about the word energy. Its

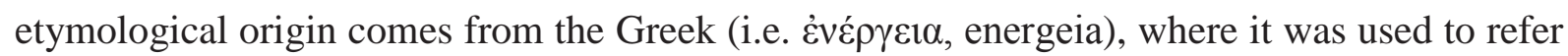
to the capacity of carrying out an activity, to operate; and that we use today in expression like "I'm full of energy", meaning "I could work for hours". In engineering and thermodynamics the term exergy has been introduced, which denotes the energy of a system available to be used, whereas anergy is defined as a form of energy that cannot be used for doing any useful work. In this context and in the forms in which energy appears nowadays, we may often hear the phrase "I'm full of anergy".

The thesis focuses on wave energy, where energy is understood as in the old Greek times. Hence, it refers to waves' capabilities to make something work (only the energy transported in the waves is considered, nor that of tides or ocean currents). Accordingly, two related - yet different - terms appear in the thesis: wave energy and wave power production. The former refers to the energy accumulated in the waves; thus, to the raw energy source. Conversely, wave power production refers to the power output of a WEC, i.e. electricity. Hence, a WEC 
harnesses the energy of the incoming waves and transforms it into useful hydraulic or electrical energy.

The purpose of the thesis has been to investigate various subjects that generally appear throughout the development of WECs. Some of them are of importance when WECs carry out initial sea trials, and others for full-scale and arrays sea testing. The need for this research is justified by the fact that the wave energy sector has sometimes overlooked these points and has not fully identified their (positive or negative) impacts on WEC's developments. Also, results show that it is now when some of these subjects should be addressed.

Accordingly, the thesis has been written primarily from a device developer's perspective. Hence, the device and the project developer might be the prime beneficiary of this research. Yet some parts of the content are probably of interest to the wave energy research community and to the wave sector in general. The thesis is directed both to the new-comer into the wave energy field, as well as to the experienced researcher familiarised with the sector. The former will find an overview to wave energy, including its activities and achievements in the first pages (Chapter II and Chapter III). References to further material are also provided. Following that, detailed descriptions on the study subjects can be found, of interest to the more experienced reader (Chapter IV). Moreover, thanks to the broad spectrum of topics covered, many research disciplines can gain from its reading.

\section{I.2 Structure of the thesis}

The thesis consists of two main parts: an introductory part (Chapter II to Chapter V) and the appendix papers (Appendix). The first introductory part provides a brief history of wave energy, introduces the research topic, describes the different disciplines addressed in the thesis and relates them. The appendix papers comprehend the core part of the research and represent the academic contribution of the work to the scientific community.

The first part is structured as follows. A brief overview of wave energy is provided in Chapter II, which includes a general description of the sector and a summary of the most important wave energy projects (Section II.1). Section II.2 highlights the characteristics of wave energy, through an overview of wave energy benefits and main differences to other sectors. Then, a comprehensive review of recommended reading is included in Section II.3, which aims at providing useful references to various wave energy research areas that are not directly addressed in this work. Section II.3.1 complements this list by a summary of European projects related to the research fields of the thesis.

The rationale of the scientific research is the main focus of Chapter III. It introduces the background of the work, justifies the selected study subjects, and outlines the structure of the thesis. Chapter IV is based on a step-by-step development programme for WECs. Consequently, a review of the state of the art of these development programmes is first provided in Section III.2, where Section III.2.1 includes examples of development programmes. This introduces the research interest and motivation (Section III.3), which 
consists of two parts: a proposed development for WECs (Section III.3.1.) and a description of the areas within a development addressed in the thesis (Section III.3.2). The latter serves to present the structure of Chapter IV.

Chapter IV is the core part of the thesis. It investigates selected research fields in accordance with the appendix papers. It analyses regulatory frameworks for wave energy developments and how they affect project execution (Section IV.1), the role of public opinion in project implementation (Section IV.2), a recently-developed way to evaluate the power performance of WECs in sea trials (Section IV.3), the opportunities to grid connect offshore wave energy projects and the synergies in this area with offshore wind (Section IV.4), the benefits of including wave energy in diversified renewable energy systems, chiefly with respect to power output variability and availability (Section IV.5), the value of wave forecasting (Section IV.6) and the economic assessment of wave energy projects (Section IV.7).

The purpose of Chapter IV is to elaborate on the study subjects of the appendix papers, while avoiding repetition of them. Hence, the common objective of Sections IV.1 to IV.7 is to investigate and inter-relate each paper within a common analysis framework, without entering into detailed descriptions. For that, each section contains a literature review of the particular study subject, analyses background knowledge on the field, and describes the methodology and main findings more succinctly than in the papers.

Chapter V relates and summarises the results: Section V.1 draws on the main conclusions and findings, and Section V.2 recommends further work to the thesis. Finally, the Appendix encompasses the eight papers enclosed to the thesis.

A last comment is provided with regard to literature review. In spite of having one dedicated chapter to the state of the art and relevant bibliography of each researched area, this is also covered on Chapter IV. Therefore, Sections IV.1 to IV.7 elaborate on past work and background references to the study subjects. This is justified by the fact that each paper focuses on different - yet related - topics (as explained in Section III.3), which motivates to include literature review together with the description of the study subject. As stated above, there is further literature review on different wave energy disciplines and on development programmes to wave energy in Sections II.3 and III.2, respectively. 


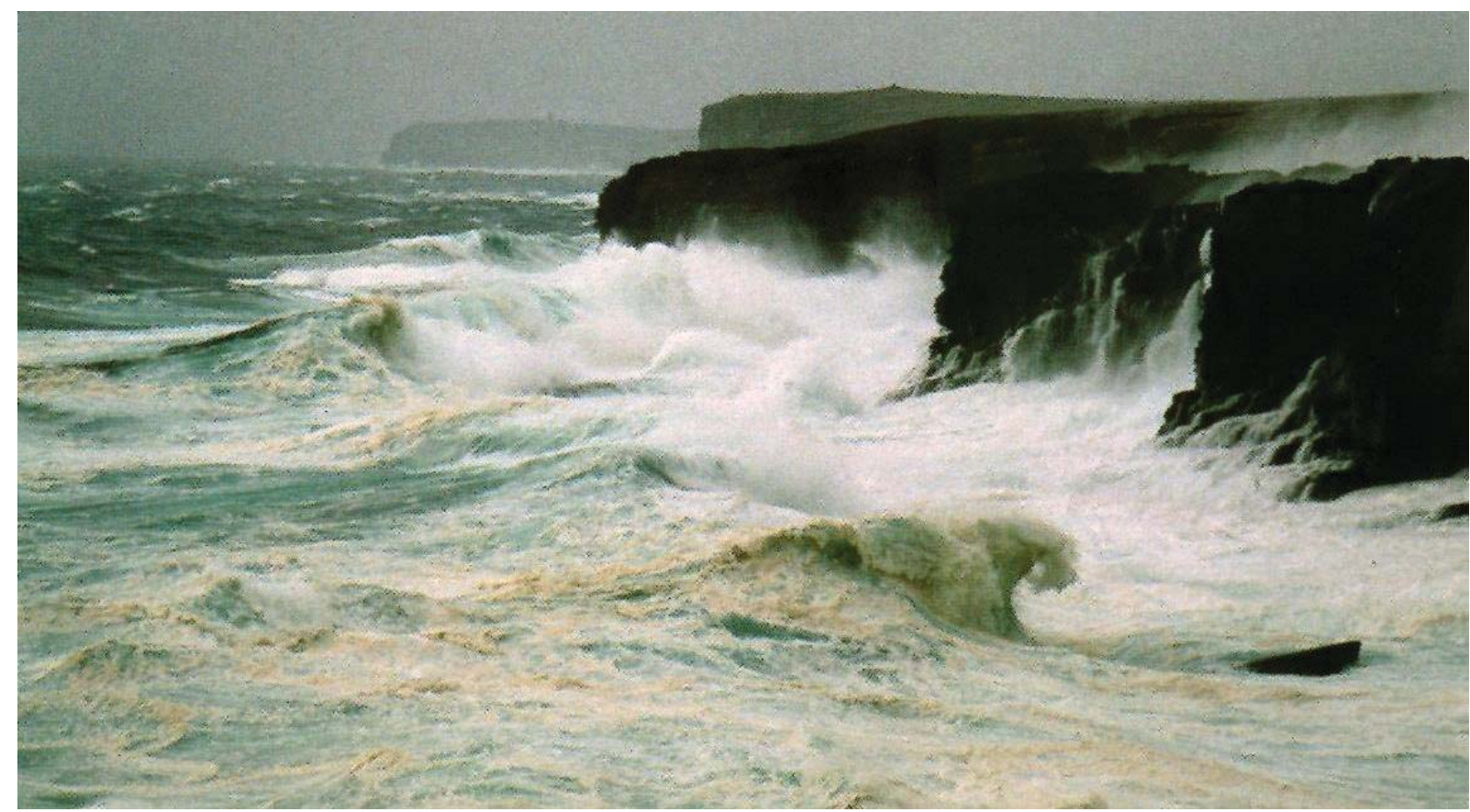

(Orkney Islands, Scotland, United Kingdom)

\section{Chapter II - History and prospects of wave energy}

This chapter overviews the main activities carried out within the wave energy sector.

It provides a general description of the sector, summarises the most important wave energy projects, and highlights the main characteristics of wave energy.

It also includes a bibliography review to various wave energy research areas that are not directly addressed in this work, and a summary of relevant European research projects. 


\section{II.1 Introduction to wave energy}

Wave energy is one of five energies available in the oceans. The energy in the waves is a concentrated form of solar energy: the sun heats the atmospheres unevenly and the differences in pressure create currents in the atmospheres (known as winds), and winds blowing over the ocean surface transfer their energy to the oceans in the form of waves. Wave generation depends on three parameters of the wind: the wind speed, fetch (the distance in the sea over which the wind transfers its energy to the waves) and duration. Waves have the characteristic that once created they can travel for many kilometres practically without energy losses. In that sense, the energy from the sun reaches the coasts, where most of the populations of coastal countries are located, in a concentrated and fairly continuous way. Nearer the coastline the energy in the waves decreases due to the interaction with the seabed.

The energy in ocean waves is theoretically enough to cover the world's electricity demand (Thorpe, 1999). When economics and feasible sites are taken into account, this number reduces - although it still offers high capabilities: waves could at least produce $10 \%$ of the world's electricity demand (WEC, 2010). In Europe alone, wave energy could provide for $15 \%$ of the electricity demand; and in the North Sea, an area where wave intensity is relatively low, it can provide for $6 \%$ of the demand of adjacent countries (Soerensen and Fernández-Chozas, 2010).

Wave energy developments are characterised by numerous inventions. The first patent on wave energy was published in France in 1799 by Girard father and son. Ever since, great number of ideas to harness the energy in the waves have been conceived; however, only few of them have succeeded to be tested in the sea. From those deployments the sector has had numerous success stories but also many failures.

Among the sector's achievements it is worth highlighting the following stories (Figure 1). Some WECs have survived the ceaseless breaking of waves over nearly two decades; the Pico Plant was commissioned in 1999 and Limpet in 2000 and both are still in operation (Falcão, 2004). Tapchan and Kværner pilot plants proved that committed wave energy programmes can succeed despite enormous oil and gas reserves (Ross, 1995). Vizhinjam wave plant in India is the best example of a desalination plant powered by wave energy; it was commissioned in the early 90s and has been operational until 2005 (Sharmila et al., 2004). Wavestar, Pico Plant and Mutriku, have proved - and documented - they can produce useful energy from the waves, with the following values for accumulated electricity production: Wavestar 53.5 MWh (up to December 2012) (Kramer et al., 2013), Pico 52 MWh (WavEC, 2012) and Mutriku 200 MWh (Section IV.1). OE Buoy and Wave Dragon have survived to the harsh sea environments for more than two or three winters (Nielsen, 2012), while others - the 5 to $20 \mathrm{~kW}$ Chinese floating OWCs - have done it for a larger number of years (You et al., 2012). Wave Dragon has also proved a wave-to-wire efficiency of 18\%, i.e. final production per incident wave energy (Frigaard et al., 2006). Lastly, several technologies have attracted investors due to their performance capabilities (i.e. Pelamis, Oyster, CETO) (Nielsen, 2012). 


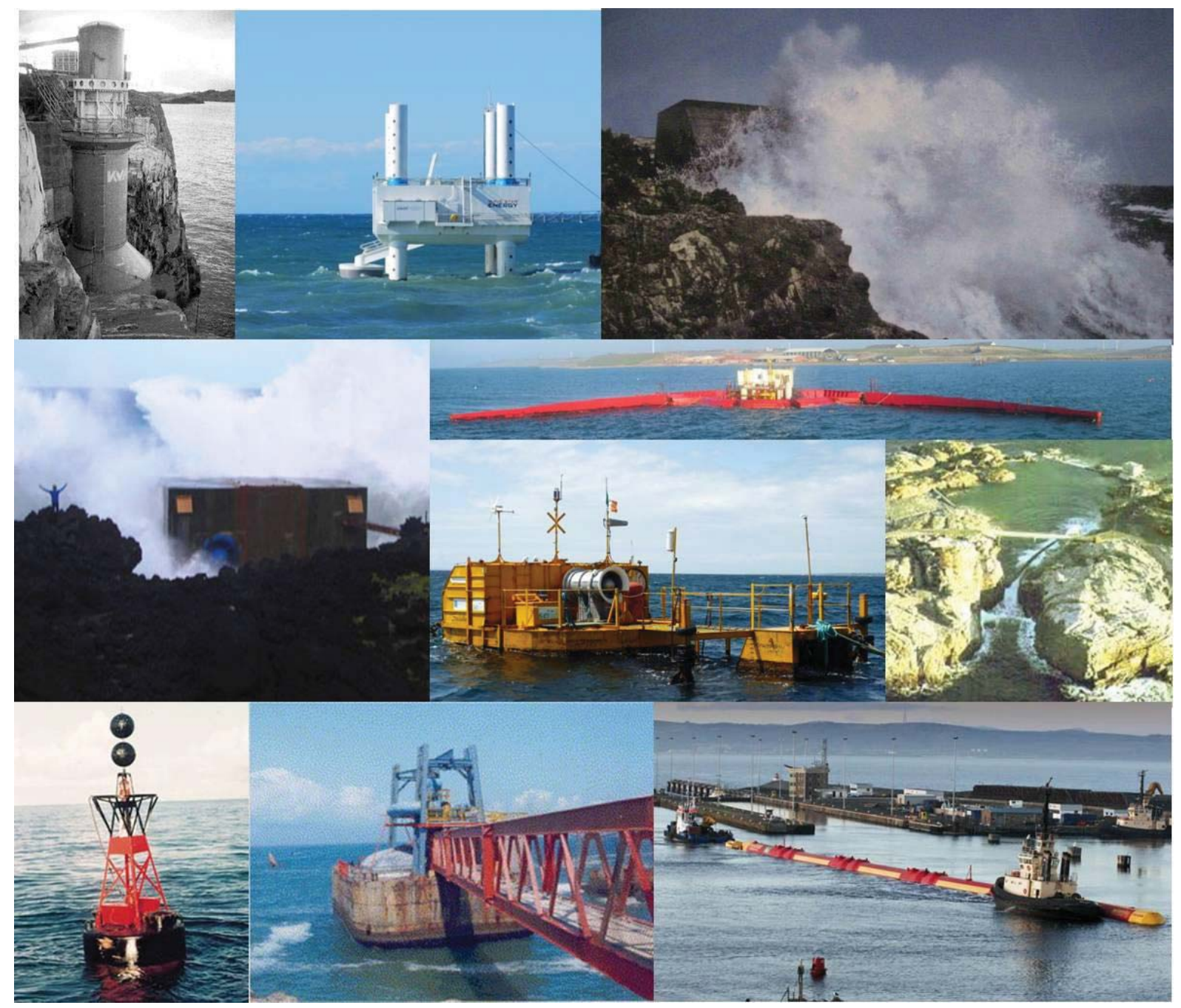

Figure 1. From left to right and from top to bottom: Kværner in Toftestallen, Norway; Wavestar in Hanstholm, Denmark; Limpet in Islay, United Kingdom; Pico Plant in Azores, Portugal; Wave Dragon in Nissum Bredning, Denmark; OE Buoy in Galway Bay, Ireland; Tapchan in Toftestallen; BD 102 in China; Vizhinjam in Kerala, India; and Pelamis in Orkney Islands, United Kingdom.

Unfortunately, many of the sector's failures, related to mooring breakings and WECs getting stranded in front of the public eyes, are retained and emphasised by the public and other stakeholders (Ross, 1995). Meanwhile, one of the biggest success stories of the sector is barely recalled. There are about three hundred OWCs navigational buoys functioning around the world in places where battery changing is inconvenient, lighting a $60 \mathrm{~W}$ bulb and driving a flashing unit, as designed by Commander Yoshio Masuda (Glendenning, 1978).

\section{II.2 Advantages and disadvantages of wave energy}

Harnessing the energy in the waves is full of opportunities to current energy systems. Wave energy is a concentrated and highly available energy source. It is close to dense populated areas and is well distributed around the globe. The visual impact is minor, the environmental impact is significantly low and it comprises an energy supply present in our planet in a continuous way. Moreover, wave energy can be predicted with good accuracy (Section IV.6) and is more constant than wind energy (Section IV.5). 
Nevertheless, the way ahead for wave realisation is beset with difficulties, particularly related to testing in real seas, due to the characteristics of ocean waves and to the costs (WEC, 2010).

In contrary to many other technologies' advancements, WECs have to be tested in real seas from a certain prototype scale onwards (this scale depends on the WEC's and on the laboratory dimensions). Sea trials are generally more complicated and expensive than laboratory testing. Permits often have to be applied for as if a conventional power plant was being installed, and the public usually has also a say. The deployment also requires suitable weather windows and specialist vessels (usually hired by the oil and gas industries). More importantly, the prototype has to be designed to survive to extreme events and operate in harsh environments, despite being a test plant. All these strongly affect the project's costs, which is characterised by capital intensive technologies. The infrequent extreme conditions at the deployment location dictate the structural design of the WEC, which is directly related to the capital costs of the WEC. However, the return of investment is given by the frequent low and medium wave states. And this also applies to early stage small scale sea prototypes.

In addition, the wave energy sector requires the development of new manufacturing systems, with novel product lines and expertise. Nevertheless, whereas most of the industries start nationally and expand later, wave energy has already reached the international dimension.

Reserves of oil, coal, gas and uranium are undoubtedly getting to an end, and new discovered non-renewable energy fields such as shale gas and oil sand can have irreversible environmental negative impacts. It seems the change from current conventional energy supplies to renewable energy systems is imperative. At this point, the continuous potential of wave energy should not be underestimated. Above all, wave energy is a promising exploitable energy source that could provide enormous advantages to energy systems.

\section{II.3 Recommended bibliography to wave energy}

There is extensive literature on wave energy. A brief review of references is presented, that describes the wave energy resource, technologies, conversion systems and developments. Further references can be found in the papers enclosed to the thesis, where there is relevant background information and related bibliography for each study subject.

A grasp of past developments on wave energy and its evolution to the current stage can be obtained by reading the three following books. Ross (1995) summarises the development of the United Kingdom wave energy sector until 1991, including the initial stages of the sector, different projects developments and achievements and political decisions around wave energy. Cruz (2008) compiles a global view on wave energy projects, including the developments of Pelamis, Wave Dragon, Archimedes Wave Swing (AWS) and LIMPET Oscillating Water Column (OWC), as well as some of theory behind wave harnessing. Lastly, Waters (2008) provides a comprehensive and understandable description of wave energy 
principles and explains the development of the Seabased WEC with special focus on the electric part. Furthermore, a broad overview of the wave energy sector can be gained through Wavenet (2003).

Latest estimates on global wave energy resources are provided by Mørk et al. (2010), while Nielsen and Pontes (2010) summarise the wave conditions at different locations.

McCormick (1981) describes and discusses nine wave energy conversion techniques from a physical and a mathematical approach. A comprehensive review of the state of the art of WECs, which includes testing stage, company information and WECs features, can be found in HMRC (2009) and an update to that report can be found in Nielsen (2012), which summarises the latest technology developments, current projects and a list of companies involved in the sector. Those reports can be complemented by the information provided in Previsic (2010). Then, CSIRO (2012) draws a comprehensive comparison among various WECs in Australian waters.

The energy conversion process, from waves to electrical energy, covers the absorption of the energy in the waves, its conversion by the Power Take-Off (PTO) system and application of control strategies. An overall overview of the conversion mechanisms and the characteristics of the steps are described by Salter et al. (2002). The understanding of the waves and how they interact with the absorbing body is the main focus of Falnes (2005), which also serves as good reference for control theory. With regard to PTO systems Mueller et al. (2007) focus on the main characteristics of the different PTOs, i.e. air turbines, hydraulic systems, water turbines and direct drive generation. In particular, Falcão (2004) concentrates on the self-rectifying air turbine of OWCs, Henderson (2005) describes the hydraulic technology of Pelamis, Knapp (2005) focuses on Wave Dragon's water turbines and Polinder et al. (2004) discuss direct drive conversion for the AWS. The recently published book by the Hydraulics and Maritime Research Centre (HMRC) on electrical systems covers the electrical systems and connections of WECs into the grid (Alcorn and O'Sullivan, 2013).

Finally, structural design for WECs is described by Journée and Massie (2001), and mooring systems are covered by Fitzgerald and Bergdahl (2007).

\section{II.3.1 European projects relevant to the thesis}

In 1991 the European Commission (EC) included wave energy in its Research and Development (R\&D) programmes (OES, 2009) and since then a large number of projects have been funded by the EC. Most of them have developed updated and exhaustive reports on the relevant research field, which are useful references beyond the ones provided above. Project's participants also provide a hint on some of the most active teams on wave energy in Europe. In the following only a few of the latest EC projects are reviewed. They are of relevance to the discussion points of the thesis.

The Sowfia project (Streamlining of Ocean Wave Farms Impact Assessment) is in line with the discussion raised in Section IV.1. It aims to remove legal, environmental and socio- 
economic barriers to the development of WECs (Sowfia, 2013). For that purpose, it will develop coordinated, unified and streamlined tools that will deal with the consenting processes, Environmental Impact Assessments (EIAs) and socio-economics of wave energy developments.

Research on grid-connection alternatives for European electricity networks have been the main focus of the following three projects. All of them deal with onshore or offshore wind energy, yet their findings are of relevance to wave energy as discussed in Section IV.4. The Tradewind project (Integrating Wind: Developing Europe's Power Market for the Large-scale Integration of Wind Power) has formulated recommendations on policy development, market rules and interconnector allocation methods to support large-scale integration of wind energy in European power markets (TradeWind, 2013). OffshoreGrid (Offshore Electricity Infrastructure in Europe) continues the TradeWind project by providing an in-depth analysis of the milestones towards a cost-efficient grid in the North and Baltic Seas (Offshoregrid, 2013). The objective has been to develop a secure, interconnected European power system, capable of integrating increasing amounts of renewable energies, particularly of offshore wind energy. In parallel, the Windspeed project (Spatial Deployment of Offshore Wind Energy in Europe) has planned the development of offshore wind in the North Sea (Windspeed, 2013). It has defined a roadmap for 2020 and 2030, analysed the interactions with other sea users and identified meshed grid connection opportunities within countries.

The following five projects share the same background as the studies addressed in Section IV.5. The author has held discussions with several of the following projects' partners, and all the results presented in the thesis have been made available and shared with the projects. Orecca (Offshore Renewable Energy Conversion Platforms) has worked towards a roadmap and a framework for knowledge sharing on offshore renewable energies (Orecca, 2013). The Marina Platform continuous the Orecca project to establish a set of criteria for the evaluation of multi-purpose platforms for marine renewable energy (MarinaPlatform, 2013). Tropos (Modular Multi-use Deep Water Offshore Platform for Harnessing and Servicing Mediterranean, Subtropical and Tropical Marine and Maritime Resources) aims to develop a floating modular multi-use platform system for use in deep waters (Tropos, 2013). H2Ocean (Development of a Wind-Wave Power Open-Sea Platform Equipped for Hydrogen Generation with Support for Multiple Users of Energy) focuses on a design of a multi-use open-sea platform, where wind and wave energy will be harvested (H2Ocean, 2013). Part of the energy will be used for on-site applications like hydrogen production or aquaculture. Mermaid (Innovative Multi-purpose Offshore Platforms: Planning, Design and Operation) works towards the optimisation of the use of space for offshore wind farms and aquaculture (Mermaid, 2013). The project investigates marine structures with shared resources such as staff allocation, transportation of staff and material from and to the platforms, use of forecasting systems, ships, etc.

The next three European projects relate to the development of forecasting tools for wind energy, the topic of Section IV.6. Anemos compared a number of statistical prediction models 
and developed forecasting software, which utilises neural network (Anemos, 2013). The Anemos project has been continued by Anemos Plus, which aims to identify instruments to implement Anemos forecasts in the best possible grid management and effective power trading (AnemosPlus, 2013). The Safewind project looks into forecasts improvement for extreme wind situations (Safewind, 2013).

With relevance to most of research fields are the projects CA-OE (Coordinated Action on Ocean Energy) (CA-OE, 2013), WavePlam (Wave Energy Planning and Marketing) (Waveplam, 2013), EquiMar (Equitable Testing and Evaluation of Marine Energy Extraction Devices in terms of Performance, Cost and Environmental Impact) (EquiMar, 2013) Waveplam and EquiMar are further explained in Section III.2 -, and Wavetrain1 and its continuation, Wavetrain2 (Wavetrain, 2013). The Wavetrain projects have been multinational Initial Training Network research projects funded by the EC under the FP7 programme. Their objective has been to create a knowledge-based community of researchers on wave energy. Both projects have focused on an extensive range of fields: hydrodynamic and PTO design, instrumentation, energy storage, costs reduction, licensing, conflicts of use of the sea area, EIA procedures, grid connection and socio-economic benefits of the sector. Project networks consisted of about thirteen European partner institutions and seventeen associated entities, entailing from research centres and device developers to project developers and consultants. Extensive research material has been produced within the two networks.

Finally, the international initiative towards ocean energy development, named the Ocean Energy Systems (OES) of the International Energy Agency, produces annual reports on the ocean energy sector and on various fields of interest to the ocean community (OES, 2013). 



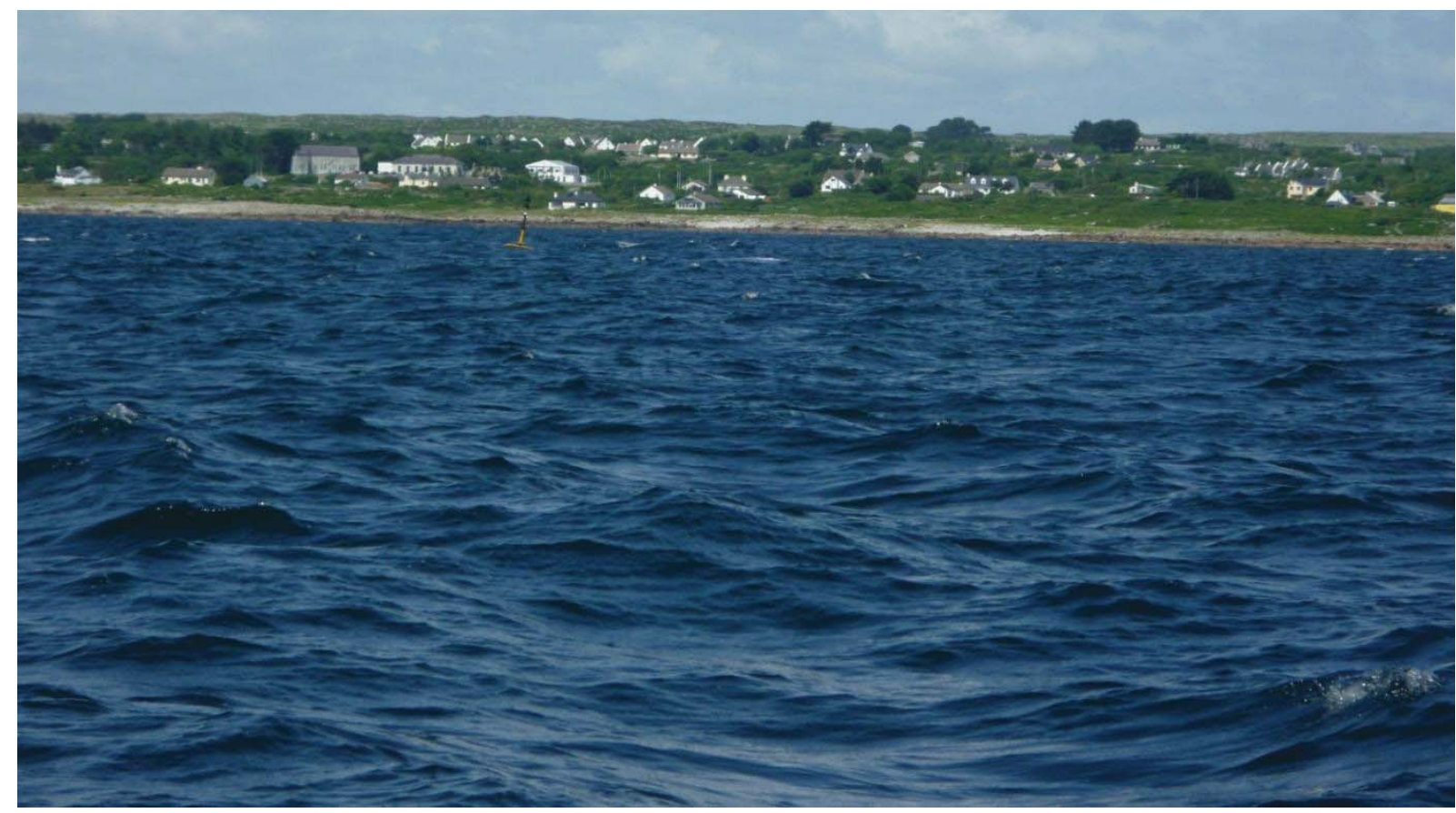

(Galway Bay, Ireland)

\section{Chapter III - Rationale}

This chapter focuses on the rationale of the scientific research: it presents the background of the work, justifies the selected study subjects, and outlines the structure of the thesis.

It first reviews the state of the art of WECs development programmes, and provides examples of them.

Then, it introduces the research interest and motivation. It overviews a proposed development for WECs and describes the areas within such a development of interest to the thesis. 


\section{III.1 Introduction}

Chapter II has reviewed the advantages and particular characteristics of the waves and some of the achievements of the sector. This chapter focuses on the different phases in the development of WECs. The development process covers from the initial concept to the final industrial commercial reality. The ultimate goal of a development is to create a technically feasible concept that when installed in profitable waters it is capable of harnessing the energy in the waves and of producing continuous electricity.

Due to their importance, WEC's developments have been the focus of the wave energy sector for several years now. An overview of development programmes for WECs is provided in Section III.2. This serves to introduce the research interest of the thesis, which is addressed in detail in Section III.3. It includes a proposal for a WEC and a project development and a presentation to the seven key areas that are analysed in the following chapter of the thesis.

Up to now the application of structured developments programmes for WECs advancements has been left to the developers themselves, and correspondingly experiences where they have and they have not been applied can be found (Section III.2.1). Ultimately, a structured progress plan can help to mitigate financial and technical risks. The core idea of such an approach is that a WEC will advance to the next development stage only when previous stages have been successfully fulfilled.

\section{III.2 State of the art of development programmes}

Several attempts have aimed to define a structured programme for WECs' developments that would be received by SMEs as unbiased and independent. In 1996 the first protocol suitable for marine engineering was published within the Offshore Wave Energy Converter (OWEC) project, under the Joule II programme of the EC (Sarmento and Holmes, 1996). It was adopted from NASA's Technology Readiness Level (TRL) process used in aviation, space and defence to manage the development of high risk, novel and complex technologies (NASA, 2013). NASA's approach, along with test programmes' documentation, served to draw a protocol suitable for ocean converters' developments. The protocol covered four phases, from initial concept through to the final pre-production machine demonstration: phase one of validation model, phase two of validation and design model, phase three of design and process and phase four of process model.

In 1998 Denmark initiated the Danish Wave Energy Programme to support new wave energy inventions. The programme made evident the need for an evaluation plan to assess the WECs and a first four-stage protocol on testing and assessment of WECs was established (Nielsen, 1999), (Kofoed and Frigaard, 2009). It covered from the proof of concept to demonstration level. Similarly, in 2002 the OWEC protocol served as the basis for the Irish Ocean Energy Development and Evaluation Protocol, under which Irish WECs were developed and tested (HMRC, 2003). The original stages remained, and details for each stage were added to the original procedures. 
Since that date, various initiatives have emerged to provide an internationally agreed structured development programmes, partly driven by Denmark and Ireland (Nielsen, 2003) (updated to (Nielsen, 2010)). Moreover, the focus has also been extended towards the establishment of standards on design and operation of WECs as well as on performance evaluation (DNV, 2005) (EMEC, 2009).

\begin{tabular}{|c|c|c|c|c|c|}
\hline & \multirow{2}{*}{ BARRIER } & \multirow{2}{*}{$\begin{array}{l}\text { Perceived } \\
\text { severity }\end{array}$} & \multicolumn{3}{|c|}{ Mitigation mechanisms } \\
\hline & & & Policies & Market & Sector \\
\hline \multirow{5}{*}{$\begin{array}{l}\text { REGULATORY } \\
\text { ISSUES }\end{array}$} & Transposition of RE targets into measures & most critical & $\sqrt{ }$ & & \\
\hline & License for sea use & most critical & $\sqrt{ }$ & & \\
\hline & Operation and grid connection license & most critical & $\sqrt{ }$ & & \\
\hline & Cable laying and construction works & mast critical & $\sqrt{ }$ & & \\
\hline & Health \& Safety and insurances & critical & $\sqrt{ }$ & $\sqrt{ }$ & $\sqrt{ }$ \\
\hline \multirow{4}{*}{$\begin{array}{l}\text { FINANCIAL } \\
\text { ISSUES }\end{array}$} & Externalities and the "real" cost of energy & most critical & $\sqrt{ }$ & & \\
\hline & Feed-in Tariff and ROCs & most critical & $\sqrt{ }$ & & \\
\hline & Capital grants and RTD support & critical & $\sqrt{ }$ & & \\
\hline & Tax relieves / other investment incentives & critical & $\sqrt{ }$ & & \\
\hline \multirow{5}{*}{$\begin{array}{l}\text { INFRASTRUCTURE } \\
\text { AND LOGISTICS }\end{array}$} & Grid integration constraints & most critical & $\sqrt{ }$ & $\sqrt{ }$ & \\
\hline & Specialized marine equipment & critical & & $\sqrt{ }$ & $\sqrt{ }$ \\
\hline & Supply chain uncertainties & critical & & $\sqrt{ }$ & \\
\hline & R\&D infrastructure & not critical & $\sqrt{ }$ & $\sqrt{ }$ & \\
\hline & Skilled workforce & not eritical & & $\sqrt{ }$ & $\sqrt{ }$ \\
\hline \multirow{5}{*}{$\begin{array}{l}\text { CONFLICTS OF } \\
\text { SEA USE }\end{array}$} & Reserved ("no-go") areas & critical & $\sqrt{ }$ & $\sqrt{ }$ & \\
\hline & Navigation routes & critical & $\sqrt{ }$ & $\sqrt{ }$ & \\
\hline & Professional fishery & critical & $\sqrt{ }$ & $\sqrt{ }$ & \\
\hline & Leisure craft and local fishing communities & not critical & & $\sqrt{ }$ & $\sqrt{ }$ \\
\hline & Modification surf (near-shore wave regime) & not critical & & & $\sqrt{ }$ \\
\hline \multirow{3}{*}{$\begin{array}{l}\text { ENVIRONMENTAL } \\
\text { ISSUES }\end{array}$} & Impacts on the marine environment & not critical & $\sqrt{ }$ & & $\sqrt{ }$ \\
\hline & Noise \& visual impacts & not critical & & & $\sqrt{ }$ \\
\hline & Socio-economic environment & not critical & & $\sqrt{ }$ & $\sqrt{ }$ \\
\hline \multirow{3}{*}{$\begin{array}{l}\text { PUBLIC } \\
\text { PERCEPTION }\end{array}$} & Public awareness & not critical & & $\sqrt{ }$ & $\sqrt{ }$ \\
\hline & Worries on electricity bill & not critical & & & $\sqrt{ }$ \\
\hline & Disbelief towards new technologies & not critical & & $\sqrt{ }$ & $\sqrt{ }$ \\
\hline
\end{tabular}

Figure 2. Overview of perceived barriers, their severity and most likely type of mitigation mechanism (Neumann, 2009). 
To face the increasing demand for agreed guidelines the EC funded two complementary projects in 2008, the Waveplam and the EquiMar project. WavePlam has looked into the nontechnical barriers hindering the development of wave energy and has developed recommended practices to mitigate them (Waveplam, 2013). Figure 2 presents the agreed challenges, i.e. regulations, finance, infrastructure and logistics, conflicts of sea use, environmental issues and public perception; their importance i.e. not critical, critical and very critical; as well as the more suitable mitigation mechanism to overcome them i.e. long-term policy measurements, the demand-offer principle and the active intervention from the sector's stakeholders (Neumann, 2009).

The EquiMar project has developed a set of protocols for both tidal and wave energy on several areas: marine energy systems, physical environment, tank testing practices, sea trials procedures, deployment assessment, EIAs and economic assessment (Ingram et al., 2011). In the same way as the other guidelines, EquiMar recommended procedures have been based on the schedule introduced in the Joule II programme, with the caveat that a fifth stage, focused on commercial prototype demonstration, has been introduced. Hence, it dedicates stage 1 to the proof of concept, stage 2 to design and feasibility studies, stage 3 to sea trials at 1:10 to 1:3 scale, stage 4 to half or full scale prototype demonstration, and stage 5 to array and commercial demonstration. Figure 3 illustrates the different stages and also relates them to NASA's TRLs. Since each stage is progressively more rigorous and expensive, it is sometimes required to return to previous stages or to repeat tests within the same stage to obtain more accessible results. This idea is represented in Figure 3 by the red arrows within each stage as well as by the circular diagram of stages. Above all, Figure 3 illustrates that the development of a WEC might be regarded as an iterative process.

Development schedules have also become of interest to utilities and device developers, who have re-introduced the TRLs approach. Fitzgerald and Bolund (2012) present the classification system for wave energy projects used in ESB and Vattenfall. Based on the nine TRLs, it is particularly focused on TRL 8 and 9, when the WEC faces the pre-commercial and the commercial levels of relevance to utility-scale projects. Then, Weber (2012) associates the readiness levels with quantifiable performance parameters, to evaluate the technological and economic aspects of the WEC at early development stages. The approach focuses on the assessment of time, cost and risk through nine Technology Performance Levels (TPLs). Whereas TRL indicates the commercial ability of a technology, TPL quantifies its economic performance.

While national and international guidelines and protocols for wave energy developments are being issued, the IEC/TC-114 group is leading efforts to draft industry standards. This group is the Technical Committee (TC) appointed by the International Electrotechnical Commission (IEC) for the preparation of standard on marine energy conversion systems (i.e. "Marine energy: wave, tidal and other water current converters") (Strategic, 2013). 


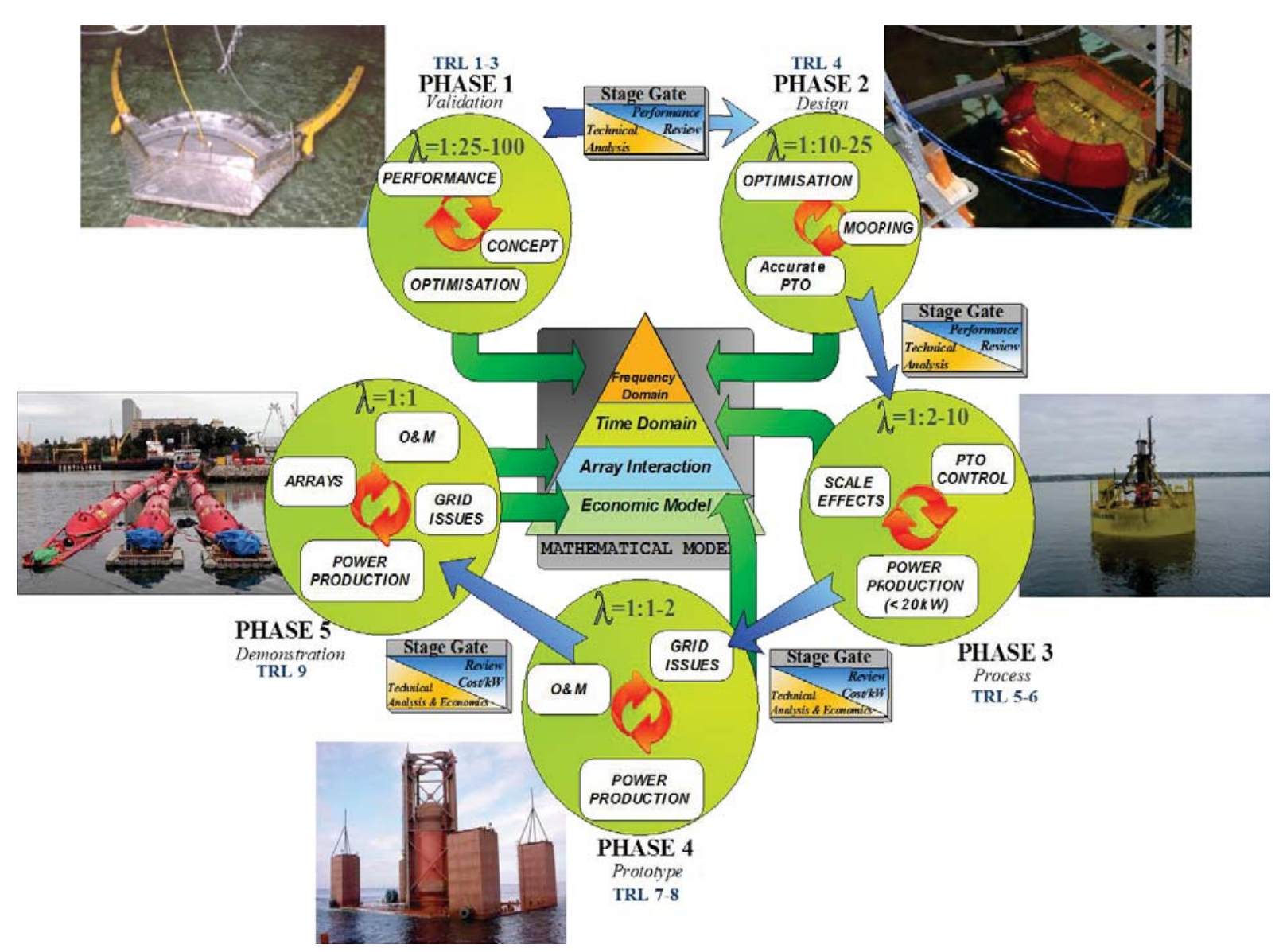

Figure 3. Overview of the five-stage WEC's development protocol supported by different programmes. Lambda ( $\lambda$ ) indicates the scale of the WEC model or WEC prototype. O\&M stands for Operation and Maintenance. The WECs illustrated are (clock-wise direction, starting from Stage 1): Wave Dragon at HMRC (Ireland), Wave Dragon at Aalborg University (Denmark), Wavebob at Galway Bay (Ireland), Archimedes Wave Swing at Aguçadoura (Portugal) and Pelamis, also at Aguçadoura (Holmes, 2010).

\section{III.2.1 Examples of development programmes}

In the following, two examples, illustrating the importance of structured development programmes are provided. The first one relates to WECs' developments and the second one covers national wave energy programmes.

Experience of WECs advancements indicates that many technologies have followed an incremental prototype development. However, many others have adopted a development approach essentially opposite to the common baseline presented above, where WEC prototypes have been deployed in the water without the expected and necessary knowledge from previous phases. The two approaches have generally led to successful and unsuccessful deployments, respectively. For example, Pelamis and Wave Dragon have largely followed a step-by-step development (Pelamis, 2013) (Soerensen and Friis-Madsen, 2010), while the Osprey, the Archimedes Wave Swing or Oceanlinx have not (Ross, 1995), (Cruz, 2008). Thus, to enhance the opportunities of project success, it is important to follow a concrete and stepwise development approach to prototype's advancements. 
Similarly, national wave energy programmes can also lead to successful results or partially fail in their outcomes. To illustrate this, the approaches of two countries to national wave energy development programmes are reviewed. The case of Denmark is analysed first, followed by the experiences of Spain.

Denmark has about 2.5 GW of wave resource, mostly concentrated in North Sea waters, and it has been estimated that it could provide one third of Danish electricity demand (Kofoed, 2009). Although the Danish National Renewable Energy Action Plan (NREAP) forecasts $30 \%$ of electricity produced from renewable sources by 2020, no contribution from wave energy has been considered.

As indicated above, in 1998 the 4-year Danish Wave Energy Program was initiated (Nielsen, 1999). With a budget of 5.4 MEUR, between forty and fifty ideas for harnessing the waves were tested. The purpose of the program was to unify the efforts in WECs development by testing the different ideas present at that time and by selecting the best ones for further R\&D. Following the initial phase of simple model testing for proof of concept, about ten ideas moved to the next stage of laboratory performance optimisation. Only one technology was selected for the next phase of real sea testing, the Wave Dragon WEC (Figure 4). In 2003 a prototype of Wave Dragon was deployed at Nissum Bredning, an inland sea area on the West part of Jutland, to prove its performance and capabilities in real-sea conditions (Nielsen, 2012). Overall, throughout this program there was a concrete line of action and efforts were focused towards one development (Kofoed and Frigaard, 2009).
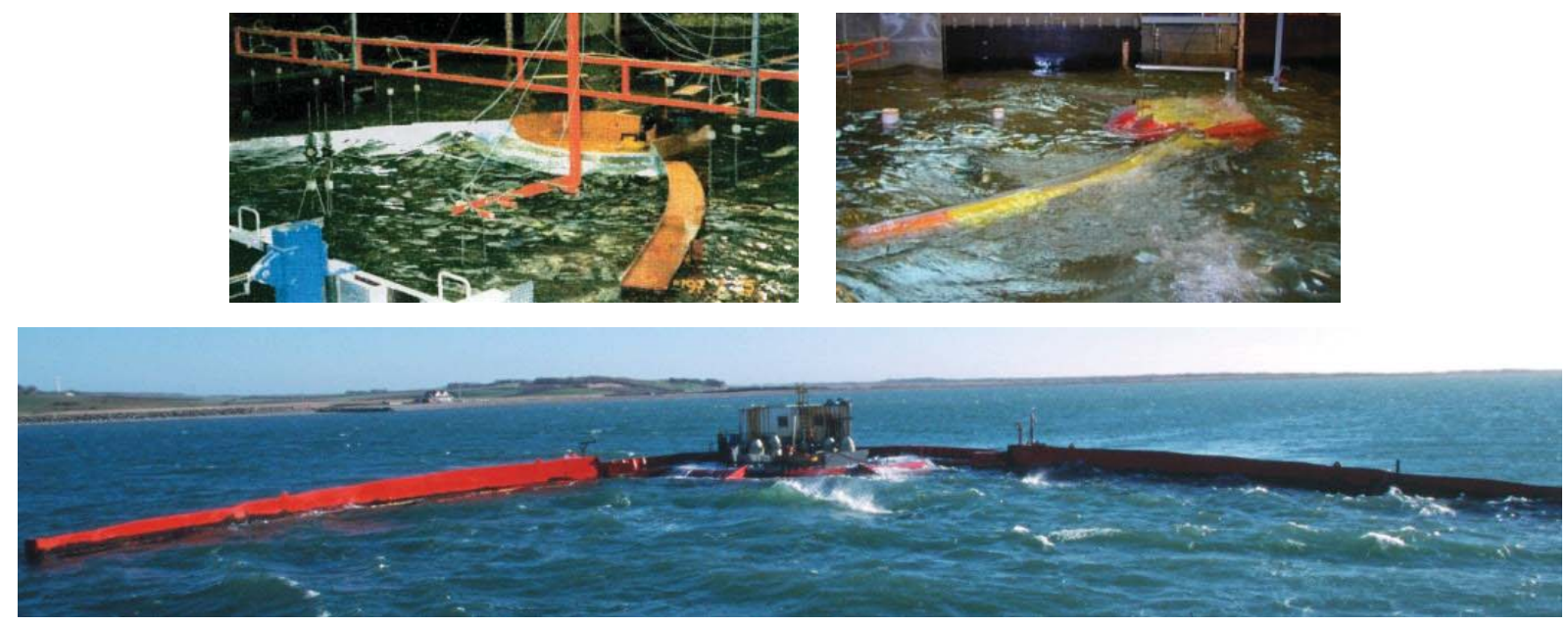

Figure 4. Development stages of Wave Dragon within the Danish Wave Energy Programme. From left to right and from top to bottom, phase 1 (proof of concept), phase 2 (design optimisation) and phase 3 (first prototype sea trials at Nissum Bredning, Denmark) (Wave Dragon, 2013).

After the Danish Wave Energy Programme, national research funding has been dedicated to R\&D projects (i.e. Partnership for Wave Energy, the Structural Design of Wave Energy Devices, etc.), laboratory testing of old and new WECs, and sea testing (Nielsen et al., 2012). However, available funding for WECs sea trials has not been sufficient and the percentage of funding dedicated to wave energy represents a small percentage of the overall renewable energy funding, i.e. about 16 MEUR have been allocated to wave energy from 1995 up to 
present time, which represents about 3\% of total available funding (ProjectsDk, 2013). Moreover, Danish Feed-In Tariff (FIT) for the electricity production of WECs is 80 EUR/MWh. Due its low value compared to other European FITs (Neumann, 2009), the Danish Transmission System Operator (TSO), Energinet.dk, has initiated a R\&D programme - the ForskVE programme - where the electricity generation by WECs in latest stages of development is paid through a project-specific FIT (ForskVE, 2013). This FIT is based on the WEC's power performance. Thus, production data is the basis of a settlement price agreed between the device developer and Energinet.dk. The Wavestar prototype installed at Hanstholm has been the first WEC receiving it. For the first two years of operation the FIT was dependent on the mechanical power at the hydraulic cylinders (Figure 5), and afterwards, it was dependent on the electrical power at the output of the generators. It has been agreed this approach is a transparent income strategy and a challenging motivating scheme (Kramer et al., 2011).

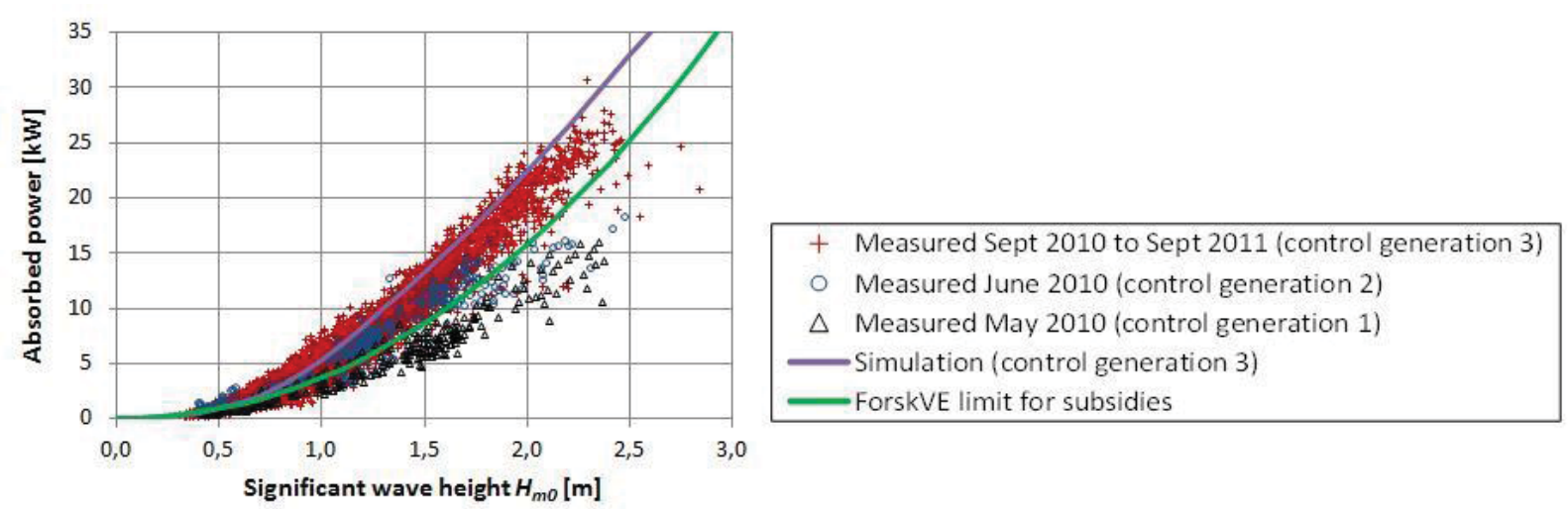

Figure 5. Power measurements from Wavestar prototype at Hanstholm and ForskVE limit for subsidies (green line). Red data points are 30-minute average values of harvested power from one float. 5740 data points are shown, i.e. 120 days operation (Kramer et al., 2011).

Besides Energinet.dk's initiative, Danish support for the electricity generated by WECs is low, and there is limited funding for sea trials. Nielsen et al. (2012) provide numbers of research funding needed at present stage to foster the Danish wave energy sector. The investment is estimated at 200 MEUR over the next 20 years, which is expected to get paid back in the following ten years due to the advantages that combined wave and wind energy projects bring (this topic is addressed in Sections IV.5 and IV.6).

For comparison, the Spanish attempt towards the establishment of a wave energy programme is described. From the author's perspective, the initiative is composed by two projects, the PSE-MAR project (Paper A) and the Ocean Lider project (Amate López, 2010) (This discussion is complemented in Section IV.1, where the Spanish FIT system and a current wave energy project are presented). PSE-MAR project run from 2005 to 2010 with 28.5 MEUR to advance the development of three WECs: Hidroflot, Oceantec and Pipo Systems. Hidroflot carried out laboratory tests in a 1:6 model with focus to deploy a $1.5 \mathrm{MW}$ prototype, a 1:4 prototype of Oceantec was deployed for sea trials, and Pipo Systems focused on the design for a first sea-prototype. At present, Hidroflot is still pending for funding to 
conduct field tests and Oceantec has stopped its development. However, a 1:5 prototype of Pipo Systems was deployed in 2011 and has recently been re-deployed off Gran Canaria, supported with 14 MEUR national and European funding (OES, 2012), and a full-scale prototype of Wedge Global will do the same at the end of 2013, supported by a national 2.5 MEUR project (i.e. Undigen project) (Santos et al., 2012).

The Ocean Lider is a 30 MEUR project - 15 MEUR national funding - coordinated by the utility Iberdrola. It counts with the participation of 20 companies and 24 research centres. The objectives of the 4-year project (2009 to 2012) cover most research areas found in wave energy developments, and expect to deliver 35 patents and 17 property records. Nine of the patents are dedicated to WECs, two for PTOs, two for mooring systems and seven for site characterisation and monitoring systems (Amate López, 2010). Overall, planned project results are large and embrace a broad range of areas.

The comparison between Denmark and Spain shows that Denmark focused efforts on a concise development plan towards WECs' advancements, although it currently lacks public resources for prototypes field trials and offers an unattractive FIT for WECs, but for the ForskVE programme of Energinet.dk. Conversely, Spain has not defined a wave energy development roadmap as such, and is providing general funding for WECs developments, including funding for WECs prototype sea trials. By 2011, two of the thirteen leading WECs derive from the first Danish programme, i.e. Wave Dragon and Wavestar (EVE et al., 2011).

\section{III.3 Research interest}

The initiatives reviewed above have shown that there is continuous interest on development programmes for WECs, which is ultimately justified by the advantages structured developments bring to technology's and project's advancements. A proper development programme in turn depends on the correct understanding of each stage. Therefore, the rationale behind the thesis has been firstly, to identify the primary phases that generally appear within the development of a WEC, until it becomes a commercial reality; secondly, within that development, to determine the issues or phases where there is a gap in research, and thirdly, to examine the identified key subjects.

Section III.3.1 describes the various challenges a development might encounter in its development. It includes the test stages identified by the EC and supported by EquiMar, as well as the non-technical challenges agreed in Waveplam. It also incorporates the performance assessment of the European Marine Energy Centre (EMEC) guidelines. As a result, the proposed programme could be regarded as a regulatory, socio-economic and technical overview of a WEC development, where the technical part includes performance evaluation, grid integration and power forecasting. The defined stages should be read as a useful guidance that overviews many of the possible aspects that may arise in the race towards commercialisation rather than the 'design path' for a project success. 
Then, Section III.3.2 introduces seven study subjects considered of importance within a development and in Chapter IV the seven areas are examined in detail, which is the core part of the thesis.

\section{III.3.1 Overview of a proposed wave energy converter development}

The demand for structured development processes comes from different stakeholders, who range from research institutes to regulatory and granting bodies, device developers and investors. Here the stages are examined from a device developer and a project developer point of view; however this approach might have interest to other bodies and to the wave energy sector as a whole.

Section III.2 has explained the development stages are reasonably well agreed upon, although different practices among device developers can be found, due to economic issues, inventor's and investor's preferences, national regulations or WEC's characteristics. Hence, the list of stages outlined below is not exhaustive and the order allocation might be subject to the particular developments and deployment locations. Moreover, reality shows different ways to go through a development and thus, WECs might follow the described path or a variant of it. Yet, in order to link the phases to previous research, these are related throughout the description to the stages agreed in and beyond the OWEC project (Figures 3 and 6). Figure 6 defines the development stages agreed in Denmark, where the Danish Wave Energy Programme has added the fifth stage of full-scale and arrays WECs demonstration (Nielsen, 2012).

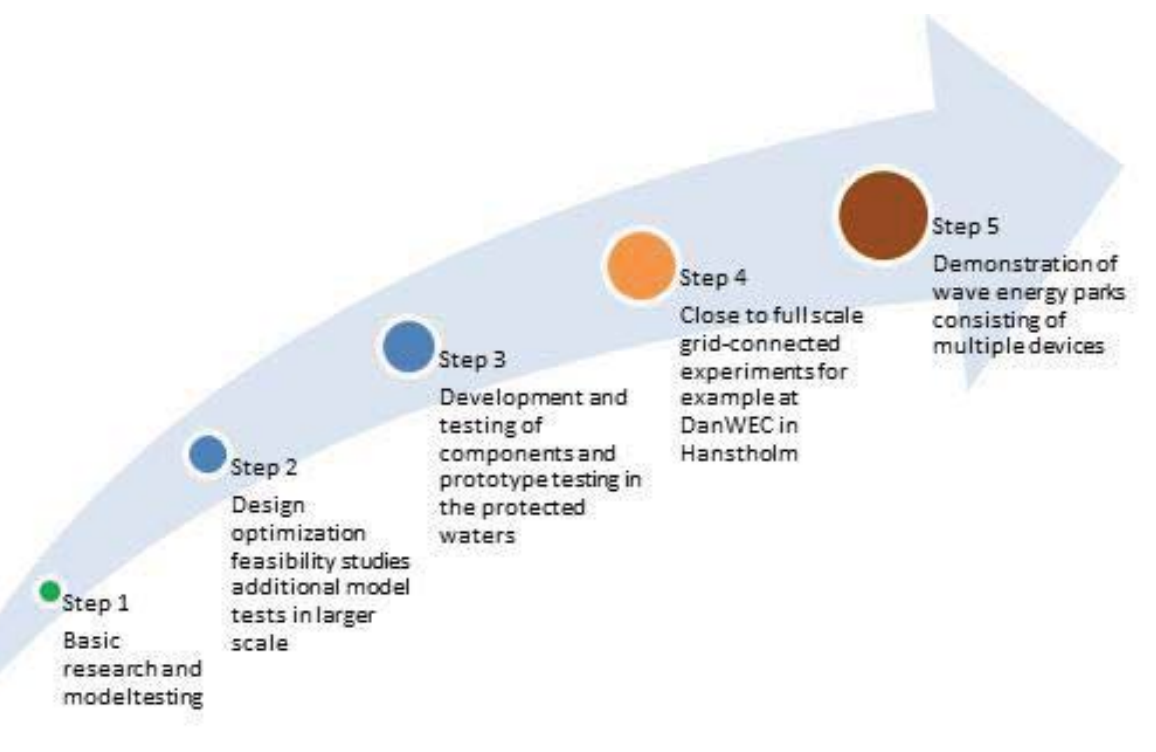

Figure 6. Typical development stages agreed in the OWEC project, in Denmark, in Ireland and by EquiMar, among others (Nielsen, 2012).

First stage starts with an idea of a wave energy conversion principle. Due to the large number of WECs that have been developed it is recommended to carry out a preliminary study that identifies comparable concepts to the proposed idea. Then, to test the working principle behind the idea, a model is tested in sea conditions that are simulated in a closed and 
controlled testing environment, i.e. in laboratory facilities. Depending on the size of the model and of the facility, different features can be analysed. Experimental laboratory covers testing in regular, in irregular and in 3D waves representative of the interesting deployment locations where e.g. survivability tests can be carried out. In parallel to laboratory testing numerical modelling is done, in order to learn about the WEC's performance generally at a lower cost than in model testing. At this stage initial reliability tests of components and subsystems can also be performed with bench testing.

The proof of concept, first laboratory and bench tests and model simulations correspond to the first and second stages of EquiMar. The aim of these stages is to obtain an initial assessment of the performance and economic capabilities of the WEC.

With data collected from laboratory tests and numerical modelling, prototype design is carried out. It involves the design of the power conversion system (PTO, control strategies and electrical components) and the structural design (size, mooring, construction methods and deployment). Then, the decision on deployment location is taken. This is normally based on the wave resource and possibly on regulations applying to that site (i.e. ease and time needed to obtain the relevant permits and to deploy). When all required permits are in place, the first prototype can be deployed. The principal objectives are to demonstrate its performance in real sea conditions, and to learn further about operation, failures and maintenance. Moreover, the deployment provides results on survivability and reliability of the WEC, as well as on power production and cost estimates that can be compared to those obtained at laboratory scale. This stage corresponds to stage 3 of EquiMar, i.e. WEC commissioning.

The initial sea trials are followed by successive deployments at increasing prototype scales in harsher sea environments, where different capabilities of the WEC are tested. Whereas stage 3 is usually happening in benign test sites with prototypes in the 1:4 to 1:10 scale, stages 4 and 5 are performed in real seas with half-scale and full-scale prototypes, respectively. Out of the field tests, a complete technical, economic and performance assessment of the WEC can be carried out. Moreover, based on power production records, it is possible to estimate the annual production and evaluate the cost of energy relatively accurately.

Also, as prototype scales advance, new facts of the deployment sites are looked at. After the first sea trials, or when reaching stage 4, network integration is needed to ensure the electricity generated can be delivered into the grid. To achieve that, the developer has to secure the transmission line and an onshore connection point, and must comply with regulations on power quality. Furthermore, at this stage the developer would normally get revenue from electricity production, according to the support mechanism agreed with the authorities.

For full-scale deployments i.e. stage 5 of EquiMar, it may be of interest to look into locations that allow combinations of different marine technologies, either in the same 
structure or by sharing the sea area. This allows benefiting of the advantages a combined wave and offshore wind energy project, for example, usually brings into a deployment.

A WEC that has successfully followed these steps and has reached the final stage can be considered to have demonstrated its operational capabilities and thus, to have proved the technology. At this point, the WEC is integrated into the energy system as one more energy source and its electricity production becomes another commodity to be traded in electricity markets. The latter requests the predictability of the power production. Having that, the electricity from the WEC can be traded, and the WEC can be considered ready for commercialisation.

Figure 7 depicts a diagram illustrating the above description, where the boxes indicate the main steps or phases of a WEC development and the arrows the development direction. Figure 7 also shows some arrows going backwards towards the initial development stages. This is in line with the circular process shown in Figure 3, and the reasons are the following. Firstly, prototypes have to suit the characteristics of the successive deployment locations and secondly, expenditures increase with completion of steps. As a result, new prototype's features or required prototype's changes are tested at laboratory scale or by simulations. For example, it is common practice that laboratory testing is conducted at various development phases and in laboratories of a large range of sizes that allow testing different conditions. Also, it is normally the case that WEC's design features are modified or finalised when the deployment location is selected (as the first and second loop of Figure 7 indicates), when the network connexion is decided or when a combined wave and wind energy project is chosen (as the third loop suggests).

\section{III.3.2 Research focus}

Many of the topics discussed above have attracted attention from the research community, whereas others have not been looked at in depth. A gap on research has been particularly found in the points that appear after the first laboratory test and prototype design; hence, on stages 3, 4 and 5 of EquiMar. As a result, some of these areas have become the focus of the thesis. As explained above, these subjects are of relevance to reach the commercialisation of WECs and need attention from the wave energy sector, yet they have not been subject of extensive research. The following lines introduce each of the seven study fields and associate them with the papers in the Appendix.

Section IV.1 and Paper A (State of the Art of Wave Energy in Spain) focus on regulations and their impact on the different development stages of a project. In particular, when planning for sea trials constraints may appear, related to the granting of permits and to the agreement on support mechanisms. Moreover, final authorisations to deploy depend, to an extent, on local, regional, national and international regulations for the site. Regulations may cover environmental, grid and spatial requirements. Experience shows it is difficult to estimate the effort and time required to deal with the regulations. 


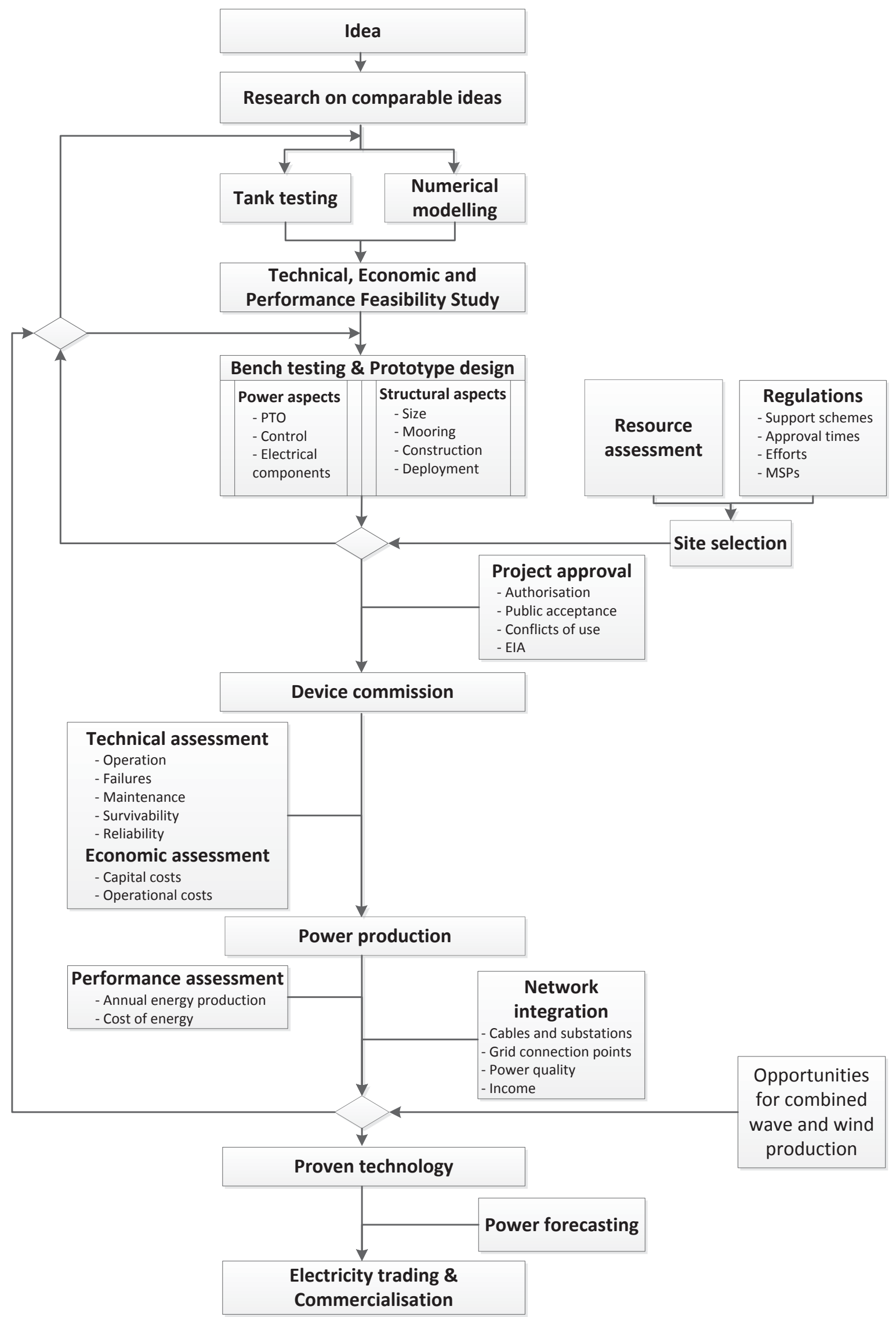

Figure 7. Proposal for a wave energy converter and a project development. 
Public opinion, another major factor considered, is the second subject of study. It is investigated in Section IV.2, Paper B (Toward Best Practices for Public Acceptability in Wave Energy: Whom, How and When to Address) and Paper C (Toward Best Practices for Public Acceptability in Wave Energy: Issues Developers Need to Address). It addresses the response of the public to the implementation of wave energy projects through six case studies. The aim of this work is to answer the questions of when, how, whom and what developers should address with the public to change project opposition or indifference into project positive realisation.

Section IV.3 and Paper D (Performance Assessment of the Wave Dragon Wave Energy Converter Based on the EquiMar Methodology) investigate an objective way to assess the power performance of WECs, of relevance at the various field trials of a development. As shown in Section III.3.1 it is a subject of current discussion among research bodies and guidelines producers.

Section IV.4 and Paper E (Integration of Wave and Offshore Wind Energy in a European Offshore Grid) describe the need of the wave energy sector to plan for future grid connection points. There are limited number of adequate grid connection points on the coastlines and only a few of these will be built offshore as part of offshore wind projects.

Section IV.5 and Paper F (Combined Production of a full-scale Wave Converter and a full-scale Wind Turbine - a Real Case Study) cover the technical advantages of diversified systems, which combine wave and offshore wind energy, based on a real situation that analyses the power production of a WEC and a wind turbine in the Danish North Sea.

Section IV.6, Paper G (Predictability of the Power Output of Three Wave Energy Technologies in the Danish North Sea) and Paper H (Economic Benefit of Combining Wave and Wind Power Productions in Day-Ahead Electricity Markets) examine the technical and economic advantages of including WECs into systems with prevailing presence of offshore wind turbines. The predictability of the wave and wind resources and of the power production of the technologies is analysed. This topic is of great importance to the offshore renewable energy sector, as more accurate forecasts allow better planning for installation periods, for O\&M activities and for storm events, in addition to the trading in the wholesale electricity market.

The last research subject (Section IV.7) regards to the economics of WECs, which are ultimately an important market driver for a wave energy project. The definition of capital costs, operation costs and the cost of energy (COE) is provided. Following that, there has been an initiative from the Danish TSO to establish an economic tool to evaluate the cost of energy of WECs at different locations. The aim of this software is the understanding of the economics behind wave energy project's development.

To conclude, this chapter has presented the different stages of a WEC development from an idea to a commercial realisation. This overview provides the structure under which the 
thesis falls. Next chapter reviews how the regulatory framework influences wave energy developments (Section IV.1) and the way stakeholders' points of view affect a deployment (Section IV.2); it addresses the need to evaluate the performance of a WEC (Section IV.3); it investigates the available grid infrastructures for wave energy projects connection (Section IV.4); it studies the reasons why ideas on combining wave and wind energy continuously emerge (Section IV.5); it evaluates one of the most commonly claimed advantages for the wave energy sector: the predictability of waves (Section IV.6); and lastly, it reviews the economics of wave energy projects (Section IV.7). 


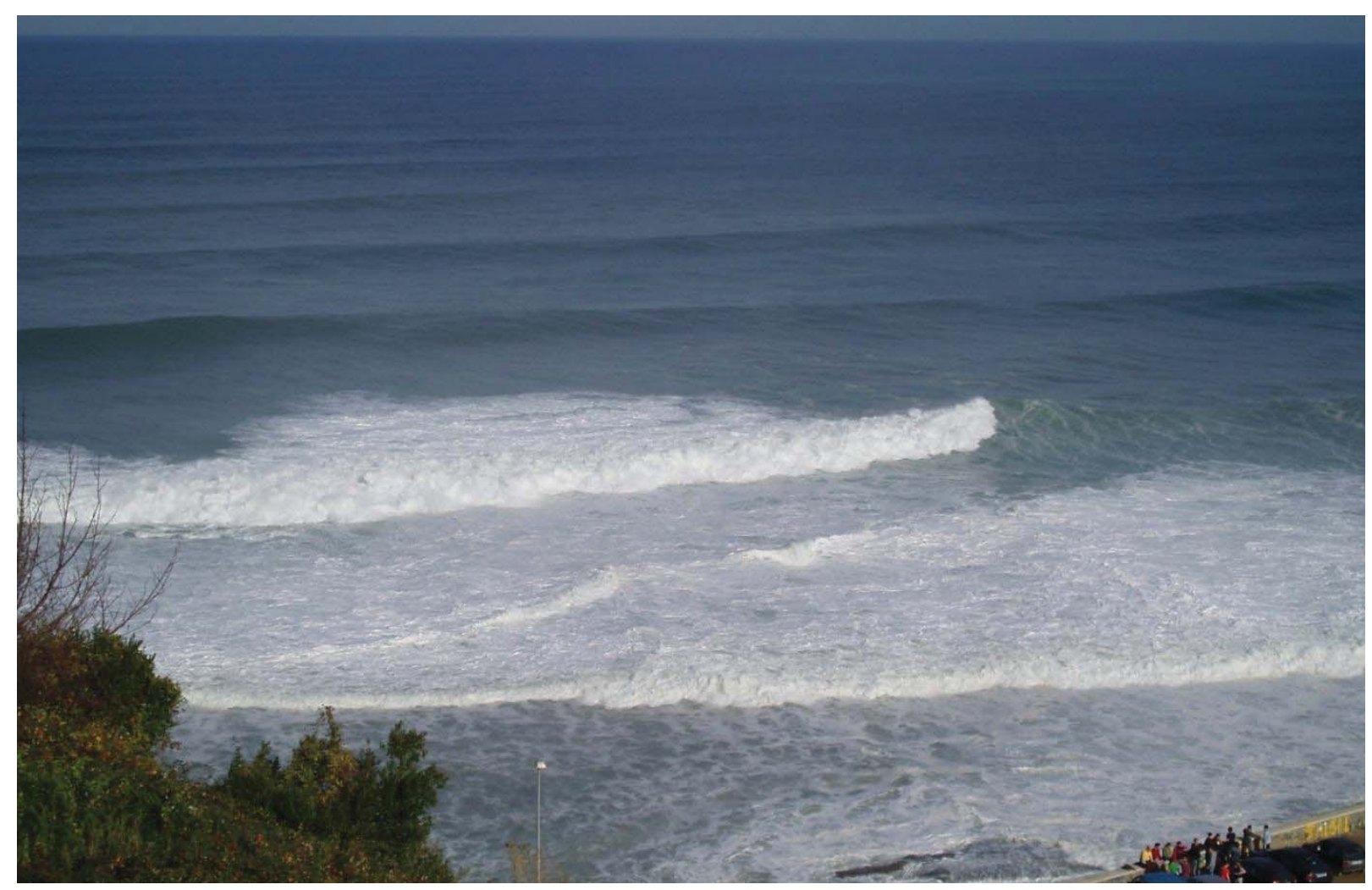

(Mutriku, Biscay, Spain)

\section{Chapter IV - Review of identified issues towards wave energy commercialisation}

This chapter analyses in detail the following topics:

- Regulatory frameworks for wave energy developments.

- The role of public opinion in project implementation.

- The assessment of the power performance of WECs in sea trials.

- The opportunities to grid connect offshore wave energy projects and the synergies in the field with offshore wind.

- The benefits of including wave energy in diversified renewable energy systems.

- The value of wave forecasting.

- The economic assessment of wave energy projects. 


\section{IV.1 Regulatory frameworks}

Regulatory frameworks typically have a large influence on the application of energy plans. They dictate support mechanisms to achieve energy targets and are the ultimately responsible for permission granting. At the same time, national regulations are related to international regulations. The following lines address how they influence WECs' advancements and the execution of energy projects.

Accordingly, this section first investigates the consistency between energy plans and regulations through the implementation of wave energy projects in Spain. Secondly, the relevant regulations pertaining to various stages of a project development are described. A case study introduces the relationship between project realisation, authorisation and support schemes. Given that national regulations might be influenced by trans-national dispositions, the interaction of national with international frameworks is then reviewed, with reference to the European Directives affecting wave energy. This introduces the next topic of Maritime Spatial Planning (MSP), where energy plans, maritime areas and regulations coexist at both national and international levels. The last point is provided by the case study of Kriegers Flak, which exemplifies the coexistence of renewable energy projects realisation and various regulations.

To start with, the relationship between energy plans and regulations is examined. Countries draft energy plans based on imports, exports, the power network capabilities, their available energy sources, industrial policies and job creation, among others. To facilitate the implementation of these energy plans, consistent regulations on energy targets and specific support mechanisms are required. Hence, there are three factors that coexist: the exploitable resources, the energy plans that take into account those potentials and the regulations that influence the realisation of the energy plans. There might be the cases that having the resources there are neither energy plans nor regulations to harness them, or that energy plans exist but regulations are not consistent with the plans. Consequently, there may be a marked difference on the stated objectives of energy plans and the regulatory framework behind them.

This leads to the case of implementation of wave energy in Spain. The state of the art of wave developments in Spain has been reviewed successively in the annual OES reports ((OES, 2009) to (OES, 2012)). However, the comparison among wave activities, national $\mathrm{R} \& \mathrm{D}$ support schemes and regulations in place has not been previously researched. Paper A compares the regulatory framework and funding mechanisms applicable to wave energy with the on-going projects in the field. It indicates that the available wave energy potential in Spain is estimated between 20 to $30 \mathrm{GW}$, which could cover $10 \%$ of the Spanish electricity demand according to the feasibility study of Greenpeace (2005). Within wave energy, a range of R\&D projects, technologies' development, projects' execution and onshore and offshore testing facilities' construction have happened along the years. However, wave energy has not been considered in any national energy plan previous to 2010, when ocean energy first forms part of the Spanish energy strategy. The target is now for 100 MW of installed capacity by 2020 
(Ren, 2012), although feed-in tariffs to all new renewable projects were suspended in 2012 (Real Decreto, 2012).

The next point deals with the fact that regulations do not only have an impact on the overall contribution of the resource into the electricity mix, but also on the evolution of smallscale WEC's developments. In fact, regulations are markedly influencing the development of a project in all its phases. With regard to wave energy projects, regulations often affect the number of facilities dedicated to wave experimental testing, including laboratories and openair test sites, the available funding to carry out the experiments, the financial opportunities (i.e. tax credits and grants) available to the SMEs behind the new technologies, the easiness and simplicity to obtain permissions for WEC prototype testing, construction and commissioning, including time and effort needed, and the economic revenue for the electricity produced.

The realisation of Mutriku OWC wave energy plant in Spain provides an exemplary case study of the relationship between the regulations in force and how they affect execution of a wave energy project. (General history and features of Mutriku project, characteristics of the location and development stages can be found in Paper A, Torre-Enciso et al. (2009) and Torre-Enciso et al. (2012); public opinion of the project is addressed in Paper C). The Mutriku project had broad political support; it was promoted by the regional government and supported by the EC through the Nereida MOWC (Mutriku Oscillating Water Column) FP6 project. Additionally, the required finance and the engineering equipment were available, including sixteen turbines and generators, which were delivered in time. Nevertheless, it took seven years from 'go-ahead' to project commissioning (Torre-Enciso et al., 2012). Two features of the project are of particular relevance: the delay in the permissions due to the EIA and the negotiations for the FIT.

The breakwater itself had its full EIA and the wave energy plant was considered a demonstration project; hence, it was concluded it was not subject of a full EIA. Certain opposition to the breakwater (and thus also to the wave energy plant) claimed there should be a full EIA of the combined plant and breakwater project, and took this issue to court (Paper C). It took three years until the case was solved and the final authorisation to operate the plant was issued. It was finally decided the plant did not need a full EIA.

The FIT had also a major impact on the project. According to the regulations in place, wave energy projects could negotiate a particular electricity generation tariff corresponding to the project investment costs. In January 2008 Mutriku applied for a specific tariff for the project, and four years later this was still waiting for authorities' decision. Mutriku was approved for the general FIT, available to all wave energy projects, of $74.6 \mathrm{EUR} / \mathrm{MWh}$, substantially lower than the project tariff it applied for and also lower than the FIT available for photovoltaic projects, of approximately 470 EUR/MWh (ITC, 2008).

Mutriku is in operation since July 2011. Table I provides some figures of the plant. It shows the accumulated energy production has been relatively smaller than the expected 
production. The reason is that the plant has been out of operation due to a severe storm for almost three winter months, the most energetic wave period. If the plant had been operating those months, accumulated power production would have reached $300 \mathrm{MWh}$ in 2011. Figure 8 illustrates the $100 \mathrm{~m}$ long plant integrated in the curve-shaped $400 \mathrm{~m}$ breakwater, still in construction in the picture.

\begin{tabular}{ll}
\hline Installed capacity & $296 \mathrm{~kW}(16 * 18.5 \mathrm{~kW})$ \\
Average wave energy potential & $7.14 \mathrm{~kW} / \mathrm{m}$ \\
$\begin{array}{l}\text { Expected annual production } \\
\text { Accumulated energy production }\end{array}$ & $600 \mathrm{MWh}$ \\
(in 2011) & $200 \mathrm{MWh}$ \\
Plant costs, including the & $6.4 \mathrm{MEUR}$ (4.4 MEUR civil \\
breakwater & works, 1.5 MEUR equipment, \\
Feed-in tariff & $0.5 \mathrm{MEUR}$ other costs) \\
& 74.6 EUR/MWh
\end{tabular}

Table I and Figure 8. On the left, operational numbers of Mutriku wave energy plant in Biscay (Spain); on the right, the plant in construction (Torre-Enciso et al., 2012).

The next topic addresses how national regulations interact with decisions on international frameworks. Of relevance to this chapter is that numerous Directives on the marine environment and on renewable energies have been set by the European Commission. In some fields, like renewable energy targets or conservation areas, they provide general guidelines, while in others they let each member state to define their own requirements (for example, whether wave plants need an EIA). Five of these Directives affect wave energy: The Renewable Energy Directive (2009/28/EC) (DirRen, 2009), The Birds Directive (2009/147/EC) and The Habitats Directive (92/43/EEC) (DirBird, 2009), The Marine Strategy Framework Directive (2008/56/EC) (DirMar, 2008) and The EIA Directive (2011/92/EU) (DirEIA, 2011). As part of The Renewable Energy Directive each member state has set their NREAPs for 2020. The sum of targets of all member states establishes $2500 \mathrm{MW}$ of installed power for ocean technologies by 2020.

Another interaction between regulations and energy plans is in the form of Maritime Spatial Planning (MSP), which appear at both national and international levels. MSP tries to minimise conflicts of use in the sea while allowing progress of maritime industries such as wave or offshore wind (Zubiate and McIlroy, 2010) (OES, 2012). For this to occur, the sectors have to engage in the creation of MSP systems; which indeed depends on clearly specified and committed energy targets. To contribute to MSP, it is also a request to understand the extent to which technologies can be deployed near to other sea users (see Section IV.4). Ultimately, MSP helps to create, define and coordinate offshore renewable sites and grid infrastructure plans at national and international levels.

MSP is one of the forms on which energy plans affect national and trans-national decisions. The following case study provides an overview of a project where renewable energy realisation and national regulations collate at an international level. Kriegers Flak is an innovative three-country joint project where trans-border power transmission is combined with wind generation from each country. It can be regarded as the first international attempt to 
interconnect different power systems and create a small-scale offshore grid. In this way, it provides best practices to future developments of offshore grids. In part due to its novelty, the project is supported by the EC with 150 MEUR. Section IV.4 and Paper E review the interest and importance of offshore grids and explain their technical challenges. This section addresses how regulations interact with the realisation of a project of this kind.

Kriegers Flak is an area in the Baltic Sea where the exclusive economic zones from Sweden, Germany and Denmark meet. The area has good wind energy potential, 15-40 m water depths and power transmission needs. The goal of the Kriegers Flak project is to interconnect three power systems, with an exchange capacity of up to $1000 \mathrm{MW}$, and install 1600 MW offshore wind capacity (Berge, 2009) (Christiansen, 2009). Both a pre-feasibility (Energinet.dk, 2009) and two feasibility studies (E-Bridge, 2010), (Schröder et al., 2010) indicate more benefits with a meshed solution than with three single grid connections. The two main challenges to implement the project are the three different regulatory systems in force and the three different power markets and networks. Regulations set different support schemes, grid codes and grid connection rules for wind energy in each country. And a common offshore grid integrating the three power networks has to be created, which involves large number of entities responsible for permissions granting.

Project completion will only be followed by Denmark and Germany. Sweden has postponed its engagement in the project mainly because of the unattractive feed-in tariff for offshore wind on Swedish grounds. Nevertheless, despite of its novelty and the difference of regulations the project realisation is planned for 2017 (ENTSO-E, 2012). To facilitate negotiations among countries and with the EC an international decision group has been appointed.

This section has presented how regulations impact on energy plans and affect the way WECs reach their operating and final commercial stage. Mutriku project shows how regulations affect time and efforts needed for project completion. It also illustrates two main factors, which are lacking, in the Spanish regulatory system: a defined licensing framework and certainty in support schemes. The importance of consistent support mechanisms has also been shown by Kriegers Flak project.

In summary, national and international projects require clarity on regulations regarding targets and support schemes, and that authorisation procedures get simplified. For the latter, it is recommended that a single integrity consent regime is introduced - broadly known as the one-stop-shop (DEA, 2006). Regulations should also be drawn in accordance with comprehensive energy plans that include milestones, binding targets and grid infrastructure upgrades. With that, MSPs could be properly defined. At the same time, clarity on support schemes would help to assure certainty for investment to foster the renewable energy projects of focus for energy plans. 


\section{IV.2 Public opinion on wave energy}

Once the regulatory environment has been analysed, it is of relevance to understand people's opinion on wave energy. The motivation behind this research work has been to learn about the views of the public and to define strategies that eventually will lead to positive public endorsement of wave energy projects. The question in focus is the following: is it possible to get closer to the elements of the formula for public acceptability?

Two factors best express the need for this research. In the first place, general opinion about harnessing the power of ocean waves is positive (Neumann, 2009) - everyone involved in wave energy is familiarised to a great extent with spontaneous enthusiastic expressions as response to his/her field of work. However, personal opinion can turn to negativity when a vicinity wave energy project is thought to disrupt the environment, affect tourism negatively or add noise in the area. That was the case of wind development at some locations. Everyday opinion on wind energy was favourable, but a certain point the Not In My Back Yard (NIMBY) 'syndrome' was claimed by many developers as a major hazard against onshore wind turbines implementation. It is important to know why acceptability can swiftly turn to hostility, especially after the literature attests NIMBYism is only one of the factors that makes or breaks a project (Krohn and Damborg, 1999), (Wolsink, 2000), (Devine-Wright, 2005), (Firestone and Kempton, 2007), (Firestone et al., 2009).

Secondly, the wave energy sector is in its development stage and therefore in the key period to approach and engage with citizens, politicians and stakeholders. It is also the moment to address and to learn from engagement strategies of successful projects that have proved effective. This will avoid making the same mistakes as other sectors, since history has shown that interesting developments can be stopped if public opinion has not been dealt with properly (BWEA, 2002).

Accordingly, public acceptability of wave energy projects has been the study subject of Papers B and C. The study proposes best practices to engage with the public. The two papers complement each other; the first one provides recommendations for developers of whom, when and how to address the public and the second one responds to what issues should be addressed. To the author best knowledge the two papers are the first ones looking into public acceptance of wave energy from a practical point of view, which is based on the six wave energy projects. A close research approach has been used by Devine-Wright (2011) based on wind, solar, marine and conventional energy developments within the United Kingdom. By contrast, this study focuses on four different countries and hence, it aims to have a broader applicability range.

Experiences in the offshore wind energy sector and in other renewable projects have proved there is no established formula to achieve public acceptability. Moreover, several case studies have shown that public opinion is strongly dependant on project location and features, although particular engagement practices may help achieve a positive public perception. Hence, the study has reviewed successful engagement strategies from different renewable 
projects. Wave energy developments have then been described and analysed. Then, the questions of whom, when, how and what developers should address have been answered.

The following wave energy developments have been selected as case studies: the Seawave Slot-cone Generator (SSG) Kvitsøy pilot project (Norway), Wave Dragon Pembrokeshire pilot project (Welsh, UK), Ocean Test Berths scoping process (Oregon, US), Mutriku pilot project (Biscay, Spain), Douglas County Wave and Tidal Energy Project (Oregon, US) and Tillamook County Columbia Energy Partners Project (Oregon, US).

The six studies have been selected for the following reasons: they examine distinct issues and look at best practices from different angles, they are recent, and they are geographically diverse (as shown in Figure 9). In fact, the six wave projects represent vividly the relationship between public acceptability of wave energy and their realisation.

For each of the six case studies, project developers' actions, politicians' implications, stakeholders' points of view and locals' response to the projects have been analysed. The analyses show a large variety of behaviours and tendencies both site and project dependent, in which citizens' concerns differ broadly. Nevertheless, the experience proves that early comprehensive information to all interested parties via two-way communication methods contributes to achieving public acceptability most effectively.

In other words, best practices show it is important to involve the public prior to submitting the planning application, in order to avoid later unexpected opposition events. Then, it is important to choose a dynamic approach that facilitates the interaction between parties, as there is an opportunity of feedback from the public about the proposed project. It is also of relevance to address most of the existing local groups and residents, bearing in mind that critical target groups require a sensitive approach. Lastly, to provide open, clear and honest information that deals with the major concerns of the public (see Figure 9). Ideally, this should include an understandable description of wave energy, embracing its advantages, technologies and working principles and a comparison with other renewable sources; hence, prevent the misrepresentation of significant project features. Additionally, it is highly recommended to stress the benefits of the project to the local communities, such as job creation, new infrastructures and energy sources, and added tourist value to the area.

Since the public is encountering wave energy for the first time, the sooner there is an effective approach with the public opinion, the more opportunities for the sector. On the contrary, if public acceptance is not promoted effectively or in due time, public opinion can become a significant hurdle for WECs' commercialisation and large scale wave energy projects' implementation. 


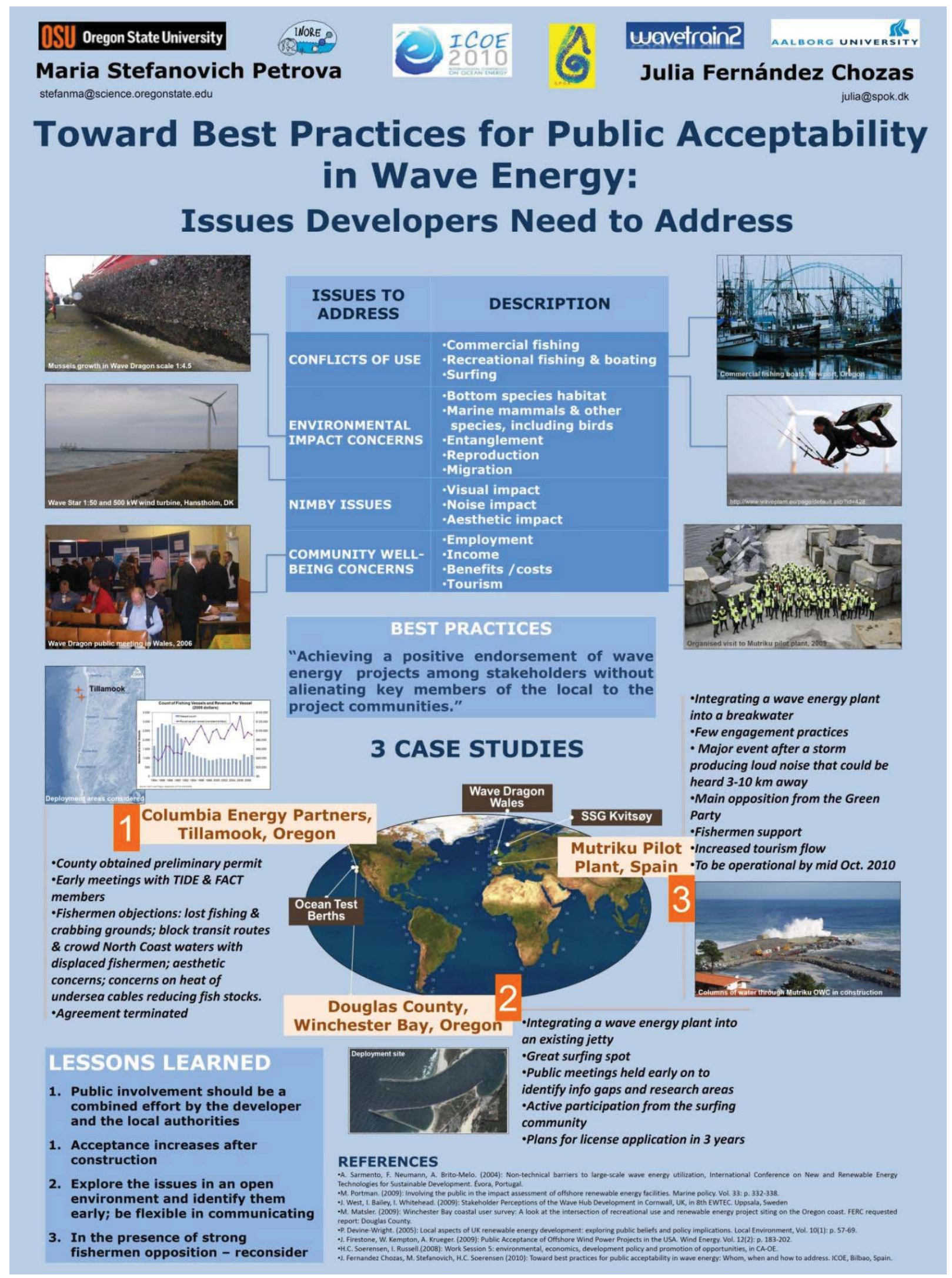

Figure 9. Poster based on Paper C presented at ICOE 2010 (Bilbao). It was awarded the first poster price. 


\section{IV.3 Performance assessment of wave energy converters}

One of the objectives throughout the different stages of a WEC development (Section III.3.1) is to show WEC's performance capabilities. This is true from the initial laboratory tests to the sea trials of the final commercial unit (Pecher, 2012). Once a WEC has carried out initial tests in the real sea the general practice among device developers is to show the production capabilities by a power matrix, which indicates the WEC's power production in different sea states. However, there is high degree of uncertainty related to these values since their origin is often unspecified. They may be derived from laboratory tests, sea trials or numerical modelling. These power matrices are used to evaluate the annual energy production of the WEC at a particular location and from this the final cost of energy of the WEC (Section IV.7).

In response to the lack of standards to evaluate the performance of WECs operating in the sea, the EquiMar consortium has proposed a methodology to cover this gap (Kofoed et al., 2012). The aim has been to establish a transparent and objective methodology that could be applied to the large number of existing wave and tidal technologies. Ultimately, the methodology would lead to quantifiable results of the power production of ocean technologies to present to all interested bodies.

To evaluate the applicability of the proposed methodology two technologies have been selected, the Pico Plant in Portugal and the Wave Dragon in Denmark. Their proven operation in real sea conditions has been the main reason why they have been included as illustrative case studies. Pecher et al. (2011) have covered the case study of Pico, and this Section and Paper D focus on Wave Dragon.

As a result, this section describes the Equimar methodology applied to the analysis of the sea trials performance data of Wave Dragon in Nissum Bredning. The work represents a first approach at validating the methodology for an offshore WEC deployment, which best justifies the novelty for this study. Moreover, there are two main differences between the studies of Pico and of Wave Dragon. The case of Pico characterises the performance of the plant at only the deployment location, whereas Paper D has assessed the WEC behaviour at other sites besides the deployment location. The difference in the PTO between Pico and Wave Dragon has also allowed for a new evaluation of the efficiencies in the intermediate conversion stages.

To start with, the EquiMar methodology covers the analysis and presentation of electrical power production data obtained in sea trials. Due to the fact that sea trials are carried out in the uncontrolled sea environment, a WEC may gather production data for only a limited number of sea states. Additionally, performance data can derive from conditions where the control settings or the WEC's configuration were not optimal. Therefore production data can be largely biased. Hence, to allow for this lack of accuracy, the methodology is based on a statistical approach that quantifies the uncertainties.

The methodology focuses on two, closely related, elements: a location and the WEC. The location is represented by its wave climate and the WEC by its dimensional characteristics. 
There are two types of locations: the 'reference location' and the 'target location'. The reference location corresponds to the sea trials site and to where performance data have been recorded. The target location represents any other site where the WEC's performance is evaluated. Each location is generally associated with different WEC's scales.

In the present study the reference location is Nissum Bredning, an inlet sea on the West part of Denmark - scaled 1:5 of the Danish North Sea - and the corresponding WEC is the Wave Dragon prototype of Nissum Bredning - scale 1:4.5 compared to a commercial North Sea Wave Dragon. The target locations are Hanstholm, in the Danish part of the North Sea, and Ekofisk, further offshore in the North Sea. These sites are suitable for a 1.5 MW Wave Dragon - 1:1.5 scale of the commercial North Sea unit - and for a 4 MW commercial Wave Dragon, respectively.

The final goal of the methodology, and hence of the case study, is to provide - the most accurate and transparent - power matrix, representative of the commercial WEC at the target location, and an estimate of the uncertainty of the given power productions, based on real sea performance data at reduced-scale.

A detailed description of the methodology can be found in Kofoed et al. (2011). The following is a summary of the procedure. First, the wave resource at the reference location is described in the form of a scatter diagram (a zoning of the scatter diagram can be done if needed, where a number of bins of the scatter diagram are combined in zones). Then, the performance matrix of the WEC is created with the recorded performance data. It is the ideal case that various performance data are available for each bin (or zone) of the scatter diagram. Then, the developer chooses the amount and the 'quality' of performance data to present, and provides these values along with statistical parameters reflecting the accuracy of the stated performance, i.e. standard deviation or confidence interval (it should be noted that good production values, not supported by any other data, leads to high uncertainties). Ideally, performance data would only be derived from sea trials, although it is also accepted to base them on numerical modelling and on laboratory testing results. In the case study, performance data of Wave Dragon are solely based on sea trials data.

The methodology characterises the device in terms of 'non-dimensional performance' which refers to the power absorbed by the machine divided by the incident wave power along the WECs' capture length (in Wave Dragon, the capture length corresponds to the width of the ramp) (IEC-TS, 2011). As this parameter is non-dimensional, the performance can be scaled, which allows the comparison between WECs and deployments. It may also permit to comply with developers' confidentiality issues.

With the information of the scatter diagram and of the performance matrix, nondimensional performances can be calculated for each bin of the performance matrix. The nondimensional performance values can be up-scaled to fit the scatter diagrams of target locations. 

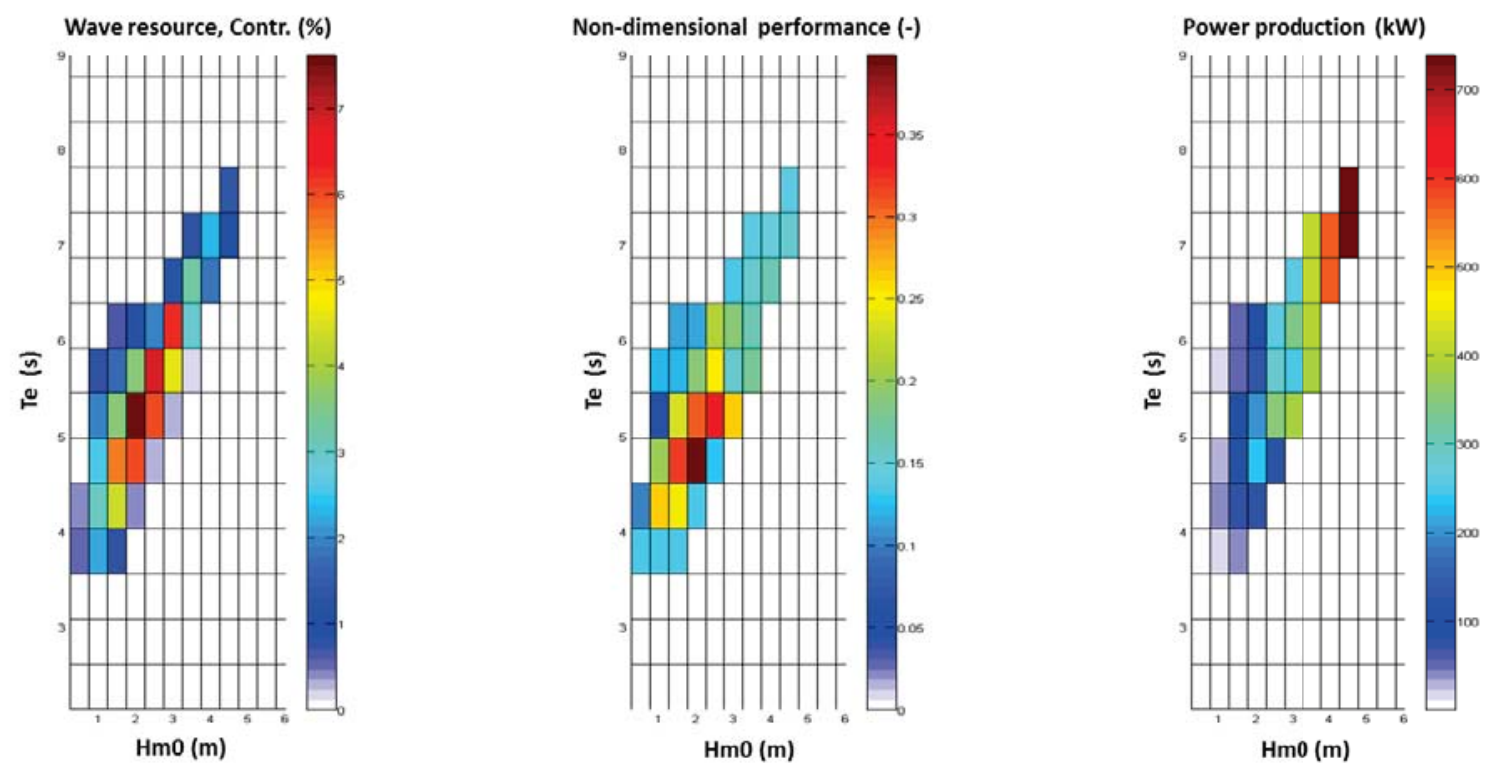

Figure 10. Matrices developed according to the described EquiMar methodology: Hanstholm scatter diagram (left figure), expressed as the contribution of each sea state to the total available wave power; non-dimensional performance of Wave Dragon at Hanstholm (figure in the middle), and power matrix of Wave Dragon at Hanstholm (right figure), for a Wave Dragon without reflectors.

Consequently, the outcome of this exercise (Paper D) has provided i) the nondimensional performance matrix and the uncertainties related to it at Nissum Bredning, ii) Wave Dragon power production estimates at the two target locations and iii) the efficiency of the different energy conversion stages. To validate the results, it is necessary to include information about both the location and the WEC's features, i.e. dimensions, installed capacity and scale. Figure 10 illustrates the incident wave power, the non-dimensional performance matrix and the power production estimates of a Wave Dragon (without reflectors) operating at Hanstholm.

Results show that the up-scaled performance data fit the environmental conditions of Hanstholm well but not those at Ekofisk (Figure 11). There, the up-scaled performance data do not overlap with the populated regions of the scatter diagram, resulting in many uncovered areas.

The methodology is characterised by three facts. Firstly, the performance calculation is an iterative process that advances together with the WEC's development. Thus, when new performance data are available, they can be included to complete the power matrix and reduce the uncertainties. Secondly, it is also possible to include more environmental parameters that characterise the dependency of the WEC towards additional environmental variables. And thirdly, the inclusion of non-dimensional values in the calculations and in the results becomes useful when developers are reluctant to show actual data, and indeed provides a good compromise between transparency and confidentiality. The methodology leaves up to developer's decision to show the calculation steps behind the results. 

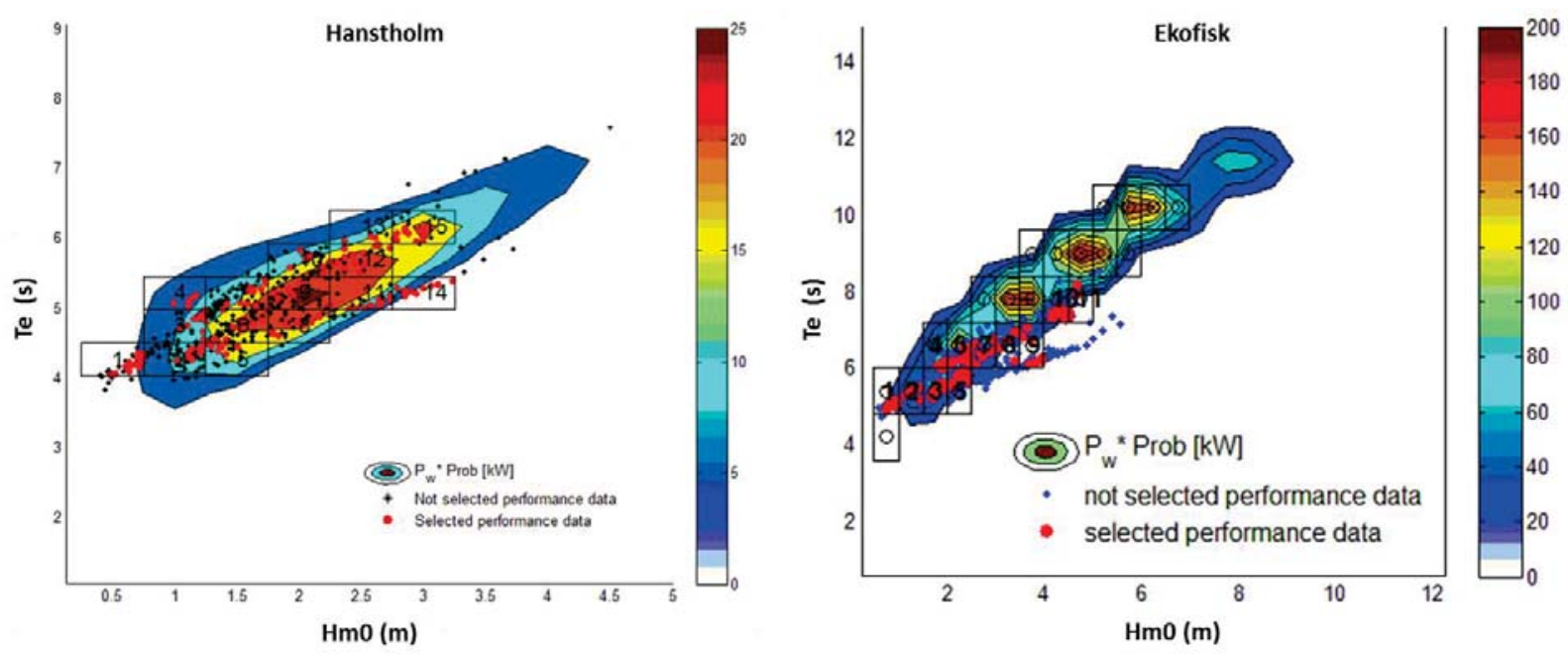

Figure 11. Overlap of up-scaled performance data with the scatter diagram of Hanstholm (left) and of Ekofisk (right). At Hanstholm the overlap is good whereas at Ekofisk there is not good correspondence between data, mainly due to the longer-period waves at Ekofisk compared to Nissum Bredning.

To finalise, general remarks and observations about the methodology, based on the experience of Wave Dragon case study, are included. First, no minimum number of data points has been established on which to base the performance results; thus, the number of points should be indicated to promote transparency.

Ekofisk shows that locations with a low correspondence between the wave climate of the reference and target location require a large number of interpolated or modelled data points. This leads to a different subject point although important when planning for sea trials. When examining a location it is recommended to look into the detailed scatter diagram defining the long term wave conditions at the site rather than into the mean wave energy values (this issue is not particularly dealt with in the thesis, but it is further described in Pecher (2012)).

Thirdly, Wave Dragon also shows that the performance at an intermediate power conversion stage might be more representative of the WEC's performance than the final electricity production. This is particularly true for WEC's prototypes, where the overall system operation does not fully reflect the optimal control situation or the capabilities of the commercial WEC. Also, there may be scale effects associated to the PTO.

Lastly, discussion can be raised on whether it is too early for technologies to apply this methodology and if device developers want to use it. Two more questions arise, are device developers willing to show sea trials data? And, is this methodology easy to understand and to present to stakeholders? The current objective is to show through experience and case studies the benefits of using it. 


\section{IV.4 Grid connection and integration of wave energy in European offshore grids}

This section discusses grid connection for wave energy from the point of view of the lack of offshore and onshore grid infrastructure to absorb large quantities of electrical power generated offshore. Accordingly, this section also addresses the opportunities of creating new grid connection points within newly defined offshore grids.

Proposed scenarios for offshore wind and wave energy developments in Europe indicate these resources could by 2020 contribute an installed capacity of $40 \mathrm{GW}$ and $3.6 \mathrm{GW}$, respectively (the 3.6 GW figure for wave energy includes tidal energy) (EWEA, 2009) (EUOEA, 2010). Undoubtedly, marine energy plants need grid connection points for the electricity generated. Connection points can be located either onshore or offshore as marine hubs, and should have enough capacity to absorb large quantities of power.

National networks were first designed to accommodate central power generation and consumption, and currently most European countries have neither high voltage transmission lines nor strong connection points along their coastlines. This results into lack of grid connection points for the new offshore electricity generation. Hence, three factors broadly justify this study: firstly, the scarcity of grid infrastructure, secondly, the fact that the interaction of wave energy and offshore grids has hardly been addressed, and thirdly, the need to address this issue at the present time. The NorNed project, an offshore cable connecting Norway and The Netherlands, took about fourteen years from planning to completion - by comparison, cable installation time was two years. This means network developments are long term objectives that ultimately take into account designated offshore wind and wave energy development areas (which are related to MSP, as addressed in Section IV.1).

Paper E identifies different proposals for offshore transmission networks, it then examines the synergies between the wave and the offshore wind energy sectors within offshore grid requirements, it reviews the existing alternatives for offshore power transmission, and it describes the economic, financial and social challenges ahead of the realisation of these offshore grids.

Interconnected offshore networks have been investigated for many years. The paper reviews numerous layouts proposed by different panel groups, research institutes and consortiums in which layouts and routes vary. However, all proposals agree on the advantages that meshed offshore grids bring to the network operation compared to radial solutions: the overall operational costs reduces because of power exchange between power systems, and, due to the possibility of transmitting power from offshore to onshore consuming centres and from onshore to oil and gas platforms; meshed grids also provide redundancy in case of system failures, and they help to decrease the variability of offshore resources through regional diversification, a particular relevant point to Section IV.5.

The proposed offshore grid layouts take into account the location of offshore oil and gas platforms and the contribution of offshore wind and solar energy, but barely any of them considers that of waves. The lack of grid connection points is not an issue that would hinder 
the development of the wave energy sector at this stage. However, it urges to already inform relevant stakeholders and coordination bodies (i.e. the EC, the European Network of Transmission System Operators for Electricity or ENTSO-E (ENTSO-E, 2013), the Agency for the Cooperation of Energy Regulators (ACER, 2013)) about the expected role of wave energy in few years' time, including marine energy plans and designated areas for wave siting, which eventually will allow for planning of network connections.

Moreover, there are obvious and explicit synergies in the requirements of wave and wind energy projects for connection points and infrastructure upgrades. Both sectors are encountering similar challenges regarding grid connection, and similarly, both sectors risk that connection points dictate the location of wave and offshore wind energy developments, rather than the available resources (which could be avoided by planned MSPs). Accordingly, combined efforts should be made to develop offshore interconnected networks suitable for the integration of farms of WECs and of offshore wind turbines.

Broadly, two alternatives exist for high voltage power transmission, with alternating current (HVAC) or with direct current (HVDC) (Ackermann, 2002). On one hand, HVAC is the simplest and cheapest connection for long-distance overhead lines onshore but for subsea transmissions it can only be used for limited distances (from $100 \mathrm{~km}$ onwards cable properties largely degrade even with inductive compensation in both ends of the cable). On the other hand, HVDC results as the best option for the connection of offshore renewables, since it allows connecting asynchronous power systems. However, it entails expensive converter stations.

There are two types of HVDC connections, those based on Line Commutated Converters (LCC) using thyristors and those based on Voltage Source Converters (VSC) using transistors. The former is a proven technology for long and high capacity links as well as for connecting asynchronous systems, but it has limitations for low transmission capacities. Conversely, VSC can connect weak grids, can provide start-up capabilities and can support the power system by controlling independently the active and the reactive power. However, some components like the DC circuit breakers have only been recently developed (CircuitBrakers, 2013) and hence the available links have currently a limited capacity of 1200 MW working at $\pm 320 \mathrm{kV}$ (ABB, 2013), some of their capabilities as the multi-terminal systems have not been proved yet, and there are neither established standards.

The last part of Paper E, which covers the challenges ahead of the realisation of these offshore grids, has been discussed in Section IV.1. It provides a comprehensive example of a challenging technical development that also faces regulatory and financial issues. Kriegers Flak shows how technical and non-technical elements co-exist and depend on that the others factors are executed, implemented and fulfilled in order to achieve the goal.

Paper E looks into current initiatives to reinforce and expand the European electricity network, the opportunities and challenges towards its realisation and the synergies in grid connection of the wave and the offshore wind energy sectors. The lack of available strong 
grid connection points onshore, which is already an issue for offshore wind farms in some countries, may hinder the development of the wave sector if network upgrades do not plan for wave energy development sites. The short-term solution for this has been the creation of a number of test sites in Europe, mostly concentrated along the Atlantic coast, where grid connection lines are facilitated (Nielsen et al., 2010). There, the so called 'plug-and-play' routine is used.

\section{IV.5 Diversified renewable systems with wave and offshore wind production}

This section focuses on the opportunities of combining the power production of different technologies in the same site in relation to the pattern of the power output. Particularly, it looks into the combined power production of WECs and wind turbines.

The term diversified renewable systems refers to an energy system composed of various renewable resources, located in a range of areas within the same or in a different energy system. These systems usually embrace solar (thermal and photovoltaic), biomass, wind, wave and tidal generation, or any combination among them. The two key benefits of diversification are that the variability of the produced power can be decreased, and power availability can be increased. These benefits can be achieved by combining different resources, the more un-correlated the better. Otherwise, when only one resource is available wind energy for example - these benefits can only be realised by aggregating the power of geographically disperse sites.

The understanding of the properties and characteristics of diversified system has been the focus of recent research in several countries. Following the core idea of the thesis, only the studies covering marine resources are investigated.

ECI (2005) examines the variability of waves and tidal currents working individually and combined at different locations in the United Kingdom, and relates them to the demand. Among the conclusions it indicates that a combined wave and tidal scenario harnessing the resources at different sites has smoother variability when compared to the tidal-only scenario, and highlights the least variability in the production in a diversified scenario composed by offshore and onshore wind, wave and tidal current productions. This study is continued by ECI (2006), and it looks into a hypothetical scenario with offshore wind, wave and tidal energy covering $20 \%$ of United Kingdom's demand. It compares the benefits of an offshore wind, wave and tidal scenario with a wind-only scenario, and concludes that the diversified system increases the capacity credit and reduces the variability and the additional balancing costs of the system.

A comparable theoretical research is done in Denmark for the offshore wind farm Horns Rev I, located off West Jutland (Soerensen et al., 2005). The analysis of co-production of wave and wind proves that the delay in winds and waves reflect in the response of the technologies. Wind turbines reach full production 1 to 6 hours before WECs do, and afterwards WECs continue at full power 6 to 8 hours after the power of offshore wind turbines starts decreasing. The study also discusses the variability of the power output and 
suggests that the half-hour variability of wind production is 3 times higher than for wave production; and this would strengthen during storm events.

The opportunities of providing all the electricity supply of a French island with offshore wind and wave energy is the study subject of Babarit et al. (2006). The analysis concludes the power outputs of the two resources are too correlated to allow for a self-sufficient renewable power system, unless a storage system is included. With that configuration high independency would be achieved, and the island could then become a net electricity exporter to the mainland.

The cross-correlation between the wave and wind resources is also the study subject of Fusco et al. (2010), with focus on a number of sites around Ireland. In the locations where the correlation is low, the combination of wave and wind energy allows for a more reliable, less variable and more predictable electrical power production than with the individual productions.

Stoutenburg et al. (2010) also look into the aggregate production of offshore wind and wave energy farms in California by studying the cross-correlation between the two resources. Their findings on variability reduction and increase of system reliability go in line with the findings of the previous studies.

Lastly, Cradden et al. (2011) investigate the same properties of diversified offshore wind and wave systems in three sites around Europe, at EMEC in Scotland, at SEM-REV in France and at the Biscay Marine Energy Platform (BIMEP) in Spain. The study investigates the correlation and the delay between waves and winds, and compares the percentage of time of no production, with full production, and the power variability for different wave and wind scenarios. It also analyses the correlation of the power output of different scenarios with United Kingdom's power demand. All results coincide with those from previous studies and indicate again that the best match to fulfil United Kingdom's power demand is by utilising both wind and wave energy sources.

All the mentioned studies conclude there are numerous benefits when co-locating in the same sea area WECs and offshore wind turbines. According to that, the thesis has investigated a range of cases where these benefits arise. Section IV.4 and Paper E have reviewed the synergies of WECs and offshore wind turbines in relation to grid connection points and offshore grids. This section focuses on the benefits of a combined wave and wind power output compared to the individual productions. And to finalise, Section IV.6 looks into the advantages of combining WECs and offshore wind turbines with respect to the predictability of the power production, which has an important impact on electricity markets.

The subject of this section is investigated through a real case study. It is based on Wavestar wave energy converter (Kramer et al., 2011) and a wind turbine from the Nordisk Folkecenter for Renewable Energy (Nordic, 2013) placed on the coast. It analyses the individual power productions of the WEC and of the wind turbine and compares them to the 


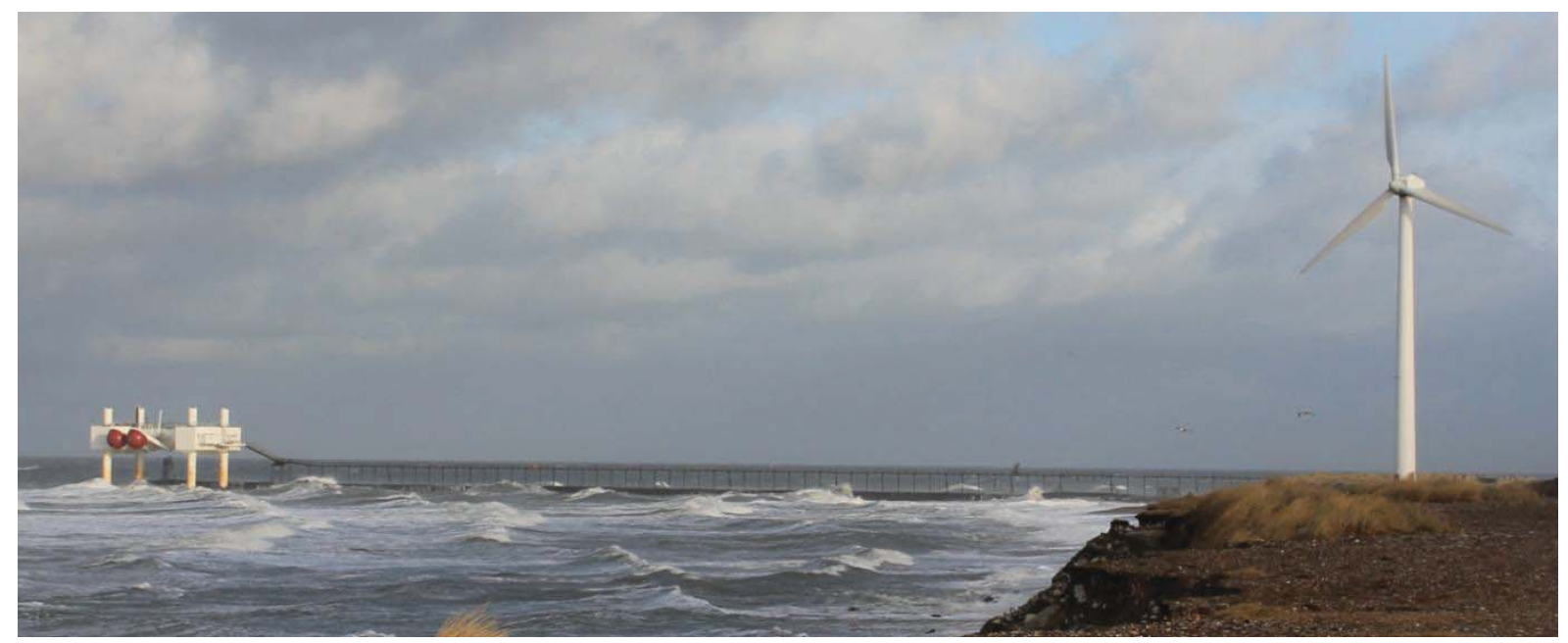

Figure 12. Wavestar (on storm protection mode) and Folkecenter wind turbine at Hanstholm, Denmark.

combined power production, based on real production data of the two technologies. To the author's best knowledge the study comprises the first research investigating and comparing real power productions of WECs and wind turbines. This study has been published in Paper F.

Wavestar and the wind turbine are located at Hanstholm, on the North-West coast of Jutland, in Denmark. Wavestar is in near-shore waters $300 \mathrm{~m}$ offshore and the wind turbine is on the coast, in a straight line $350 \mathrm{~m}$ from the WEC (Figure 12). The Wavestar prototype at Hanstholm corresponds to a section of the full-scale WEC, and it is rated at $110 \mathrm{~kW}$. It was deployed in September 2009, and since September 2010 it has achieved relatively continuous power production (Vidal et al., 2012). The wind turbine was manufactured in 1996 and has been in operation from that date. It is rated at $525 \mathrm{~kW}$.

Simultaneous power production data from both technologies are available for a fivemonth period, ranging from January to May 2011. (In order to compare the performance of the two technologies, non-dimensional power productions - expressed as a percentage of maximum power output - have been used throughout the study). Also, wave and wind measurements on the same site have been recorded for that period. The two sets of measurements have been used to compare the resources and the power productions, since results on the combined power output strongly depend on the relationship between waves and winds.

The most indicative findings of this research relate to the characteristics of the combined power production compared to the individual productions of the two technologies. Overall, the combined power output is smoother and provides higher availability than the individual productions. A smooth or less variable output refers to the fact that both the peaks and the fast changes found in the individual productions reduce when these are combined. The study shows the percentage of time with power productions above $80 \%$ drops to $3 \%$ of the time when the technologies are combined, compared to $11 \%$ and $9 \%$ of the time if the WEC and the wind turbine work alone, respectively. Figures on power output variability indicate that 


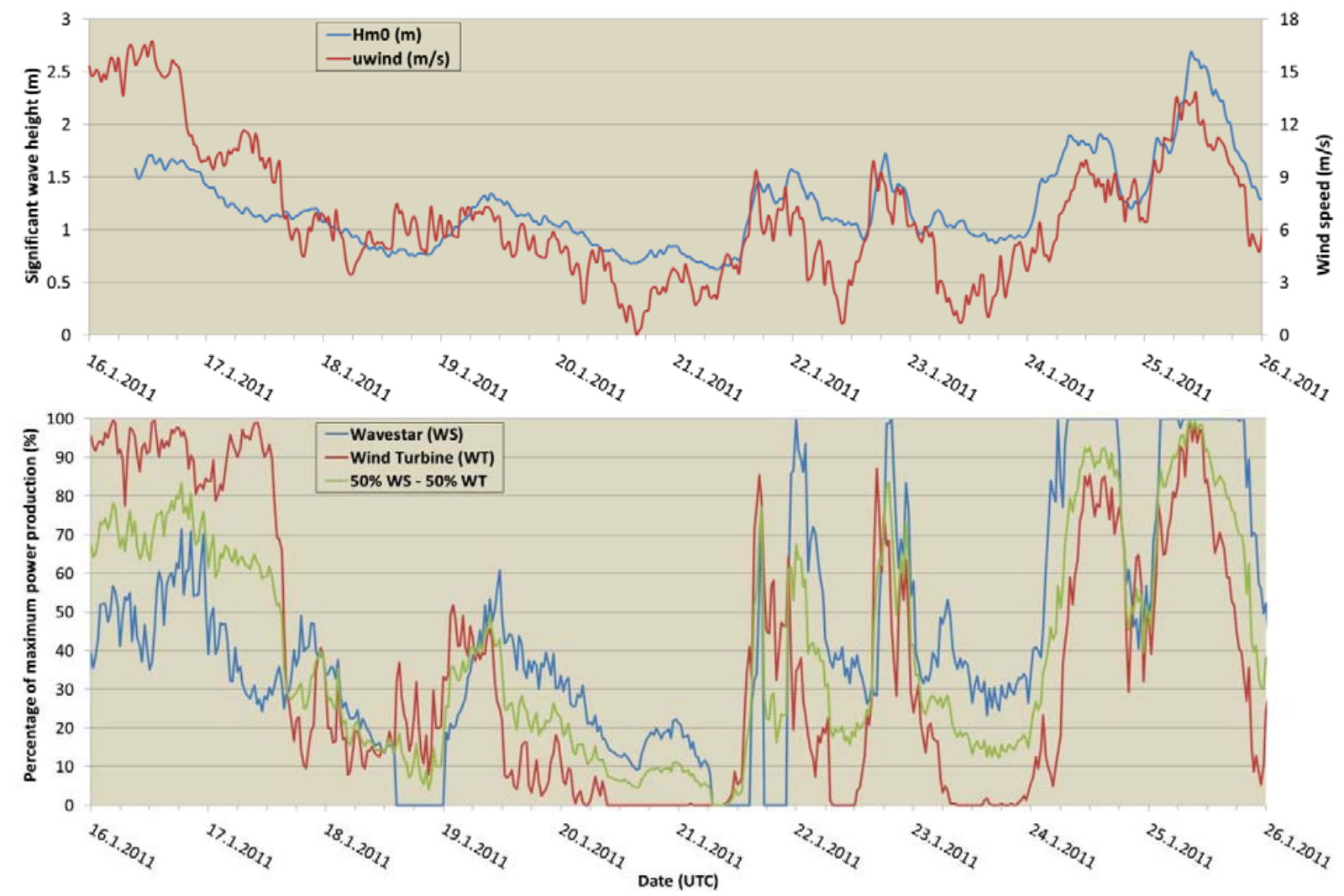

Figure 13. Significant wave height (blue), wind speed (red), and real power productions of Wavestar (blue), of the wind turbine (red) and a combination of both (green), expressed as a percentage of maximum power output, during 10 days of January 2011.

the combined scenario reduces the variability of the power output $11 \%$ to $31 \%$. Availability is improved thanks to a significant reduction of the time the combined power production drops to zero ( $6 \%$ of the time), compared to the periods where the individual productions are at null power (13\% of the time for wind and $36 \%$ for wave).

These two properties are related to the inherent characteristics of waves and winds and their relationship, which have also been examined. A cross-correlation study indicates high relationship between the two resources (cross-correlation factor of 0.8) and an average phase shift between a wind and the corresponding waves of about 3 hours that can go up to 9 hours. This is related to the fact that Hanstholm is dominated by wind seas. Waves also present lower variability and slower changes than winds. These two features affect the pattern of the individual and the combined power production. In order to compare them, Figure 13 illustrates the evolution of the wave and the wind resource (upper graph) and the power production of Wavestar, of the wind turbine, and of a combination of the two in equal parts, i.e. 50\%:50\% scenario (lower graph). (Paper $\mathrm{F}$ has investigated three combined wave-wind scenarios: the 75\%:25\% wave-wind scenario, the 50\%:50\% and the 25\%:75\%). FernándezChozas et al. (2013) discuss which pair of parameters (i.e. $H_{m 0}$ and $u_{\text {wind }}$ or $H_{m 0}{ }^{2.5}$ and $u_{\text {wind }}{ }^{3}$ ) describe more accuratey the relationship between the resource and the response of the two technologies. Results indicate the evolution of $H_{m 0}$ and $u_{\text {wind }}$ is more correlated with the power production of Wavestar and the wind turbine than for the other pair of values. 
Results obtained in this study are site specific and are based on two technologies with more than one decade of difference in gained operating experience. Whereas Wavestar was first deployed in Hanstholm in 2009, the wind turbine was commissioned 13 years before. Overall, the study has shown the combined production is less variable and more available than the individual productions, which is in line with the findings of the studies introduced at the beginning of the section. These properties are of upmost importance to the operation of the electrical grid. TSOs have to secure continuous electricity supply and the variability inherent to some renewables, like wave and wind energy, has been claimed to work against that request. However, despite the fact that the general advantages of combined developments have been identified, Paper F evaluates the case of one WEC and one ashore wind turbine. A change in power outputs' pattern is expected if several WECs and offshore wind energy turbines, and if more than one type of WEC are considered. In addition, the study location has been Hanstholm, where there is high correlation between waves and winds. Instead, the benefits of a combined wave and wind energy system will be more evident in a location with predominant swell waves.

In line with the impetuous for diversified systems, new ideas emerge for common structures and WECs that can harness both the energy of waves and winds (Casale et al., 2011). Furthermore, recent European projects are evaluating the construction of combined platforms suitable for wave and wind power production, hydrogen production, aquaculture, offshore service facilities and/or leisure activities (as explained in Section II.3.1).

This section has first reviewed the general benefits of diversified systems based on theoretical studies; and secondly, it has investigated the benefits of a combined wave and wind energy system based on real power production data at Hanstholm. The first and the second part of the section corroborate the benefits in the power output of diversified systems with co-production of wave and offshore wind. Beyond these, Section IV.6 identifies additional technical and economic benefits for combined wave and wind energy systems.

\section{IV.6 Wave and wind forecasting and balancing costs}

One of the most commonly mentioned advantages of wave energy is related to the predictability of waves. Sentences like 'waves are predictable' or 'waves are more predictable than winds' can largely be found in the literature. Also the author wrote in 2009: 'wave energy presents the following advantages: can be forecasted several days ahead' (Paper A). However, a quantifiable number evaluating wave predictability is not easily found on literature and research on wave forecasting is limited to few studies (Rugbjerg et al., 2006), (Pinson et al., 2012). As a result, the aim of this research has been to quantify the predictability of waves.

Because of the fact that waves are created by winds, waves can be forecasted at a particular site by knowing the corresponding winds that affect wave generation and propagation, and the site's characteristics. Based on that principle, an increasing number of 
wave forecast's models are being developed (Kirkegaard et al., 2010), (Meteo Group, 2012), (Storm Geo, 2012).

Accurate wave forecasts are of benefit to a number of fields. Merchant and fishing fleet aside, waves forecasting provides significant advantages for the offshore wind and the wave energy sector. For example, to schedule installation and maintenance activities, to define control strategies according to the predominant wave conditions, or to plan for storm events. Moreover, accurate wave forecasting can also be of interest to electricity markets. In the dayahead electricity market, all the electricity that will be generated and consumed on the next day is traded, and hence, electricity producers bid in the market the electricity they expect to produce on the next day. In the case of Denmark, which participates in the Nord Pool Spot, gate closure of day-ahead markets is at noon (Nord Pool Spot, 2009). Thus, bids have to be made at least 12 to 36 hours ahead the actual generation hour (Figure 14). This applies to all electricity producers, both for conventional power plants and for renewable generation. For hydropower plants, coal or gas fire plants, day-ahead bids are significantly accurate. However, for wind power producers or eventually for wave power producers - when technologies reach the commercial stage -, bids might have a considerable error related to the partial unpredictability of the resources. The error in the power production estimates has an associated cost. In electricity markets this is known as balancing costs.

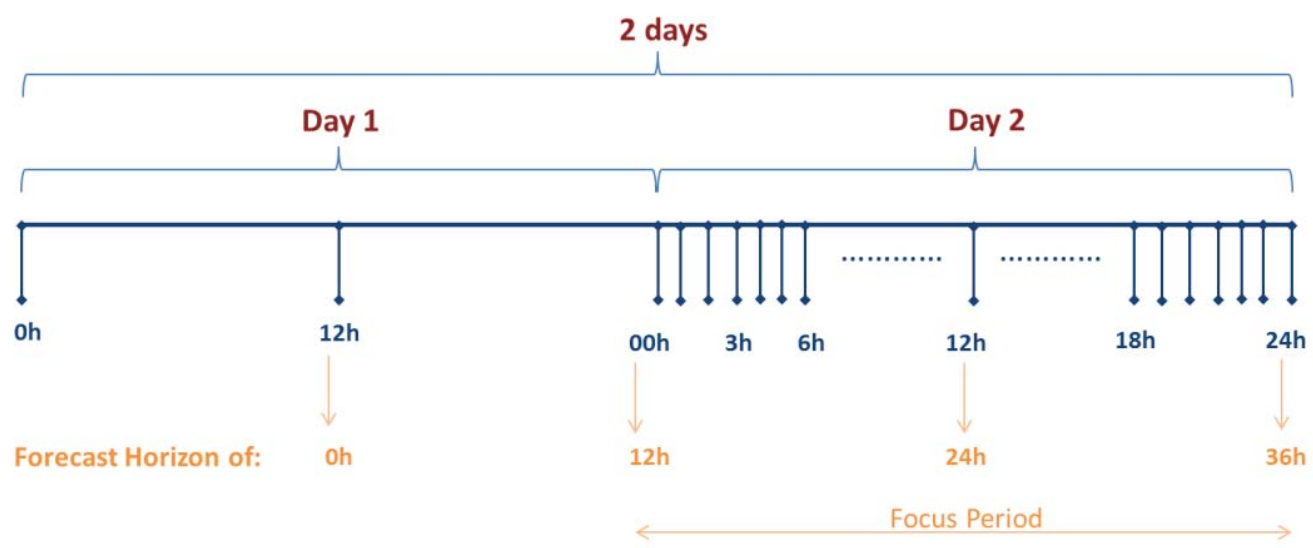

Figure 14. Focus period and forecast horizons of the Danish day-ahead electricity market.

Energinet.dk is the Danish national body responsible of managing the grid, including the imbalances of the electric system (Energinet.dk, 2013). The introduction of large quantities of wind generation into the Danish system has increased system imbalances, and Energinet.dk invests on balancing premium tariffs that wind producers receive to manage their power imbalances (IEA, 2011). Accordingly, Energinet.dk has raised its interest on the imbalances wave generation would add or reduce to the system, compared to the current imbalances of wind production. It aims to have an estimate of the balancing costs of wave energy compared to the current balancing costs of wind energy. This issue is the scope of the research project "Analysis of power output predictability of wave and wind", to which the studies presented in this section form part (PSO, 2013). 
In line with this, the purpose of this study has been first, to quantify how accurately waves can be predicted and compare that value to the estimations on winds predictability; second, expand the calculations to wave and wind power productions predictability; third, based on the power productions estimate the errors incurred in the bids to the day-ahead market, both for wave and for wind energy; and lastly, evaluate economically those errors and assess the economic benefits, in terms of reduction in balancing costs, of including wave energy in a system based on wind energy solely. Four scenarios are considered in the study: the wind-only scenario, where the wind turbines work individually; the wave-only scenario, where the WECs work alone; the combined wave scenario, with all WECs working combined; and combined wave and wind scenario, embracing all technologies.

On the whole, the research focus has been on establishing the economic value to waves' predictability. To the author's knowledge, it is the first comprehensive study on wave power forecasting in North Sea waters, both for waves and for WECs' power productions. The work is formed by several studies: Paper G, Paper H, (Fernández-Chozas, 2012b), (FernándezChozas, 2012c) and (Fernández-Chozas et al., 2013).

Very few studies have previously related wave forecasting with balancing costs incurred by wave power productions. ECI (2006) is the most comprehensive review on the impact on balancing costs when adding $52 \%$ of wave energy in a $100 \%$ wind scenario. It focuses on various sites along the British coast. Conversely, extensive work has been carried out for wind forecasting and balancing costs of wind (Costa et al., 2008), (Kariniotakis et al., 2004), (Morthorst, 2007), (IEA, 2011), (Holttinen, 2005).

Research on wave forecasting can beneficiate of wind predictability analyses. There, two parameters generally evaluate the accuracies of the forecasts, the mean absolute error (MAE) and the root mean square of the error (RMSE). The former parameter quantifies the error of the measurements in absolute values and is mostly utilised by TSOs and grid regulations, whereas the latter evaluates statistically the errors and is mostly used by academia. Besides, MAE can be directly related to a cost, whereas RMSE cannot. Since the final goal of this research is making an economic estimate (i.e. provide a value for balancing costs) it is more coherent to express forecast errors in terms of MAEs (forecast errors expressed in terms of RMSEs, scatter indices and cross-correlation coefficients can be found in the author's references provided above). When wave heights and wind speeds forecasts are evaluated the indices MAE and MAE/Mean are provided, and for power productions the parameter NMAE is given, where $N$ indicates normalised, and thus NMAE is the normalised value of MAE, in terms of maximum power production.

$$
\begin{aligned}
& M A E=\frac{1}{N} \sum_{i=1}^{N}\left(\left|P_{M O D}-P_{O B S}\right|\right)_{i} \\
& R M S E=\sqrt{\frac{1}{N} \sum_{i=1}^{N}\left(\left|P_{M O D}-P_{O B S}\right|\right)_{i}^{2}} \\
& N M A E=\frac{1}{P_{\text {rated }^{*} N}} \sum_{i=1}^{N}\left(\left|P_{M O D}-P_{O B S}\right|\right)_{i}
\end{aligned}
$$


The study location has been Hanstholm, on the Danish part of the North Sea (see Section IV.5), where both forecast and observed wave and wind data were available for a five-month autumn and winter period (i.e. from October 2010 to February 2011). Forecast data have been provided by the Danish Hydraulic Institute and measured data by the Danish Coastal Authority. Both sets of values were obtained at $1.3 \mathrm{~km}$ distance and at the same time periods. The comparison between the sets of observed data with forecast data provided an estimate on waves and winds forecasts' accuracy for different forecast horizons. Figure 15 illustrates these values for the significant wave height, the zero-crossing wave period and the wind speed. Fernández-Chozas et al. (2013) show their predictabilities represent more accurately technologies' power output predictability than the corresponding available wave or wind energy.

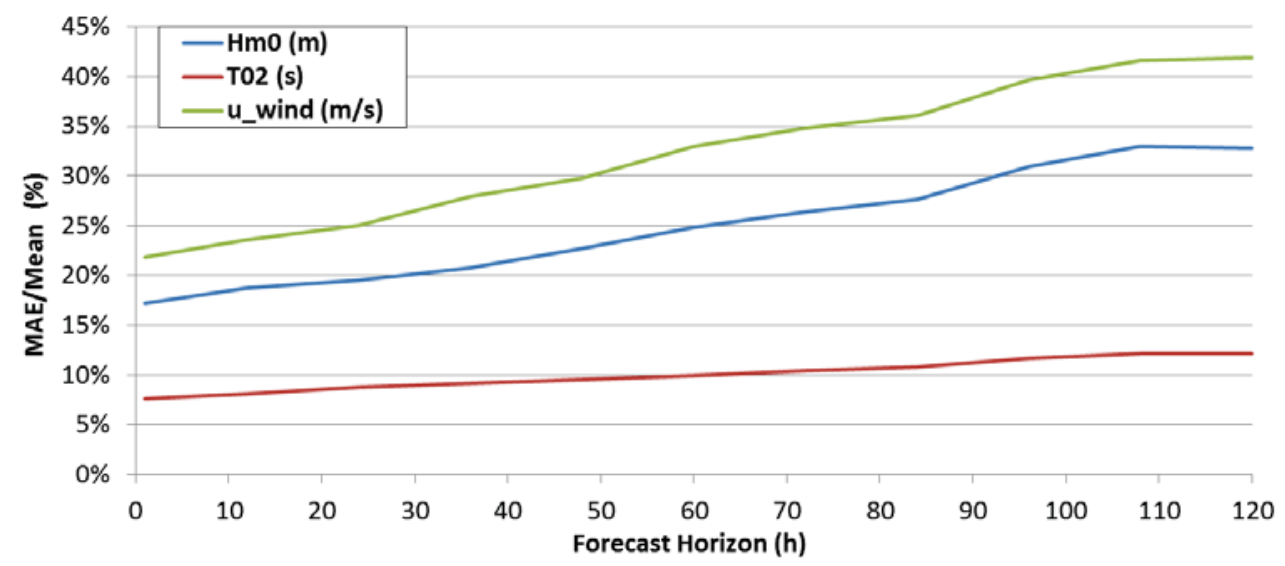

Figure 15. 5-day forecast errors, in terms of MAE/Mean, of the significant wave height (in blue), the zero crossing period (in red) and the wind speed (in green) at Hanstholm during the study period.

Then, the predictability of the power outputs of wave and wind technologies have been obtained (Figure 16). With forecast and observed data of waves and winds, along with the power matrices of three WECs and the power curves of two offshore wind turbines, forecast and observed power production data have been modelled for the wave and the wind technologies, respectively.

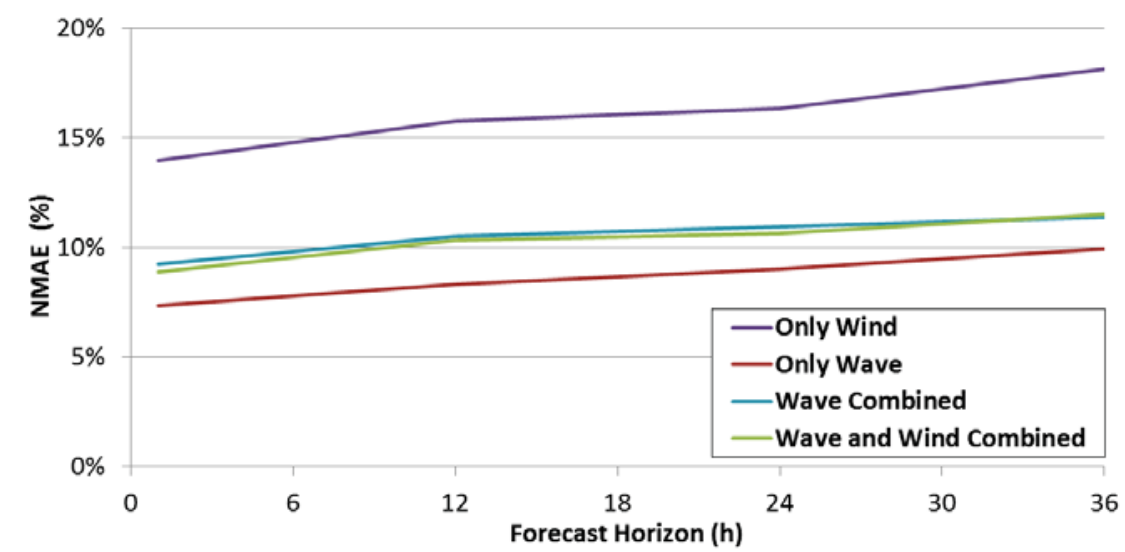

Figure 16. Day-ahead forecast errors (in terms of NMAE) of the power production of: wind turbines (in purple), WECs (in red), WECs working combined (blue) and WECs and wind turbines combined (in green) at Hanstholm. 
The selected WECs are Pelamis (Henderson, 2005), Wave Dragon (Tedd et al., 2006) and Wavestar (Kramer et al., 2011), and their power matrices have been scaled to suit the predominant wave conditions at the study site. The two power curves are the generic power curve for offshore turbines (McLean, 2008) and the power curve representing Horns Rev I farm (Soerensen et al., 2005). Again, the comparison between the two sets of modelled values has provided results on the forecasts errors of WECs' and wind turbines' power productions. Figure 16 shows the errors in the predictability, in terms of NMAE, for day-ahead forecast horizons and for the four scenarios of the study.

From the previous calculations, the errors in day-ahead power productions' forecasts have been estimated for every day of the study period assuming that the electricity generated by the wind turbines and the WECs has been traded in the Danish day-ahead electricity market. Thus, relevant forecasts horizons are 12 to 36 hours.

Balancing costs associated to the errors in those day-ahead forecasts have been calculated. Balancing costs are dictated by a two-price model, where two factors interact: the direction of the imbalances of the traded power production, and the direction of the imbalances of the general power system. Day-ahead forecasts can under-predict or overpredict the real amount of power that is produced. Accordingly, a producer buys or sells the difference between predicted and real power. Then, system imbalances can cause the electric system to be in excess or in deficit of power - in other words, request downward regulation or upward regulation -, which influences the amount that is charged or paid to the producer, i.e. upward, downward or electricity market price. (For every hour of the study period the upward and downward regulation price and the electricity market price are known from Energinet.dk (2013). Consequently, there are four possible cases (Figure 17):

a) A forecast overestimating the production and a system in deficit of power. The producer buys power at up-regulation price.

b) A forecast overestimating the production and a system in excess of power. The producer buys power at market price.

c) A forecast underestimating the production and a system in deficit of power. The producer sells power at market price.

d) A forecast underestimating the production and a system in excess of power. The producer sells power at down-regulation price.

Consequently, balancing costs have been calculated for the four original scenarios based on modelled day-ahead power productions forecasts and on modelled real-time productions, and on market and balancing electricity prices. 

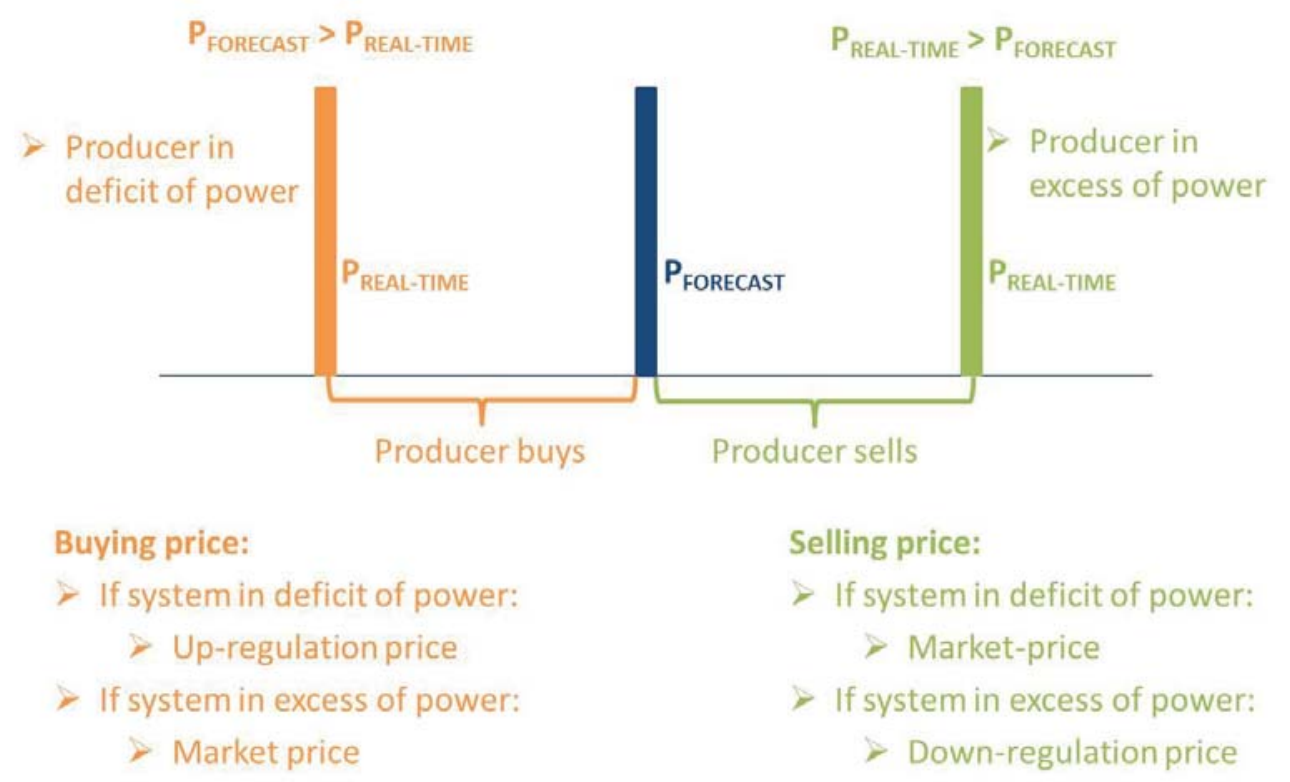

Figure 17. Illustration of the two-price model applicable in Denmark to calculate balancing costs. $P_{\text {forecast }}$ represents day-ahead production forecasts and $\mathbf{P}_{\text {real-time }}$ the actual production in the generation hour.

Results on balancing costs go in line with the findings on forecasts accuracies. When wave energy is integrated in a wind-only system, power productions' forecast accuracies improve. Similarly, any scenario with contribution of wave energy presents smaller balancing costs than the wind-only scenario. The reduction of overall balancing cost compared to the wind-only scenario reaches $45 \%$ when WECs work individually, $40 \%$ when WECs work combined and $35 \%$ in the combined wave and wind scenario.

As a result, this study has investigated the predictability of the wave and wind conditions at Hanstholm for forecast horizons of up to five days. It has also examined the accuracies in the power productions' forecasts of WECs and of wind turbines, working alone and combined for day-ahead horizons. And finally, it has evaluated the costs associated with the lack of accuracy of the forecasts. Results suggest that for day-ahead forecasts, in terms of MAE/Mean and NMAE, waves are 23\% more predictable than winds, the power output of WECs is $35 \%$ more predictable than for wind turbines, and the inclusion of wave energy in a wind-only system reduces balancing costs up to 35\%. In a nutshell, results have shown the benefits of waves' predictability.

These findings are in line with Rugbjerg et al. (2006), whose study location shares common features with the project study site, with Pinson et al. (2012) and with ECI (2006), who concludes a diversified system with wave and wind energy decreases the additional balancing costs by $36 \%$ compared to the wind-only scenario. Similarly to this study, ECI (2006) is based on three WECs, to account for the different response of WECs to sea conditions. However, it does not optimise the WECs for the predominant wave conditions of the study site.

It should be noted this study is dependent on the study location and its metocean characteristics, and on the power matrices and on the power curves of the selected 
technologies. Throughout the study different results on wind speed and wind power forecasting have been provided, in order to compare predictability of waves and winds under the same assumptions and with the same conditions. It is important to emphasise that these results are based on calculations specific for this case study, but they do not fully reflect the state of the art of wind forecasting. Moreover, due to the high correlation between waves and winds in the study location, the benefits wave energy brings to the case study are limited. In a location with predominant swell waves the benefits of a combined wave and wind energy system increase.

To finalise, a last remark on this study is included. This research has requested extensive work on data management, including data gathering, processing and analysis. A throughout resource assessment of the study site has also been carried out and accordingly, WECs' power matrices have been optimised to maximise technologies' power productions in the study period. Project assumptions and features, methodology, power productions' predictabilities as well as detailed calculations, results and discussions are covered extensively in FernándezChozas et al. (2013).

\section{IV.7 Economic assessment of wave energy projects}

This section elaborates on the economic assessment of WECs and of wave energy projects. Davey et al. (2009) describe in depth economic and financial procedures to evaluate WECs and how the uncertainties in these assessments should be handled. In order to avoid repetition, this section only introduces the main considerations of economic assessments and describes and enumerates available software related to the matter.

There are four major parameters related to the economic assessment of WECs: the capital expenditures (CAPEX), the operational expenditures (OPEX), the power production and the WECs lifetime. (The marginal cost is a parameter usually found in energy economics which depends on the cost of the fuel; however, since the fuel of WECs - the sea water - has no cost, this parameter is not considered here).

- CAPEX indicate a WEC's investment costs, with units of cost per installed unit of power.

- OPEX represent the O\&M costs, as a cost per unit of energy produced.

- The power production evaluates the performance of the WECs along its lifetime. In Section IV.3 the power production of a WEC has been calculated with a site's scatter diagram and with the WEC power matrix (Section IV.3 has also described the use of power matrices and the uncertainties related to them). Hence, power production is also dependent on the deployment location.

CAPEX, OPEX and the power production are used to calculate the cost of energy (COE), which shows the cost of each unit of energy produced by a WEC throughout its lifetime. The 
COE is used to assess WEC's economic feasibility throughout the various development stages (Figure 7). It is defined as follows, where the WEC's lifetime, in years, is indicated by $n$.

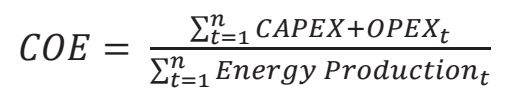

Often, the COE is calculated as a levelised cost of energy (LCOE). The difference between COE and the LCOE is that the latter takes into account the variation in time of money value, which is represented by the discount rate $(r)$.

$$
L C O E=\frac{\sum_{t=1}^{n} \frac{{\text { CAPEX }+O P E X_{t}}_{(1+r)^{t}}}{(1+)^{t}}}{\sum_{t=1}^{n} \frac{\text { Energy Production }}{(1)}}
$$

The Danish TSO, Energinet.dk, has developed an open-source tool to calculate the COE of WECs (COE, 2013). It derives the cost of energy based on the expected production of a WEC at a particular location. The tool allows inclusion of both numerically or experimentally obtained production values. It also allows the evaluation of a WEC deployment in a range of locations (i.e. three locations in the Danish North Sea, in Portugal and in EMEC) while scaling the WEC's features to the selected site.

The tool offers transparency and simplicity, in order to provide understanding of the calculations steps and to promote a clear analysis of the results. It has been made mandatory that all projects receiving public funding from Energinet.dk track their COE through this standardised spreadsheet-based method, which has been conceived as an open source economic-evaluation tool. Moreover, the tool provides good agreement between WEC's scales and locations, and the five selected sites represent different wave conditions. Yet there are some improvements to be made to the tool, such as the inclusion of costs of installation and of O\&M activities, the evaluation of arrays or the inclusion of more sites.

Whereas the COE tool from Energinet.dk only evaluates the COE, and has been particularly developed for wave energy, the following software packages analyse the economic and financial feasibility of various renewable energies. These are Navitas (Navitas, 2013), RETScreen (Retscreen, 2013) and TEOWEC (Teillant et al., 2012). Navitas has been developed by HMRC to analyse and compare wave, tidal and offshore wind energy technologies and projects. It can input power matrices for WECs and it operates with hourly values, which provides full weather window analyses. RETScreen is a spreadsheet-based open-source tool developed in Canada for the technical and financial analyses of renewable energy, energy efficiency and cogeneration projects. Calculations for wave energy projects are based on available incoming power (i.e. $\mathrm{kW} / \mathrm{m}$ ) and it uses monthly averages. The TEOWEC software has been developed by the Centre for Ocean Energy at the National University of Maynooth (NUIM). It is a techno-economic WEC assessment tool that combines device and operational modelling.

Beyond the economic parameters and evaluation tools, it should be noted renewable projects bring important non-quantifiable benefits, and thus, the economics might not be the 
sole project decision parameter. Wave energy developments increase long term security of energy supplies, thus, they provide certainty on future energy prices and energy sources availability, and promote job creation as well as technology development, among others (La Regina et al., 2006), (Soerensen and Naef, 2008) (Huckerby et al., 2012). 



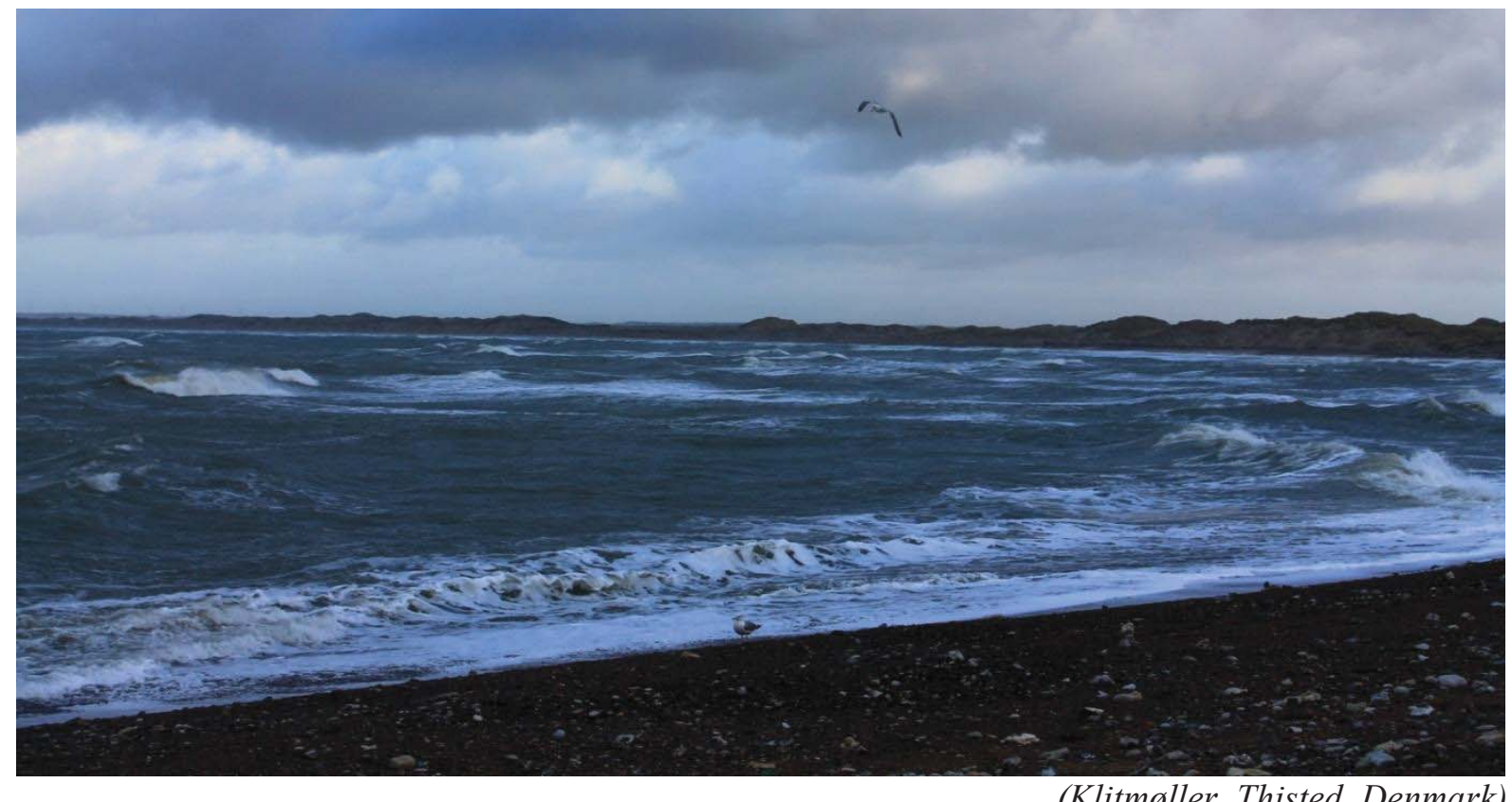

(Klitmøller, Thisted, Denmark)

\section{Chapter V - Summary of results}

This chapter provides an overview and relates the main findings of the thesis, and discusses further complementary studies. 


\section{V.1 Overview of results}

This thesis has covered various areas that appear throughout the development of a WEC. It has first underlined the different stages a development goes through and it has analysed in depth some of these stages. The ultimate goal has been to provide an indication of the effort needed to realise a commercial WEC, to highlight some of the difficulties that appear along this development, and to examine relevant benefits wave energy brings to energy systems. The thesis has addressed subjects that fall within technical as well as within non-technical fields. Experiences have shown both areas interact, and therefore it has been decided to focus on both domains and to highlight their relationships.

Chapter III has presented various elements that can appear throughout the development of a WEC until it reaches the commercial stage. Section III.3 and Figure 7 have provided a first indication on how these elements are interconnected and interrelated. Then, Chapter IV has gone beyond the enumeration of elements and has described in depth some relevant areas within the development career: regulations, social issues, evaluation of performances, network developments, diversified renewable energy systems, electricity markets and project economics. In Chapter IV it has been also highlighted the development stage where these elements become more evident: Sections IV.1 and IV.7 have addressed a matter that can affect a development from its early up to the final stages of maturation, Sections IV.2 and IV.3 have investigated topics that appear in the first sea trials and onwards, and Sections IV.4, IV.5 and IV.6 have covered topics relevant to large scale prototype testing.

This section summarises and relates the findings of Chapter IV in particular and of the thesis in general. It addresses the affinities, relationships and dependencies among the research topics of the thesis. The benchmark of the discussion is the relationship among elements presented in Section III.3.

The baseline of the thesis has been the trajectory for WEC's developments introduced in Section III.3, which elaborates on regulatory, economic, social and technological categories. The aim of Section III.3 has been to emphasise the relationships between the different elements affecting a development, and to highlight the importance of taking all them into account. It has also been shown how successful deployments are linked to incremental developments, whereas failures can be associated to a lack of them (Section III.2.1).

WECs developments are notably related to governmental approaches towards wave energy programmes. Section IV.1 and Paper A have examined the consistency between R\&D activities related to wave energy and the regulations and support schemes in place. The scenario chosen for this analysis has been Spain. The Spanish energy portfolio includes wave energy, although the efforts for its development seem unfocused. Sections III.2.1 and IV.1 have shown that public funds are available for $R \& D$ projects as well as for sea trials. However, these researches lack a common methodology and framework. Contrarily, as described in Section III.2.1, the Danish Wave Energy Program followed a coherent and a stepwise development strategy, and efforts were focused on the development of a WEC 
among the different ideas presented. With fewer economic resources invested in Denmark than in Spain, two of the thirteen leading WECs by 2011 derive from the first Danish programme. Nevertheless, at present, Danish funding for sea trials of large scale prototypes is limited.

Section IV.1 has also investigated the relationship between support mechanisms and national regulations. The cases of Denmark and Spain have shown the benefits of concrete support schemes. A new R\&D programme introduced in Denmark allows for a projectdependent tariff, and enhances the motivation to improving the capabilities of the WEC by getting higher income (Section III.2.1). It is also a transparent method, where values are set up according to realistic performance expectations. This approach has been probably the goal of the Spanish project-dependent FIT that Mutriku applied for, although finally nothing came of it (Section IV.1). Current FIT for the electricity production of WECs in Denmark is 80 EUR/MWh, of the same value as in Spain until it was suppressed. This is a low FIT compared to the support mechanism offered in other countries and to other industries.

Moreover, based on Mutriku case study, Section IV.1 has highlighted how regulations affect project execution. Mutriku has shown a delay in project permission granting due to a regulatory gap on EIAs requirements. In addition, this gap also affects the lack of guidelines on public engagement in wave energy projects, which also Mutriku project exemplifies. Papers $\mathrm{B}$ and $\mathrm{C}$ have examined the extent to which public opinion can affect realisation of wave energy projects, showing that if device and project developers are left alone to decide on whether to address the public or not, valuable demonstration projects may never be realised. The two papers have focused on four different countries, and hence they have covered diverse practices among developers. Moreover, the study on public opinion, which has been carried out in collaboration with M. Stefanovich (Oregon State University), has allowed the inclusion and comparison of wave energy projects in Europe and in the United States. This has provided for a broad range of case studies on projects acceptability to research on.

With regard to public opinion and the relationship between a WEC and a location, a discussion point drawn by Margheritini (2011) follows. It is based on the experiences on two full-scale projects of the SSG WEC in Norway (Margheritini et al., 2009) and in Denmark (Vicinanza et al., 2012), which were never commissioned. Margheritini (2011) emphasises the importance for a project developer to understand the 'powers' that may arise at the deployment location. On one hand, there are unwritten hierarchies and controlling powers among the public, while different powers might coexist in the wave project realisation 'game': the power of the project developer, the territorial power and the power of the opposition. This also highlights the need of taking into account public opinion at every deployment site.

Section IV.1 has also concluded that a strong relation and coherence between energy plans and regulations should predominate. Ambitious energy targets without the proper framework for development are prone to never be realised. Following this idea, the role of 
Maritime Spatial Planning (MSP) has been introduced (Section IV.1). MSP promotes national and cross-national coordinated offshore technologies siting. Of relevance to this, is the study subject of Section IV.4 and Paper E. It has been shown that offshore grid connection points for electricity transmission lack, and that the network is having its first expansion towards offshore grids without taking into account the role of wave energy. All these urge for MSP and comprehensive energy planning, where time windows and designated areas for WECs siting are established; and most noticeable, for regulations taking that into account. In line with this, Spok ApS and the European Ocean Energy Association (EU-OEA) did a collaborative work in response to the open consultation launched by ENTSO-E on the Eurogrid 2020 plan (ENTSO-E, 2010). The objective was to highlight the eventual contribution of wave energy into European electricity systems (Rousseau et al., 2010).

Section IV.3 elaborates on the EquiMar methodology to evaluate equitably the power performance of WECs in different locations. Wave Dragon (Paper D) and Pico Plant case studies are the first - and still the only ones up to the time of writing - proving the applicability of the methodology with real power production data. The methodology is based on non-dimensional power performances that represent the production capabilities of WECs independently on their dimensions. It ultimately proposes a novel way of characterising a technology's efficiency, except for the fact that at present, when efficiencies are stated, it typically remains unspecified what the value exactly indicates. For example, efficiencies can be in terms of energy absorbed by the machine per incident wave energy, wave-to-wire efficiency, which can be calculated for regular or irregular wave states, or efficiency of the PTO. Instead, the methodology promotes a unified way of stating non-dimensional performances - and thus efficiencies - in which the values behind the calculations are specified. Then, non-dimensional performances are converted into power matrices, where the uncertainties and the origin of the stated numbers are known. Meanwhile, some device developers argue on whether it is a current need to provide exact performance data of the WECs, when wind turbine manufacturers, for example, do not provide exact values of intermediate operation capabilities for the turbines that they are selling.

Next point has focused on the combination of different marine technologies in the same site as an alternative of increasing the installed capacity of the one energy source. Sections IV.4, IV.5 and IV.6, and the corresponding papers, have suggested a number of added technical and economic benefits for a project where WECs and wind turbines share the sea area and the grid connection. The economics of a combined development improve because the spare capacity of the cables reduces (due to the inherent delay of waves to winds and the smoother variations in the power output) and the utilization of the sea area increases. A combined project also results into a more predictable (Paper G), less variable and highly available (Paper F) power output, and higher accessibility to the wind turbines' structure (Beels et al., 2011). Moreover, WECs and wind turbines share common synergies in relation to marine policies, marine stakeholders and MSPs (Sections IV.1 and IV.2); there are also synergies within offshore grids and the lack of available strong grid connection points onshore (Section IV.4 and Paper E); and a more continuous power production is enhanced 
when technologies are combined (Section IV.5). Accordingly, efforts to develop offshore interconnected networks suitable for the integration of WECs and offshore wind turbines are envisaged (Paper E) and projects combining the two technologies are emerging (Section II.3.1). For example, Wavestar aims to deploy a full-scale prototype in the existing offshore wind farm Horns Rev II. The benefits of this deployment to the current power production of the turbines are shown in Marquis et al. (2012), and the findings, which counted with the contribution of the author, support the benefits enumerated above. Furthermore, current tendencies also show that it is also in light of device developers to create a commercial reality that combines the power of two or more resources in the same structure.

It could however be argued that the inclusion of WECs in an offshore wind project may compromise the finance of the wind project, given the wind sector is leading the wave sector in decades of time and in technological developments. However, this does not apply for the development of offshore floating wind turbines, which could be considered at the same development stage than WECs (Vanucci, 2011) (MIC, 2012) (Gueydon et al., 2012). Also, they are the only feasible solution to harness the wind resource in locations with water depths above 50 meters.

In line with combined renewable energy portfolios, Section IV.6 has elaborated extensively on waves forecasting and on its effect on combined wave and wind energy systems. It has looked into the predictability of waves and of winds, into the predictability of the power output of WECs and of wind turbines, and into the economic benefits of including wave in wind energy systems to reduce the amount of balancing power needed, and therefore to reduce balancing costs. All calculations are based on the west coast of Denmark and on the Danish electricity market, and hence results are largely influenced by the metocean conditions of the site. For the 12 to 36 hours forecast horizons, the main findings are that waves are $23 \%$ more predictable than winds (in terms of MAE/Mean), that the power output of WECs is 35\% more predictable than that of wind turbines (in terms of NMAE/NMean) and that by including wave energy in an wind-only energy system balancing costs reduce by $35 \%$.

Section IV.7 has presented some tools to evaluate the economic feasibility of wave energy projects. The cost of energy tool of the Danish TSO has been particularly developed to assess wave energy projects, and its results strongly depend on the power performance of the WEC at a selected location. In turn, this depends on the accuracy of the power matrix, a point that goes in line with the discussion raised in Section IV.3.

To finalise, it is interesting to address the relationship between the offshore wind and the wave energy sector, as well as the contribution of the former to the latter. In some countries, offshore wind has opened the debate with politicians and stakeholders on the available offshore renewable sources, and it has also raised awareness of the role of public opinion. With regard to installation and operation of bottom mounted turbines, the offshore wind energy sector has accumulated about two decades of know-how. Moreover, the bibliography also shows that, in various wave energy research areas, there are links to wind energy 
developments. Due to that, the offshore wind energy sector is generally considered the predecessor of the wave energy sector, which is true in numerous disciples where they share synergies (i.e. grid connections, regulatory frameworks, sea space) but which does not apply to other areas where important differences between them can be found (i.e. resource characteristics, laboratory and full-scale testing, forecasting). The thesis has reviewed subjects where the experiences of wave energy are related to the experiences of wind energy, and some others where results show there are strong differences when waves are investigated. As a result, it can be concluded that, despite the fact that research in some of the study areas has been thoughtfully done for the wind energy sector, doing it for wave energy adds an important innovation to research.

As a whole, the thesis has briefly described the advantages and history of wave energy, has overviewed the stages of WEC developments, and has examined the interaction of regulatory frameworks, of the public opinion and of grid connection points with wave energy projects. It has also investigated the assessment of performances for WEC deployments, and has elaborated on the technical and economic advantages of combined marine energy system formed with WECs and offshore wind turbines. Hence, the scope of the thesis has been broad, it has embraced areas that can be categorised within technical and non-technical disciplines, and it has been based on the understanding of WEC's developments, from the perspective of device developers.

The novelties of this research and the added value of the thesis to the research community have been: addressing key problems that appear throughout prototype field trials and until the WEC reaches the commercial stage, providing an overall understanding of the challenges the wave energy sector is facing to become a significant part of the electricity mix, proposing solutions to the identified hurdles, and highlighting the benefits wave energy brings to a wind-only system and to day-ahead electricity markets. Moreover, the thesis has also contributed to the development of existing WECs, particularly to Wave Dragon and to Wavestar. Above all, the thesis has aimed at providing new insights on wave energy developments. Thanks to the diffusion of the results through a large range of dissemination channels, the findings of this thesis are already part of industry's and academia's discussions.

\section{V.2 Further recommended work}

This section recommends complementary studies to the research presented in the thesis.

Chapter III has described the phases of a WEC development required to successfully reach the commercial stage. However, there are two essential features within these developments which have a large degree of uncertainty. These are the time to go from concept to market and the necessary expenditures. Experience has shown that WEC's developments tend to be delayed, due to unforeseen difficulties, and that the cost of development is significant and tends to be underestimated. Accordingly, it is recommended that typical timescales of a WEC development and corresponding R\&D expenditures are investigated. This 
might be helpful in the dialog with stakeholders and to compare wave energy advancements to technologies developed in other industries.

Section IV.3 has shown that the EquiMar methodology has been applied only to Pico Plant and to Wave Dragon power production data. Hence, it is suggested that further research is carried out to determine its applicability for other wave and tidal technologies, and possible improvements to it.

Then, Section IV.4 has reviewed proposed expansions of the European network but has not looked into suitable wave siting areas and how they coincide with the proposed expansion of the grid. Further investigation on wave energy development locations is recommended, in order to propose concrete inputs to power network developments.

With regard to diversified systems and the combined power output of WECs and of offshore wind turbines, it is interesting to investigate the pattern of the power production on locations where waves and winds are less-correlated than in the Danish North Sea, and thus, where the benefits of including wave energy are more evident. This can be done in swell dominated locations, i.e. along the Atlantic coast.

It is also recommended to expand the study by analysing the effect on the power production of several WECs and offshore wind turbines, located either in the same site or in a large area; as well as to examine the consequences of regional diversification of wave energy, in order to reduce the fluctuations of wave power.

The analysis of wave predictability in swell dominated locations might indicate further conclusions on wave power forecasting. It is also of interest to investigate the impact of WECs power production predictability and balancing costs in other electricity markets than in the Danish Nord Pool.

Overall, the analysis of real power production data would also improve the scope of the works presented in Sections IV.5 and IV.6.

Lastly, it is recommended that the effect of arrays, the costs of maintenance, and new wave energy sites are included in the cost of energy tool developed by the Danish TSO (Section IV.7). 

(Faial, Azores, Portugal)

\section{References}




\section{References}

ABB. (2013). [Online]: "Differences Between HVDC Light and Classic HVDC". www.abb.dk/industries/us/9AAF400197.aspx [Accessed January 3rd, 2013].

ACER. (2013). [Online]: www.acer.europa.eu [Accessed January 3rd, 2013].

Ackermann T. (2002). "Transmission Systems for Offshore Wind Farms" IEEE Power Engineering Review, Vol. 22(12), pp. 23-27.

Alcorn R. and O’Sullivan D. (2013). “Electrical Design for Ocean Wave and Tidal Energy Systems", Institution of Engineering and Technology (IET).

Amate López J. (2010). “Ocean Lider, Ocean Renewable Energy Leaders”, in Proceedings of the 3rd International Conference on Ocean Energy (ICOE). Bilbao.

Anemos. (2013). [Online]: www.windpowerpredictions.com [Accessed January 3rd, 2013].

AnemosPlus. (2013). [Online]: www.anemos-plus.eu [Accessed January 3rd, 2013].

Babarit A., Ben Ahmed H., Clément A. and Debusschere V. (2006). "Simulation of electricity supply of an Atlantic island by offshore wind turbines and wave energy converters associated with a medium scale local energy storage”, Renewable Energy, Vol. (31), pp. 153-169.

Beels C., Troch P., Kofoed J.P., Frigaard P., Kringelum J., Kromann P., Donovan M.H., De Rouck J. and De Backer G. (2011). "A methodology for production and cost assessment of a farm of wave energy converters". Renewable Energy, Vol. 36.

Berge A. (2009). "Kriegers Flak and its Way to Become a Best Practice Area”, in Proceedings of European Offshore Wind Conference (EOW 2009). Stockholm.

BWEA. (2002). "Best Practice Guidelines: Consultation for Offshore Wind Energy Developments". British Wind Energy Association (BWEA).

CA-OE. (2013). [Online] www.ca-oe.net [Accessed January 3rd, 2013].

Casale C., Serri L., Stolk N., Yildiz I. and Cantú M. (2011). "Synergies, innovative designs and concepts for multipurpose use of conversion platforms". Deliverable of WP4 to Orecca Project.

Christiansen H. E. (2009). "Kriegers Flak. From National to International Solution for Grid Connection of Offshore Wind Plants". Copenhagen: Energinet.dk, contribution to the Windspeed workshop.

Circuit Breakers. (2013). [Online]: 
www.abb.com/cawp/seitp202/65df338284e41b3dc1257aae0045b7de.aspx [Accessed January 3rd, 2013].

COE. (2013). COE Calculation tool Energinet.dk. [Online]: energinet.dk/DA/KLIMA-OGMILJOE/Energi-og-klima/Forskning-i-vedvarende-energi/Sider/Boelgekraft.aspx [Accessed January 3rd, 2013].

Costa A., Crespo A., Navarro J., Madsen H. and Feitosa E. (2008). "A review on the young history of the wind power short-term prediction". Renewable and Sustainable Energy Reviews, Vol. 12.

Cradden L., Mouslim H., Duperray O. and Ingram D. (2011). "Joint Exploitation of Wave and Offshore Wind Power", in Proceedings of the 9th European Wave and Tidal Energy Conference (EWTEC). Southampton.

Cruz J. (2008). “Ocean Wave Energy - Current Status and Futures Perspectives”. Springer.

CSIRO. (2012). “Ocean renewable energy: 2012-2050: An analysis of ocean energy in Australia”. Commonwealth Scientific and Industrial Research Organisation (CSIRO).

Davey T., Harrison G. and Stallard T. (2009). "Procedures for Economic Evaluation". Deliverable 7.2.1 to the EquiMar project.

DEA. (2006). "Offshore Wind Farms and the Environment. Danish experiences from Horns Rev and Nysted". Copenhagen: Danish Energy Authority.

Devine-Wright P. (2005). "Beyond NIMBYism: towards an integrated framework for understanding public perceptions of wind energy". Wind Energy, Vol. 8 (2), pp. 125-139.

Devine-Wright P. (2011). "Public Engagement with Renewable Energy: From NIMBY to Participation". Earthscan.

DirBird. (2009). EU Birds Directive 1979 (Directive 2009/147/EC) and Habitats Directive 1992 (92/43/EEC). [Online]:

ec.europa.eu/environment/nature/legislation/index_en.htm [Accessed December 10th, 2012].

DirEIA. (2011). EU EIA Directive (2011/92/EU). [Online]: ec.europa.eu/environment/eia/eia-legalcontext.htm [Accessed December 10th, 2012].

DirRen. (2009). EU Renewable Energy Directive (2009/28/EC). [Online]: ec.europa.eu/energy/renewables/targets_en.htm [Accessed December 10th, 2012].

DirMar. (2008). EU Marine Strategy Framework Directive (2008/56/EC). [Online]: ec.europa.eu/environment/marine/eu-coast-and-marine-policy/marine-strategyframework-directive/index_en.htm [Accessed December 10th, 2012]. 
DNV. (2005). "Guidelines on design and operation of wave energy converters". Carbon Trust, report commissioned by DNV (Det Norske Veritas).

E-Bridge. (2010). "Kriegers Flak combined grid solution feasibility study". [Online]: www.50hertz.com/de/file/2010-02-24_Final_Feasibility_Study_Public.pdf

ECI. (2005). "Variability of UK Marine Resources". Environmental Change Institute (ECI), University of Oxford, The Carbon Trust.

ECI. (2006). "Diversified renewable energy sources”. Environmental Change Institute (ECI), The Carbon Trust.

EMEC. (2009). "Assessment of Performance of Wave Energy Conversion Systems", European Marine Energy Centre (EMEC).

Energinet.dk. (2013). [Online]: www.energinet.dk/EN/El/Engrosmarked/Udtraek-afmarkedsdata/Sider/default.aspx. [Accessed January 3rd, 2013].

Energinet.dk. (2009). "An Analysis of Offshore Grid Connection at Kriegers Flak in the Baltic Sea - Joint Pre-feasibility Study".

[Online]: energinet.dk/EN/News/Documents/KriegersFlakPrefeasibilityReport.pdf

ENTSO-E. (2010). "Research and Development Plan: European Grid Towards 2020 challenges and Beyond”. European Network on Transmission System Operators for Electricity (ENTSO-E).

ENTSO-E. (2012). "Regional Investment Plan North Sea". European Network on Transmission System Operators for Electricity (ENTSO-E).

ENTSO-E. (2013). [Online]: www.entsoe.eu [Accessed January 4rd, 2013].

EquiMar. [Online]: www.equimar.org [Accessed January 3rd, 2013].

EU-OEA. (2010). "Waves of Opportunity: Ocean Energy European Road Map". European Ocean Energy Association (EU-OEA).

EVE, Wavegen, UCC, Wave Energy Centre, Robotiker, Wave Dragon, EU-OEA and KaneCres (2011). "Wave Energy State of the art, non-technological barriers and best practices". Waveplam Project.

EWEA. (2009). “Pure power”. European Wind Energy Association (EWEA).

Falcão A. F. (2004). "First-generation wave power plants: current status and R\&D requirements". Transactions of the ASME, Vol. 126, pp. 384-388.

Falnes J. (2005). “Ocean waves and oscillating systems: linear interactions including wave energy extraction”. Cambridge University Press. 
Fernández-Chozas J. (2012a). "Energía undimotriz". Editorial Académica Española. ISBN 978-3-659-02998-1.

Fernández-Chozas J. (2012b). "Predictability of Wave Energy and Electricity Markets". Modern Energy Review, Vol. 4 (1).

Fernández-Chozas J. (2012c). "Predictability of wave parameters at Hanstholm, Denmark". Progress Report WP7: Wave resource and forecast. Deliverable 26 to the Wavetrain2 Project.

Fernández-Chozas J., Soerensen H.C. and Kofoed J.P. (2013). "Final project report: Analysis of Power Output Predictability of Wave and Wind". Energinet.dk, PSO project 10791. Aalborg University DCE Technical Report No. 156.

Firestone J. and Kempton W. (2007). "Public opinion about large offshore wind power: Underlying factors”. Energy policy, Vol. 35 (3), pp. 1584-1598.

Firestone J., Kempton W., and Krueger A. (2009). "Public Acceptance of Offshore Wind Power Projects in the USA”. Wind Energy, Vol. 12 (2), pp. 183-202.

Fitzgerald J. and Bergdahl L. (2007). "Considering Mooring Cables for Offshore Wave Energy Converters", in Proceedings of the 7th European Wave and Tidal Energy Conference (EWTEC). Porto.

Fitzgerald J. and Bolund B. (2012). “Technology Readiness for Wave Energy Projects. ESB and Vattenfall classification system", in Proceedings of the 4th International Conference on Ocean Energy (ICOE). Dublin.

ForskVE. (2013). [Online]: www.energinet.dk/EN/FORSKNING/ForskVEprogrammet/Sider/ForskVE-programmet.aspx [Accessed January 8th, 2013].

Frigaard P., Tedd J., Kofoed J.P. and Friis-Madsen, E. (2006). "3 years experience with energy production on the Nissum Bredning Wave Dragon prototype", in Proceedings of the 4th Workshop of the Coordinated Action of Ocean Energy workshop (CA-OE), Lisbon.

Fusco F., Nolan G. and Ringwood J. (2010). "Variability reduction through optimal combination of wind/wave resources - An Irish case study". Energy, Vol. 35, pp. 314325.

Glendenning I. (1978). “Wave Power - A Real Alternative?”. Ocean Management, Vol.4, pp. 207-240.

Greenpeace. (2005). "Renovables 2050. Un informe sobre el potencial de las energías renovables en la España peninsular”. Greenpeace. 
Gueydon S., Harding S., Fernández-Chozas J., Johnson P. and Freeman K. (2012). "Floating Wind Turbine Challenge". European Wind Energy Conference EWEC2012 (Poster Presentation). Copenhagen.

H2Ocean. (2013). [Online]: www.h2ocean-project.eu [Accessed January 3rd, 2013].

Henderson. (2005). "Design, simulation, and testing of a novel hydraulic power take-off system for the Pelamis wave energy converter". Edinburgh: Ocean Power Delivery Ltd.

HMRC. (2003). "Ocean Energy: Development and Evaluation Protocol. Part 1: Wave Power". Cork, Ireland: HMRC: Hydraulic Maritime Research Centre.

HMRC. (2009). "State of the art analysis". Deliverable 2.1 to Waveplam Project, HMRC, University Cork.

Holmes B. (2010). "EquiMar: Engineering and Technical Overview", EquiMar workshop. Bilbao. [Available Online]: http://www.chrissmithonline.co.uk/files/engineeringoverview.pdf [Accessed January 10th, 2013].

Holttinen H. (2005). “Optimal electricity market for wind power”. Energy Policy.

Huckerby J., Jeffrey H., Sedgwick J., Jay B. and Finlay L. (2012). “An International Vision for Ocean Energy - Version II”. Ocean Energy Systems Implementing Agreement (OESIEA).

IEA. (2011). "Harnessing Variable Renewables - A Guide to the Balancing Challenge". International Energy Agency (IEA).

IEC-TS (2011). "Marine Energy - Wave, Tidal and other Water Current Converters. Part 1: Terminology", IEC Technical Specification 62600-1, Edition 2011-2012.

Ingram D., Smith G., Bittencourt-Ferreira C. and Smith H. (2011). "Protocols for the Equitable Assessment of Marine Energy Converters". The University of Edinburgh on behalf of the EquiMar consortium.

ITC. (2008). “Por la que se revisan las tarifas eléctricas a partir de 1 de enero de 2009”. Order ITC/3801/2008.

Journée J. and Massie W. (2001). “Offshore Hydromechanics”. Delft University of Technology.

Kariniotakis G., Pinson P., Siebert N., Giebel G. and Barthelmie R. (2004). "The state of the art in short-term prediction of wind power - from an offshore perspective". Sea Technology Week.

Kirkegaard J., Kofoed-Hansen H., Sloth P. and Tacher E. (2010). "Metocean forecasting for ports and terminals". Delft, The Netherlands: Port Infrastructure Seminar. 
Knapp W. (2005). "Water Turbines for Overtopping Wave Energy Converters", in Proceedings of the 2nd Workshop of the Coordinated Action on Ocean Energy (CA-OE). Uppsala.

Kofoed J.P., Pecher A., Margheritini L., Holmes B., McCombes T., Johnstone C., Bittencourt C., Retzler C. and Myers L.E. (2012). "A Methodology for Equitable Performance Assessment and Presentation of Wave Energy Converters Based on Sea Trials". Renewable Energy, Elsevier.

Kofoed J.P. (2009). "Ressourceopgørelse for bølgekraft i Danmark". Report No.59 for the Clima Commission.

Kofoed J.P. and Frigaard P. (2009). "The Development of wave energy devices the Danish case". The Journal of Ocean Technology, Maritime and Port Security, Vol. 4 (2).

Kofoed J.P., Pecher A., Margheritini L., Holmes B., McCombes T., Johnstone C., Bittencourt C., Retzler C. and Myers L.E. (2011). "Data Analysis and Presentation to Quantify Uncertainty”. Deliverable D4.2 to EquiMar Project.

Kramer M., Marquis L., and Frigaard P. (2011). "Performance Evaluation of the Wavestar Prototype", in Proceedings of the 9th European Wave and Tidal Energy Conference (EWTEC). Southampton.

Kramer M., Vidal E., Marquis L. and Frigaard P. (2013). "Status and perspectives for the Wavestar demonstrator at Hanstholm". Abstract to the 10th European Wave and Tidal Energy Conference (EWTEC). Aalborg.

Krohn S. and Damborg S. (1999). "On public attitudes towards wind power". Renewable Energy, Vol. 16, pp. 954-960.

La Regina V., Patrício S., Neumann F. and Sarmento A. (2006). "The Role of Socioeconomic Impact Assessment (SIA) and Environmental Impact Assessment (EIA) for Understanding Benefits from Wave Energy Deployment”. World Renewable Energy Congress. Florence.

Margheritini L. (2011). "EIA scoping based on new technology classification". Orkney Islands: Wavetrain2 course on Environmental impact assessment and licensing and environmental monitoring.

Margheritini L., Vicinanza D. and Frigaard P. (2009). "SSG wave energy converter: Design, reliability and hydraulic performance of an innovative overtopping device". Renewable Energy, Vol. 34.

MarinaPlatform. (2013). [Online]: www.marina-platform.info [Accessed January 3rd, 2013]. 
Marquis L., Kramer M., Kringelum J., Fernández-Chozas J. and Helstrup Jensen N.E. (2012). "Introduction of Wavestar wave energy converters in the Danish offshore wind farm Horns Reef 2", in Proceedings of the 4th International Conference on Ocean Energy (ICOE). Dublin.

McCormick M. (1981). “Ocean wave energy conversion”. John Wiley \& Sons Inc.

McLean J.R. (2008). "Equivalent Wind Power Curves". Deliverable 2.6 of the Tradewind Project, Garrad Hassan.

Mermaid. (2013). [Online]: www.mermaidproject.eu [Accessed January 3rd, 2013].

Meteo Group. (2012). [Online]: www.meteogroup.se [Accessed December 28th, 2012].

MIC. (2012). "Floating Offshore Wind Foundations: Industry Consortia and Projects in the United States, Europe and Japan”. Main(e) International Consulting (MIC).

Morthorst P. (2007). "Detailed investigation of electricity market rules". Deliverable D4.1 to the TradeWind project.

Mueller M., Polinder H. and Baker N. (2007). "Current and novel electrical generator technology for wave energy converters". International Electric Machines and Drives Conference.

Mørk G., Barstow S., Kabuth A. and Pontes T. (2010). "Assessing the Global Wave Energy Potential", in Proceedings of the 29th International Conference on Ocean, Offshore and Arctic Engineering (ASME). Shanghai.

NASA Technology Readiness Level Definitions. (2013). [Online]: esto.nasa.gov/files/TRL_definitions.pdf [Accessed January 3rd, 2013].

Navitas. (2013). [Online]: www.ucc.ie/en/hmrc/projects/ [Accessed January 3rd, 2013].

Neumann F. (2009). "Non-technological barriers to wave energy implementation". Wave Energy Centre, Deliverable 2.2 to the Waveplam Project.

Nielsen K. (1999). "Bølgekraft - forslag til forsøg og rapportering”. Bølgekraftudvalgets secretariat. Danish Energy Agency.

Nielsen K. (2003). "Development of Recommended Practices for Testing and Evaluating Ocean Energy Systems”. OES (Ocean Energy Systems), Annex II.

Nielsen K. (2010). "Development of Recommended Practices for Testing and Evaluating Ocean Energy Systems”. OES (Ocean Energy Systems), Annex II.

Nielsen K. (2012). “Ocean Energy Technology Study”. DanWEC; Technical Report No.1 for The Alliance for Offshore Renewables. 
Nielsen K. and Pontes T. (2010). "Generic and Site-related Wave Energy Data”. Annex II. Task 1.1 International Energy Agency Ocean Energy Systems (IEA-OES).

Nielsen K., Krogh J., Helstrup Jensen N., Kofoed J.P., Friis-Madsen E., Vang Mikkelsen B. and Jensen A. (2012). "Bølgekraftteknologi : strategi for forskning, udvikling og demonstration 2012”. Partnership of Wave Energy, Aalborg University, DCE Technical Report 146.

Nord Pool Spot. (2009). "The Nordic electricity Exchange and the Nordic Model for a Liberalised Electricity Market”. Denmark: Nord Pool Spot.

Nordic Folkecenter for Renewable Energy. (2013). [Online]: www.folkecenter.net [Accessed January 3rd, 2013]

OES. (2009). “Annual Report 2008”. Ocean Energy Systems (OES).

OES. (2012). “Annual Report 2011”. Ocean Energy Systems (OES).

OES. (2013). [Online]: www.ocean-energy-systems.org [Accessed January 3rd, 2013].

Offshoregrid. (2013). [Online]: www.offshoregrid.eu [Accessed January 3rd, 2013].

Orecca. (2013). [Online]: www.orecca.eu [Accessed January 3rd, 2013].

Pecher A. (2012). "Performance evaluation of Wave Energy Converters". Aalborg: PhD Thesis (DCE Thesis no. 38), Aalborg University.

Pecher A., Le Crom I., Kofoed J.P., Neumann F. and de Brito Azevedo E. (2011). "Performance assessment of the Pico OWC power plant following the EquiMar Methodology", in Proceedings of the International Symposium of Offshore and Polar Engineering (ISOPE 2011). Hawaii.

Pelamis. (2013). [Online]: www.pelamiswave.com [Accessed January 5th, 2013].

Pinson P., Reikard G. and Bidlot J. (2012). "Probabilistic forecasting of the wave energy flux". Applied Energy, Vol. 93.

Polinder H., Damen M. and Gardner F. (2004). "Linear PM generator system for wave energy conversion in the AWS", in IEEE Transactions on Energy Conversion, Vol. 19 (3).

Previsic M. (2010). "Deployment Effects of Marine Renewable Energy Technologies - Wave Energy Scenarios". Prepared by RE Vision Consulting, LLC on behalf of the U.S. Department of Energy.

Projects Dk, (2013). Wave Energy Projects Denmark. [Online]: tinyurl.com/ahsrhqm [Accessed January 4 ${ }^{\text {th }}, 2013$ ]. 
PSO. (2013). "Analysis of power output predictability of wave and wind". [Online]: energiforskning.dk/node/4527 [Accessed January 10th, 2013].

Real Decreto. (2012). Real Decreto-ley 1/2012. (2012). [Online]: www.boe.es/boe/dias/2012/01/28/pdfs/BOE-A-2012-1310.pdf [Accessed December 10th, 2012].

Ren. (2012). Renewable Energy Action Plans of all EU Member States. [Online]: ec.europa.eu/energy/renewables/action_plan_en.htm [Accessed December 10th, 2012].

RetScreen International. (2013). [Online]: www.retscreen.net [Accessed January 4th, 2013].

Ross D. (1995). "Power from the waves". Oxford University Press.

Rousseau N., Soerensen H.C. and Fernández-Chozas J. (2010). "Response to ENTSO-E consultation: research and development plan EUROGRID 2020". European Ocean Energy Association (EU-OEA) to ENTSO-E.

Rugbjerg M., Soerensen O. and Jacobsen V. (2006). "Wave forecasting for offshore wind farms", 9th International Workshop on Wave Hindcasting and Forecasting. Victoria.

Safewind. (2013). [Online]: www.safewind.eu [Accessed January 3rd, 2013].

Salter S., Taylor J. and Caldwell N. (2002). "Power conversion mechanisms for wave energy". Engineering for the Maritime Environment, Vol. 126.

Santos M., Lafoz M., Blanco M., García-Tabarés L., García F., Echeandía A. and Gavelain L. (2012). "Testing of a full scale PTO based on a switched reluctance linear generator for wave energy conversion", in Proceedings of the 4th International Conference on Ocean Energy (ICOE). Dublin.

Sarmento A. and Holmes B. (1996). "Wave Energy Converters; Evaluation and development Program”. Annex III.10 to the Offshore Wave Energy Converter Project (OWEC).

Schröder S., Meibon P., Spiecker S. and Weber C. (2010). "Market impact of an offshore grid - a case study", in Proceedings of the IEEE PES General Meeting 2010. Minneapolis.

Sharmila N., Jalihal P., Swamy A. and Ravindran M. (2004). "Wave powered desalination system”. Energy, Vol. 29 (11).

Soerensen H.C. and Fernández-Chozas J. (2010). "The Potential for Wave Energy in the North Sea", in Proceedings of the 3rd International Conference on Ocean Energy (ICOE). Bilbao.

Soerensen H.C. and Friis-Madsen E. (2010). "Wave Dragon from Demonstration to Market", in Proceedings of the 3rd International Conference on Ocean Energy (ICOE). Bilbao. 
Soerensen H.C. and Naef S. (2008). "Report on Technical Specification of Reference Technologies (Wave and Tidal Power Plant)". Copenhagen: Deliverable 16.1 to the Needs Project.

Soerensen H.C., Nielsen K., Steenstrup P., Friis-Madsen E. and Wigant L. (2005). "Bølgekraftanlæg ved Horns Rev - Screening (Wave energy deployment at Horns Rev Wind Farm)”. Copenhagen: PSO project 2004: 5705.

Sowfia. (2013). [Online]: www.sowfia.eu [Accessed January 3rd, 2013].

Storm Geo. (2012). [Online]: www.stormgeo.com [Accessed December 28th, 2012].

Stoutenburg E., Jenkins N. and Jacobson M. (2010). "Power Output Variability of Co-located offshore wind turbines and wave energy converters in California”. Renewable Energy, Vol. 35.

Strategic. (2013). Strategic Business Plan of TC 114. [Online]: www.iec.ch/cgibin/getfile.pl/sbp_114.pdf?dir=sbp\&format=pdf\&type=\&file=114.pdf [Accessed January 4th, 2013].

Tedd J., Kofoed J.P., Knapp W., Friis-Madsen E. and Soerensen H.C. (2006). "Wave Dragon, prototype wave power production". World Renewable Energy Congress. Florence.

Teillant B., Costello R., Weber J. and Ringwood J. (2012). "Productivity and economic assessment of wave energy projects through operational simulations". Renewable Energy, Vol. 48.

Thorpe T. (1999). “A Brief Review of Wave Energy”. ETSU Report No. R-120 for the UK Government.

Torre-Enciso Y., Marqués J. and Marina D. (2012). "Mutriku-First year review", in Proceedings of the 4th International Conference on Ocean Energy (ICOE). Dublin.

Torre-Enciso Y., Ortubia I., López de Aguileta L. and Marqués J. (2009). "Mutriku wave power plant: from the thinking out to the reality", in Proceedings of the 8th European Wave and Tidal Energy Conference (EWTEC). Uppsala.

TradeWind. (2013). [Online]: www.trade-wind.eu [Accessed January 3rd, 2013].

Tropos. (2013). [Online]: www.troposplatform.eu [Accessed January 3rd, 2013].

Vanucci D. (2011). "State of the art of design tools and standards for offshore renewable energy conversion systems". Deliverable of WP3 of the Orecca Project.

Vicinanza D., Margheritini L., Kofoed J.P. and Buccin M. (2012). “The SSG Wave Energy Converter: Performance, Status and Recent Developments”. Energies, Vol. 5 (2). 
Vidal E., Hansen R. and Kramer M. (2012). "Early Performance Assessment of the Electrical Output of Wavestar's prototype", in Proceedings of the 4th International Conference on Ocean Energy (ICOE). Dublin.

Waters R. (2008). "Energy from ocean waves. Full scale experimental verification of a wave energy converter". Acta Universitatis Upsaliensis Uppsala.

WavEC. (2012). Newsletter 17 of the Wave Energy Centre (WavEC), published on July 2012. [Online]: news.wavec.org/archive/news/index64-1.html [Accessed January 10th, 2013].

Wave Dragon. (2013). [Online]: www.wavedragon.net [Accessed January 5th, 2013].

Wavenet. (2003). "Final report of the European Thematic Network on Wave Energy". Wavenet report.

Waveplam. (2013). [Online]: http://www.waveplam.eu [Accessed January 3rd, 2013].

Wavetrain. (2013). [Online]: www.wavetrain2.eu [Accessed January 3rd, 2013].

Weber J. (2012). "WEC Technology Readiness and Performance Matrix - finding the best research technology development trajectory", in Proceedings of the 4th International Conference on Ocean Energy (ICOE). Dublin.

WEC. (2010). Survey of Energy Resources. World Energy Council (WEC).

Windspeed. (2013). [Online]: www.windspeed.eu [Accessed January 3rd, 2013].

Wolsink M. (2000). "Wind power and the NIMBY-myth: institutional capacity and the limited significance of public support”. Renewable Energy, Vol. 21, pp. 49-64.

You Y., Sheng S., Wu B. and He Y. (2012). "Wave energy technology in China". Philosophical Transactions of the Royal Society, Vol. 370.

Zubiate L. and McIlroy J. (2010). "Wave and Tidal Energy in the Maritime Spatial Planning Process", in Proceedings of the 3rd International Conference on Ocean Energy (ICOE). Bilbao. 


\section{Appendix - Papers enclosed to the thesis}

Paper A: J. Fernández-Chozas and H. C. Soerensen, "State of the Art of Wave Energy in Spain”, in Proceedings of IEEE 3rd Annual Electrical Power and Energy Conference (EPEC), Montreal, Canada, 2009.

Paper B: J. Fernández-Chozas, M. Stefanovich and H. C. Soerensen, “Toward Best Practices for Public Acceptability in Wave Energy: Whom, How and When to Address", in Proceedings of the $3^{\text {rd }}$ International Conference on Ocean Energy (ICOE), Bilbao, Spain, 2010.

Paper C: M. Stefanovich and J. Fernández-Chozas, "Toward Best Practices for Public Acceptability in Wave Energy: Issues Developers Need to Address", in Proceedings of the 3rd International Conference on Ocean Energy (ICOE), Bilbao, Spain, 2010.

Paper D: S. Parmeggiani, J. Fernández-Chozas, A. Pecher, E. Friis-Madsen, H. C. Soerensen and J. P. Kofoed, "Performance Assessment of the Wave Dragon Wave Energy Converter Based on the EquiMar Methodology", in Proceedings of the 9th European Wave and Tidal Energy Conference (EWTEC), Southampton, United Kingdom, 2011.

Paper E: J. Fernández-Chozas, H. C. Soerensen and M. Korpås, "Integration of Wave and Offshore Wind Energy in a European Offshore Grid", in Proceedings of the 20th International Symposium of Offshore and Polar Engineering (ISOPE), Beijing, China, 2010.

Paper F: J. Fernández-Chozas, J. P. Kofoed, M. M. Kramer and H. C. Soerensen, “Combined Production of a full-scale Wave Converter and a full-scale Wind Turbine - a Real Case Study", in Proceedings of the 4th International Conference on Ocean Energy (ICOE), Dublin, Ireland, 2012.

Paper G: J. Fernández-Chozas, N. E. Helstrup Jensen, H. C. Soerensen, J. P. Kofoed and A. Kabuth, "Predictability of the Power Output of Three Wave Energy Technologies in the Danish North Sea", in Proceedings of the 9th European Wave and Tidal Energy Conference (EWTEC), Southampton, United Kingdom, 2011.

Paper H: J. Fernández-Chozas, N. E. Helstrup Jensen and H. C. Soerensen, "Economic Benefit of Combining Wave and Wind Power Productions in Day-Ahead Electricity Markets", in Proceedings of the 4th International Conference on Ocean Energy (ICOE), Dublin, Ireland, 2012. 



\title{
Paper A: State of the Art of Wave Energy in Spain
}

\author{
Published in
}

Proceedings of IEEE 3rd Annual Electrical Power and Energy Conference (EPEC), 2009. 

This paper can be accessed at

< ieeexplore.ieee.org/xpl/freeabs_all.jsp?reload=true\&arnumber=5420989> 

Paper B: Toward Best Practices for Public Acceptability in Wave Energy: Whom, How and When to Address

\author{
Published in
}

Proceedings of the 3rd International Conference on Ocean Energy (ICOE), 2010. 



\title{
Toward Best Practices for Public Acceptability in Wave Energy: Whom, When and How to Address
}

\author{
J. Fernandez-Chozas ${ }^{1,2}$, M.A. Stefanovich ${ }^{3}$, H.C. Sørensen ${ }^{1}$ \\ ${ }^{1}$ Spok ApS \\ Blegdamsvej 4, 2200 Copenhagen, Denmark \\ E-mail: julialspok.dk \\ E-mail: hcs@wavedragon. net \\ ${ }^{2}$ Department of Civil Engineering, Aalborg University \\ Sohngaardholmsvej 57, 9000, Aalborg, Denmark \\ ${ }^{2}$ Environmental Sciences Graduate Program \\ Oregon State University, \\ Corvallis 97331, Oregon, U.S.A. \\ E-mail: stefanmadscience. oregonstate. edu
}

\begin{abstract}
Wave energy (WE) has the potential to eventually cover more than half of the world's electricity demand. The WE sector is still nascent; some technologies are approaching commercialization but others are in their infancy. Likewise, public opinion about WE is emerging. Public perception has been identified as a non-critical barrier of WE development provided public opinion is properly handled from the early stages of the sector. The public is now having its first acquaintance with WE, thus, the sooner there is an effective approach, the more opportunities will there be for the sector.

Research shows there are different techniques of addressing the public. This paper discusses different approaches as to whom, when and how developers should address by focusing on the experience of several renewable energy projects and the achieved results. The experience proves that early information dissemination to all interested parties via two-way communication methods contributes to achieving public acceptability most effectively.
\end{abstract}

Keywords: Best practices, opinion, public acceptability and wave energy

\section{Introduction}

Ocean energy is one of the largest renewable energy (RE) sources available on the planet. It includes different conversion principles, wave energy (WE) being one of them. The global WE resource has been estimated to be between 1-10 TW, which can provide $25-200 \%$ of the world's electricity demand by 2005 [1]. Numerous technologies have been proposed for its extraction, some approaching commercialization while others are still in the concept stage. Likewise, public opinion about WE is emerging. Acceptability of $\mathrm{RE}$ projects is very high generally, but when it comes down to implementing specific projects, acceptability turns to negativity and even hostility. It is important to know why this happens, especially after the literature attests NIMBY (Not In My Back Yard) is not the most crucial factor that defines public opposition to RE projects [2-6]. Particularly, the deployment of wave energy converters (WECs) raises concerns in relation to their environmental impact (EI) and about prioritization in the uses of the ocean commons.

It has been shown that RE projects often fail not because of technical difficulties but because of the lack of attention to stakeholders' concerns. Although there is no general and simple formula that guarantees obtaining full acceptability, several approaches to public engagement have turned to be successful. The paper is written from a developers' perspective. It discusses different actions undertaken by developers toward achieving public acceptability and focuses on providing answers as to whom, when, and how needs to be addressed in the initial stages of a WE project.

\subsection{Best Practices}

What are best practices? What distinguishes best practices from any other practice in gaining public acceptability for developing WE projects? Is there a difference in best practices for WE projects in comparison to developing other RE projects? Are best practices globally defined or site specific? Can we talk 
about best practices in Europe versus best practices in the United States or other regions and countries?

For the purposes of this paper, best practices in gaining public acceptability for developing WE projects refers to achieving positive endorsement of WE projects among stakeholders (i.e. individuals or organizations with a stake in something, usually in the local economy or environment [7]) without alienating key members of the local to the project communities. In other words, best practices do not center on the speed for going through regulatory hurdles but on creating a positive environment for effective communication through broad-based participation.

Identifying all the best practices developers have used in other RE projects is a difficult process, and besides, those identified may even be subject to debate, particularly when applied to the WE sector [8].

Methodologically, we provide case studies of WE developments that not only illustrate the applicability of the best practices concept but also explain its rationale. The case studies are selected based on three criteria:

- They examine distinct issues and look at best practices from different angles.

- They are geographically diverse.

- They are recent.

\section{EIA}

The questions raised in this paper (i.e. whom, when and how the public should be involved in WE projects) stem from legislative and permitting requirements. The Environmental Impact Assessment (EIA) is the tool used for examining the impacts of a project on the environment and on the socio-economic system. The first two steps of an EIA are the screening and the scoping process. Ideally, the screening is conducted by the competent authorities when a developer applies for a site permit [9]. Nevertheless, screening is not widely found [10].

In the European context, Directive 85/337/EEC defines the EIA process [11] and it is in accordance with the Aarhus Convention, thus, establishing public participation as an important part of the EIA [12].

According to this Directive, WE projects may be subject to an EIA depending on their nature (i.e. demonstration or commercial project), size and location. Thus, WE projects may undergo screening to assess whether the project has a significant EI or not. If the impact is relevant, a scoping document is prepared, which clearly states what the EIA will examine and at what level of detail, and comments can be received upon it from all stakeholders and the public [13]. Ultimately, the obligation to carry an EIA depends on each country's legislation, which determines the manner and opportunities for involvement in the decision making process.

So far, European WE demonstration projects have not been subject to a full EIA, but sometimes to an Environmental Impact Statement (EIS). For the latter, developers need to demonstrate awareness of the EIs of the project [14]. Commercial WE projects, however, are expected to be subject to a full EIA process.
In the US, public participation occurs mostly as part of the EIA process, in the framework of the National Environmental Policy Act (NEPA) of 1969. According to NEPA, federal agencies authorizing or funding a project are responsible for performing environmental reviews of the project. The Federal Energy Regulatory Commission (FERC) licensing procedure is an extensive technical process, in which the developer prepares a NEPA document (either an environmental assessment (EA) or an EIS) [15]. However, FERC establishes a preliminary permit or a "temporal exemption" for demonstration projects. This allows developers to experiment with the technology, as long as the project does not have commercial purposes [11].

In both Europe and the US, the extent of the EIA process depends on whether it consists of a demonstration or a commercial WE project. A lengthy EIA process can become a regulatory barrier to the sector's development and to its financial status.

Likewise, the questions addressed in the following section have to be considered along with the project's nature. The recommendations generally apply to commercial projects, although demonstration projects can eventually benefit from them. Then, the case studies show the importance of the EIA in the development process and the positive and negative effects it may have on the projects.

\section{Wave Energy and Public Acceptability}

Public acceptability of RE projects is influenced by factors such as scale, location and key characteristics of the project development [16]. Ongoing research suggests there are certain misconceptions about offshore RE projects coming from the lack of understanding of the technology and scientific findings [17-18]. Particularly, Sarmento et al. [19] comment that public acceptability of WE projects depends on a mixture of social aspects and competences over the project location. Devine-Wright [20] adds that local opposition is a form of placeprotective action related to pre-existing emotional attachments and place-related identity processes.

According to the wide variety of stakeholder's and local communities' reasons involved in supporting or opposing a project [21] hereunder follows a discussion on: Who are the stakeholders? When is the best time for developers to approach them? What is the most effective way to approach?

\subsection{Whom should developers address?}

Since the public differs from project to project and from site to site, it is recommended to first conduct a critical and relevant stakeholder analysis and second, to identify the issues relevant to that stakeholder or target group [7, 22].

Generally, the target groups who require notable attention are: i) tourism businesses, ii) surfing groups and iii) local, professional and recreational fishermen (this analysis does not consider stakeholders related to sectors imposing "no-go areas", i.e. navigation).

First, areas with consolidated tourism tend to perceive $\mathrm{RE}$ technologies as damage to the tourist potential of their sites due to an environment disruption [23]. The 
discussions with local tourism businesses and tourists' demands should review the EIs of the project, particularly noise and visual impact (note these mainly depend on the device location with respect to shore), as well as the experience of other regions developing WECs and their impact on tourism. Current European WE pilot plants, as well as some offshore wind energy farms, are attracting an unexpected tourism flow in the area [24].

Second, surfing communities worry about possible modifications of the near-shore wave regime and alteration of coastal processes. So far, studies [10, 25] examining these impacts have not shown negative results. What is more, since surfing waves are created not only by wind waves but also by steep changes in the bathymetry, precisely where is worst to install WECs, device deployments are expected to have a minor effect on surfing.

Third, fishing communities may be particularly affected when traditional fishing methods (i.e. trawling) are prohibited due to the underwater cables around the projects [26-27]. This can be seen as a positive impact, regarding past predatory exploitation activities carried by fishermen [28]. Moreover, the experience of the offshore wind sector shows that compensatory fees for loss of fishing grounds are generally available [29].

\subsection{When should they be addressed?}

Early public involvement is identified as a key element for the successful implementation of RE projects [30-31]. Early communication can mitigate potential threats before a more general protest is formed that could turn later into unexpected opposition [32]. It can also avoid misinformation by media or rumors that may likely misrepresent important facts of the project. Moreover, the earlier developers learn about any potential changes in the project the better, since working in the ocean environment makes unexpected changes much more expensive than onshore.

While the public is involved in the scoping process in the US, in some European countries the granting authority decides whether the public should be involved early on in the process or not at all [30]. The latter approach can save time initially but may lead to many problems in the long run, as case study 1 shows.

\subsection{How should they be addressed?}

Oftentimes public acceptability of RE projects increases when familiarity with the technology rises and observations of similar projects are possible [32-33]. Hansen et al. [34] comment that WE can possibly become more popular than wind energy because of the minimized visual and noise impact. However, it is a big challenge due to the "low public knowledge" on WE. It is therefore important to be aware of the level of WE understanding in selecting the most appropriate tools for addressing stakeholders.

Essentially, there are three ways for involvement: through passive information, planning participation and financial participation [16, 26, 35-36]. In general, the former is regarded as a bad practice if there is a lack of WE knowledge or no previous related activity in the area. Likewise the latter option is not considered since WE has not yet become financially attractive [28].
The recommended strategy, namely planning participation, directly involves stakeholders in the planning phase through two-way communication techniques, incorporates negotiated changes into the project, provides motivation for the public, generates interest in the project and other energy related issues and can deal earlier with misconceived threats [28].

Nevertheless, this strategy may carry some drawbacks related to fulfilling public demands and the time required for that. As a result, it is becoming common to hold a communication process managed by an independently appointed party. This method assures that the public and stakeholders' views are fairly represented in the process. It has proved effective in Belgium with several wind projects as well [37].

\section{Case studies}

\subsection{SSG Kvitsøy pilot project, Norway}

The Norwegian based company Wave Energy AS (WEAS) develops the technology Seawave Slot-Cone Generator (SSG), a WEC of the overtopping type. The $150 \mathrm{~kW}$ pilot project [38] comprises of a 10x17x6m (width-length-height) concrete civil structure module to be built on a rocky shoreline (Fig.1). WEAS was not obliged to carry an EIA nor an EIS for the pilot project. The project had none of them, but obtained the construction permit.

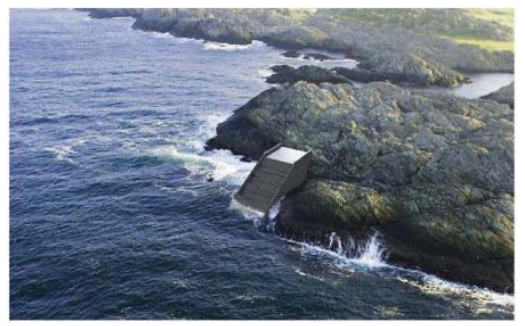

Figure 1: SSG pilot plant in Kvitsøy island, Norway [39].

Location: It is located in Kvitsøy island, west coast of Norway. The island has a high tourist value due to its natural resources, particularly for the greenstone rock. The location was chosen for its WE resource (i.e. the near-shore average WE power is estimated at $19.6 \mathrm{~kW} / \mathrm{m}$ [39]) and for its remote characteristics. There was no particular competence in the deployment site besides some possible interference with kayaking and canoeing activities.

Engagement strategies: Generally, public engagement practices were very few and there were neither specific awareness campaigns nor public exhibitions or other relevant engagement strategies.

The project consortium included the Municipality of Kvitsøy as "a key to [...] ensuring [...] cooperation with the island inhabitants". The Municipality planned to involve the locals with the construction of a local museum dedicated to WE and the particular SSG project. Nevertheless, the museum was never realized.

Besides radio programs, TV programs and newspapers gave relevant project information, which mainly focused on the SSG pilot project and WEAS locally-based 
company. No general WE information was provided. Additionally, a project website was established.

Public opinion: There was very high project acceptance among the local inhabitants. The highlighted benefits of the project were added tourist value to the area and to some extent new RE sources as an alternative to existing diesel generators.

The opposition to the project came from only one individual who had a summer house in the island. He had had related activities with EIAs and his main complaint was the lack of an EIA for the project. His opposition campaign involved contacting most of the responsible authorities behind the project, at the local, national and EU level, and writing in local newspapers.

He wrote objection letters and delivered an official complaint to Kvitsøy municipality against the construction approval. This objection was denied twice by the Municipality but was taken further to a regional commissioner. The latter also denied the objection, but then it was delivered together with the objection against the above decision to the Norwegian Department of Environment and Energy.

In addition to this, he found two unknown issues related to WEAS and the project. First, that WEAS did not have the money required for the decommissioning phase, approximately in ten-year time. And second, that it planned to blast rocks for the construction works.

The opposition campaign resulted into additional project delays and increased public opposition. As a result, the project consortium decided to stop the project and choose a different location, already before the last objection was solved.

\subsection{Wave Dragon Pembrokeshire pilot project}

Wave Dragon (WD) Pembrokeshire project consists of the deployment of a $7 \mathrm{MW}$ demonstrator, off Southwest Wales, UK. The device will be tested for 3-5 years, whereupon it will be removed from the temporary deployment zone to a final one 40-45 km further offshore, with 21-25 kW/m WE potential.

Location: The demonstration site was selected due to a predominant wind and wave direction and good WE potential (i.e. up to $15 \mathrm{~kW} / \mathrm{m}$ ), proximity to grid connection points and proximity to land, including a major port. The site is also away from commercial shipping interests and outside of military firing ranges.

These criteria defined a site surrounded by ecologically sensitive areas (i.e. it is within Pembrokeshire Coast National Park), which, in spite of this, was pointed by the Countryside Council for Wales as the most suitable location. The area is also characterized by tourism, associated service industries and potting activities for lobsters fishing [10].

Engagement strategies: The developer made substantial efforts to engage stakeholders, local organizations and the public from the earliest stages [40] in order to share their plans and gain feedback. This engagement was coordinated by an offshore wind energy consultant. There were a series of one to one discussions with relevant stakeholders, a formal project briefing, with 40 people representing 25 organizations, and a public exhibition. The later gathered over 200 people. The project also launched a website giving access to the most important documents (www.wavedragon.co.uk).

Public opinion: The major concerns varied significantly among the target groups. While statutory stakeholders (i.e. Milford Haven Port Authority, Maritime and Coastal, Guarding, Department of Trade and Industry, etc) were interested in navigational safety issues, nonstatutory stakeholders like local groups and individuals were concerned about WD intrusion (i.e. visual impact, impact on local beaches, sensitivity of the local marine environment and effects on tourism) and the precedent an initial demonstrator project could set for a larger one [40].

To face the wide variety of concerns WD carried several studies: geophysical, benthic and archeological records studies, navigation surveys, and studies on fisheries, coastal processes, birds, subsea noise and ecology, among others. Particularly, WD produced theoretical visibility mapping to predict the visual influence of the WEC (Fig.2). This proved to be highly enlightening for stakeholders and allayed many concerns about the proximity of the device to the coast and the effects on tourism [10].

The local fishing community highly supported the project once initial concerns over loss of sea space for potting were allayed. Moreover, the Marine Fisheries Agency repeated their overwhelming position of support and strongly commended WD communication and engagement with local fisheries [10]. In addition, WD is considering allowing local fishermen to drop mussel ropes off the device and harvest the catch.

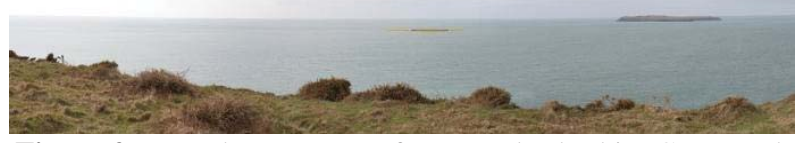

Figure 2: WD photomontage from Pembrokeshire Coast Path at Hooper's Point (250 mm viewing distance) [10].

According to an independent research activity [40], there is a significant degree of local support and no organized opposition to the project at this stage.

Timeline and EIA: The total process carried by WD can be divided into five distinct phases: i) scoping, ii) initial survey work, iii) discussion on initial survey results to inform full EIA surveys, iv) EIA surveys and v) discussion with survey results [10].

WD performed expensive and extensive EI studies even though it was only applying for permission to use the site as a test area. The reason may be explained as follows: On one hand, there was no clearly defined consent process for a WE demonstrator unit in the UK by the project time. The consent process was adapted from other contexts and authorities were not prepared [28]. Therefore, it was WD's responsibility to decide what to include and how to approach the EIA process. On the other hand, WD had a deadline to use the project funding and was actually worried of having the project stopped due to lack of EI studies. Thus, the uncertainties in the 
licensing process along with WD's fear of jeopardizing the project funding, led WD to carry out a full EIA. The process involved more than 13 authorities and including the feasibility assessment and consent, it lasted for four years (Fig.3).

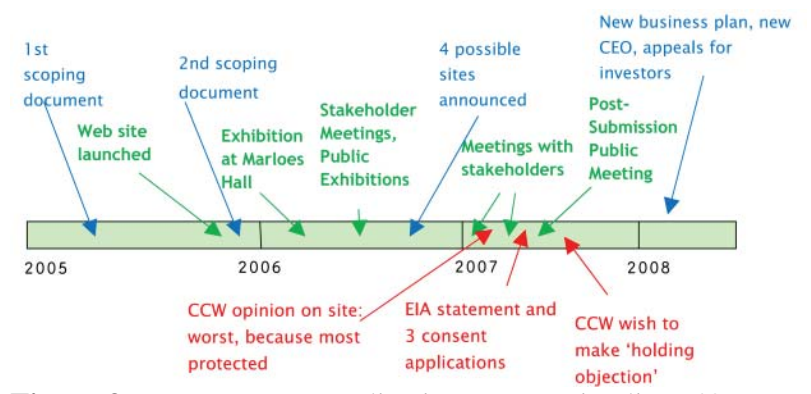

Figure 3: Wave Dragon application process timeline [40].

The project stalled after scoping studies, engagement and consent applications. Funding problems are cited as the main reason in addition to difficulties of the complex process [40]. The project is finally back on track (by 2010) with the final consent expected in 2011.

\subsection{Ocean Test Berths scoping process}

The Northwest National Marine Renewable Energy Center (NNMREC) is a partnership between Oregon State University (OSU) and the University of Washington (UW) sponsored by the Department of Energy (DOE) in the Pacific Northwest area of the US. OSU and UW collaborate toward WECs and tidal energy devices commercialization, inform decision makers and boost technology development.

NNMREC has proposed to construct, deploy and operate an Ocean Test Berth (OTB) about $2 \mathrm{~km}$ off Newport, Oregon, US. The OTB will be an integrated and standardized test center to test, develop and validate WECs. The first development of OTB is the Mobile Ocean Test Berths (MOTB), where WECs can be tested without grid connection.

Engagement strategies: DOE, as the funding agency of the project, has initiated the preparation of a draft EA of the MOTB, according to NEPA requirements. Its purpose is to i) identify any adverse environmental effects, ii) evaluate viable alternatives to the proposed action, iii) describe the relationship between local short-term uses of the environment and the maintenance and enhancement of long-term productivity, and iv) characterize any irreversible and irretrievable commitments of resources [41]. DOE also issued a Notice of Scoping for the MOTB. The Notice of Scoping provides details about the project and is publicly available in order to get input on issues that should be considered in the EA.

DOE held a meeting where the public could provide comments, to be incorporated in the draft EA. After, the public will be notified and allowed to comment on the Draft. Subsequently, the public comments will be incorporated in the final EA. Then, DOE will either determine a Finding of No Significant Impact or proceed with a full EIS [42].

Public Opinion: About 25 people attended the DOE community scoping meeting. Most of them represented the general public, but there were also representatives of state agencies and local businesses and some commercial and recreational fishermen. Most of the questions raised focused on the test site location. It was suggested that the MOTB was in a very busy area for recreational fishermen. Several people asked about the total closure area and whether the MOTB could be moved within the test site. Some questions focused on the mooring design and the devices to be tested.

Newport community has seen plans for harnessing WE for several years ahead. By 2006, Oregon suitability for WE development was made public [43] and since 2004 there have been strong efforts to establish a NNMREC in Oregon [44]. Efforts included building strong support at the state and federal levels, collaboration with industries, utilities and the communities, and outreach to the fishermen and crabbers community. In addition, specialists and University professors have been informing coastal communities about WE development opportunities in Oregon [45].

FINE (Fishermen Involved in Natural Energy), the local community and representatives from federal and state resource agencies are now involved in the MOTB site selection. FINE was established in Newport as an advisory group, whose purpose is to represent the community interests, especially those of fishermen and crabbers, in making decisions about the actions taken in the County waters. The reason for its creation was the County's concern that WEC developers could obtain permits without engaging the community.

DOE decision as a result of the scoping process will probably be favorable. This is due to the early community involvement and the organized approach that puts local and fishermen interests on par with WE development.

Scoping is viewed as "the most important stage" for determining the quality of an EIA and as "the most problematic phase" [30]. This case study shows that with early stakeholder involvement, the second part of the definition might need to be changed.

\section{Discussion}

The presented case studies provide good baseline data to discuss the following questions:

\section{- Are there differences in best practices for WE projects in comparison to developing other RE projects?}

The inherent characteristics of WE makes the research and development stage more difficult than for other RE technologies in relation to technology testing. WE prototypes above a certain scale have to be tested in real seas and their size has to be adjusted to the sea states where are deployed. This makes WECs not only large in size but very expensive to test.

On top of this, WE developers may have to deal with regulatory hurdles, long and expensive EIAs, and an opposing public opinion to obtain permits to deploy demonstration projects.

Case study 2 describes one of the main barriers for WD development, the expensive and extensive EI studies that had to be performed [28], in spite of it being a 
demonstration project. WE pilot projects should be exempt from complex EIA processes that would represent a barrier for the development.

\section{- Are best practices globally defined or site specific?}

There are some universal best practices, such as early and local participation, and some site-specific issues, which depend on the community priorities. In different locations particular stakeholders might need to be stressed over others.

It could be inferred from Case study 1 that it should be the responsibility of the local authority to organize public acceptance campaigns and to collaborate with developers for their realization, since the local authority knows better the inhabitants, their culture as well as the community habits. Particularly, WEAS believes it should be the developer's decision whether to carry public acceptance campaigns or not when deploying pilot projects, even though it should aim at. He should not be obliged by national or international laws, but by the local authority.

- Can we talk about best practices in Europe versus best practices in US or other regions and countries?

In the US [46], local communities form groups, such as FINE or FACT (Fisherman Advisory Committee for Tillamook), which represent the community interests. In their meetings anyone can express an opinion about an issue relevant to the local community. Eventually, these groups help coastal communities come out with a unified position and speak up their interests, when holding discussions on WECs siting, for example.

So far, European experience for WE does not reveal any organized groups as such to aid in reaching a common community decision. This is neither found in the wind energy sector, except for organized anti-wind farm groups.

\section{Conclusions}

Public involvement is considered positive in the long run despite the fact that it can extend the timeline for public approval almost indefinitely. In other words, as long as the public has any concerns about a proposed project, the project will not be implemented if those concerns are not addressed in a satisfactory manner.

For example, WD firmly believed in an early and open approach [35]. According to the high levels of public acceptability to the Wales project, this strategy has proved to bring direct benefits to the project [10]. Nevertheless, the experience has also shown that negotiations with stakeholders could last indefinitely and eventually result into a time consuming and expensive process.

Besides, it seems that RE projects are generally more penalized by the local communities and sometimes also by the authorities with regard to their EIs and the EIA process than non-RE ones.

Here, the authorities, particularly the local ones, play a major role. They should aid developers in addressing stakeholders and local communities. Moreover, strategic planning policies like Strategic Environmental
Assessment along with Marine Spatial Planning, are desirable to avoid or minimize conflicts of WE with other sea uses or damage to visual, cultural or archaeological resources [47]; these usually being the origin of public opposition to WE projects [21].

The paper has proposed some recommendations for an effective public acceptability process. For further research and a better understanding of the difficulties for developers in achieving best practices, we recommend conducting further interviews with developers. Once commercial deployments take place we will see what is actually happening and how the reality fits with the anticipated positive and negative impacts of WE and their consequences on public opinion.

\section{Acknowledgements}

The $1^{\text {st }}$ author acknowledges the funding by the ECMarie Curie program, through the project FP7-PEOPLEITN 215414 (Wavetrain2). The first two authors also acknowledge the International Collaboration Incentive Scheme (ICIS) scholarship, awarded by the International Network on Offshore Renewable Energy (INORE). The $2^{\text {nd }}$ author would like to thank the Oregon Sea Grant for awarding her the inaugural Malouf scholarship. The authors would also like to thank all participants in interviews and conversations for their sincerity and openness in sharing their perspectives and experiences with us, especially Lucia Margheritini, WAVEnergy AS, Fred Gardner, Meleah Ashford, Kaety Hildenbrand, Amanda Gladics, David Langston and Erik Friis-Madsen.

\section{References}

[1] M.T. Pontes, A. Falcao. (2001): Ocean Energies: Resources and Utilisation. 18th World Energy Conference, London,UK.

[2] P. Devine-Wright. (2005): Beyond NIMBYism: towards an integrated framework for understanding public perceptions of wind energy. Wind Energy, Vol. 8, pp. 125-139.

[3] J. Firestone, W. Kempton. (2007): Public opinion about large offshore wind power: Underlying factors. Energy policy, Vol. 35, pp. 1584-1598.

[4] J. Firestone, W. Kempton, A. Krueger. (2009): Public Acceptance of Offshore Wind Power Projects in the USA. Wind Energy, Vol. 12, pp. 183-202.

[5] S. Krohn, S. Damborg. (1999): On public attitudes towards wind power. Renewable Energy, Vol. 16, pp. 954-960.

[6] M. Wolsink. (2000): Wind power and the NIMBY-myth: institutional capacity and the limited significance of public support. Renewable Energy, Vol. 21, pp. 49-64.

[7] BWEA. (2002): Best Practice Guidelines: Consultation for Offshore Wind Energy Developments. British Wind Energy Association (BWEA).

[8] J. West, I. Bailey, I. Whithead. (2009): Stakeholder Perceptions of the Wave Hub Development in Cornwall, UK. 8th European Wave and Tidal Energy Conference, Uppsala, Sweden. 
[9] L. Kørnøv et al. (2007): Tools for sustainable development. Aalborg University, Aalborg, Denmark.

[10] I. Russell, H.C. Soerensen. (2007): Wave Dragon: results from UK EIA and consenting process. Proceedings of the 7th European Wave and Tidal Energy Conference, Porto, Portugal.

[11] T.Simas, et al. (2009): Existing Legislation, Perspectives and Evolution of Other Similar Technologies. Deliverable D6.1.1 to the Equimar Project.

[12] C. Redgwell. (2007): International Regulation of Energy Activities. Energy Law in Europe. 2nd Edition. New York : Oxford University Press, pp. 13-114.

[13] H.C. Soerensen, I. Russell. (2008): Work Session 5: environmental, economics, development policy and promotion of opportunities. Coordinated Action on Ocean Energy.

[14] L. Margheritini, A.M. Hansen, P. Frigaard. (2010): A method for EIA Scoping of Wave Energy Converters Based on Classification of the Used. Elsevier Editorial System(tm) for Environmental Impact Assessment Review, Manuscript Draft.

[15] T. Konnert (2009): The role of FERC in authorizing hydrokinetic technology projects. Oceanography, Vol. 23, pp. 54-59.

[16] G. Walker. (1995): Renewable energy and the public. Land Use Policy, Vol. 12, pp. 49-59.

[17] A. Fatuzzo. (2009): The marine renewable energy industry, a new challenge for coastal management. Case study: Wave energy in Portugal. Sea Science Faculty of University of Cadiz, Spain, and Wave Energy Center, Lisbon, Portugal.

[18] D. Hunter. (2009): Public perceptions of wave energy on the Oregon coast. Anthropology, Oregon State University, Corvallis, Oregon, USA, p. 168.

[19] A. Sarmento, F. Neumann, A. Brito e Melo. (2004): Nontechnical barriers to large-scale wave energy utilisation. International Conference on New and Renewable Energy Technologies for Sustainable Development, Évora, Portugal.

[20] P. Devine-Wright, (2009): Rethinking NIMBYism: the role of place attachment and place identity in explaining place-protective action. Journal of Community and Applied Social Psychology, p. DOI: 10.1002/casp. 1004.

[21] M. Stefanovich, J. Fernandez-Chozas. (2010): Toward Best Practices for Public Acceptability in Wave Energy: Issues developers Need to Address. 3rd International Conference on Ocean Energy, Bilbao, Spain.

[22] J. Stevenson. (2009): Mapping the political landscape of wave energy development off the Oregon Coast. Marine Resource Management, Oregon State University, Corvallis, Oregon, USA.

[23] C. Huertas-Olivares. (2006): Environmental impact of pilot plants: identification of common and diverse aspects in the four pilot plants both in the impacts and evaluation methodologies proving recommendations. Deliverable 22 to the Wavetrain project, Wave Energy Centre, Lisbon, Portugal.

[24] DEA. (2006): Offshore Wind Farms and the Environment. Danish experiences from Horns Rev and Nysted. Danish Energy Authority, Denmark.

[25] C. Beels, et al. (2009): Numerical Simulation of the Wake Effects in the Lee of a Farm of Wave Dragon Wave Energy Converters. 8th European Wave and Tidal Energy Conference, Uppsala, Sweden.

[26] C. Huertas-Olivares, et al. (2008): First Outcome of the Waveplam Project: Assessment of Non-technical Barriers and Best Practices. 2nd International Conference on Ocean Energy, Brest, France.

[27] H.C. Soerensen, S. Naef. (2008): Report on Technical Specification of Reference Technologies (Wave and Tidal Power Plant). Deliverable 16.1 to Needs project, Copenhagen, Denmark.

[28] F. Neumann. (2009). Non-technological barriers to wave energy implementation. Deliverable 2.2 to the Waveplam Project, Lisbon, Portugal.

[29] U. Henfridsson, et al. (2007): Wave Energy Potential in the Baltic Sea and the Danish Part of the North Sea, with Reflections on the Skagerrak. Renewable Energy, Vol. 32, pp. 2069-2084.

[30] M. Portman. (2009): Involving the public in the impact assessment of offshore renewable energy facilities. Marine policy, Vol. 33, pp. 332-338.

[31] G. Dalton. (2009): State of the art analysis. Deliverable 2.1 to the Waveplam Project, Cork, Ireland.

[32] H.C. Soerensen, et al. (2001): Experience with and strategies for public involvement in offshore wind projects. Offshore Wind Energy EWEA Special Topic Conference, Brussels, Belgium.

[33] E. Pavlides. (2008): A Viable Marine Renewable Energy Industry: Solutions to Legal, Economic and Policy Challenges. R. Williams $7^{\text {th }}$ Marine Law Symposium.

[34] L.K. Hansen, et al. (2003): Public acceptance of wave energy. 5th European Wave Energy Conference, Cork, Ireland.

[35] K. Hammarlund. (1999): Planning for acceptance Windpower in a social landscape. European Wind Energy Conference, Nice, France.

[36] F. Van Erp. (1996): Siting processes for wind energy project in Germany. Public participation and the response of the local population. Arbeiten zur Risiko Kommunikation, Forschung Zentrum Jülich KFA.

[37] H.C. Soerensen, N. Rousseau. (2009): Best Practice. Deliverable 2.3 to the Waveplam Project.

[38] M. Bakke. (2008): Full-scale demonstration of robust and high-efficiency wave energy converter. Final publishable executive summary. 
[39] L. Margheritini, D. Vicinanza, P. Frigaard. (2009): SSG wave energy converter Design, reliability and hydraulic performance of an innovative wave energy device. Renewable Energy, Vol. 34, pp. 1371-1380.

[40] P. Devine-Wright. (2009): Beyond Nimbyism Case Study: Wave Dragon Wave Energy Project Pembrokeshire, South Wales. [Online]

www.sed.manchester.ac.uk/research/beyond_nimbyism/de liverables/reports_WaveDragon_Final.pdf.

[41] DOE. (2010): Notice of Public Scoping and Public Scoping Meeting. Department of Energy (DOE), EERE Public reading room, Golden, Colorado, USA.

[42] L. Margason. (2010): DOE Community Scoping Meeting. DOE/EERE, Newport, Oregon, USA.

[43] EPRI. (2004): Survey and characterization of potential offshore wave energy sites in Oregon. Electrical Power Research Institute (EPRI), Palo Alto, California, USA.
[44] OSU. (2010): History of Wallace Energy Systems \& Renewable Facility. Oregon State University, USA. [Online]: http://eecs.oregonstate.edu/wesrf/history.html.

[45] M. Previsic. (2008): Alternative energy development in the West Coast ocean energy environment, West Coast ocean energy resources. Portland, Oregon, USA.

[46] M. Portman. (2010): Marine renewable energy policy: Some US and international perspectives compared. Oceanography, Vol. 23, pp. 98-105.

[47] IEA-OES. (2006): Review and analysis of ocean energy systems development and supporting policies. AEA Energy \& Environment on the behalf of Sustainable Energy Ireland for the IEA's Implementing Agreement on Ocean Energy Systems (IEA-OES). 
Paper C: Toward Best Practices for Public Acceptability in Wave Energy: Issues Developers Need to Address

\author{
Published in \\ Proceedings of the 3rd International Conference on Ocean Energy (ICOE), 2010. \\ (This paper was awarded ICOE 2010 Best Poster award)
}





\title{
Toward Best Practices for Public Acceptability in Wave Energy: Issues Developers Need to Address
}

\author{
M. A. Stefanovich ${ }^{1}$ and J. Fernández-Chozas ${ }^{2,3}$ \\ ${ }^{1}$ Environmental Sciences Graduate Program \\ Oregon State University, Corvallis 97331, Oregon, USA \\ E-mail:stefanmalscience. oregonstate.edu \\ ${ }^{2}$ SpokApS, Blegdamsvej 4, 2200 Copenhagen, Denmark \\ ${ }^{3}$ Department of Civil Engineering, Aalborg University \\ Sohngaardholmsvej 57, 9000 Aalborg, Denmark \\ E-mail:julia@spok.dk
}

\begin{abstract}
At this initial stage of development, opinion toward wave energy is mainly positive. Interviews with developers, presentations about wave energy at local community meetings, and the literature show that there are four main types of issues developers need to address when discussing their projects with local populations: conflict of use of the ocean space, environmental impact, NIMBY (Not in My Back Yard), and community well-being concerns. The importance of these issues is presented and suggestions for best ways to approach them are provided. Examples and case studies from both sides of the Atlantic Ocean illustrate that despite similarities in the types of issues developers typically address at each site, the way of approaching the issues and the priorities given vary.
\end{abstract}

Keywords: Best practices, opinion, public acceptability and wave energy.

\section{Introduction}

Provided that wave energy (WE) has a large potential for producing electricity [1] and looking at the proposed WE deployment scenarios [2], it can be assumed that WE may become a significant contributor to the global renewable energy (RE) mix. At this initial stage of development of the WE sector, it is very important not to make the same mistakes that other RE sectors have made in some countries and to gain public acceptability from the early stages. This key period will only occur once, and if it is not dealt with efficiently and proactively, it may take several years to regain pubic trust in the sector. Since when obtaining a permit for a particular site, WE developers can be legally (depending on the nature of the project - demonstration or commercial) or morally, or both, obliged to discuss their development plans and intentions with local communities, the way they approach these communities will leave a long-lasting impression about the sector as a whole. Thus, developers act as good-will ambassadors not only for their own projects, but also for the WE sector. This article focuses on the issues developers need to address when discussing WE projects with local communities to achieve more efficiently public acceptability.

Public acceptability is not a new phenomenon - it has often been encountered with the adoption of new technologies, the placing of architectural monuments and works of art in public locations. Most of it has to do not so much with the form or function of the new development but with its symbolic meaning. Since the majority of wave energy converters (WECs) are in the experimental rather than commercial stage, citizens around the world do not have enough information to form an opinion about their impact yet [3-5]. Coastal communities, who will likely be the most impacted, either positively or negatively by this new technology, wonder how much change will be brought by it regarding conflicts of ocean use, community well-being (including employment, income, electricity rates, property values, and tourism flow), noise, visual, aesthetic, and environmental impact (EI).

Experience from different REs makes it possible for WE developers to learn about concerns that local communities typically have had with RE projects: how they perceived the new technology, the developers' approach to the community, or commitment to engagement practices. Although there is no general and simple formula that guarantees obtaining full acceptability of WE projects, several approaches have turned out to be successful. This paper focuses on the developers' experiences from recent WE projects on both sides of the Atlantic Ocean. To illustrate the major points, three case studies are presented: an European pilot project in Mutriku, Spain, and two US commercial projects from Oregon - the Douglas County Wave and Tidal Energy Project and the Tillamook County Columbia Energy Partners Project. 


\section{Public Acceptability of WE Projects}

At this initial stage of WE development, the general opinion toward WE is mainly positive. Interviews with local community members and results from national surveys show that respondents are mainly supportive of WE development. For example, a survey carried out in 25 EU member-states reveals that $60 \%$ of respondents favor ocean energy use, while $24 \%$ have a neutral attitude [8]. Another survey, conducted in Portugal, shows that $71 \%$ of respondents support WE development, noting that investment should be further increased [3]. Survey results in the US from Oregon and Washington and British Columbia, Canada reveal that the majority of respondents also have positive attitudes toward WE development [9]. Therefore, since opinion toward WE is mainly positive, what issues may lead the public to oppose WE projects?

Sarmento et al. [10] assert that public acceptability of WE projects can be found in a mixture of societal concerns and competing uses of the area proposed for development. Thus, there are different factors within each project that lead the public to either support or oppose a project. The general consequences of each factor can be identified and addressed within the framework of an environmental impact assessment (EIA) process [11].

\subsection{Best Practices}

The importance of achieving public acceptability necessitates a discussion about best practices. What are the issues that need to be addressed so that best practices can be achieved?

For the purposes of this paper, best practices in gaining public acceptability for developing WE projects refers to achieving the positive endorsement of WE projects among stakeholders without alienating key members of the local to the project communities. Stakeholders are defined as individuals or organizations with a stake in something (in this case -the ocean) [6]. In other words, best practices do not center on the speed for going through regulatory hurdles, but on creating a positive environment for effective communication.

Identifying all of the best practices developers have used in other RE projects is a difficult, even impossible task; and besides, those identified may even be subject to debate, particularly when applied to the WE sector [7]. Case studies of pilot and commercial WE projects not only illustrate the applicability of the best practices concept, but also explain its rationale. The case studies are selected based on three criteria: a) They examine distinct issues and look at best practices from different angles; b) They are geographically diverse, and c) They are recent.

\section{Issues to be Addressed}

The common uses of the deployment area have to be analyzed for each particular project. WE developers typically have to justify and explain the reasons behind project development since often they are seen as intruders into an ocean area with already predefined uses. Despite that, developers should utilize different methods for informing, and moreover, involving local communities in the project development process [11]. They should look at community engagement as a way of establishing long-term relationships and keep up the communication with local communities.

Interviews with developers, participation in community presentations about WE projects, and the literature review show that the issues developers should address with local communities can be summarized in four main areas: conflict of use of the ocean space, environmental concerns, NIMBY (Not In My Back Yard), and community well-being concerns. Table 1 shows a summary of these issues. The four major issues are organized according to type rather than importance. No-go areas, such as military zones, safety zones, and navigation routes are not included in Table 1 . It is expected that they would be classified and addressed by the Marine Spatial Planning (MSP) process before commercial WE development starts. In this regard it should be noted that while European countries are working on creating MSP and some already have it completed [12], the US is now in the process of creating spatial maps that can be used for siting and planning by the WE sector [13].

Some of the questions raised by a particular issue belong to more than one issue area; for example, questions about property values could fall either under NIMBY because of the visual impact, or under community well-being, when property values are perceived in economic terms. Because of the complexity of the issues, this may actually be the case with most of the questions presented in Table 1.

\subsection{Conflicts of use in the project area}

The most common uses of the WECs' deployment area are typically commercial fishing, recreational fishing, and surfing. The main concerns fishermen have are how much space will be taken away from existing fishing grounds and what will that mean in economic and employment terms.

Despite the fact that fishing quotas are declining and fish stocks are being depleted, fishing continues to be an integral economic sector for many rural communities on both sides of the Atlantic Ocean. US Pacific commercial fishing industry data, for example, shows that 2008 commercial sales amounted to about 15B USD for the states of California, Oregon, and Washington, and that recreational fishing contributed 250M USD just in Oregon [14]. Surfing has also been identified as an important economic activity $[15,16]$.

Because of the substantial economic contribution of the fishing and surfing sectors, developers need to be prepared to answer questions about the WECs' effects on these sectors. They should be able to explain the way WE technologies work and stress the fact that most of them are still in the experimental stage, i.e., studies show that WE is about 20 years behind wind in technological development [17]. 


\begin{tabular}{|c|c|c|}
\hline Issue: & Description: & Questions developers should be prepared to answer: \\
\hline $\begin{array}{l}\text { Conflicts of use in } \\
\text { the project area }\end{array}$ & $\begin{array}{l}\text { - Commercial fishing } \\
\text { - Recreational fishing \& } \\
\text { boating } \\
\text { - Surfing }\end{array}$ & $\begin{array}{l}\text { - Why are you interested in this particular site? } \\
\text { - What is the footprint of the proposed project or the exclusion area } \\
\text { of the WECs? } \\
\text { - Is the project going to displace existing (fishing) jobs? } \\
\text { - What would the effect be on the surfing waves? }\end{array}$ \\
\hline $\begin{array}{l}\text { Environmental } \\
\text { Impact (EI) } \\
\text { Concerns }\end{array}$ & $\begin{array}{l}\text { - } \text { Bottom species habitat } \\
\text { - Marine mammals \& other } \\
\text { species, including birds } \\
\text { - Entanglement } \\
\text { - Reproduction } \\
\text { - Migration }\end{array}$ & $\begin{array}{l}\text {-Can you prove that your project is benign to the environment? } \\
\text {-Have you done any EI analysis? Have you thought of mitigation } \\
\text { measures? Can you guarantee the survivability of your WECs? } \\
\text { - Have any of your devices experienced accidents, e.g., sinking, } \\
\text { hydraulic leaks, etc. during testing or at another location? What are } \\
\text { the lessons learned? } \\
\text { - Are you going to remove your devices after the deployment period? }\end{array}$ \\
\hline NIMBY issues & $\begin{array}{l}\text { - Visual impact } \\
\text { - Noise impact } \\
\text { - Aesthetic impact }\end{array}$ & $\begin{array}{l}\text { - How does wave energy work? What types of devices are out there? } \\
\text { - What type of devices will be deployed and why? } \\
\text { - Shall we be able to see or hear the devices during operation? } \\
\text { - How big are they - installed capacity and size-wise? } \\
\text { - Are they aesthetically pleasing? } \\
\text { - How far from the shore will they be located? }\end{array}$ \\
\hline $\begin{array}{l}\text { Community well- } \\
\text { being concerns }\end{array}$ & $\begin{array}{l}\text { - Employment } \\
\text { - Income } \\
\text { - Benefits /costs } \\
\text { - Tourism }\end{array}$ & $\begin{array}{l}\text { - How will the community be impacted? } \\
\text { - Is the cost of electricity going to go up? } \\
\text { - Is your commercial project going to be economically viable? } \\
\text { - Will tourism flow increase or decrease? }\end{array}$ \\
\hline
\end{tabular}

Table 1: Issues developers need to address

\subsection{Environmental Impact (EI) concerns}

Local communities are concerned about the EI of WECs on the marine habitat and species. It is necessary to develop a generic understanding of the interaction between a few experimental WECs and arrays of WECs, on one hand, and the marine environment, biological communities, and individual species, on the other hand [30]. Although the general impression is that fishermen are not welcoming WE because WECs will displace them, this needs further review. Fishermen also worry about the EI of WECs, because, in the words of a wave and tidal developer, they are like farmers, who want to preserve the habitat and the species they depend on. Therefore, it is really important for developers to address EI concerns. In this respect, developers might find it useful to examine the available research, which focuses specifically on the EI of WECs [31-34]. Developers have to keep informed of scientific findings, which although sometimes inconclusive provide a framework for evaluating EI and could serve as the basis for further discussions.

\subsection{NIMBY issues}

The NIMBY syndrome describes the theoretical support for RE development but opposition to specific local projects because of the perceived consequences regarding noise and visual impact [18, 19]. Many consider NIMBY to be too simplistic to explain all the variables determining the general and local public acceptance of a specific project [18, 20-25]. Moreover, some researchers have found evidence from the wind industry for exactly the opposite effect - local people becoming more favorable toward wind farms after their construction and the degree of acceptance increasing with proximity to them [26, 27]. How strong will
NIMBY concerns be in relation to WE development, remains to be seen.

Noise impact, like visual and aesthetic impacts, depends on the location of the WECs with respect to the shore and distance to populated areas. If WECs are placed near-shore the impact is likely more critical than if placed offshore. Noise from WECs is not expected to cause a negative impact [28]. However, no general assumptions can be made as different factors take place in the discussion.

In any case, to mitigate and avoid possible conflicts due to noise, visual or aesthetic concerns, the offshore wind energy sector, for example, has proposed open to the public planning sessions, where the configuration and the number of the devices in a farm are discussed and analysed prior to any final decision [29]. This has proved to be a good practice that WE developers might want to adopt.

\subsection{Community well-being concerns}

Community well-being is a complex term that refers to the "degree to which the needs and wants of a population are being met" [35]. Since coastal communities are economically dependent on fishing and tourism, they are especially vulnerable while sharing a narrow resource base with other sectors, like WE. That is why coastal communities are mostly concerned with access to natural resources, income, and employment.

An under-informed public may generally be unaware of the benefits of nascent RE projects [36]. However, WE deployment will eventually provide relevant benefits such as added value to the local area, especially regarding accumulation of expertise [28], along with improved security of energy supply, an increase of RE sources in the electricity mix, and a 
decrease of harmful and undesired emissions. Projections for job creation are also favorable - 19 jobs/MW of installed capacity [37].

Commonly, there is a concern about a rise in electricity rates due to the high costs of WECs. Here, it is essential to remark that investment costs are measured in cost per $\mathrm{kW}$, while the cost of electricity production is measured in cost per kWh. The former costs have been assessed for different WECs to be at about 2 MEUR/MW in 2020 [38]. The latter have been estimated at 10-25 cEUR/kWh for the EU countries[39] and 20-30 cUSD/kWh for the US, going down to 4.5 cUSD/kWh with technology improvements [40, 41].

Conclusions about the impact of WECs on tourism before any devices are operational should not be made. While Danish and UK offshore wind experiences show either no effect or an increase in tourism flow, US research on tourists' perceptions and intentions of visiting certain beaches with visible wind turbines indicates negative attitudes and avoidance [42]. Lilley et al. conclude, "we would not advise developers of offshore wind to claim that there will be no negative impact on tourism" [42]. Only experience will show what the impact of WECs on tourism and property values will be and if there will be regional variations.

\section{Case studies}

\subsection{Mutriku pilot plant, Spain}

The WE plant (Fig.1) consists of 16 Voith Hydro Wavegen turbines rated at $18.5 \mathrm{~kW}$ each, based on the Oscillating Water Column (OWC) principle.The annual WE potential of Mutriku is estimated at $7.14 \mathrm{~kW} / \mathrm{m}$ [43]. The Basque Government (BG), the Basque Energy Agency (EVE), along with the European Commission, finance the project.

Mutriku is a coastal fishing village near Bilbao in Northern Spain. For many years the construction of a new breakwater outside the existing harbor has been discussed as a protection mechanism - to tame the swell and increase safety access. Once the City Council agreed on building the breakwater, the BG proposed to integrate a WE plant in it. Some of the advantages of combining the two are shared costs for the civil works and minimized visual impact of the WE plant.

Engagement strategies: Public engagement practices were few. At the beginning, the BG and EVE presented the WE project to the City Council and the public. They provided mainly general technical information and an overview of the benefits the plant would bring to the community. These events did not seek the Council's or the public's input; nevertheless, the majority of the Council members supported the plant, partly because its construction came along with the breakwater.

The major engagement event took place after a severe storm produced a loud swooshing noise as the wind was passing through the moulds of the chambers in construction. The noise was so loud that it could be heard in two villages close to Mutriku, approximately 3 to $10 \mathrm{~km}$ away. In order to explain the origin of the noise and mitigate the public fear about further noise,
EVE organized an exhibition covering Mutriku's construction works and timeline.

Public opinion: Some locals formed opposition groups to protest the construction of the breakwater. Then, since both the WE plant and the new harbor were a joint project, the initial opposing groups turned also against the WE plant. One of the main voices of those groups came from the Green Party (Berdeak), which now has environmental competences in the City Council.

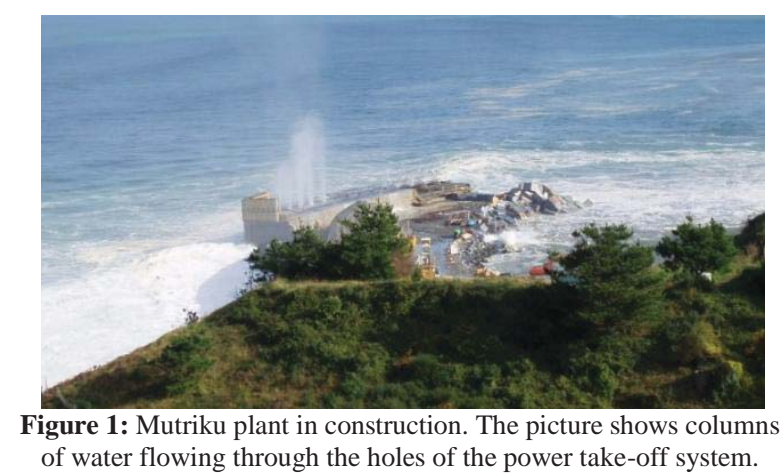

Fishermen, on the other hand, supported the project from the beginning because they saw it as an improvement to their harbor.

Since the opposition groups were more active than the supportive groups, however, the impression was created that the WE plant was an imposed project, not welcomed by the local public. But when the new BG announced plans to reduce the project budget (due to the financial crisis) and stop the construction works, the local support got active too. People raised complaints, as they did not want the project only partially finished.

EIA: After the screening phase the competent authority concluded that the WE project was not subject of a full EIA. The breakwater (without the WE plant) had its full EIA and the WE plant was a demonstration project. However, the opposition claimed there should be a new EIA for both the breakwater and the WE plant. They took the issue to court against the authority giving the environmental approval.

The plant was expected to be operational by June 2009, but due to some damage in the chambers of the plant during the storms, it will most likely start functioning in late 2010. This delay, however, is not related to the EIA issue, which is still waiting for court approval.

According to a member of the Mutriku City Council, the Council had neither the time nor the resources to deal with public acceptance of the project. He believes public involvement should be a combined effort by the developer and the local authority, although above all, it should be the developer's responsibility. The recommendation is to involve the public from as early as the planning phase. Besides, he also thinks that although the new access to the harbor raised significant opposition at first, people got used to it and welcomed it after its completion. Last but not least, the new WE 
plant has provided the village with added tourist value, which unfortunately, the local public is generally not aware of.

\subsection{Douglas County Wave and Tidal Energy Project (WTEP) in Oregon, U.S.A.}

Douglas County, Oregon has proposed a commercial WTEP near the town of Winchester Bay. The project consists of an OWC device with a total installed capacity of $3 \mathrm{MW}$ [49]. The technology supplier, as in the Mutriku project, is Wavegen.

Location: The OWC device will be constructed on or adjacent to the existing Umpqua River South Jetty, located about $3 \mathrm{~km}$ off the Oregon Coast highway, close to a National park and a marina - both attracting tourists, surfers, beach goers, and fishermen (Fig. 2).

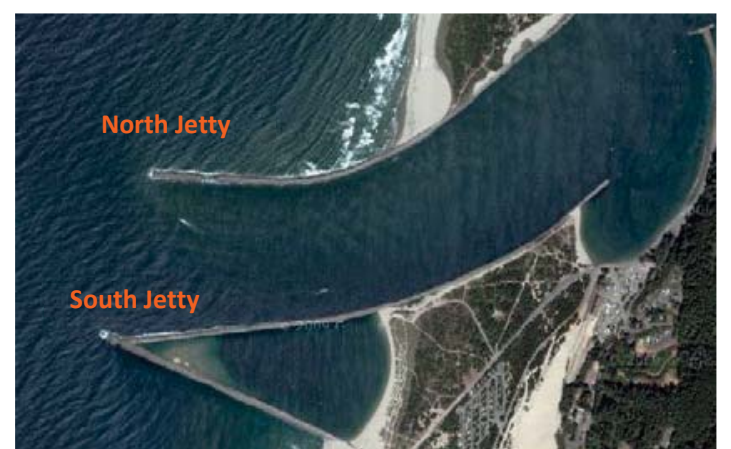

Figure 2. Douglas County South Jetty - proposed site for the Wave and Tidal Energy Project (Image obtained from Google Earth)

The project area is sparsely populated - the nearest city is Winchester Bay with 488 inhabitants and the closest big city is Reedsport with 4,378 inhabitants [50]. The area is transitioning from a marine commerce, logging, and commercial fishing to tourism [51]. A survey of visitors to the South Jetty shows that surfers visit the Jetty twice more often than fishermen and three times more often than beach-goers, and that although surfers spend the least amount of money per average visit, they still make a large economic contribution to the area [16].

Engagement strategies: When Douglas County filed for a Preliminary Permit Application to develop the WTEP, it started providing information to regulatory agencies and key stakeholders to better define the issues associated with the proposed project. As part of the first stage consultation, the County and the Federal Energy Regulatory Commission (FERC) held public meetings to identify any information gaps or research areas that needed to be resolved prior to submission of the license application. Some of the identified issues were the WE impacts on: fish and wildlife, seabed and dune habitats, construction and maintenance, electromagnetic fields, potential noise and aesthetic resources, surfing and attenuation of WE, national security and navigational safety, and decommissioning [52, 53].

Besides the FERC required meetings, the County and Wavegen held additional meetings with the general public and with groups with specific interests, one of which was the large surfing community in the area.
Public Opinion: The coastal population of Douglas County has been exposed to the WE concept since 2006, when seven permit applications were filed with FERC for WE development in Oregon. Two of them were in the County waters, the WTEP and the Ocean Power Technology (OPT) Reedsport Wave Park [52]. Since then, local fishing and surfing groups have stated their will to participate in all WE-related discussions. They have been part of the so-called "Settlement Agreement," initiated by the Governor of Oregon to give equal representation to all interests in discussions on coastal issues.

Because of the particular surfing environment near the proposed WTEP, the surfing community has been very active in all discussions, which can be described as "open and up-front" [55]. The Surfrider Foundation has remained engaged throughout the process to ensure that possible adverse effects are addressed appropriately. For example, it has presented some physiographic data and economic analysis of the impact of the surf in the area, and more specifically, the particular surfing spot. Although the surfing community did not welcome the project at first, surfers have been open and supportive of WE, trying to discuss their concerns with the developer. "In general, because the technology is so new, people don't know what to expect from it, so the best thing has been exploring the issues in an open environment, so that they are identified early, which helps finding alternative solutions as well," said the person in charge of permitting for WTEP [55].

After examining the bathymetry, the device design, and the WE potential, the County and Wavegen are conducting feasibility and technology studies. If the cost and engineering continue to support the project, the County will carry additional studies, necessary for a FERC license, which it plans to apply for in 3 years.

\subsection{Columbia Energy Partners (CEP) and} Tillamook County, Oregon, U.S.A.

Columbia Energy Partners (CEP) is a private investor company from Washington State. The company's main goal is rather than developing one particular device, to diversify its portfolio with various RE options [44]. It has already invested in one solar and several wind energy projects. In 2009, CEP decided to investigate the possibility of deploying WECs. Tillamook County in Oregon had already obtained a preliminary permit to carry feasibility studies for harnessing WE in its territorial waters and requested proposals from WE developers. CEP responded and signed an Agreement for Cooperation with the Tillamook Intergovernmental Development Entity (TIDE) [45].

Location: TIDE has a FERC preliminary permit for developing six sites, each $1.6 \mathrm{~km}$ by $4.8 \mathrm{~km}$ along the boundary of the Territorial Sea. CEP defined two of the six sites - off Garibaldi and Netarts - to be of particular interest for the company.

Engagement strategies: CEP approached TIDE to see if there would be local community support for WE development first, and then organize town-hall 
meetings. CEP had five in-person meetings with members of TIDE and the Fishermen's Advisory Committee for Tillamook (FACT), and two meetings only with FACT members. FACT is a nongovernmental body whose purpose is to provide a strong unified voice from the fishing community to TIDE, researchers, and developers by giving input and advice on WE-related issues [45].

Public Opinion: Objections about the two CEPselected sites came mostly from the fishing community. During the meetings CEP explained that installation was at least five years away. Despite that, fishermen were worried. They appreciated the early discussions with the developer but were concerned about potential conflicts. For example, fishermen worried that at the Garibaldi site, the devices would lie in the middle of important Chinook fisheries, while at Netarts, in prime crabbing grounds, "They can't just come in here and grab up fishing grounds without offering anything in return," the co-chair of FACT said at one of the meetings [46]. In addition, commercial fishermen worried that WE parks would not only cost fishermen money in lost grounds, but would also block central transit routes and crowd North Coast waters with displaced fishermen.

Fishermen had aesthetic concerns as well - they did not particularly like the proposed Pelamis devices because of their size and risk of hydraulic fluid leaks. Fishermen also raised concerns that the undersea cables would produce heat, thus raising bottom sea temperatures, which would diminish fish stocks. Despite the fact that CEP responded to a request for proposals for two of the already six permitted sites, members of FACT objected to the chosen locations and after six-month deliberations proposed others, far from the originally permitted ones, closer to the shore, in the viewshed of an affluent residential community where placing any WECs would have met with strong NIMBY opposition, and where the WE potential would have been significantly less.

When CEP terminated its agreement with TIDE, four reasons were mentioned: the location was not suitable for WE project development, the site was in a high public visibility area, difficulty connecting to the grid, and financial problems. The main reason, however, was the inability to reach a common ground with the local fishing groups. Although members of the surfing community and the Surfrider Foundation were not particularly in favor of WE development in the proposed area, their representatives did not attend any of the CEP meetings and did not raise any objections [48]. Strong fishing opposition was the primary reason CEP withdrew its participation.

\section{Discussion}

The case studies presented here illustrate the importance of the four issue areas for approaching WE development. Not all issues are of equal importance to the local project communities - the Mutriku project community raises EI and NIMBY concerns, while CEP and WTEP center more around conflict of use and community well-being concerns. Ultimately, in any location, developers need to address all four types of issues; however, the timing of addressing the issues depends on the priorities of each community. One issue (e.g., surfing) might need to be stressed before another (e.g., fishing). Initially, attention should be paid therefore, to groups with specific issues. For example, Douglas County held public meetings not only with the general public, but also with special interest groups like surfing. As a result, members of the surfing community had the opportunity to openly discuss issues important to them, raise their concerns in a non-threatening environment, and eventually contribute to the project development. Moreover, Mutriku case study shows that some important issues may emerge during the project development, and these should be addressed in time.

The way developers approach the four types of issues varies for two main reasons: the regulatory framework in the country where the WE project is deployed and the characteristics of the local population. Regarding the former, the Mutriku case study shows that the project was decided at the county level and the City Council went along with the decision. The City Council was not given the responsibility to either present the project or engage in discussions about the project with the local population. However, members of the City Council see that as a deficiency and make the case that public acceptance campaigns should be mainly the responsibility of the developer.

As far as the second reason is concerned - knowing the characteristics of the local population - the CEP case study is a good example. The company decided to investigate the local "climate," despite studies published by the Electrical Research Power Institute (EPRI) that defined one of the locations as a "sweet spot" for WE development in Oregon, based on 10 siteselection criteria, among which "minimal conflict with competing uses of sea space (shipping lanes, fishing grounds, and protected marine areas) and likelihood of public acceptance" [17]. What EPRI did not account for when writing the report, was the strong grass roots organization of local communities of interest and place, like TIDE and FACT. The idea about their creation is expressed in these words, "We can either wait until someone runs roughshod over us, or we can make sure we have a say in what happens"[46]. Whether the CEP experience is an expression of "having a say" or rather an example of strong WE opposition, remains to be seen.

For achieving best practices in addressing the issues described here, it is recommended that developers become aware of the experiences their colleagues have had with similar projects. Despite the fact that there are no universal practices, it is logical to expect that neighbouring to the proposed project communities will have similar concerns. Yet, this is not a $100 \%$-prove situation either. Examining the geodemographic characteristics of the local population, their values, and the population dynamics (e.g., the presence of trusted leaders or organizations), and the goals of the 
community (some may be happy with increased tourism flow while others may not) - would give an indication of the issues that could serve as motivating factors for either support or opposition to the proposed WE project. Once the issues are identified, developers should build engagement programs around the three Cs: connections (within and between people), communication (direct and indirect) and change (support transition through adaptation) [58]. Such engagement strategies have already been successfully applied to many natural resource use and RE projects [59].

\section{Conclusion}

It is important to discuss best practices in relation to public acceptability of WE because the WE sector has only recently started to be viewed as a RE player and has gotten the attention of both policy makers and investors. While the pressure is on WE developers to move from prototype testing to commercialization, and deploy WECs, local communities feel threatened, under-informed, and scared about what is in store for them, their local environment and their future. As the experience from many RE projects and the case studies presented here show public acceptability needs to be recognized as a critical challenge for the successful implementation of the WE sector. To aide WE development, it is important not only to convince key stakeholders in politics and business, but also to win the hearts and minds of the general public. A strong foundation for that will likely be based on openly addressing the issues that are important to the local communities and involving them in project development from the beginning.

\section{Acknowledgements}

This research was made possible in part because of a scholarship provided by the International Collaboration Incentive Scheme (ICIS), awarded by the International Network on Offshore Renewable Energy (INORE). The $1^{\text {st }}$ author would like to thank the Oregon Sea Grant for awarding her the inaugural Malouf scholarship. The $2^{\text {nd }}$ author acknowledges the funding by the EC-Marie Curie program, through the project FP7-PEOPLE-ITN 215414 (Wavetrain2). The authors would also like to express their gratitude to all participants in interviews and conversations for their sincerity and openness in sharing their perspectives and experiences. Special thanks go to: Fred Gardner, David Langston, Félix Azpiazo, Yago Torre-Enciso, Iñigo Agirre, Jon Norling, and Ron Yockim.

\section{References}

[1] World Energy Council. (2007): Survey of Energy Resources, W.E. Council, Editor London, UK.

[2] European Ocean Energy Association. (2010): Waves of opportunity: Ocean Energy European Road Map 2010, EU-OEA.
[3] A. Fatuzzo. (2009): The marine renewable energy industry, a new challenge for coastal management. Case study: Wave energy in Portugal, in Sea Science Faculty and Wave energy Center, Universidad de Cadiz: Cadiz, Spain and Lisbon, Portugal.

[4] D. Hunter. (2009): Public perceptions of wave energy on the Oregon coast, in Anthropology. Oregon State University: Corvallis.

[5] M. Stefanovich. (2009): Demographics Should Inform Wave Energy Policy in Sea Technology. Compass Publications, Inc.: Arlington, VA 22209 U.S.A. .

[6] BWEA. (2002): Best practice guidelines: Consultation for offshore wind energy developments. British Wind Energy Association.

[7] J. West, I. Bailey, I. Whitehead. (2009): Stakeholder Perceptions of the Wave Hub Development in Cornwall, UK, in the 8th European Wave and Tidal Energy Conference. Uppsala, Sweden.

[8] European Commission (2006): Energy Technologies: Knowledg-Perception-Measures. European Commission Community Research: http://ec.europa.eu/research/ energy/pdf/energy_tech_eurobarometer_en.pdf.

[9] M. Stefanovich. (2009): Building Community Support for Renewables, S. Lacey, Editor. Renewable Energy World: Maine, USA.

[10] A. Sarmento, F. Neumann, A. Brito-Melo. (2004): Nontechnical barriers to large-scale wave energy utilisation, International Conference on New and Renewable Energy Technologies for Sustainable Development. Évora, Portugal.

[11] M. Portman. (2009): Involving the public in the impact assessment of offshore renewable energy facilities. Marine policy. Vol. 33: p. 332-338.

[12] L. Kornov, et al. (2007): Tools for sustainable development. Aalborg University: Aalborg, Denmark. p. 355-399.

[13] G. Goldfarb. (2009): Marine Spatial Planning in Oregon: An emerging story. in A Forum hosted by the Nature Conservancy. Newport, Oregon.

[14] NOAA. (2008): Fisheries economics of the United States 2008, in Fisheries economics and sociocultural status and trend series, N.M.F.S.O.o.S.a. Technology, Editor.

[15] D.L.Stone, et al. (2008): Exposure assesment and risk of gastrointestinal illness among surfers. Journal of Toxicology and Environmental Health, Vol.71(24): p. 1603-1615.

[16] M. Matsler. (2009): Winchester Bay coastal user survey: A look at the intersection of recreational use and renewable energy project siting on the Oregon coast. FERC requested report: Douglas County.

[17] EPRI (2004): Survey and characterization of potential offshore wave energy sites in Oregon, in EPRI. E21/EPRI WP-OR-003, May 17, 2004, E.P.R. Institute, Editor. Electrical Power Research Institute: Palo Alto, CA. 
[18] S. Krohn, S. Damborg. (1999): On public attitudes towards wind power. Renewable Energy Vol. 16: p. 954960.

[19] P. Devine-Wright. (2005): Local aspects of UK renewable energy development: exploring public beliefs and policy implications. Local Environment, Vol. 10(1): p. 57-69.

[20] J. Firestone, W. Kempton, A. Krueger. (2009): Public Acceptance of Offshore Wind Power Projects in the USA. Wind Energy. Vol. 12(2): p. 183-202.

[21] P. Devine-Wright. (2005): Beyond NIMBYism: towards an integrated framework for understanding public perceptions of wind energy. Wind Energy. Vol. 8(2): p. 125-139.

[22] J. Firestone, W. Kempton. (2007): Public opinion about large offshore wind power: Underlying factors. Energy policy, 35(3): p. 1584 - 1598.

[23] M. Wolsink. (2000): Wind power and the NIMBY-myth: institutional capacity and the limited significance of public support. Renewable Energy, Vol. 21. p. 49-64.

[24] L. Smith. (2010): The great NIMBY debate: How to win local support, in realPower. British Wind Energy Association: UK. p. 23-25.

[25] K. Michaud, J. Carlisle, E.R.A.N. Smith. (2008): Nimbyism vs. environmentalism in attitudes toward energy development. Environmental Politics. Vol.17(1): p. 20-39.

[26] C. Warren, et al. (2005): "Green-on-green": Public perceptions of wind power in Scotland and Ireland. Journal of Environmental Planning and Management, Vol. 48(6): p. 853 - 875.

[27] E. Pavlides. (2008): Rhode Island Wind Alliance, in Roger Williams 7th Marine Law Symposium. A Viable Marine Renewable Energy Industry: Solutions to Legal, Economic, and Policy Challenges: Bristol, Rhode Island.

[28] H.C. Soerensen, S. Naef.(2008): Report on Technical Specification of Reference Technologies (Wave and Tidal Power Plant), in Deliverable 16.1 - RSIa to the Needs Project. Spok ApS: Copenhagen.

[29] H.C. Sorensen, et al. (2001): Experience with and strategies for public involvement in offshore wind projects, in Offshore Wind Energy, EWEA Special Topic Conference. Brussels, Belgium.

[30] Oregon International Port of Coos Bay. (2008): Regular Commission Meeting. Coos Bay, Oregon, U.S.

[31] G. Boehlert. (2007): Ecological Effects of Wave Energy Development in the Pacific Northwest. [cited 2010 February 10]; Available at: http://hmsc.oregonstate.edu /waveenergy/.

[32] C. Huertas-Olivares. (2006): Environmental impact of pilot plants: Identification of common and diverse aspects in the four pilot plants both in the impacts and evaluation methodologies proving recommendations, in Deliverable
22 to the Wavetrain project. Wave Energy Centre: Lisbon.

[33] T. Simas, A. Moura. (2010): Uncertainties regarding environmental impacts, in deliverable D6.3.1 to th Equimar project, W.E. Centre, Editor. Lisbon, Portugal.

[34] L. Margheritini, A.M. Hansen, P. Frigaard. (2010): A method for EIA scoping of Wave Energy Converters based on classification of the used technology. Submitted to Environmental Impact Assessment Review.

[35] R.J. Johnston, D. Gregory, D. Smith. (1994): Dictionary of human geography. Blackwell Publishers: Cambridge, MA.

[36] G.J.Dalton, D.A. Lockington, T.E. Baldock. (2008): A survey of tourist attitudes to renewable energy supply in Australian hotel accommodation. Renewable Energy. Vol. 33: p. 2174-2185.

[37] H.C. Soerensen, I. Russell.(2008): Work Session 5: environmental, economics, development policy and promotion of opportunities, in Coordinated Action of Ocean Energy (CA-OE).

[38] Carbon Trust, Future Marine Energy. (2006): London, UK. p. 38.

[39] S. Gonzalez Herraiz. (2008): The ocean energy sector In the programmes of the European Commission, D. TREN, Editor. European Commission Directorate-General for Energy and Transport: www.waveplam.eu/files/ downloads/Ocean\%20energy\%20SGH\%20(shorten).pdf.

[40] Ocean Energy Council. (2008): Wave Energy. [cited 2010 February 10] Available at: http://www.oceanenergy council.com/index.php/Wave-Energy/Wave-Energy.html

[41] Y. Yin. (2009): Is Wave Energy Comparatively Sustainable in Oregon?, in Political Science. Oregon State University: Corvallis. p. 99.

[42] M.B.Lilley, J. Firestone, W. Kempton. (2010): The Effect of Wind Power Installations on Coastal Tourism. Energies. Vol. 3(1): p. 1-22.

[43] W.K. Tease, Lees, A. Hall. (2007): Advances in oscillating water column air turbine development. in 7th European Wave and Tidal Energy Conference. Oporto, Portugal.

[44] Columbia Energy Partners. (2010): Climate change: Our generation's greatest challenge. [cited May 20, 2010]; Available from: http://columbiaenergypartners.com/.

[45] M. Labhart. (2009): Tillamook County: So what's been happening in regards to Wave and Wind Energy. in 2009 Ocean Renewable Energy Conference IV. Seaside Convention Center - Seaside, Oregon: http://www.fsl. orst.edu/cfer/Spotlight/Labhart/Labhart_TIDE_Overview. pdf.

[46] B. McEwen. (2008): Off Oregon's coast, wave power makes a splash, in The Oregonian. Portland, Oregon. 
[47] C. Profita. (2007): Wave energy projects crash into ocean fishing turf: Storm clouds gather as ocean users compete for priority, in The Daily Astorian. Astoria, Oregon.

[48] J. Norling. (2010): Columbia Energy Partners (CEP) proposed wave energy development in Tillamook County, Oregon, personal communication. Corvallis, Oregon.

[49] Douglas County Wave and Tidal Energy Project. (2008): Notice of Intent and Preliminary Application Document, in FERC, No.12743. May 23.

[50] U.S. Census Bureau. (2007): U.S. Census Bureau Data for the Oregon Coast, in www.census.gov

[51] Port of Umpqua. (2007): Port of Umpqua data, in http://portofumpqua.com/index.html

[52] Pacific Energy Ventures. (2009): Oregon Wave Energy Database, Oregon Wave Energy Trust, Editor. Portland, Oregon.

[53] R. Yockim. (2008): Douglas County Wave and Tidal Energy Project, Notice of Intent and Preliminary Application Document, in FERC. P12743.

[54] P. Stauffer. (2010): Reedsport Wave Energy Process, S.F.O. Chapter, Editor.

[55] R. Yockim. (2010): Wave and Tidal Energy Project in Douglas County, Oregon. personal communication. Corvallis, Oregon.

[56] M. Stefanovich. (2009): Wave energy and public opinion in the State of Oreogn: Summary of results from the Oregon Energy Policy Survey. Oregon Wave Energy Trust: Corvallis, Oregon.

[57] International Energy Agency - IEA. (2006): World Energy Outlook 2006, OECD, Editor

[58] F. Conway, et al. (2010): Ocean space, ocean place: The human dimensions of wave energy in Oregon. Oceanography. Vol. 23(2): p. 40-49.

[59] J. Fernandez-Chozas, M. Stefanovich, H.C. Soerensen (2010): Toward Best Practices for Public Acceptability in Wave Energy: Whom, When and How to Address. ICOE, Bilbao, Spain. 

Paper D: Performance Assessment of the Wave Dragon Wave Energy Converter Based on the EquiMar Methodology

\author{
Published in
}

Proceedings of the 9th European Wave and Tidal Energy Conference (EWTEC), 2011. 



\title{
Performance Assessment of the Wave Dragon Wave Energy Converter Based on the EquiMar Methodology
}

S. Parmeggiani ${ }^{1,2}$, J. Fernández-Chozas ${ }^{2,3}$, A. Pecher ${ }^{2}$, E. Friis-Madsen ${ }^{1}$, H.C. Sørensen ${ }^{1,3}$, J.P. Kofoed ${ }^{2}$

${ }^{1}$ Wave Dragon Ltd.

869 High Road, N12 8QA London, U.K.

stefano@wavedragon.net; efm@wavedragon.net; hcs@wavedragon.net

${ }^{2}$ Department of Civil Engineering, Aalborg University

Sohngaardholmsvej 57, 9000 Aalborg (Denmark)

sp@civil.aau.dk; jfch@civil.aau.dk; afsp@civil.aau.dk; jpk@civil.aau.dk

\author{
${ }^{3}$ Spok ApS \\ Blegdamsvej 4, 2200 Copenhagen (Denmark) \\ julia@spok.dk; consult@spok.dk
}

\begin{abstract}
At the present pre-commercial phase of the wave energy sector, device developers are called to provide reliable estimates on power performance and production at possible deployment locations. The EU EquiMar project has proposed a novel approach, where the performance assessment is based mainly on experimental data deriving from sea trials rather than solely on numerical predictions. The study applies this methodology to evaluate the performance of Wave Dragon at two locations in the North Sea, based on the data acquired during the sea trials of a 1:4.5 scale prototype. Indications about power performance and production of the device at the target locations, as well as on the applicability of the methodology, are provided.
\end{abstract}

Keywords - Wave Dragon, Performance assessment, Sea trials, EquiMar, Nissum Bredning, Hanstholm, North Sea, Ekofisk, Wave-to-wire, Wave energy.

\section{INTRODUCTION}

The wave energy resource around the globe is very large, with a particularly high potential for extraction along the Western European coast. If properly harnessed, wave energy can become a large-scale contributor to the European electricity mix [1].

At present Wave Energy Converters (WECs) are approaching the commercial stage. In this phase it is very important to provide the energy industry, stakeholders, investors and any other group of interest with a reliable assessment of the performances of full-scale commercial devices.

Numerical modelling is often used to calculate the power performance of a device, mainly due to its flexibility. However, predictions might not always be accurate enough to state the performance of a WEC in real sea conditions since features like the real-time control of the device and the influence of local conditions might not have been fully considered in the model.
Another possible approach is to assess the performance of a WEC based on data acquired during real sea trials of a reduced-scale prototype. In this case operational issues often neglected by numerical models are taken into consideration. Sea trial results can be up-scaled and fitted to the wave resource at the target location for the deployment of the fullscale devices, limiting the use of numerical models only to complement the experimental data.

This second approach has been recently proposed by the EquiMar project of the European Commission [2]. With this methodology, the EquiMar consortium aims to provide device developers and stakeholders with an equitable and general procedure to assess the performance of any WEC at different scales and locations, based on the results of sea trials.

Encouraging the sea trial of reduced-scale prototypes before reaching the full-scale commercial stage, the methodology also rewards a step-by-step development plan. Within this strategy any new phase of development, with its specific goals and objectives, is justified only by the good results of the previous one.

The adoption of a similar common approach, also known as Technology Readiness Assessment (TRA), would help to reduce capital risks in the product funding programmes [1].

The present study applies the EquiMar methodology to the Wave Dragon (WD) WEC, by assessing its performance at two different locations in the North Sea. These have been selected according to WD on-going and future development plans. The evaluation is based on the data acquired at the 1:4.5 scale prototype tested since 2003 in Nissum Bredning (NB), a benign location in Northern Denmark.

The results, relative to a setup without wave reflectors, show a wave-to-wire non-dimensional performance of $23 \%$ at an offshore location having yearly mean wave powers of 6 $\mathrm{kW} / \mathrm{m}$. This equals to yearly power productions of $0.64 \mathrm{GWh}$.

For a high North Sea wave climate of $24 \mathrm{~kW} / \mathrm{m}$ results show that too few experimental data are available to provide a 
reliable estimate of the performance for the envisaged device size.

Moreover, some indications will be drawn about the applicability of the proposed methodology, which had not been widely applied yet. Practical considerations on how to plan sea trials in order to increase the applicability will be addressed.

The content of the paper is as follows:

i) Presentation of WD technology, its development history and plans for future commercialisation;

ii) Detailed description of EquiMar methodology;

iii) Power production estimate of WD at two different locations in the North Sea, including the evaluation of its performances at different stages of the wave-towire model;

iv) Discussion of the results regarding the power performances of WD and the applicability of the methodology;

v) Conclusions and recommended further work.

\section{WAVE DRAGON}

The WD is a slack-moored floating WEC of the overtopping type. Incoming waves are focused towards the doubly curved ramp of the device by two wing reflectors, surging it without breaking and overtopping into a reservoir placed at a higher level than the mean water level (Fig. 1).

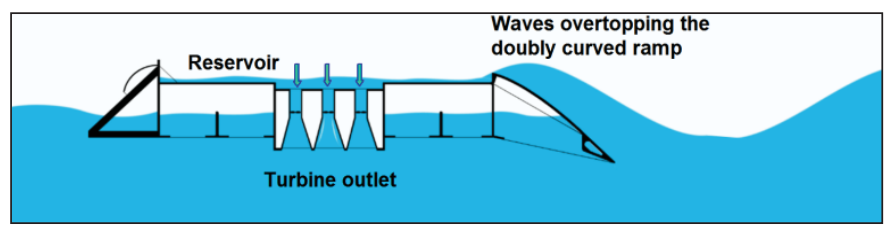

Fig. 1 - The Wave Dragon working principle.

The Power Take-Off (PTO) system of the device consists of several variable speed low-head hydro-turbines directly coupled to Permanent Magnet Generators (PMG). The power production takes place as the water stored in the reservoir is led back to the sea through the turbines.

The turbines are of axial type with fixed propeller blades and guide vanes. The rotational speed of the turbines is controlled in accordance to the available pressure head by means of a back-to-back frequency converter system. The turbines are activated in a cascade fashion by the control system depending on the water level in the reservoir. The PTO system has been proved to maintain a very high efficiency across the whole span of working conditions.

\section{Wave-to-wire model}

The energy conversion chain from wave-to-wire of WD can be broadly described in four different stages, corresponding to the following power levels:

Overtopping power: is the potential power of the waves overtopping the ramp crest of the device:

$$
P_{\text {crest }}(\mathrm{kW})=\rho \cdot g \cdot R_{c} \cdot q
$$

It is proportional to the crest level $R_{c}(\mathrm{~m})$, corresponding to the height of the crest freeboard above the mean water level, and to the overtopping flow $q\left(\mathrm{~m}^{3} / \mathrm{s}\right) . \rho=1025 \mathrm{~kg} / \mathrm{m}^{3}$ is the salt water density and $g$ is the gravity acceleration $\left(\mathrm{m} / \mathrm{s}^{2}\right)$.

Hydraulic power: is the potential energy stored in the reservoir that can be effectively harnessed by the turbines:

$$
P_{\text {hyd }}(\mathrm{kW})=\rho \cdot g \cdot H_{t} \cdot q
$$

It is proportional to the working head of the turbines, $H_{t}$ (m), defined as the difference between the water level in the reservoir and the mean water level. The power loss with respect to $P_{\text {crest }}$ is due to $H_{t}$ being lower than $R_{c}$.

Estimated power: is the power produced by the turbines assuming they are working at their optimal speed. It is derived from the characteristic curve of the turbines by knowing $H_{t}$. It can be expressed as:

$$
P_{\text {est }}(\mathrm{kW})=P_{\text {hyd }} \cdot \eta_{\text {turb }}
$$

where $\eta_{\text {turb }}(-)$ is the turbine's efficiency.

Actual power: is the power delivered to the grid. It is a function of the efficiencies of the generators, $\eta_{P M G}(-)$, and the frequency converters, $\eta_{f c}(-)$. In case of optimal turbine speed the relation is:

$$
P_{\text {act }}(\mathrm{kW})=P_{e s t} \cdot \eta_{P M G} \cdot \eta_{f c} .
$$

\section{Wave Dragon development phases}

WD has followed the 5-stage development proposed by the Waveplam project according to the TRA approach [3]. A preliminary phase of extended tank testing of a 1:51.8 scale model carried out at HMRC and Aalborg University served as the proof of concept and to optimize the design of the device [4]. In parallel with it, the WD optimised propeller turbine was developed with EU support and thoroughly tested in the test facility at Technical University Munich.

The results of this phase were used in the up-scaling of the device to the 1:4.5 scale prototype. This has been deployed since 2003 in NB, a benign site in Northern Denmark. The Wave Dragon Nissum Bredning (WD-NB) prototype was the first floating WEC to deliver power to an onshore grid.

Highly instrumented, it also allowed investigating many features impossible to consider at reduced scale. Among these were the control strategy and test of the PTO, the remote monitoring and control system and various issues related to the manufacturing, operation, maintenance and survivability of the device [5].

Currently, WD is involved in various projects to deploy larger scale units at different locations. Among others, the company has recently obtained a national grant to carry out a structural certified design of a 1:1.5 scale North Sea WD to be deployed at the Danish Wave Energy Centre (DanWEC) at Hanstholm, Northern Denmark. Moreover, the feasibility 
study will also consider full-scale multi-MW WD units to be deployed in the North Sea and the Atlantic Ocean.

\section{WD pre-commercial units}

In the following, reference will be made to three different scales of WD: one is the WD-NB, for which the performance data have been recorded, and the remaining two are larger scale devices. These correspond to a 1:1.5 scale device of a North Sea WD, to be deployed at Hanstholm, and to a fullscale North Sea WD.

The main geometrical and power features of the three precommercial devices are summarised in Table I.

TABLE I

SUMMARY OF WAVE DRAGON FEATURES

\begin{tabular}{|l|ccc|}
\hline \multirow{2}{*}{\begin{tabular}{l} 
Scale ratio \\
\cline { 2 - 4 }
\end{tabular}} & $\begin{array}{c}\text { Nissum } \\
\text { Bredning }\end{array}$ & $\begin{array}{c}\text { DanWEC } \\
\text { (Hanstholm) }\end{array}$ & $\begin{array}{c}\text { North Sea } \\
\text { (Ekofisk) }\end{array}$ \\
$\begin{array}{l}1: 4.5 \\
0.3-0.6\end{array}$ & $1: 1.5$ & $1: 1$ \\
$\begin{array}{l}\text { Width } \\
\text { (with reflectors) }\end{array}$ & $58 \mathrm{~m}$ & $6 \mathrm{~kW} / \mathrm{m}$ & $24 \mathrm{~kW} / \mathrm{m}$ \\
$\begin{array}{l}\text { Width (without } \\
\text { reflectors) }\end{array}$ & $21.6 \mathrm{~m}$ & $170 \mathrm{~m}$ & $260 \mathrm{~m}$ \\
$\begin{array}{l}\text { Length } \\
\text { Height }\end{array}$ & $33.3 \mathrm{~m}$ & $64.8 \mathrm{~m}$ & $97.2 \mathrm{~m}$ \\
$\begin{array}{l}\text { Device Rated } \\
\text { Power }\end{array}$ & $3.6 \mathrm{~m}$ & $96 \mathrm{~m}$ & $150 \mathrm{~m}$ \\
\hline
\end{tabular}

\section{METHODOLOGY USED}

The EquiMar methodology aims to use a dataset containing measured power levels at the prototype scale to estimate the power production of the same WEC at different scales and locations.

The ultimate goal of the methodology is to provide a power matrix for the target location, where the power output of the device is defined for every sea state together with an estimate of the accuracy of the stated performance $[6,7]$.

\section{A. Environmental Matrix}

The wave climate at the target location is characterised by an environmental matrix. Typically for a WEC this is a 2D matrix including only wave height and period, known as scatter diagram (SD).

In this study, the SD is defined by $H_{m 0}(\mathrm{~m})$, significant wave height derived from the frequency domain analysis of a wave record, and $T_{e}$ (s), the energy period. The dimension of the matrix bins has been varied depending on the target location considered.

\section{B. Performance data derived from the sea trials}

The data considered in the study correspond to two datasets, acquired respectively in autumn 2004 and summer 2006 at two different test sites in NB, i.e. Test site 1 and Test site 2 (Fig. 2). The water depth at these locations ranges between 5.3 and $6.1 \mathrm{~m}$, depending on the tide.
Both datasets are relative to data recorded in the absence of the wing reflectors, which were removed at that time due to maintenance. The data recorded at WD-NB include, among others, the wave conditions, floating position, overtopping flow, water level in the reservoir, turbine activity and power delivered to the grid. They consist of 30 minutes long time series acquired at $10 \mathrm{~Hz}$, enough to include in average a number of 1000 waves and allow for a statistical analysis.

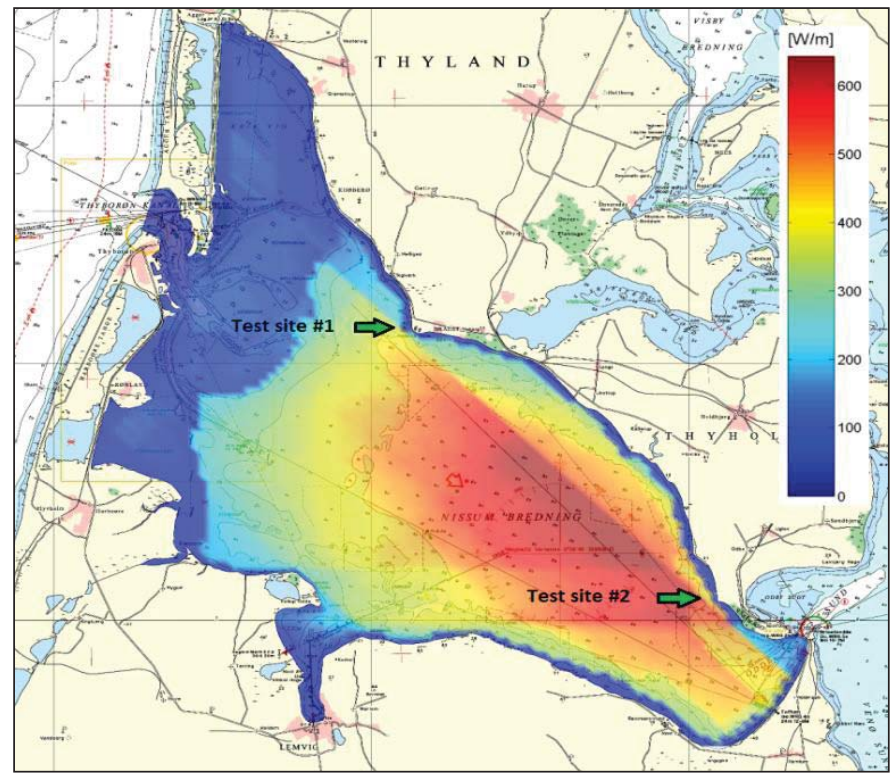

Fig. 2 - Nissum Bredning map with mean energy flux; the position of the two test sites considered is indicated.

The wave features were recorded by using a pressure transducer placed roughly $4 \mathrm{~m}$ above the sea bed and $50 \mathrm{~m}$ in front of the device, at the anchor pile. From the pressure measurements the wave elevation was derived applying linear wave theory [8].

The wave elevation time series were analysed in the frequency domain and values of significant wave height $H_{m 0}$, energy period $T_{e}$ and peak period $T_{p}$ were derived.

The overtopping flow into the reservoir, $q$, was measured indirectly: assuming the average volume of water in the reservoir is the same at the start and end of the $30 \mathrm{~min}$ of each record, the input, i.e. the overtopping flow, is equal to the output, i.e. the water flow out of the turbines. The latter was calculated by recording the working speed and head of each turbine and by knowing their characteristic curve. The main drawback of this method is that it neglects the spill of water out of the reservoir, which in some cases at WD-NB was significant especially at low crest levels [8]. Water spill can be reduced through the adoption of an appropriate control strategy at full-scale, as it will be discussed ahead in the paper.

The floating level, $R_{c}$, and floating position of the device has been derived from the combined measurements of 4 pressure transducers placed below the platform. The water level in the reservoir, from which the turbine head $H_{t}$ has been 
calculated, has been determined from the measurements of 3 pressure transducers placed on the bottom of the reservoir.

Finally, the working speed of each turbine and the power delivered to the grid $\left(P_{a c t}\right)$ by each generator were also recorded.

\section{Zoning}

The objective of the methodology is to define the power performance of the device across the whole SD with a reasonable level of accuracy.

The wave states tested during the sea trials have to be upscaled according to the scale ratio between the prototype and the unit to be deployed at the target location. The extent to which the up-scaled wave conditions cover the SD of the target location determines the accuracy of the estimates.

In principle, it is desirable that the bins of highest wave power contribution at the target location are well covered by performance data. However, since the time of sea trials is limited and the wave conditions cannot be controlled like in a wave tank, enough data might not be available to do so.

In this case, the methodology suggests to group together the bins into zones, for which the average performances are defined. This allows providing an estimate on the performance also for regions in the SD where no or few data have been collected during the trial period. In any case, the zones should be kept as small as possible whenever enough data points are available, in order to have a good resolution of the resulting power matrix.

In regions where too few or no data points are available, the average performance of the zones can be predicted by a numerical model. These zones are hereafter referred to as "numerical zones", whereas zones where the performance assessment is based on experimental data are called "experimental zones".

In this study the zoning has been done manually, covering the regions of greater contribution to the total wave power resource of the location.

For both experimental and numerical zones, the dimensions of the zones correspond to one bin of the SD.

\section{Performance assessment and data selection}

The performance data acquired at WD-NB was divided by the wave power at the trial location available across the width of WD ramp. These values are called non-dimensional performances $\eta(-)$.

By using non-dimensional quantities the power performance can be estimated at any location of interest, provided the available wave power is known (i.e. a SD is available) by multiplying the wave power by the respective $\eta$.

The estimate of the non-dimensional performance for each zone is the average $\eta$, based on all the selected data points for which the wave conditions belong to the zone. In order to describe the accuracy of the estimate, the standard deviation, $\sigma$ (-), and the confidence interval, $C I$ (-), for a confidence level of $95 \%$ are also calculated for every zone.

The latter is evaluated assuming a Student's-t distribution:

$$
C I=t^{*} \cdot \sigma / N^{0.5}
$$

where $t^{*}(-)$ is a statistical parameter depending on the size of the sample considered, $N(-)$, and the confidence level chosen.

During the sea trials not all recorded data may correspond to optimal performances (the control system may not function well or the control strategy might be improved over time, etc.). Therefore, lower performances are more often recorded than expected at full scale, where every component of the device is expected to work optimally.

In order to have an estimate representative of the performance of a full-scale device, a criterion has to be adopted to account only for those data referring to optimal working conditions. In any case, a minimum amount of data should be considered in every zone and the methodology should reward the increasing number of data considered.

Moreover, the data selection criterion should not only favour the highest $\eta$ but also the accuracy of the estimate: a balance between considering the optimal $\eta$ and the lowest $C I$ should be found.

In this study the minimum amount of data points initially considered for every zone was set to 5 . All data points were ordered according to their $\eta$ and then the 5 highest were initially selected.

Whenever the $\eta$ of the highest point was more than $10 \%$ higher than the following one, that data point was disregarded. This was meant to discard outlier data points which would significantly increase the $C I$ of the average estimate, being these points too high compared to the rest of the set to be considered reliable.

The first tentative value for the $\eta$ of a zone is the average between the remaining data points. The number of data points considered in the average is then increased until a $10 \%$ drop is achieved in $\sigma$ of the sample considered. In this way the optimal average $\eta$ is approached while maintaining a sufficient accuracy of the estimate.

\section{E. Power contribution and average performance}

Each bin of the SD corresponds to a sea state, for which the probability of occurrence, prob (-), is known and the wave power, $P_{w}(\mathrm{~W} / \mathrm{m})$, can be calculated as:

$$
P_{w}(W / m)=\frac{1}{16} \rho g H_{m 0}^{2} \cdot C_{g}
$$

where $C_{g}(m / s)=\frac{1}{2}\left[1+\frac{2 k d}{\sinh (2 k d)}\right] \cdot \frac{g T_{e}}{2 \pi} \cdot \tanh (k d)$ is the group velocity, $k\left(\mathrm{~m}^{-1}\right)=2 \pi / L$ is the wave number, $L(\mathrm{~m})$ the wave length, $d(\mathrm{~m})$ is the water depth.

This value is multiplied by the width of the ramp of WD, in order to consider the total usable wave power.

The contribution of each wave state to the total wave power resource available at the target location can be calculated as: 


$$
\text { Contr }_{\text {bin }}=\frac{\text { prob }_{\text {bin }} \cdot P_{w, b i n}}{\sum_{S D} P_{w, b i n}}
$$

Every parameter characterizing a zone, generically called $X$ (e.g. $H_{m 0}, T_{e}, \eta$ ), is given by the weighted average of $X$ of the bins belonging to that zone, where the weight is the product prob $\cdot P_{w}$ of each bin. This corresponds to:

$$
X_{z o n e}=\sum_{z o n e} X_{b i n} \cdot \text { Contr }_{\text {bin }}
$$

The contribution of each zone is given by the sum of the contribution of each bin of the zone.

The average $\eta$ of the device at the target location, based on the zones considered in the assessment, is:

$$
\eta_{\text {average }}=\frac{\sum_{\text {zone }=1}^{\text {Nzones }}\left(\eta_{\text {zone }} \cdot \text { prob }_{\text {zone }} \cdot P_{w, \text { zone }}\right)}{\sum_{z \text { zone }=1}^{N \text { zones }}\left(\text { prob }_{z o n e} \cdot P_{w, \text { zone }}\right)}
$$

An unbiased estimate of the average $\sigma$ can be given by:

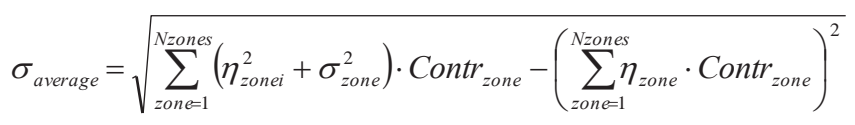

\section{F. Numerical Complementation}

When the performance data are not abundant enough in regions of the SD with a significant wave power contribution to the overall resource, the experimental data can be complemented by the predictions of numerical models.

In this case, the average numerical performance is called $\eta_{\text {num }}$ and its accuracy is defined by the accuracy of the numerical model used.

Performance values derived numerically have to be well distinguished from those drawn from experimental data, the use of the latter being the main objective of the methodology.

In this study, the numerical model used allows for predictions of the overtopping flow $q$, depending on the environmental features and on the setup of WD.

The numerical model has been adapted from a general overtopping model suitable for high crest applications [9], which has been updated to suit the specific case of WD after the tank testing of a reduced-scale model of it [10]. Features of the model include the description of the effect of the reduced crest height and limited draft of the device, of the wave steepness and of the specific geometry of WD. However, the model does not account for the effect of the hydrodynamic response of the WD.

The model can be applied whether or not wing reflectors are present. For the case considered in this study (no reflectors) the accuracy of the predictions with respect to the experimental data of the tank tests is $\pm 5 \%$.

Constant ratios $H_{m o} / R_{c}$ and $R_{c} / H_{t}$ are considered for all wave conditions, in order to provide numerical estimates of $P_{\text {crest }}$ and $P_{h y d}$, according to Eq. 1 and 2 respectively. These ratios are calculated as mean values, based on the data points selected in all the experimental zones.

Then, $P_{e s t}$ and $P_{a c t}$ are derived according to Eq. 3 and 4 by assuming constant efficiencies of the various components of the PTO system: $\eta_{\text {turb }}=0.91, \eta_{P M G}=0.94$ and $\eta_{f c}=0.98$ [11].

\section{G. Target locations for the study}

The target locations considered in the study are Hanstholm and Ekofisk, both located in the North Sea off the west coast of Jutland, Denmark (Fig. 3).

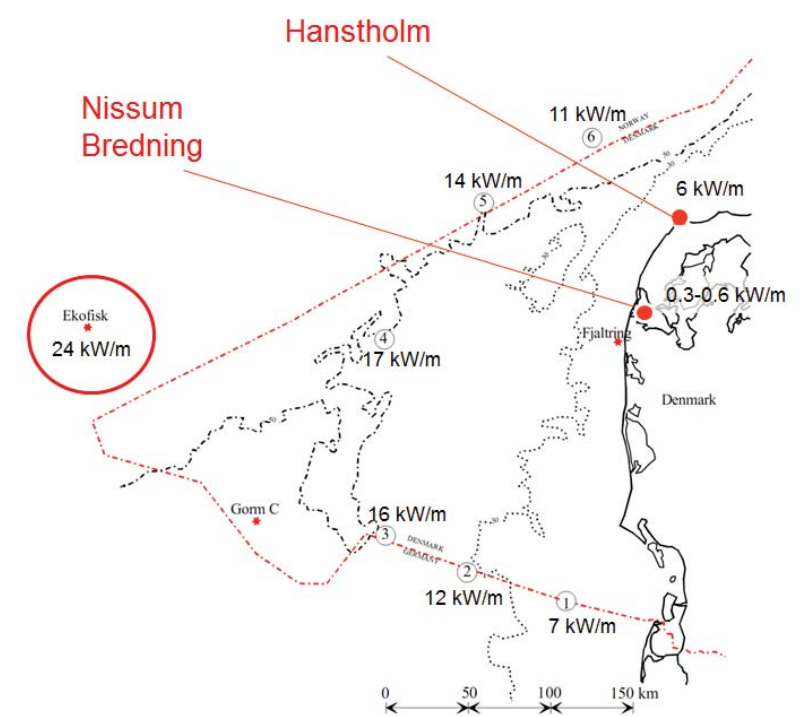

Fig. 3 Map of the Danish part of the North Sea including the locations considered in the study and their relative mean wave energy fluxes. In NB this corresponds to $0.3 \mathrm{~kW} / \mathrm{m}$ at test site \#1 and $0.6 \mathrm{~kW} / \mathrm{m}$ at test site \#2.

At Hanstholm the mean energy flux is $6 \mathrm{~kW} / \mathrm{m}$ at $d=12-30$ $\mathrm{m}[12]$. The wave climate is characterized by a wind sea on top of a non-constant swell coming from the Atlantic Ocean.

Hanstholm wave climate is suitable for the deployment of a 1:1.5 North Sea WD unit, rated at 1.5 MW.

Due to this, the location has been considered very useful to evaluate the feasibility of the device at an intermediate step between the reduced-scale prototype and the multi-MW WD versions. The deployment of the $1.5 \mathrm{MW}$ unit would in every case prove the economic feasibility of the device and its power production capabilities.

Moreover, Hanstholm is the location of a new developed wave energy test site, DanWEC, where two other devices are being tested [13].

Structural design work for the 1:1.5 scale WD is currently ongoing. 
Ekofisk, at $d=70 \mathrm{~m}$, has a mean annual wave power resource of $24 \mathrm{~kW} / \mathrm{m}$, suitable for a full-scale WD rated at 4 MW. Ekofisk is reasonably close to the Danish part of the North Sea, which gives the reason for considering the possible power performance of a Wave Dragon in this scenario.

Moreover, the location presents the interesting opportunity of working with combinations of wave energy plants and offshore oil and gas platforms and wind farms, an option that has already been evaluated for the near future [14].

In addition, a similar wave climate as Ekofisk can be found further north along the British coast and also near the southern Norwegian coast.

\section{RESULTS}

The four power levels listed in section II-A have been recorded at WD-NB. However, the described methodology is applied only to the first two of them, $P_{\text {crest }}$ and $P_{\text {hyd }}$.

$P_{\text {est }}$ and $P_{\text {act }}$ are estimated from $P_{\text {hyd }}$ (see Eq. 3 and 4), along with the provided efficiencies of the PTO components: $\eta_{\text {turb }}=$ $0.91, \eta_{P M G}=0.94$ and $\eta_{f c}=0.98$.

This is meant to give figures representative of the performance of a large-scale device in optimal working conditions, whereas the recorded values of $P_{\text {est }}$ and $P_{\text {act }}$ at WD-NB were not as such.

Indeed, the values of $P_{\text {est }}$ measured at WD-NB were affected by scale effects caused by the small-sized turbines used, mainly due to high friction at the rotor axis, as well as by the effect of marine growth in the draft tubes. The resulting recorded efficiencies of the turbine were in most operational situations around $60 \%$.

The same affected the measurements of $P_{a c t}$, which in addition corresponded at WD-NB often to non-optimal working speeds of the turbines, whereas a commercial fullscale WD would work at optimal speeds.

In optimal conditions, provided the control strategy would ensure a constant PTO efficiency for different wave states, $\eta_{\text {est }}$ and $\eta_{\text {act }}$ are proportional to $\eta_{h y d}$. Therefore, it is possible to refer to the hydraulic power level in order to draw indications about the trend of the non-dimensional performance and power production of WD for different wave conditions.

However, the estimates on the power production should be referred to $\eta_{a c t}$, which represents the wave-to-wire nondimensional performance of WD.

\section{A. Hanstholm}

A WD to be deployed in Hanstholm would be three times larger in size than WD-NB. It would be deployed at a water depth $d=30 \mathrm{~m}$, reachable within a few kilometres offshore, and rated at $1.5 \mathrm{MW}$ with a set of 8 turbines of $185 \mathrm{~kW}$ each.

The SD considered has been discretized into bins of $0.5 \mathrm{~m}$ in $H_{m 0}$ and $0.474 \mathrm{~s}$ in $T_{e}$.

The zoning process revealed to be quite easy, since the wave climate at Hanstholm is very consistent with the one characterizing the test location, i.e. NB. In these conditions, a good overlap between the up-scaled performance data and the higher probability wave states has been found, reducing the number of numerical predictions required (Fig. 4).

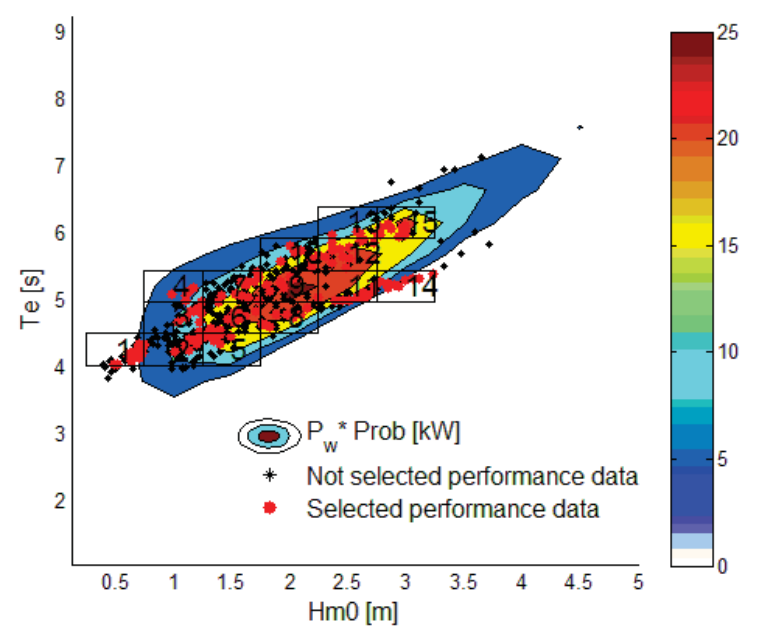

Fig. 4 - Scatter Diagram at Hanstholm including wave power resource, upscaled performance data points and zones. The dominant wind sea has a peak in wave power at $H_{m 0}=2 \mathrm{~m}$ and $T_{e}=5.2 \mathrm{~s}$ [12].

The performance assessment includes 15 experimental zones and 19 numerical zones. The latter have been used mainly in those regions of high wave resource that were not available for testing during the sea trials (Fig. 5).

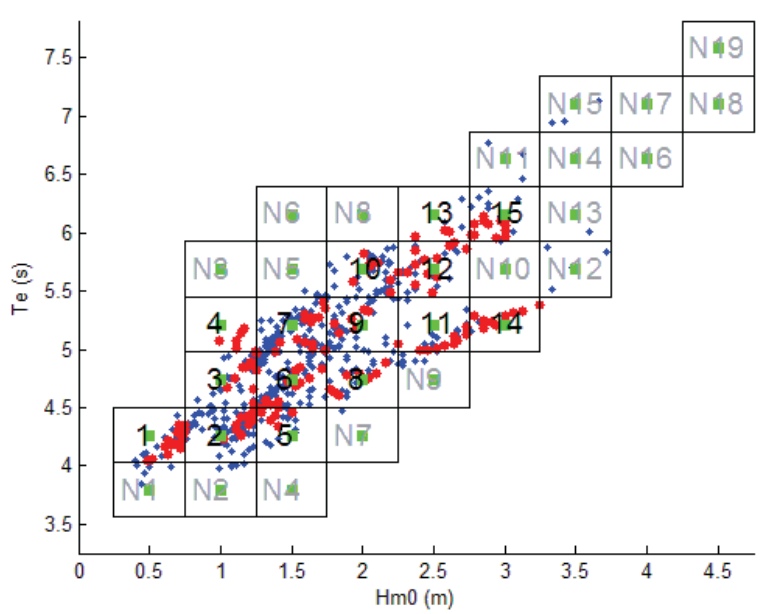

Fig. 5 - Zoning at Hanstholm: the regular zones are named in black and the numerical ones in light grey. Performance data points are marked in blue and the selected data points in red. A green square identifies the representative wave state for each zone.

The experimental zones correspond to $60.2 \%$ of the total wave resource at the location. A total of 150 performance data points have been selected in the performance assessment according to the procedure outlined in section III-D.

In these zones it has been possible to estimate the accuracy of the hydraulic non-dimensional performances through $\sigma$.

Table II summarizes the results at Hanstholm. The influence of including the numerical zones on the assessment of the yearly power production, based on $P_{a c}$, can be noticed. 
TABLE II

SUMMARY OF WD PERFORMANCE AT HANSTHOLM

\begin{tabular}{|l|cc|cc|}
\hline & \multicolumn{2}{|c|}{ Experimental Zones } & \multicolumn{2}{c|}{$\begin{array}{c}\text { Experimental and } \\
\text { Numerical Zones }\end{array}$} \\
\cline { 2 - 5 } & $\begin{array}{r}\text { Mean } \\
\text { value }\end{array}$ & $\begin{array}{c}\text { Standard } \\
\text { Deviation }\end{array}$ & $\begin{array}{c}\text { Mean } \\
\text { value }\end{array}$ & $\begin{array}{c}\text { Standard } \\
\text { Deviation }\end{array}$ \\
\hline Contr. (\%) & \multicolumn{3}{|c}{88} \\
$\boldsymbol{\eta}_{\text {hyd }}(-)$ & 60.2 & 0.27 & - \\
$\boldsymbol{\eta}_{\text {act }}(-)$ & 0.32 & 0.043 & 0.23 & - \\
$\boldsymbol{P}_{\text {hyd }}(\mathbf{k W})$ & 0.27 & - & 99 & - \\
$\boldsymbol{P}_{\text {act }}(\mathbf{k W )}$ & 116 & 16 & 83 & - \\
Power & 97 & - & & - \\
Production & 514 & - & 642 & - \\
(MWh/year) & & & &
\end{tabular}

Since Hanstholm is the location that has proved to fit better with the experimental data, its results are discussed in detail.

The trend of the non-dimensional performance of WD in the experimental zones, based on the crest and hydraulic power level, is visualized in Fig. 6. The ratio between the two $\eta$, representing the conversion efficiency between $P_{\text {crest }}$ and $P_{h y d}$, is also displayed.

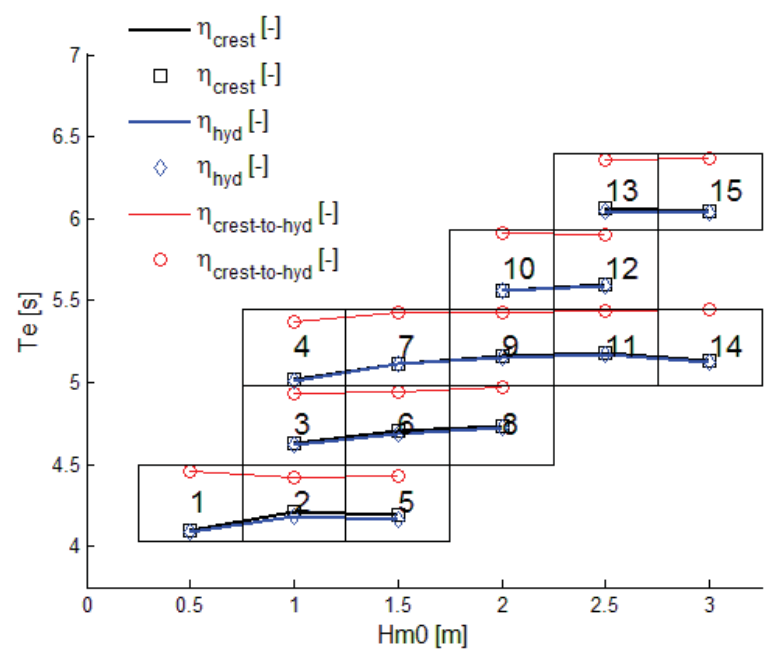

Fig. 6 - Estimates of $\eta_{\text {crest }}$ and $\eta_{\text {hyd }}$ of WD deriving from the application of the EquiMar methodology, shown over experimental zones with the same $T_{e}$. Conversion efficiency between $\eta_{\text {crest }}$ and $\eta_{\text {hyd }}$ is shown in red. The zero for each $\eta$ is the lower bound in the y-axis of the zone. This trend is due to a nonoptimal control caused by the lack of operating turbines at WD-NB, which led to often fill the reservoir causing spill losses.

Fig. 8 is an overview of the power contribution of each zone (experimental and numerical), as well as the wave-towire performance of WD in each zone both in terms of $\eta_{\text {act }}$ and $P_{a c t}$. The latter (Fig. 8c) is the power matrix.

\section{B. Ekofisk}

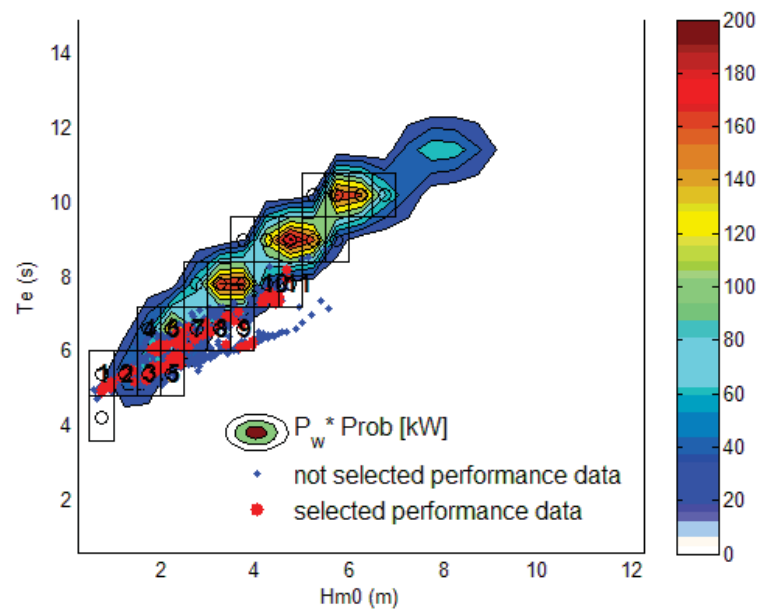

Fig. 7 - SD of Ekofisk including wave power resource, up-scaled performance data points and zones. The experimental zones (numbered) leave almost uncovered the most energetic parts of the SD, so several numerical zones (un-numbered) have been added.

A WD to be deployed at Ekofisk ( $d=70 \mathrm{~m}$ ), often referred to as a North Sea WD, would be a full-scale device 4.5 times larger in size than WD-NB. It would be rated at $4 \mathrm{MW}$ with a set of 16 turbines of $250 \mathrm{~kW}$ each.

The SD considered has been discretized into bins of $0.5 \mathrm{~m}$ in $H_{m 0}$ and $1.2 \mathrm{~s}$ in $T_{e}$.

In this case the zoning process revealed to be more difficult than at Hanstholm. Indeed, the wave resource at the target location is generally characterized by waves with relative longer $T_{e}$ than in NB. Therefore, the regions with the highest power contribution of the SD were covered by performance data only to a minor extent and an extensive use of the numerical predictions had to be done (Fig. 7).

A total of 11 experimental zones and 13 numerical zones have been considered. The former covered $21.3 \%$ of the total wave power resource, including 111 selected performance data points. After adding the numerical zones the energy coverage increased to $82.2 \%$. Results are shown in Table III.

TABLE III

SUMMARY OF WD PERFORMANCE AT EKOFISK

\begin{tabular}{|c|c|c|c|c|}
\hline & \multicolumn{2}{|c|}{ Experimental Zones } & \multicolumn{2}{|c|}{$\begin{array}{l}\text { Experimental and } \\
\text { Numerical Zones }\end{array}$} \\
\hline & $\begin{array}{l}\text { Mean } \\
\text { value }\end{array}$ & $\begin{array}{l}\text { Standard } \\
\text { Deviation }\end{array}$ & $\begin{array}{l}\text { Mean } \\
\text { value }\end{array}$ & $\begin{array}{l}\text { Standard } \\
\text { Deviation }\end{array}$ \\
\hline Contr. (\%) & \multicolumn{2}{|c|}{21.3} & \multicolumn{2}{|c|}{82.2} \\
\hline$\eta_{\text {hyd }}(-)$ & 0.26 & 0.026 & 0.18 & - \\
\hline$\eta_{\text {act }}(-)$ & 0.22 & - & 0.15 & - \\
\hline$P_{h y d}(\mathbf{k W})$ & 633 & 62 & 424 & - \\
\hline $\begin{array}{l}P_{a c t}(k W) \\
\text { Power }\end{array}$ & 532 & - & 356 & - \\
\hline $\begin{array}{l}\text { Production } \\
\text { (MWh/year) }\end{array}$ & 992 & - & 2562 & - \\
\hline
\end{tabular}




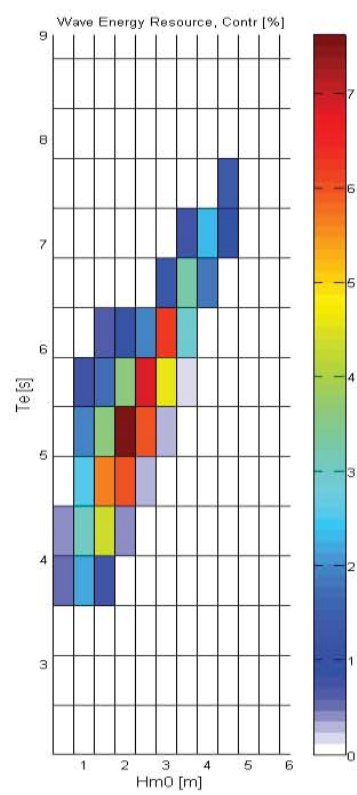

(a)

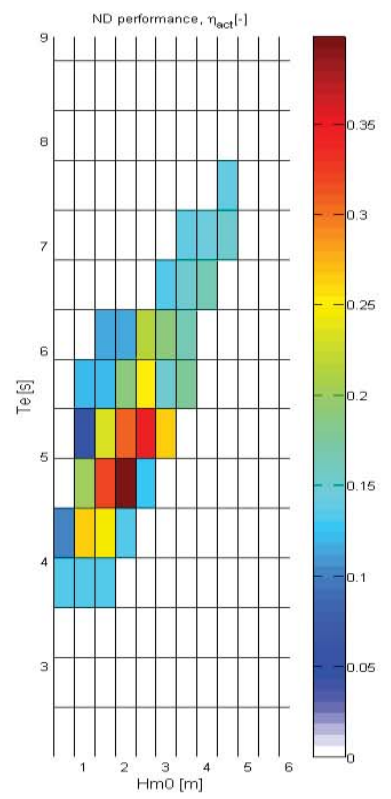

(b)

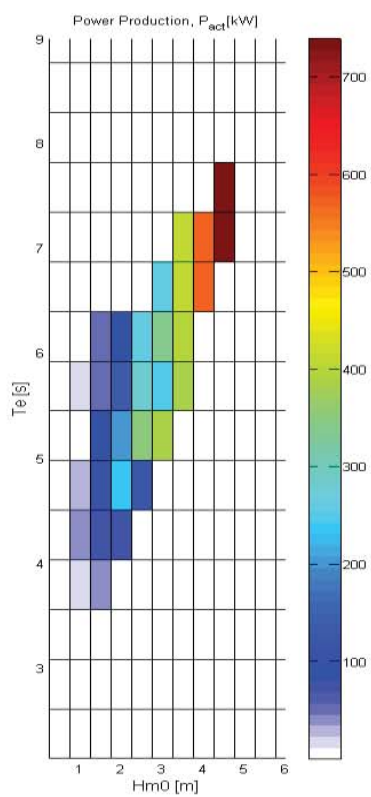

(c)

Fig. 8 - Matrices of (a) contribution of each zone to the total power resource (b) $\eta_{\text {act }}$ of WD and (c) $P_{a c t}$ of WD, at all zones considered at Hanstholm. The latter is the power matrix.

\section{DISCUSSION}

\section{A. Data selection and accuracy of results}

The results shown are influenced by the criterion of data point selection, but only to a minor extent.

If the proposed criterion had to be adjusted increasing the $\sigma$ of the estimate, it is suggested to include more of the highest data points rather than of the lowest.

In the first case, the accuracy of the estimate would decrease, but its mean value would increase towards the optimal one; in the second case, both values would decrease, having an overall negative effect on the quality of the results.

\section{B. Average performance of WD at the target locations}

Wave-to-wire average non-dimensional performances of 23\% and 15\% respectively at Hanstholm and Ekofisk have been found.

These correspond to yearly power productions of $0.64 \mathrm{GWh}$ at Hanstholm and 2.56 GWh at Ekofisk. However it should be noticed that the results at Ekofisk are to a very high degree based on the predictions of the numerical model, which has not yet been calibrated with real sea data.

These figures are conservatives, referring to a configuration without the wave reflectors. It has been estimated that the average increase in annual wave power flux provided by the reflectors would be of $30 \%$ [15].

As shown in Fig. 8, the highest wave power contribution is given by zone $9\left(H_{m 0}=2 \mathrm{~m}, T_{e}=5.2 \mathrm{~s}\right)$, with $7.6 \%$ of the overall available wave power; values above $5 \%$ are also given in zones 6, 8, 11, 12 and 15.
The highest $\eta_{a c t}=0.4$ is achieved by far in zone $8\left(H_{m 0}=2\right.$ $\left.\mathrm{m}, T_{e}=4.74 \mathrm{~s}\right)$; values of $\eta_{\text {act }}$ above 0.25 are also achieved in zones 2, 6, 9, 11, 12 and 14 .

$P_{\text {act }}$ increases with $H_{m 0}$, showing a fairly clear dependency, while it is quite constant over $T_{e}$. Maximum values are reached in the numerical zones $\mathrm{N} 18\left(H_{m 0}=4.5 \mathrm{~m}\right.$, $\left.T_{e}=7.1 \mathrm{~s}\right)$ and $\mathrm{N} 19\left(H_{m 0}=4.5 \mathrm{~m}, T_{e}=7.6 \mathrm{~s}\right)$, corresponding respectively to $P_{a c t}$ of $739 \mathrm{~kW}$ and $733 \mathrm{~kW}$.

\section{Wave-to-wire energy conversion}

Fig. 6 shows the evolution of the non-dimensional performances relative to the crest and hydraulic power levels over the experimental zones.

The same trend can be observed for $\eta_{\text {crest }}$ and $\eta_{\text {hyd }}$, which grow with $H_{m 0}$, determining the conversion efficiency $\eta_{\text {crest-to- }}$ hyd to be very high and constant and meaning that the reservoir at WD-NB was close to be full in most of the cases considered. This is due to the fact that the data selected correspond to the optimal hydraulic performance of the device, when the turbines were not able to process the large overtopping volumes incoming in the reservoir.

At full-scale, once the optimal control strategy has been implemented, this trend would actually be the opposite, $\eta_{\text {hyd }}$ and $\eta_{\text {crest-to-hyd }}$ decreasing with $H_{m 0}$. With the aim of reducing the spill losses, the water level in the reservoir will be lowered in wave conditions with high $H_{m 0}$ indeed, so to be able to accommodate the next incoming wave group and therefore increase the power production.

This kind of strategy would be favoured by the adoption of wave-by-wave predictive algorithms, which have already shown to be possible through the use of digital filters [8]. 
Using the $\eta_{\text {wave-to-wire }}$ resulting from the study, the different conversion efficiencies along the WD energy conversion chain have been analysed, provided the PTO efficiencies are known and the $\eta_{\text {crest-to-hyd }}$ has also been estimated.

Table IV summarizes the wave-to-wire conversion efficiencies of WD at the two tested locations. The given figures are only based on the results of the experimental zones so to be more reliable, being not influenced by the limitations of the numerical model which has shown a tendency to underestimate the overtopping flow measured.

TABLE IV

SUMMARY OF WD ENERGY CONVERSION EFFICIENCIES

\begin{tabular}{|l|l|l|}
\hline & Hanstholm & Ekofisk \\
\hline $\boldsymbol{\eta}_{\text {wave-to-crest }}$ & $35 \%$ & $28 \%$ \\
$\boldsymbol{\eta}_{\text {crest-to-hyd }}$ & $92 \%$ & $93 \%$ \\
$\boldsymbol{\eta}_{\text {hyd-to-est }}=\boldsymbol{\eta}_{\text {turb }}$ & $91 \%$ & $91 \%$ \\
$\boldsymbol{\eta}_{\text {est-to-act }}=\boldsymbol{\eta}_{\boldsymbol{P M G}} \cdot \boldsymbol{\eta}_{\boldsymbol{f c}}$ & $92 \%$ & $92 \%$ \\
$\boldsymbol{\eta}_{\text {wave-to-wire }}=\boldsymbol{\eta}_{\text {act }}$ & $27 \%$ & $22 \%$ \\
\hline
\end{tabular}

The lower overtopping efficiency at Ekofisk is against expectations, but can be explained by the fact that zones with high $\eta$ at WD-NB correspond to a low probability sea states at the target location, limiting the average non-dimensional performance. This is more evident where the correspondence between the two wave climates is not very good, such as at Ekofisk.

Table IV shows that the primary energy conversion, i.e. the overtopping efficiency, limits the wave-to-wire conversion efficiency. With respect to this, it has already been mentioned that the adoption of the optimal control strategy would reduce the water spill and increase the overtopping efficiency, decreasing in turn $\eta_{\text {crest-to-hyd }}$.

\section{Applicability of the methodology to $W D-N B$}

The applicability of the methodology has been found to highly rely on the correspondence between the high probability wave conditions at the sea trials and those at the target location.

When the correspondence is good (e.g. Hanstholm) a higher number of performance data points can be used in the performance assessment. This allows providing more reliable estimates, for which figures on the accuracy can also be given.

On the other hand, when the wave conditions at the sea trial location do not correlate well with the wave climate of the target location (e.g. Ekofisk) the use of experimental data is possible only in a reduced number of zones, requiring an increasing use of numerical predictions and limiting the reliability of the results.

Therefore, the correct choice of the sea trial location is essential to apply this methodology. Whenever possible, this should be based on the detailed wave climate of the target location for future deployment rather than only on its mean annual wave power.

$\mathrm{NB}$, the location of the sea trials used in the study, is an inlet sea with locally generated, fetch-limited wind seas, which cannot represent well the wave conditions in the deep parts of the North Sea. Here waves are generally longer due to swells, limiting the scalability of the performance found in NB.

As a consequence, the performance estimates provided at Ekofisk are mostly based on numerical predictions. Due to the limitations shown by the numerical model in predicting the overtopping flow, a drop in the $\eta_{\text {hyd }}$ of $8 \%$ can be observed when the estimate includes the numerical zones. This also indicates that the numerical model still needs to be calibrated by large scale tests in real sea.

\section{E. Indications for further WD performance assessment}

Future plans for commercialization of WD include the deployment of full-scale units in the Atlantic Ocean off Wales and Portugal [3]. In the performance assessment of $\mathrm{WD}$ at these locations, characterized by swells longer than in the North Sea, it would be difficult to use the EquiMar methodology with the current dataset. Therefore, at present the performance assessment of WD at these locations is likely to be derived almost entirely through numerical models.

However, the deployment and test of a large-scale WD at Hanstholm would provide a better basis for the performance assessment at Ekofisk or Atlantic locations based on experimental data, making the DanWEC test centre very useful.

\section{CONCLUSIONS AND FURTHER WORK}

WD is now in a pre-commercial phase. At this stage, it is very important to be able to provide reliable estimates on the performance of large-scale commercial devices at possible target locations.

The EU project EquiMar has proposed a methodology to assess the performance of WECs at target locations in an equitable way and based on real sea trials of prototypes. The methodology allows estimating the non-dimensional and power performance in different zones of the SD at the target location based on experimental data, providing also a measure of the related uncertainty. Average non-dimensional performances can also be derived, based on the contribution of each zone to the overall wave power resource of the location.

The present study applies this methodology to the WD WEC. Performances are estimated for a 1:1.5 scale WD rated at 1.5 MW to be deployed at Hanstholm in the Danish part of the North Sea (at the DanWEC test centre) and of a full-scale $4 \mathrm{MW}$ unit deployed at Ekofisk, in the offshore North Sea.

The study is based on performance data measured during the sea trials of a 1:4.5 scale pre-commercial demonstrator deployed between 2003 and 2006 in Nissum Bredning, a benign site in Northern Denmark. The dataset considered is relative to a setup of WD without wave reflectors.

The performance assessment has been mainly based on experimental data at Hanstholm, whereas at Ekofisk a significant number of numerical predictions has been required. This is due to the fact that the wave climate at 
Ekofisk did not fit very well with the one at the sea trials test at $\mathrm{NB}$, location characterized by wind driven seas only.

The overtopping model used for the numerical predictions was developed through the tank testing of a small-scaled model of WD at Aalborg University.

The study considered 4 different power levels characterizing the wave-to-wire model of WD: the potential power derived from the overtopping flow over the crest of the ramp, the potential power corresponding to the water level in the reservoir, the estimated power produced in the case of optimal working conditions of the turbines and the actual power delivered to the grid.

The efficiencies along the wave-to-wire energy conversion chain of WD have been analysed. It does not come as a surprise that the stage most limiting the wave-to-wire performance is the conversion efficiency from the kinetic and potential energy mix of the waves to pure potential energy in water in the reservoir ("power level 1").

However, this can be further optimised at full-scale through the adoption of the already well defined turbine control strategy.

Since a scale effect limited the values of the wave-to-wire non-dimensional performances $\eta_{\text {est }}$ and $\eta_{\text {act }}$ measured at WD$\mathrm{NB}$, these have been derived from the measured $\eta_{\text {hyd }}$ through the well-known efficiencies of the PTO components. In any case, this highlights the importance of being aware of the consequences of scale effects whenever the measured performance refers to small-size prototypes.

The average non-dimensional performance of WD has been found to be 23\% at Hanstholm and 15\% at Ekofisk. These figures are considered highly conservative as they refer to a setup without wave reflectors.

The average $\eta$ achieved at Ekofisk has been found to be lower than at Hanstholm. An explanation has been found in the non-optimal correspondence between the wave climates at NB and Ekofisk, leading to a lower average $\eta$ when some of the higher performances recorded at WD-NB correspond to low probability of occurrence at the target location.

Even though the use of numerical predictions allowed considering in both cases the major part of the wave power resource in the performance assessment (88\% at Hanstholm and $82.2 \%$ at Ekofisk), a large use of numerical calculations goes against the stated objective of the EquiMar methodology of relying mostly on experimental data. In this case, the uncertainty of the estimates increases and cannot be quantified, depending more on the reliability of the numerical model than on the statistical treatment of the experimental data.

On the other hand, an availability of 95\% can be generally expected from $\mathrm{WD}$, so that also in this sense the figures given can be considered conservative.
The poor correspondence between the wave climate experienced at WD-NB and those characterizing possible deployment locations in the Atlantic Ocean limits the application of the used methodology, as the performance assessments here would primarily be based on numerical predictions.

Further work can be expected to assess the performances of WD at these locations. In light of this, the update of the numerical model used and its calibration on data coming from real sea trials would increase the reliability of the provided estimates.

\section{ACKNOWLEDGMENT}

The authors gratefully acknowledge the financial support from the European Commission through the 7th Framework Programme (the Marie Curie Initial Training Network WaveTrain2 project, Grant agreement number 215414, and the EquiMar project, Grant agreement number 213380) which made this work possible.

\section{REFERENCES}

[1] HMRC, State of the Art Analysis, The Waveplam project, contract n. EIE/07/038/S12.466832, 2009.

[2] (2010) EquiMar website. [Online]. Available: http://www.equimar.org/

[3] H.C. Soerensen and E. Friis-Madsen, "Wave Dragon from Demonstration to Market", in Proc. ICOE 2010, 2010, paper 10156.

[4] T. Hald and J. Lynggaard, "Hydraulic Model Tests on Modified Wave Dragon”, Aalborg University, Hydraulic and Coastal Laboratories, Danish Energy Agency Project no: ENS-51191/00-0067, Phase 3, Tech. Report, 2011.

[5] H.C. Soerensen, "Sea Testing and Optimisation of Power Production on a Scale 1:4.5 Test Rig of the Offshore WEC Wave Dragon", contract n. ENK5-CT-2002-00603, project n. NNE5-2001-00444, Final Tech. Report,2006.

[6] Kofoed J.P., Pecher A., Margheritini L., Holmes B., McCombes T., Johnstone C., Bittencourt C., Retzler C.,Myers L.E. (2010), " Data Analysis \& Presentation to Quantify Uncertainty", EquiMar Deliverable D4.2.

[7] D. Ingram, G. Smith, C. Bittencourt-Ferreira and H. Smith., "Protocols for the Equitable Assessment of Marine Energy Converters", Chap. II.B - Sea Trials, University of Edinburgh, School of Engineering, Edinburgh, United Kingdom ISBN: 978-0-9508920-2-3, 2011.

[8] J. Tedd, "Testing, Analysis and Control of Wave Dragon WEC", Ph.D. thesis DCE Thesis No. 9, Department of Civil Engineering, Aalborg University, Aalborg, Denmark, Oct. 2007.

[9] J.W. van der Meer and J.P.F.M Jannssen, "Wave run-up and wave overtopping at dikes", Task Committee Reports, ASCE, Tech. Report, 1995.

[10] S. Parmeggiani, J.P. Kofoed and E. Friis-Madsen, "Experimental Modeling of the Overtopping Flow on the Wave Dragon WEC", in Proc. ISOPE 2011, paper n. 2011-TPC-476, 2011.

[11]H.C. Soerensen and E. Friis-Madsen, "Wave Dragon MW - Development and validation of technical and economic feasibility of a multi MW Wave Dragon offshore wave energy converter", Contract n. 019883, Final Publishable Activity Report, 2009.

[12] K. Nielsen and T. Pontes, "Generic and Site-related Wave Energy Data", Report T02-1.1 OES IA Annex II Task 1.2, Final Tech. Report, 2010.

[13] (2011) DanWEC website. [Online]. Available: http://www.danwec.com/

[14]J. Fernández-Chozas, H.C. Soerensen and M. Korpås, "Integration of Wave and Offshore Wind Energy in a European Offshore Grid", in Proc. ISOPE 2010, paper n. 10TPC-770, 2010.

[15] M. Kramer and P. Frigaard, "Reflectors to focus Wave Energy", in Proc. EWTEC 2005, 2005.

[16] A. Pecher, I. Le Crom, J.P. Kofoed, F. Neumann, E. de Brito Azevedo, "Performance assessment of the Pico OWC power plant following the EquiMar Methodology", in Proc. ISOPE 2011, paper n. TPC-447. 


\title{
Paper E: Integration of Wave and Offshore Wind Energy in a European
} Offshore Grid

\author{
Published in
}

Proceedings of the $20^{\text {th }}$ International Symposium of Offshore and Polar Engineering (ISOPE), 2010. 



\title{
Integration of Wave and Offshore Wind Energy in a European Offshore Grid
}

\author{
J. Fernández-Chozas \\ Spok ApS / Department Civil Engineering Aalborg University \\ Copenhagen / Aalborg, Denmark \\ H. C. Soerensen \\ Spok ApS \\ Copenhagen, Denmark \\ M. Korpås \\ SINTEF Energy Research \\ Trondheim, Norway
}

\begin{abstract}
High wave and offshore wind energy potentials are located along the West and North coasts of Europe, respectively. In the near future, these resources should significantly contribute to the European electricity mix, but there is hardly any grid infrastructure available for large scale integration of offshore renewable energy sources. According to this, the paper covers i) public and private initiatives for offshore transmission networks, ii) the synergies between the wave and the offshore wind energy sector within an offshore grid, iii) power transmission options for offshore generation and iv) the challenges ahead of the realisation of an offshore grid.
\end{abstract}

KEY WORDS: VSC; HVDC; meshed; grid; offshore; wave energy; wind energy;

\section{INTRODUCTION}

In 2008, the European Union (EU) primary energy consumption was covered by oil $(\sim 39 \%)$, natural gas $(\sim 24 \%)$, coal $(\sim 16 \%)$, nuclear power ( $\sim 12 \%)$, hydropower ( 4\%) and other renewable energy (RE) sources ( 6\%) (BP, 2009; EEA, 2008; IEA, 2009). Thus, $80 \%$ of EU primary energy consumption in 2008 was dependent on limited resources, such as fossil fuels and uranium, of which two thirds (about 1200 million tonnes oil equivalent) were imported resources. Additionally, the electricity demand in the EU is expected to grow at a rate of $1.5 \%$ in the period $2000-2030$, the current interconnections capacities are insufficient to increase the power exchange (EC, 2006) and about $50 \%$ of the existing power plants in the EU are arriving to the end of their lifetime.

This scenario imposes two key energy requirements for the EU in order to secure a more independent, long term energy supply: i) increase the share of electricity generation based on RE sources in the energy mix and ii) reinforcement of the existing power grid. Except biomass, RE sources must be exploited at the origin sites (ECF, 2008) which, in turn, requires a grid infrastructure interconnected to different areas at the generation locations. In particular, offshore wind energy (OWE) from the North and West of Europe and wave energy
(WE) from western oceans could play a significant role to fulfil i) but there are weak interconnections between EU member states (Van Hulle, 2009), the power market is inflexible and fragmented and there is a lack of offshore electricity grids (EWEA, 2009a). According to (EOEA, 2009), if grid connections issues are not solved by 2020, ocean energy scenarios as shown in Table 1 will not be achievable and offshore RE sources will compete for grid connection points.

Table 1. Ocean energy scenario in the EU (EUOE, 2010).

\begin{tabular}{lcccccc}
\hline Year & $\mathbf{2 0 2 0}$ & $\mathbf{2 0 2 5}$ & $\mathbf{2 0 3 0}$ & $\mathbf{2 0 3 5}$ & $\mathbf{2 0 4 0}$ & $\mathbf{2 0 5 0}$ \\
& & & & & & \\
\hline GW & 3.6 & 20 & 54 & 105 & 166 & 188 \\
TWh $/ \mathrm{y}$ & 9 & 53 & 150 & 317 & 546 & 645 \\
\hline
\end{tabular}

Grid integration of OWE and WE demands either direct connections to shore (i.e. radial connections), which require grid upgrades at every connection point onshore, or a comprehensive planned offshore grid within a European wide transmission network (i.e. meshed offshore grid). Van Hulle (2009) reveals that there is no optimal grid solution if every country implements its own onshore and offshore national power markets, which corresponds to the former strategy. On the other hand, if the grid is internationally designed, the overall costs are reduced because the cables can work as interconnectors (i.e. for power exchange between power systems) as well as for power transmission from offshore generation sites to onshore and offshore (e.g. offshore oil and gas platforms) consuming centres.

Furthermore, a meshed offshore grid within a wide transmission network brings several additional advantages. It provides crosscountry access to energy storage facilities and redundancy in case of a system failure (Koldby and Hyttinen, 2009); it improves the national and international electricity exchange and it decrease the natural variability of some RE sources through regional diversification (Fig. 1) (Diesendorf, 2007; ECI, 2006). These reduces the need for baseload generation significantly, brings additional reserve capacity and allows covering peaks of the demand with imports of power instead of running power plants at low capacity, which above all results in lower electricity power prices (Higgins, 2008; Kenitzer, 2007; Van Hulle, 2009). Nevertheless, the realisation of such network faces relevant 
technical, legal, timing and economic challenges.

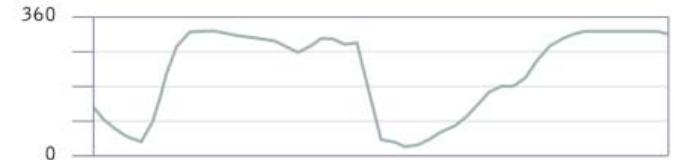

68,400

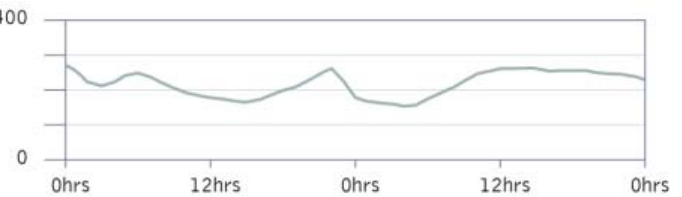

Fig. 1. Horns Rev I+II (above) and all OWE farms in the North Sea (below) power output (MW) on April 3-4, 2006 (Woyte et al, 2008).

This article is an overview of OWE and WE integration into the European electricity grid. Firstly, it reviews public and private initiatives for European offshore transmission networks; secondly, it presents the synergies between the WE and the OWE sectors within an offshore grid; thirdly, it describes power transmission options for offshore generation: HVAC (high voltage alternating current), line commuted converter (LCC) based HVDC (high voltage direct current) and voltage source converter (VSC) based HVDC; and lastly, it identifies the challenges ahead of an offshore grid based on the experiences from a small-scale version of it (i.e. Kriegers Flak).

\section{BACKGROUND}

There are a considerable number of offshore grid plans covering the North and the Baltic Sea area due to the concentration of good potential sites for OWE development (Fig. 2). These plans come from policies at the European and national level along with initiatives from the academia, grid companies and various industries (EWEA, 2009a).

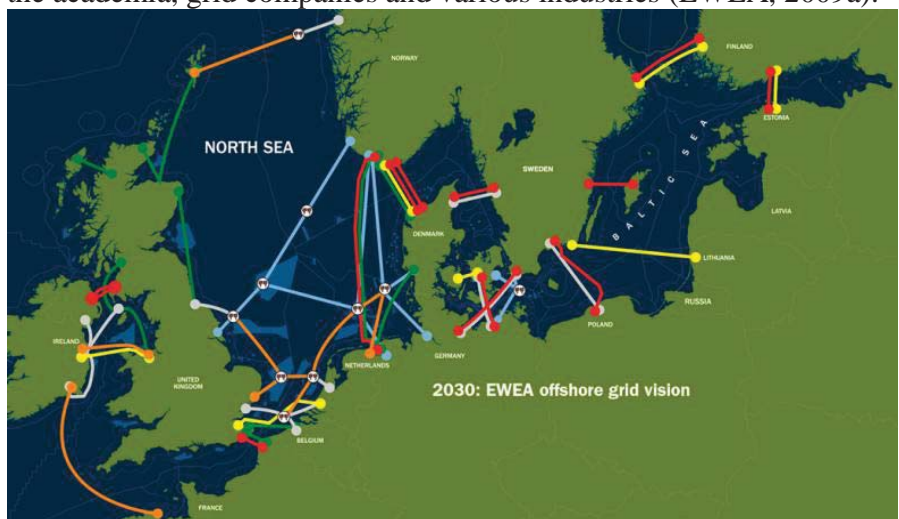

Fig. 2. EWEA's 20 Year Offshore Network Development Master Plan and Europe OWE development and concession zones (in light blue). Lines in red are cables currently operating; in yellow, planned or under construction; in green and in blue, under study; and in white and in orange, proposed by EWEA for 2020 and 2030, respectively (EWEA, 2009a).

\section{Plans at the European level}

The European Commission (EC) coordinates the activities for offshore electricity interconnection within the Trans-European Energy Network (TEN-E) (EC, 2006). Particularly, TEN-E guidelines specify 42 projects of highest priority eligible for EU funding. Along with the Priority Interconnection Plan (EC, 2007), the European Economic Recovery Plan (EERP) (EU, 2008), includes support to TEN-E and RE projects. EC (2009) establishes the budget for EERP implementation in 2009-2010 for gas and electricity infrastructures, and OWE projects. It allocates 2.365 bEUR for the former and 565 mEUR for the latter.

The Second Strategic Energy Review sets the EU Energy Security and Solidarity Action Plan. It considers six priority infrastructures promoting EU's energy needs, four of which are electricity related: a
Baltic Interconnection Plan, a Mediterranean Energy Ring, NorthSouth gas and electricity interconnections within Central and SouthEast Europe, and a Blueprint for a North Sea offshore grid.

\section{Research Programmes and Coordination Initiatives}

Intelligent Energy Europe (IEE) from the EC has funded three projects relevant to OWE and offshore grid development in the North and the Baltic Sea. Tradewind developed a EU-wide power flow scenario including various offshore grid configurations; Windspeed is working on a decision support system tool for OWE deployment in central and southern North Sea; and OffshoreGrid will develop a scientificallybased view on an offshore grid in northern Europe along with a suitable regulatory framework.

Besides, EWIS, Power Cluster and ISLES projects are co-financed EU projects. EWIS looks into onshore and offshore grid reinforcements for wind energy integration, Power Cluster focuses on the challenges of the OWE sector in the North Sea; and the latter examines the feasibility of an offshore electricity network linking offshore RE sites in Ireland, Northern Ireland and Western Scotland.

Some coordination initiatives include: ACER (Agency for the Cooperation of Energy Regulators), ENTSO-E (European Network of Transmission System Operators for Electricity), ERI (Electricity Regional Initiative), NICER (North Sea Initiative: Centres for Excellences on Renewables), the North Sea Countries Offshore Grid Initiative and the Energy Grid Initiative.

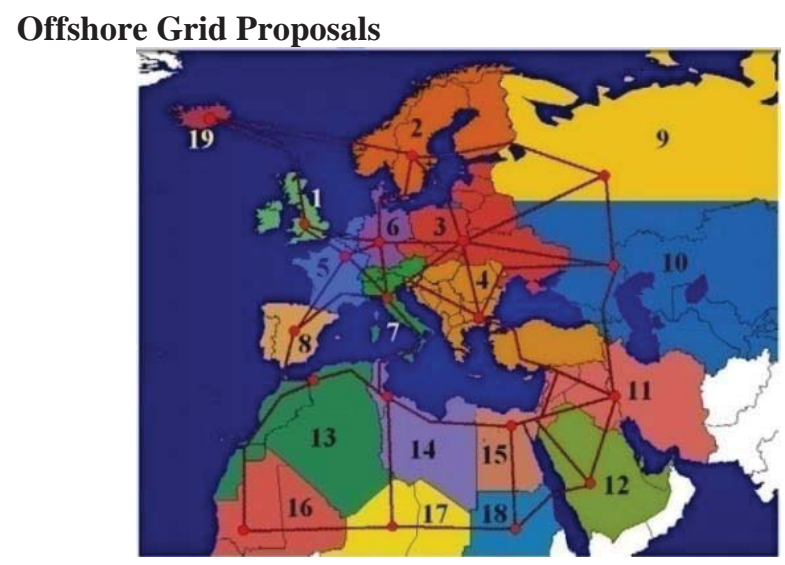

Fig. 3. Power system layout proposed in (Czisch, 2008). It is divided into 19 regions connected with HVDC technology to provide 100\% RE.

Similarly, there have been several discussions on possible offshore grid configurations. Already in the 1930s, Buckminster Fuller proposed a Global Energy Grid that would interconnect the world to supply all the energy needs from RE sources. Later proposals include: an Irish Sea grid (Watson, 2002); the Supergrid concept (Corbett, 2009; Veal, Byrne and Kelly, 2007); Czisch study (Czisch, 2008) (Fig. 3); Greenpeace scenario (Woyte et al, 2008); EWEA's 20 Year Offshore Network Development Master Plan (EWEA, 2009a) and the SuperSmart Grid concept (Schellekens et al, 2010).

It is remarkable that within the wide range of offshore grid proposals, none of them specifically considers WE electricity generation. They assume offshore RE electricity generation will be covered by OWE and on a later stage WE might become a secondary offshore contributor. Nevertheless, WE potential in Europe is large, the WE sector is close to reach the commercial stage and both the OWE and the WE sectors are facing similar grid connection challenges to become large scale contributors to the electricity mix. Indeed, studies indicate that it could be useful to create spaces combining OWE and WE, share the cost of grid connections and make it possible for more power to be harnessed from one site, thus making the project more 
economically viable (EOEA, 2010).

\section{WAVE AND OFFSHORE WIND ENERGY WITHIN A COMMON OFFSHORE GRID}

The offshore potential in Europe consists both of ocean energy and wind energy. The term ocean energy includes WE, tidal current, tidal range, osmotic energy and ocean thermal energy (Soerensen, 2009). High WE potentials are located along the West coasts of Europe (Fig. 4) and a large offshore wind resource can be found along the North and West coastlines (Fig. 5). Nonetheless, in areas with low WE potential like the North Sea, wave energy converters (WECs) can produce 10-75 TWh/y (Soerensen and Fernandez-Chozas, 2010); in comparison to 125-169 TWh expected production in 2020 by offshore wind turbines (OWTs) in the same area. According to these, Europe has ambitious ocean energy (Table1) and OWE (Table 2) development scenarios.

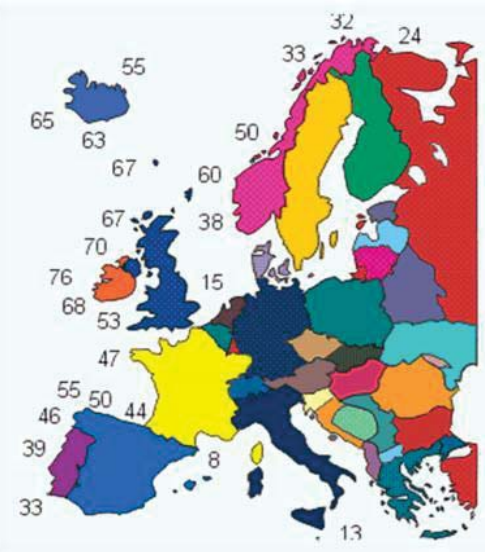

Fig.4. WE in Europe in $\mathrm{kW} / \mathrm{m}$ width of oncoming wave (CA-OE, 2006)

WECs are chosen according to the wave climate in the sea where are deployed. Since more than one solution can remain attractive for the market, the number of WE conversion concepts is very large. According to their location with respect to shore there are onshore, near-shore and offshore devices. The formers are placed on the coastline or integrated into fixed structures, near-shore devices are usually bottom-mounted at moderate water depths (20-30 m), and the latter are generally floating devices deployed at deep waters. Although there is hardly any WE commercial technology, there are several fullscale prototypes close to the commercial stage. On the other hand, the OWE sector has installed a number of bottom-mounted OWTs in the North and the Baltic Sea, where water depths increase slowly with distance from shore and allows deployment sites relatively far offshore. Nonetheless, there is an ongoing research on floating platforms to allow OWTs deployment at other potential sites with a steeper coastline.

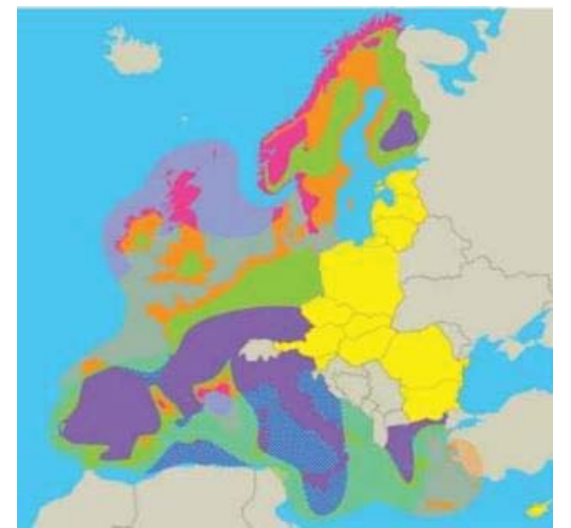

Fig. 5. Wind potentials in the EU, 1989. Pink coloured represents the strongest potential; orange, very high potential, green, high-medium potential; and purple medium/low potential (EC, 2008).
Table 2. Offshore wind energy scenarios

\begin{tabular}{|c|c|c|c|c|}
\hline & \multirow{2}{*}{$\begin{array}{l}\text { Installed } \\
\text { capacity } \\
\text { (GW) } 2015^{1}\end{array}$} & \multirow{2}{*}{$\begin{array}{c}\text { Installed } \\
\text { capacity (GW), } \\
2020 \text { low } \\
\text { scenario }^{2}\end{array}$} & \multicolumn{2}{|c|}{$\begin{array}{l}\text { Installed and planned } \\
\text { capacity (North Sea) }\end{array}$} \\
\hline & & & GW & TWh \\
\hline Belgium & 1.446 & 1.8 & 3.85 & 13.1 \\
\hline Denmark & 1.276 & 2.3 & 1.58 & 5.6 \\
\hline Finland & 1.33 & 0.4 & - & - \\
\hline France & 1.07 & 4 & 1 & 3.4 \\
\hline Germany & 10.298 & 8 & 26.42 & 97.5 \\
\hline Ireland & 1.603 & 1 & - & - \\
\hline Italy & 0.827 & 0.5 & - & - \\
\hline Netherlands & 2.834 & 4.5 & 12.04 & 41.7 \\
\hline Norway & 1.553 & NA & 1.29 & 4.9 \\
\hline Poland & 0.533 & 0.5 & - & - \\
\hline Spain & 1.976 & 1 & - & - \\
\hline Sweden & 3.312 & 3 & - & - \\
\hline UK & 8.756 & 13 & 22.24 & 80.8 \\
\hline Total & 37.442 & 40 & 68.42 & 247 \\
\hline
\end{tabular}

Once OWTs and WECs are fully developed they will both harness offshore power and hence a conflict of use for the deployment area might be foreseen. Nevertheless, the sectors share significant synergies from which they can both beneficiate, and will barely compete.

Firstly, WECs harness the available resource on the sea surface or below it, whereas OWTs harness the resource tens of meters above the sea level. Therefore, near-shore WECs can be deployed in the same site as OWTs, precisely in between them, as in any case there has to be a certain distance between the turbines to avoid shadow effects. Placed together, they can share the grid connection. Moreover, it has to be noticed that cable costing is not linear in function of the number of the cables as the same route and laying procedure might be applied for more than one cable (Ricci et al, 2009).

Secondly, the WE potential decreases close the coastline due to the interaction with the seabed. It is preferred to deploy offshore WECs at deep waters than at the shallow areas where OWTs are being deployed in the short term. In the medium and long term, due to higher energy potentials and large space demands, both OWE and WE farms will be located further offshore; nonetheless, it can actually be assumed there is enough sea for both.

Thirdly, WE and OWE encounter similar challenges on grid connection. A fundamental consideration for both sectors is that the deployment sites are dictated by the best locations for energy resource. However, the majority of these is far from the main load centres and often has only a weak distribution network available, what can result in costly grid reinforcements and hence project costs may be prohibitive (Ricci et al, 2009). The project can turn economically viable if transmission capacity is shared.

Fourthly, a combination of the power output of both resources results in smoother variations of the generated power, better predictability and higher capacity credit (ECI, 2005), provided that WE peaks generally occurs 6-8 $\mathrm{h}$ later than wind energy peaks (Fig. 6) (Soerensen et al, 2005), and that WE has greater predictability and less variability than wind energy (Soerensen and Naef, 2008). Furthermore, this will reduce the spared capacity and the cost of the connection.

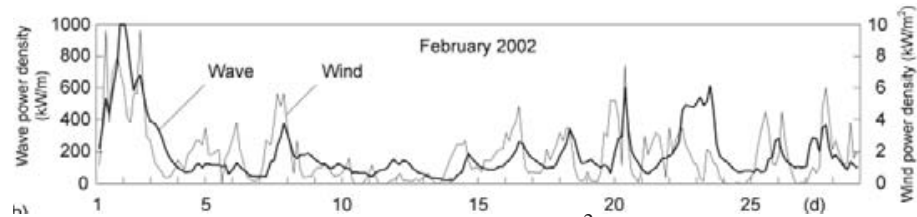

Fig. 6. WE $(\mathrm{kW} / \mathrm{m})$ and OWE density $\left(\mathrm{kW} / \mathrm{m}^{2}\right)$ (Edinburgh, 2006)

According to this, ECI (2006) shows that a RE mix of tidal energy, $\mathrm{WE}$ and onshore wind energy (with the two latter accounting for 
$\sim 45 \%$ each) reduces the long term variability of the electricity supply by $\sim 37 \%$, increases the capacity credit of the mix by $\sim 20 \%$ and reduces the balancing costs associated with the variability by $\sim 37 \%$.

As a result, considering the synergies between the OWE and the WE sector, and that power transmission is a common challenge, efforts should be made to develop cost-effective offshore networks that are reliable and suitable for integration of farms of WECs and OWTs.

\section{OFFSHORE POWER TRANSMISSION OPTIONS}

Eventually, WECs will be connected in arrays (Fig. 7) to form parks using similar farm concepts and technologies as the OWE sector (Ackermann, 2002; Bresesti et al, 2007; Czech et al, 2009). The collection system can follow a string or a star configuration, where different voltage levels regions can be found: low voltage (LV), medium voltage (MV) and high voltage (HV). Above all, the number of collection voltage levels is a trade off between investment costs and power losses (Czech et al, 2009). Thus, it depends on the cables length and the rated power.

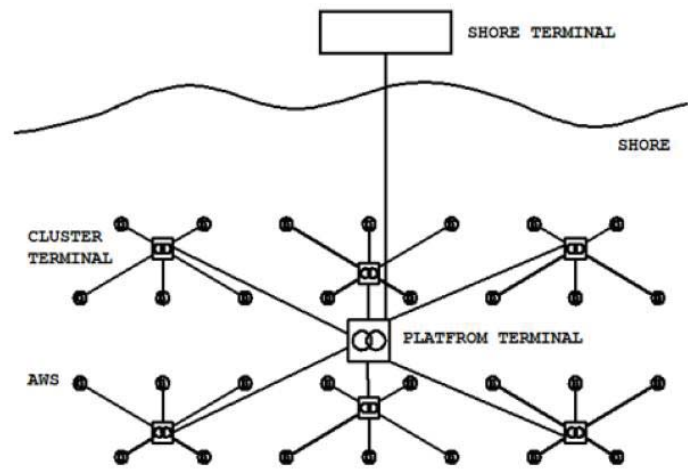

Fig. 7. Example of a star layout in a farm of offshore WECs named Archimedes Wave Swing (Czech et al, 2009).

For large farms (i.e. several MW) located far offshore the following configuration usually applies: in the LV region the converters (i.e. OWTs and WECs) are connected in parallel or in series, and likely to a cluster terminal; in the MV region the cluster terminals are connected to a collection point; and in the HV region the collection point is connected either directly to shore or to another common collection point that collects the power from different clusters. LV and MV levels use alternating current (AC). HV transmission can be either at $\mathrm{AC}$ or at direct current (DC). Considering that farms tend to be larger and transmission distances are increasing, $\mathrm{HV}$ levels are becoming useful in order to minimise power losses (Ackermann, 2002).

\section{HVAC and HVDC for Offshore Power Transmission}

There are advantages and disadvantages in using HVAC and HVDC connections for subsea power transmission. On one hand, HVAC connections are simpler and have lower costs than HVDC in short distances (about $50 \mathrm{~km}$ ), since the HVAC offshore collection point does not comprise expensive converter valves. On the other hand:

- HVAC has limited transmission distances. The distributed capacitance of AC subsea cables is much higher than in overhead lines. Reactive power increases with voltage and cable length, and therefore transmission in long distances require large reactive power compensation devices at both ends of the cable. Thus, HVDC cable losses are smaller than in HVAC.

- HVDC needs less cabling than equivalent HVAC (Koldby and Hyttinen, 2009).

- DC transmission can asynchronously connect the offshore network and the main grid (Ackermann, 2002; Bresesti et al, 2007). This has three direct consequences: firstly, the connection barely contribute to the short-circuit power if a fault on the main grid occurs and it can decouple both grids to isolate the offshore network from onshore disturbances; secondly, the offshore DC terminal can collect the generated power at various frequencies from multiple generators and convert it to a common grid frequency; and thirdly, it can interconnect asynchronous regions for the exchange of power.

As a result, DC is becoming more interesting for remote offshore RE generation farms. There are two schemes of HVDC, line commutated converter (LCC) based HVDC and voltage source converter (VSC) based HVDC.

\section{HVDC Transmission: LCC-HVDC and VSC-HVDC}

HVDC enable large power transmission over long distances via submarine, underground or overhead lines; through two conversion stations connected by a DC link. The type of DC link depends on the application; LCC-HVDC uses monopolar, bipolar, tripolar or back-toback, whereas VSC-HVDC transmission circuit is by nature bipolar (i.e. a pair of conductors each at a high voltage with respect to ground in opposite polarity). The conversion station is the terminal equipment in which DC current is converted to AC current (inversion) and vice versa (rectification). It includes the converter valves and the connection to the AC grid. The circuit of LCC-HVDC differs from the VSC-HVDC in the converter valves. The former is based on LCCs using thyristors as the switching element and the latter is based on VSCs using insulated gate bipolar transistors (IGBTs).

The advantage of LCC-HVDC technology is its proven track record in large capacity point-to-point transmission links over long distances and in interconnecting strong synchronous and asynchronous power systems (Zervos et al, 2008). Moreover, LCCs have fewer losses than VSCs and offer higher voltage and power ratings (Martínez de Alegría et al, 2009). Nevertheless, for low offshore transmission capacities this scheme has several limitations and undesirable characteristics which, on the other hand, VSC-HVDC technology (ABB, 2010; Schettler, Huang and Christl, 2000) overcomes (Table 3):

- It can independently control the active and the reactive power over the complete operation range at each end of the line and thus, it can provide power system support capabilities (Sandeberg and Stendius, 2008). Active power control can be used for frequency regulation in the grid, so it can support the AC power systems at the ends of the DC link and be connected to weak AC networks (i.e. an offshore network) (Martínez de Alegría et al, 2009). Reactive power control can be used to regulate the voltage on the onshore side and to supply reactive power to the offshore generators. On the other hand, LCC consumes $50-60 \%$ of its active power as reactive power (Bresesti et al, 2007) according to the thyristors firing angle, which must be supplied externally.

- It provides start-up capability (Sandeberg and Stendius, 2008); thus, it can start a dead grid. LCC requires a receiving network of a strength exceeding the power of the HVDC link, thus, an auxiliary start-up system would be needed in the offshore farm (Koldby and Hyttinen, 2009).

- VSCs have very high switching frequencies in comparison to LCCs. Thus, the harmonic distortion of the AC voltage is much lower, fewer filters are required and the converter stations can be smaller and cheaper (Bresesti et al, 2007).

- VSCs do not need communication between stations during normal operation because the control is based on measurements of the DC voltage (Sandeberg and Stendius, 2008). 
Table 3. Comparison between HVAC, LCC-HVDC and VSC-HVDC technology (Zervos et al, 2008)

\begin{tabular}{|c|c|c|c|c|}
\hline \multirow{2}{*}{\multicolumn{2}{|c|}{$\begin{array}{l}\text { Capacity distance } \\
\text { dependent? }\end{array}$}} & HVAC & LCC-HVDC & VSC-HVDC \\
\hline & & Yes & No & No \\
\hline \multicolumn{2}{|c|}{ Power losses } & $\begin{array}{l}\text { Distance } \\
\text { dependent }\end{array}$ & $\begin{array}{c}\text { Total: } 2-4 \% \\
\text { Converter:1-2\% }{ }^{1}\end{array}$ & $\begin{array}{c}\text { Total: } 5-10 \% \\
\text { Converter: } 4-5 \%^{1}\end{array}$ \\
\hline \multicolumn{2}{|c|}{ Start-up capability } & (Yes) & No & Yes \\
\hline \multicolumn{2}{|c|}{$\begin{array}{l}\text { Network support } \\
\text { capability }\end{array}$} & Limited & Limited & $\begin{array}{l}\text { Large range of } \\
\text { possibilities }\end{array}$ \\
\hline \multicolumn{2}{|c|}{$\begin{array}{l}\text { Substantion } \\
\text { dimensions }\end{array}$} & Small & $\begin{array}{l}\text { Capacity dependent. } \\
\text { Twice that of VSCs }\end{array}$ & $\begin{array}{l}\text { Capacity dependent }{ }^{3} \text {. } \\
\text { Larger than HVAC } \\
\text { substation }\end{array}$ \\
\hline \multirow{3}{*}{ Cost } & $\begin{array}{l}\text { Converter } \\
\text { station }^{4}\end{array}$ & & & $0.11 \mathrm{mEUR} / \mathrm{MW}$ \\
\hline & Cable $^{4}$ & & $\begin{array}{c}132 \mathrm{kV}, 3 \text {-core } \\
\text { XLPE : } 1.5 \mathrm{mEUR} / \mathrm{km}\end{array}$ & $\begin{array}{l}\text { At } 150 \mathrm{kV}, 350 \mathrm{MW} \text { : } \\
0.445 \mathrm{mEUR} / \mathrm{km} \text { - pair }\end{array}$ \\
\hline & $\begin{array}{l}\text { Installation } \\
\text { of } 1 \text { cable }^{4}\end{array}$ & $\begin{array}{c}0.1 \\
\mathrm{mEUR} / \mathrm{km}\end{array}$ & $0.1 \mathrm{mEUR} / \mathrm{km}$ & $0.1 \mathrm{mEUR} / \mathrm{km}$ \\
\hline
\end{tabular}

1 (Martínez de Alegría, 2009); ${ }^{2}$ (EWEA, 2009a); ${ }^{3}$ A 600 MW, 400 kV VSCHVDC converter station requires ca. $300 \times 300 \mathrm{~m}^{2} ;{ }^{4}$ (Lazaridis, 2005).

The major advantage of VSC-HVDC over LCC-HVDC is its operation principle (ABB, 2010). It uses pulse width modulation (PWM) techniques to synthesise a sinusoidal voltage on the AC side (Sandeberg and Stendius, 2008). This fundamental frequency voltage (Ug) across the converter series impedance defines the power flow between the AC and the DC sides. By changing the phase angle between $\mathrm{Ug}$ and the voltage on the AC bus, it controls the active power flow between the converter and the network. The reactive power flow is determined by Ug amplitude, which is controlled by the width of the pulses from the converter bridge. PWM switching frequencies are in the range of $1-2 \mathrm{kHz}$, in comparison to LCC switching frequencies of 50-60 Hz (Martínez de Alegría et al, 2009). Thus, PWM technologies can control both the magnitude and phase of the voltage within certain limits, allowing independent and fast control of active and reactive power flows.

\section{HVAC or VSC-HVDC for Offshore Power Transmission}

Provided that VSC-HVDC technology offers better characteristics than LCC-HVDC, which are the determining factors to choose between VSC-HVDC and HVAC technology for offshore power transmission? These are mainly the cable length and the power capacity.

HVAC has lower cost with short cable lengths, but AC power losses are distance dependent and as the distance increases high charging currents appear (Fig. 8) using up much of the transmission capacity. In such cases, VSC-HVDC becomes a preferable and necessary option, even though VSC-HVDC conversion stations are more expensive than the transformer substations because of the transistors and filters (Ackermann, 2002), and have constant high power losses (i.e. dependent on the switching frequencies) (Bresesti et al, 2007). As a result, VSC-HVDC becomes more economically attractive than HVAC for large transmission distances (Ackermann, 2002; Bresesti et al, 2007; Sandenberg et al, 2008; Woyte et al, 2008).

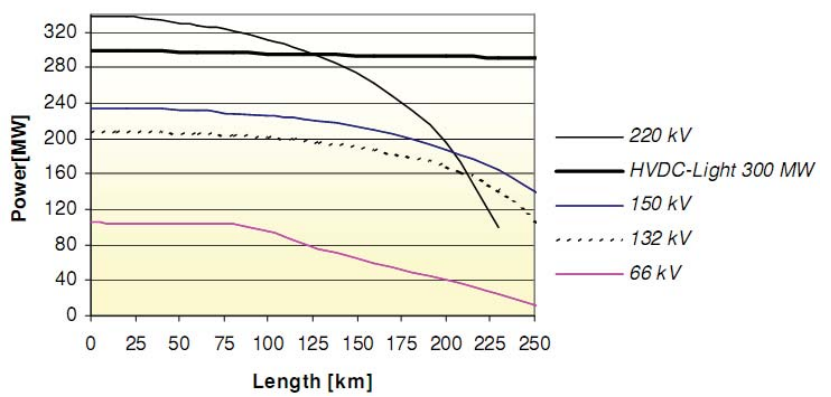

Fig. 8. Maximum lengths for HVAC with tuned inductive shunt compensation in both ends (Johannesson et al, 2009).
Besides, VSC-HVDC technology offers a wide range of applications and provides good control capabilities for an offshore interconnected grid. Trötscher and Korpås (2009) find that transmission lines built to form a meshed offshore grid not only optimise the capacity factor of OWTs from $45 \%$ to $70 \%$, but also provide a higher utilisation of the grid infrastructure and facilitate the power exchange between power systems. In such a grid, VSC-HVDC would become more economic. What is more, Trötscher and Korpås (2009), and Trötscher, Korpås and Tande (2009), point out that a meshed power grid will seldom be built in one step but in several steps as demand for capacity materialises; thus, it requires flexible technology that allows to gradually build up meshed structures.

Nevertheless, there are several technical challenges related to VSCHVDC technology:

- Multi-terminal VSC-HVDC systems are still new for the power system industry.

- VSC-HVDC has presently limited capacity. According to (Zervos et $\mathrm{al}, 2008)$ the upper limit for the converters is approximately 400-500 MW and for the cables $600 \mathrm{MW}$ at $\pm 150 \mathrm{kV}$; according to (ABB, 2010) the technology now reaches $1200 \mathrm{MW}$ at $\pm 320 \mathrm{kV}$.

- DC circuit breakers are in the development stage. Among others challenges, DC demands faster breaking times in comparison to AC, since the zero crossing makes it easier to break AC than DC (Koldby and Hyttinen, 2009).

- There is lack of standards on VSC-HVDC technology and connections (i.e. type of HVDC converter and DC voltage levels). Since the converter size is voltage dependent, comprises a significant cost and converters are currently being built, standardization is lagging and already selected choices might become standards. However, there is lack of experience to base the standards on. IEC Technical Committee TC 115 and Cigré study committee B4 are carrying activities with HVDC, which can likely develop into standards (Koldby and Hyttinen, 2009).

- The technology for installation of submarine cables can reach about $1000 \mathrm{~m}$, which does not hinder an offshore grid development in the North Sea but in e.g. the Mediterranean Sea (Martínez de Alegría et al, 2009).

Apart from this, there are other possible power transmission solutions but their development is less advanced than the presented technologies:

- Hydrogen generation. This alternative has two major drawbacks, the low efficiency of the conversion processes and that a market for hydrogen does not exist (Martínez de Alegría et al, 2009).

- Gas insulated transmission lines working with a low pressure mixture of air and SF6. Their application is in bulk power transmission at moderate distances. They offer high rating capacities and no power losses, but they need extreme temperatures.

- AC transmission system with low network frequency (Zervos et al, 2009).

- Four or six-phase bipolar HVAC systems (Zervos et al, 2009).

\section{Current Application of VSC-HVDC Technology}

One of the existing VSC-HVDC links is BorWin 1 project. It corresponds to the first VSC-HVDC offshore connector and collection system (Johannesson et al, 2009). It names the connection from the OWE farm Bard Offshore 1 to the offshore collection point Borkum2 and the $400 \mathrm{MW}, 230 \mathrm{~km}$ transmission link from Borkum2 to the mainland. Bard Offshore 1 is located $128 \mathrm{~km}$ offshore the German coastline in the North Sea at $40 \mathrm{~m}$ water depths. The farm has a capacity of $400 \mathrm{MW}$, comprising 80 turbines rated at $5 \mathrm{MW}$ each. Each turbine delivers its AC power to an offshore substation (i.e. $36 / 170 \mathrm{kV})$. Then, a $170 \mathrm{kV}, 1 \mathrm{~km}$ submarine AC cable delivers the power to Borkum2 offshore converter station, from where the power runs through a bipolar VSC-HVDC circuit to shore. This comprises 
two $\pm 150 \mathrm{kV}, 128 \mathrm{~km}$ long submarine cables that run to a transition point onshore where they are connected to other $75 \mathrm{~km}$ long underground cables that transmit the power to the converter station onshore. The project cost is estimated to 400 mUSD (ABB, 2008).

Likewise, VSC-HVDC technology can be used for power transmission to offshore oil and gas platforms. Troll A transmits the power to an offshore North Sea platform via two bipolar $67 \mathrm{~km}$ long submarine cables, rated at $41 \mathrm{MW}, \pm 60 \mathrm{kV}$ each, that drive two 40 MW very high voltage motors. Similarly, a $292 \mathrm{~km}$ long submarine cable rated at $78 \mathrm{MW}, \pm 150 \mathrm{kV}$, will power by 2010 the Valhall oil field in the North Sea from the Norwegian shore, replacing the current gas turbines.

The next section reviews a European attempt to integrate offshore RE generation and power exchange in the same project, named Kriegers Flak. It provides a good overview of the challenges ahead of and of the benefits of a joint project.

\section{CHALLENGES AHEAD OF A COMMON OFFSHORE GRID \\ Kriegers Flak (KF)}

Kriegers Flak (Berge, 2009; Christiansen, 2009) is an area in the Baltic Sea where the Exclusive Economic Zones from Sweden, Germany and Denmark met their borders. The area comprises a region with good wind energy potential, $15-40 \mathrm{~m}$ water depths and power transmission needs, which has resulted into plans of installing 1600 MW of OWE: 400 MW for Germany and 600 MW for Denmark and Sweden. Four possibilities have been considered to connect the OWE farms to shore: i) radial connections, ii) back-to-back connection using HVAC, iii) multi-terminal connection using VSC-HVDC, without KF 1 farm, and iv) multi-terminal connection using VSC-HVDC also connecting KF 1 with HVAC (Fig. 9). The three last options allow an exchange capacity of $400 \mathrm{MW}, 600 \mathrm{MW}$ and $1000 \mathrm{MW}$, respectively. The ultimate goal of KF project is to replace the single national solution by a common international one, hence allowing power systems interconnection.

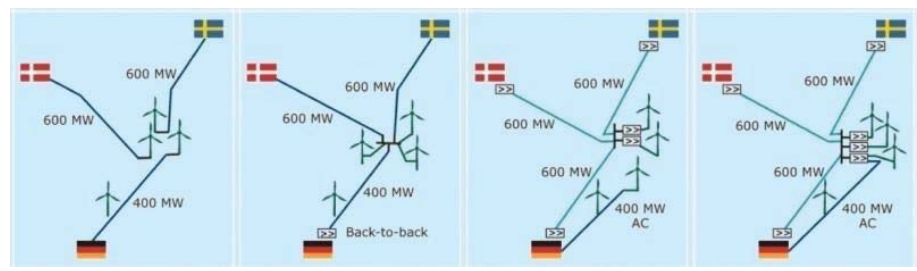

Fig. 9. Kriegers Flak connection possibilities (Christiansen, 2009)

The results from a pre-feasibility study (Kriegers Flak Pre-Feasibility Report, 2009) indicate a positive benefit for a combined solution compared to separate grid connections, but big challenges are ahead. These can be classified as technical, legal and economic challenges. Technical issues include the interconnection of two asynchronous power systems (i.e. North Europe and Central Europe) and the upgrade of the onshore grid to accept the planned power capacity. Legal issues comprise the differences among countries in the support schemes for wind power, in the regulatory frameworks and in the grid codes, grid access and grid connection rules, among others; besides a common power market does not exist. An additional challenge is the high cost of the project, mostly due to the interconnector investment. On top of these, the coordination is resulting complex ${ }^{1}$ and there are still uncertainties on how much installed OWE capacity will be and when.

\footnotetext{
${ }^{1}$ The transmission system operator (TSO) in Sweden has recently decided to abandon the project due to the low feasibility of the wind farm project at Swedish ground compared to other wind farm sites in Northern Europe.
}

On the other hand, the main drivers of KF are the socio-economic benefits (i.e. increase security of energy supply, electricity generation based on RE sources, access to cheapest energy, job creation) and technology development. Furthermore, the learning experience of this project is considered crucial for further integration of interconnectors within offshore RE generation projects. Therefore, the EU is supporting $\mathrm{KF}$ by involving an external coordination group, i.e. Adamowitsch group, which coordinates Baltic and North Sea OWE transmission infrastructures and possible grid topologies; and with 150 mEUR, aimed to ensure a joint interconnection solution (EC, 2009).

\section{Legislation, Timing and Economics of an Offshore Grid}

Kriegers Flak provides a good overview of the obstacles that emerge on a project that involves more than one power market and legal system. Since it can be regarded as a small-scale variant of an interconnected offshore grid, the same challenges addressed above along with additional legislative, timing and economic issues, will eventually arise for a large scale development.

Firstly, regarding legislation, an optimal offshore grid requires a clearly defined legal framework in all the stages of the project (e.g. grid planning, grid construction and grid O\&M) (Huertas-Olivares et al, 2008). At this stage it is essential to define and coordinate maritime spatial planning for offshore RE sites and grid infrastructures at national and international levels, aimed to create a central plan with milestones and binding targets. This will assure certainty for investment and lead to a stepwise development of the grid. Moreover, national policies should look beyond their national energy demands to improve Europe's security of supply.

Secondly, the timing of the project is among others related to the supply chain. Overall estimations calculate that $1000-2000 \mathrm{~km}$ of cable should be laid each year, which demands specially built vessels and submarine trenching robots. Currently, there is a limited number of those available (Martínez de Alegría, 2009) and it can be anticipated that there will be strong competence also from the OWE and WE sectors.

Furthermore, previous experiences show that timing and legislation are strongly related. In particular, the major reason for delay of electricity transmission projects is the complexity of application and authorisation procedures (EC, 2007). For instance, while the installation time of NorNed LCC-HVDC submarine link was 2 years, it took about 14 years from planning to project completion. Moreover, since a common offshore grid requires the integration of several power networks, a substantial number of entities might be responsible for permissions granting, hence resulting in time-consuming legal and licensing procedures.

In order to prevent these constraints i) authorization procedures must get simplified through the introduction of a single integrity consent regime (i.e. one-stop-shop) at national and international levels (DEA, 2006); and ii) a central government body not influenced by national policies has to be set.

In addition, several questions have been raised about the economic feasibility of an interconnected offshore project provided that the initial investment for radial connections is lower than for meshed connections (Trötscher and Korpås, 2009). Nevertheless, Trötscher and Korpås (2009) and Trötscher, Korpås and Tande (2009) prove that the total cost of an optimal grid (i.e. the cost over the entire lifetime of connecting OWE farms, oil and gas rigs and onshore power systems using meshed configurations), is hundreds million Euros lower than a radial one.

Furthermore, because a project of this nature brings several nonquantifiable contributions to e.g. the economic activity, securing long 
term supplies, access to RE sources and certainty about future energy prices and energy sources availability (La Regina et al, 2006); the project cost cannot be the solely decision parameter. Likewise, the externalities associated to the energy conversion processes and the energy resources (Soerensen and Naef, 2008), clearly decide in favour of large offshore RE utilisation and against conventional energy sources (i.e. imported resources in 2006 cost 350 bEUR to the EU). Last but not least, the IEA (2008) predicts an expenditure of 135 bEUR over 2007-2030 to cover electricity consumption growth, replacement of aging infrastructures and strengthen the integration of national markets, under a 'business-as-usual' scenario, in which coal and gas continue to dominate the electricity supply.

\section{CONCLUSIONS}

This paper presents an overview of a European interconnected offshore grid to harness high WE and OWE available resources.

It is highly recommended a joint collaboration between the OWE and the WE sectors to develop a meshed offshore grid. Both share common synergies in relation to governmental marine policies, marine stakeholders, spatial constraints and weak available grid connection points. Particularly, their cooperation brings two main advantages: firstly, share transmission cable costs, and secondly, smooth power output in time while reducing the spare capacity of the transmission lines.

Besides, a meshed offshore grid becomes cost-effective if planned i) to transmit the power generated offshore to the coast, ii) to exchange power between power systems, and iii) to transmit the power to offshore oil and gas platforms. Hence, cost-effective networks demand an overall optimized grid design that avoids suboptimal solutions based on individual and national projects. To achieve this, it is also recommended the cooperation among countries, harmonization of legal rules, simplification of authorization procedures (i.e. one-stopshop method) and international spatial maritime planning.

VSC-HVDC is the most suitable technology to connect offshore RE generation and thus to create a meshed offshore grid. On one hand, it can collect the power from multiple non-synchronized generators, it can be connected to a weak AC network and it provides start-up and power system support capabilities. On the other hand, it can interconnect asynchronous systems (i.e. UK, Ireland, Northern Europe and Continental Europe are not united into a single synchronous network) through long submarine and underground cables and exchange power in two directions.

Even though there are still relevant technical, legal and economic challenges ahead of an offshore interconnected grid, to agree that organizations in different countries are planning to have such network is not a minor step (Koldby and Hyttinen, 2009). Last but not least, as other authors have stated a concept on this scale has already been realized for the gas industry, even including pipelines crossing continents.

\section{ACKNOWLEDGEMENTS}

The $1^{\text {st }}$ author acknowledges the funding by the EC-Marie Curie program, through the project FP7-PEOPLE-ITN 215414 (Wavetrain2). The authors also acknowledge Waveplam and Windspeed projects, funded under IEE Programme (Contract EIE/07/038/SI2.466832 and IEE/07/759/S12.499460), as well as the advices from Elena Giménez Romero (ABB Consulting and Service, System Studies).

\section{REFERENCES}

ABB (2008). "NordE.ON 1. The World's Largest Offshore Wind Farm," Elanders.

ABB (2010). "Differences Between HVDC Light and Classic HVDC," http://www.abb.com/industries/ap/db0003db004333/b8a81e7c435f 37bac125755800373a31.aspx

Ackermann, T (2002). "Transmission Systems for Offshore Wind Farms," IEEE Power Engineering Review , Vol 22 (12), pp 23-27.

Anderson, B, et al (2005). "VSC transmission," Paris: Technical Report 69, CIGRE WG B4.37.

Berge, A (2009). "Kriegers Flak and its Way to Become a Best Practice Area," European Offshore Wind (EOW). Stockholm.

BP (2009). "BP Statistical Review of World Energy,"

Bresesti, P, Kling, W, Hendriks, R, and Vailati, R (2007). "HVDC Connection of Offshore Wind Farms to the Transmission System," IEEE Transactions on Energy Conversion, Vol 22 (1), 37-43.

CA-OE (2006). "Ocean Energy Conversion in Europe; Recent Advancements and Prospects," Coordinated Action on Ocean Energy (CA-OE), Centre for Renewable Energy Sources.

Christiansen, HE (2009). "Kriegers Flak. From National to International Solution for Grid Connection of Offshore Wind Plants," Energinet.dk, Windspeed Workshop. Copenhagen.

Corbett, J (2009). "A Cost Benefit Analysis of Developing Offshore Wind Farms in Conjunction with Interconnectors," European Offshore Wind (EOW). Stockholm.

Czech, B, Bauer, P, Polinder, H, Zhou, Y, and Korondi, P (2009). "Comparing the electrical Transmission Systems fro Archimedes Wave Swing Parks," 8th European Wave and Tidal Energy Conference, EUSEW. Uppsala.

Czisch, G. (2008). "Low Cost but Totally Renewable Electricity Supply for a Huge Supply Area - a European/Trans-European Example," Claverton Energy Conference. Bath.

DEA (2006). "Offshore Wind Farms and the Environment. Danish experiences from Horns Rev and Nysted," Copenhagen: Danish Energy Authority (DEA).

Diesendorf, M (2007). "The Base-Load Fallacy," Institute of Environmental Studies.

EC (2006). "TEN-E Guidelines Specify a European-Wide Energy Transmission Network" EC.

EC (2007). "Communucation from the Commission to the Council and the European Parliament - Priority Interconnection Plan," EC.

EC (2008). "Interconnecting Europe," EC.

EC (2009). "Regulation (EC) No 663/2009 of the European Parliament and of the Council," EC.

ECF (2008). "Global Investments for Climate and Energy Security. A Cross-Sector Perspective, ” European Climate Forum (ECF).

ECI (2005). "Variability of UK Marine Resources," Environmental Change Institute (ECI), University of Oxford, The Carbon Trust.

ECI (2006). "Diversified renewable energy resources," Environmental Change Institute (ECI), University of Oxford, The Carbon Trust.

Edinburgh, TU (2006). "Matching Renewable Energy Generation with Demand," Scottish Executive.

EEA (2008). "Energy and Environment Report 2008," European Environment Agency (EEA).

EU (2008). "European Economic Recovery Plan," EU.

EOEA (2009). "Best Practice," European Ocean Energy Association (EOEA) for the Waveplam Project.

EOEA (2010). "Waves of Opportunity," Ocean Energy European Road Map. European Ocean Energy Association (EOEA)

EWEA (2009a). "Oceans of Opportunity," European Wind Energy Association (EWEA).

EWEA (2009b). “Pure power, ” European Wind Energy Association (EWEA).

Henfridsson, U, Neimane, V, Strand, K, Kapper, R, et al. (2007). "Wave Energy Potential in the Baltic Sea and the Danish Part of the North Sea, with Reflections on the Skagerrak," Renewable Energy, Vol 32, pp 2069-2084. 
Higgins, P (2008). "The Future of Electricity: Liberalisation, Long Distance Transmission, HVDC and Supergrids," Barrister, Trans Mediterranean Renewable Energy Co-operation (TREC).

Huertas-Olivares, C, Soerensen, H, Rousseau, N, Villate, J, et al (2008). "First Outcome of the Waveplam Project: Assessment of Non-technological Barriers and Best Practices," 2nd International Conference on Ocean Energy (ICOE). Brest.

IEA (2008). "World Energy Outlook 2008," OECD/IEA.

IEA (2009). "World Energy Outlook 2009," OECD/IEA.

Johannesson, K, Gustafsson, A, Karlstrand, J, and Jeroense, M (2009). "HVDC Light Cables for Long Distance Grid Connection," European Offshore Wind (EOW). Stockholm.

Kenitzer, S (2007). "The Power of Multiples: Connecting Wind Farms can Make a More Reliable - and Cheaper - Power Source," American Meteorological Society.

Koldby, E, and Hyttinen, M (2009). "Challenges on the Road to an Offshore HVDC Grid," Nordic Wind Power Conference, Bornholm.

Kriegers Flak Pre-Feasibility Report (2009). http://www.energinet.dk/NR/rdonlyres/789F38D3-1296-404CBD64-EB3E641A51D6/0/KriegersFlakPrefeasibilityReport.pdf

La Regina, V, Patrício, S, Neumann, F, and Sarmento, A (2006). "The Role of Socio-economic Impact Assessment (SIA) and Environmental Impact Assessment (EIA) for Understanding Benefits from Wave Energy Deployment," World Renewable Energy Congress. Florence.

Lazaridis, L (2005). "Economic Comparison of HVAC and HVDC Solutions for Large Offshore Wind Farms under Special Consideration of Reliability," Master's Thesis, Royal Institute of Technology. Stockholm.

Martínez de Alegría, I, Martín, J, Kortabarria, I, Andreu, J, and Ibañez Ereño, P (2009). "Transmission Alternatives for Offshore Electrical Power," Renewable and Sustainable Energy Reviews, Vol 13 (5), pp 1027-1038.

Ricci, P, Lopez Mendia, J, Plaza Macias, J, Scuotto, M (2009), "Guidance protocols on choosing of eletrcical connection configurations," Deliverable D5.1 to Equimar project.

Sandeberg, P, and Stendius, L (2008). "Large Scale Offshore Wind Power Energy Evacuation by HVDC Light ${ }^{\circledR}$," EWEC. Brussels.

Schellekens, G, Battaglini, A, Lilliestam, J, McDonnell, J, Patt, A (2010). " $100 \%$ renewable electricity - A roadmap to 2050 for Europe and North Africa" Report.
Schettler, F, Huang, H, and Christl, N (2000). "HVDC Transmission Systems Using Voltage Sourced Converters-Design and Applications," IEEE PES Summer Meeting, Vol 2, pp 715-720. Seattle.

Soerensen, HC (2009). "Wave Energy: a Future Resource for Electricity," Forum Geoökologie, Vol 20 (1), pp 18-23.

Soerensen, HC, Nielsen, K, Steenstrup, PR, Friis-Madsen, E, and Wigant, L (2005). "Bølgekraftanlaeg ved Horns Rev (Wave energy deployment at Horns Rev Wind Farm), " report for PSO, Eltra.

Soerensen, H, and Fernandez-Chozas, J (2010). "The Potential for Wave Energy in the North Sea," International Conference on Ocean Energy (ICOE). Bilbao.

Soerensen, H, and Naef, S (2008). "Report on Technical Specification of Reference Technologies (Wave and Tidal Power Plant)," Deliverable 16.1 - RSIa to the Needs Project.

Teske, S (2008). "Global Energy Scenario," Greepeace International, European Renewable Energy Council (EREC).

Trötscher, T, and Korpås, M (2009). "Optimal Design of a Subsea Power Grid in the North Sea," European Offshore Wind (EOW). Stockholm.

Trötscher, T, Korpås, M, and Tande, JO (2009). "Optimal Design of Subsea Grid for Offshore Wind Farms and Transnational Power Exchange," European Wind Energy Conference (EWEC). Stockholm.

Van Hulle, F (2009). "Integrating Wind. Developing Europe's Power Market for the Large Scale Integration of Wind Power," Deliverable to Tradewind project.

Veal, C, Byrne, C, Kelly, S (2007). "The Cost-benefit of Integrating

Offshore Wind Farm Connections and Subsea Interconnectors in the North Sea," European Offshore Wind (EOW). Berlin.

Watson, R (2002). "An undersea transmission grid to offload offshore wind farms in the Irish Sea," Proc. 3rd International Workshop on Transmission Networks for Offshore Wind Farms. Stockholm.

Woyte, A, De Decker, J, and Vu Van, T (2008). "A North Sea Electricity Grid [R] evolution, ” Brussels: 3E for Greenpeace.

Zervos, A, Lins, C, Ackermann, T, Tröster, E, Short, R, and Teske, S (2008). "Global Energy Grid Scenario," Greenpeace International, European Renewable Energy Council (EREC). 
Paper F: Combined Production of a full-scale Wave Converter and a full-scale Wind Turbine - a Real Case Study

\author{
Published in
}

Proceedings of the 4th International Conference on Ocean Energy (ICOE), 2012. 



\title{
Combined Production of a full-scale Wave Converter and a full-scale Wind Turbine - a Real Case Study
}

\author{
J. Fernández-Chozas ${ }^{1}$, M.M. Kramer ${ }^{1,2}$, H.C. Sørensen ${ }^{3}$ and J.P. Kofoed ${ }^{1}$ \\ ${ }^{1}$ Department of Civil Engineering, Aalborg University \\ Sohngaardholmsvej 57, 9000 Aalborg, Denmark \\ E-mails: jfch@civil.aau.dk; jpk@civil.aau.dk; mmk@civil.aau.dk \\ ${ }^{2}$ Wave Star A/S \\ Park Allé 350A, Brøndby, Denmark \\ E-mail:mmk@wavestarenergy.dk \\ ${ }^{3}$ SPOK ApS \\ Blegdamsvej 4, 2200 Copenhagen, Denmark \\ E-mail: consult@spok.dk
}

\begin{abstract}
High wave and offshore wind potentials are present along the West and North coasts of Europe. Eventually these renewable sources will become large-scale contributors to the electricity mix.

The objective of the paper is examining the advantages in combining the power production of wave converters and offshore wind turbines. The opportunities of providing a smooth and continuous power output are investigated.

The study is based on simultaneous, real power productions from Wavestar wave converter and a $525 \mathrm{~kW}$ wind turbine of the Nordic Folkecenter, at Hanstholm, Denmark. It examines the metocean conditions at the site and the relationship between the wind and the wave resource, and analyses the power productions of the wave converter and the wind turbine working individually and in combinations according to five different scenarios.

The analysis on environmental conditions indicates there is high correlation between winds and waves, characterised by an average delay of 2 to 3 hours. Up to 9 hours-delay the correlation remains high.

Regarding power productions, results show every portfolio combining wave and wind technologies provides important benefits: minimises the percentage of time of zero-production and reduces the peaks; thus, it smoothens out the power output.
\end{abstract}

Keywords: combined wind and wave, Hanstholm, North Sea, wave energy, Wavestar, wind energy.

\section{Introduction}

This paper investigates the pattern of the power production of combinations of co-located wind and wave technologies, based on real power productions. It is expected that the joint production provides more stable power outputs than wind and wave technologies working individually.

The idea of combining marine renewables has gained lot of interest in the last years and so is the number of designs merging wind and wave conversion mechanisms [1]. However, there is no real deployment combining both resources and research on the area is based on desk-work. Three studies assess the correlation between winds and waves, and the advantages of harnessing them together to improve the reliability and decrease the variability of the power production. The studies are based on Ireland [2], California [3] and Denmark [4]. The European project Marina Platform is also looking into this subject [5].

The pattern of the power output is related to the electric system operation. The grid requires a nonvariable and continuous production from all generation technologies, including renewables. According to this, the aim of the study is to identify the portfolios of wave and wind that minimise the zero-production and reduce the variability.

The fact that waves are more constant than winds and the delay between both resources provides the background of the study. The paper examines the metocean conditions at Hanstholm and the pattern of the power output of different energy portfolios combining wind and wave.

This analysis is the first approach towards the study of real power productions of full-scale wave and wind converters. It also focuses on the environmental characteristics of Hanstholm, located in an area with continuous interest on renewables development. 
Indeed, Wave Star and Dong Energy are collaborating towards the deployment of a commercial $600 \mathrm{~kW}$ converter at Horns Rev 2 offshore wind farm, off the West coast of Denmark [6], a location with comparable metocean conditions as those investigated here.

\section{Methodology}

\subsection{Time period}

The study covers a 5-month period, from January to May 2011. The location has strong seasonal variability, where January is the most energetic month and May the least [7-8].

All times and dates in the paper are expressed in the Coordinated Universal Time (UTC) system.

\subsection{Study location - Hanstholm}

Hanstholm is located on the North-West coast of Jutland, Denmark, in the Danish part of the North Sea.

Figure 1 shows the four relevant sites of the study. Wave buoy-data are recorded about $1.5 \mathrm{~km}$ North-West off the harbour, weather data are obtained at the harbour and the technologies are located on the NorthEast. Wavestar prototype is installed near-shore and the wind turbine ashore.

The 350 meters length between Wavestar and the turbine provides a valid representation of the typical distance between wave devices and wind turbines in a common space (i.e. at Horns Rev 2). Moreover, the fact the turbine is lying on the shoreline and is facing offshore for the dominating wind directions allows to assume that the power output of the turbine represents production patterns of offshore turbines.

Therefore, it is accepted the technologies illustrate production patterns of an offshore real deployment.

Additionally, to study the relationship between waves and winds it is assumed that both are recorded at the buoy location; thus, that the wind from offshore remains undisturbed. For that, winds with mean direction in the interval $\left[45^{\circ}, 220^{\circ}\right]$ are disregarded and only the winds coming from the sea are considered.

\subsection{Metocean conditions at Hanstholm}

The wave climate at Hanstholm is characterised by a wind sea on top of a non-constant swell coming primarily from West-North-West and West direction. The long-term average wave power at $17 \mathrm{~m}$ depths is 7 $\mathrm{kW} / \mathrm{m}$ and the 100-year wave is $8.3 \mathrm{~m}$ [9]. At $5 \mathrm{~m}$ depth, where Wavestar is located, the available mean wave power is about $3 \mathrm{~kW} / \mathrm{m}$.

Winds at Hanstholm generally arrive from West, South-West and East directions. The strongest winds, with wind speeds up to $25-30 \mathrm{~m} / \mathrm{s}$, come from NorthWest, West and South-West [8].

Wave measurements are provided by a nondirectional Waverider buoy (positioned at 474700E and $6332100 \mathrm{~N}$, UTM32 system) at $17 \mathrm{~m}$ water depths. Wind data are recorded by a weather station at $20 \mathrm{~m}$ above ground (475467E and 6331036N, UTM32).

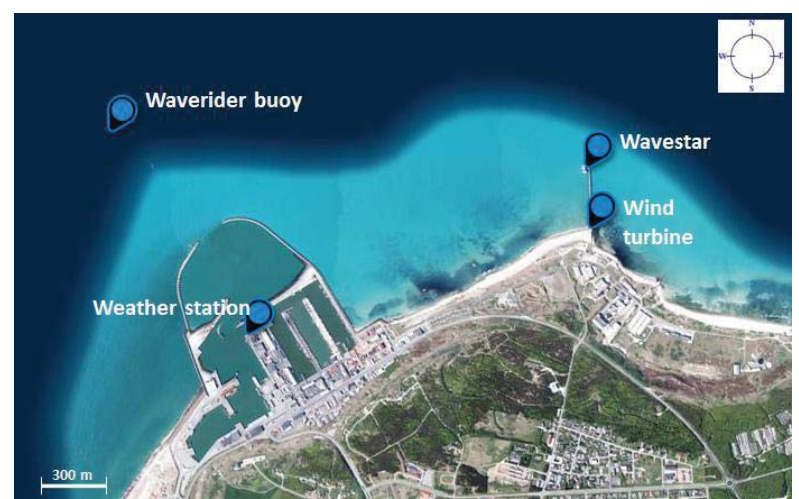

Figure 1. Location at Hanstholm of the wave buoy, the weather station, Wavestar converter and the wind turbine [10]

To study the relationship between waves and winds the following formula is used [2]:

$$
C C(t)=\frac{1}{N} \sum_{k=1}^{N-t} \frac{\left[\left(x(k)-\mu_{x}\right)\left(y(k+t)-\mu_{y}\right)\right]}{\sigma_{x} \sigma_{y}}
$$

The cross-correlation $C C$ is a function of a time lag $t$, which reflects the temporal relationship between two variables, $x$ and $y$, representing the wind speed and the significant wave height, respectively. $k$ is a counter indicating time, $N$ is the number of samples, $\mu$ the sample mean and $\sigma$ the standard deviation.

$C C$ indicates the degree to which the variation in one parameter, $x$, is reflected in the variation of the other parameter, $y$. $C C$ ranges from 0 , indicating no correlation, to 1 , which denotes perfect correlation.

The time lag at which the correlation reaches a maximum is defined as the average delay.

\subsection{Wave and wind technologies}

Real data on power productions have been provided by the Wavestar machine at Hanstholm (rated at 110 $\mathrm{kW}$ ) and a $525 \mathrm{~kW}$ wind turbine (Figure 2).

\section{Wavestar wave energy converter}

Wavestar is a near-shore multi-point absorber. The prototype at Hanstholm is installed at $5 \mathrm{~m}$ water depths and $300 \mathrm{~m}$ offshore, aside Roshage pier. It has two round floats attached to a bridge structure (Figure 2), which is secured to the sea bed by four steel piles cast into concrete foundations. The floats can move in heave direction, thereby pumping hydraulic fluid into a hydraulic manifold system. This produces a flow of high pressure oil into a hydraulic motor coupled to an electrical generator [11].

The device interrupts power production when the significant wave height exceeds 2.5 meters. Then, the machine starts the storm protection mode, un-ballasting the floats and retracting the hydraulic cylinders, which pull the floats out of the water (Figure 3).

\section{Folkecenter wind turbine}

The wind turbine was manufactured by the Nordic Folkecenter for Renewable Energy in 1992 on the shoreline in front of Roshage pier [12]. It is rated at 525 $\mathrm{kW}$ and has an average production of $1.5 \mathrm{GWh} / \mathrm{y}$ (i.e. 3000 full-load hours). The tower is $40 \mathrm{~m}$ high and the blades are $17 \mathrm{~m}$ long. 
Table 1 presents the environmental conditions where Wavestar's device at Hanstholm and the wind turbine operate at maximum capacity (i.e. design point) and when operation is interrupted (i.e. cut-in and cut-out limits).

\begin{tabular}{llccc}
\hline & & Design & Cut-in & Cut-out \\
\hline $\begin{array}{l}\text { Wavestar } \\
\text { (Hanstholm) }\end{array}$ & $\mathbf{H}_{\mathrm{m} \mathbf{0}}(\mathrm{m})$ & 2.0 & 0.5 & 2.5 \\
$\begin{array}{l}\text { Wind } \\
\text { Turbine }\end{array}$ & $\begin{array}{l}\mathbf{u}_{\text {wind }} \\
(\mathrm{m} / \mathrm{s})\end{array}$ & 16 & 4 & 25 \\
\hline \multicolumn{4}{l}{ Table 1. Technologies operating conditions at Hanstholm. }
\end{tabular}

\subsection{Power production data}

Time-series of Wavestar's production are available since May 2010. The paper is based on production data from January to May 2011 expressed as 30-minute average values. Data correspond to hydraulic power measured at the output of the two cylinders connected to the floats.

This machine of Wavestar is over-rated compared to the commercial converter. It has a nominal power of $110 \mathrm{~kW}$ for two floats whereas the commercial unit is rated at $600 \mathrm{~kW}$ for 20 floats. To be consistent with the performance of the $600 \mathrm{~kW}$ device, Wavestar's power output data are down-rated to $60 \%$ of maximum power production (i.e. it is assumed the installed generator capacity is reduced by $60 \%$, which implies that all power peaks above $60 \%$ are filtered).

Throughout the study period the prototype has been set in different operational modes, including storm protection, reparation, stopped due to calm seas or harvesting energy. Additionally, different control strategies have been tested since the installation of the device [13] and experience on Wavestar's performance and control has been gained. In fact, power production has improved during 2012 [14]. For that reason, the operation data presented in this paper should be read as initial prototype performance results.

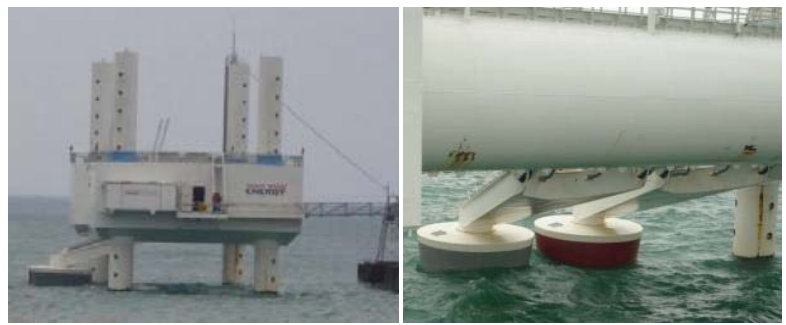

Figure 2. Wavestar operating at Hanstholm.

From 1996 there is available production data of the wind turbine as 15-minute average time-series of electrical power delivered to the grid. To match Wavestar's data 30-minute average values of turbine's production are calculated as a weighted average of the 15-minute time-series for January to May 2011.

\subsection{Evaluation of power productions}

The characteristics in the power productions of the wave and the wind converter are investigated in five different scenarios: $100 \%$ wave, $75 \%: 25 \%$ wave-wind, 50\%:50\% wave-wind, 25\%:75\% wave-wind, and 100\% wind.

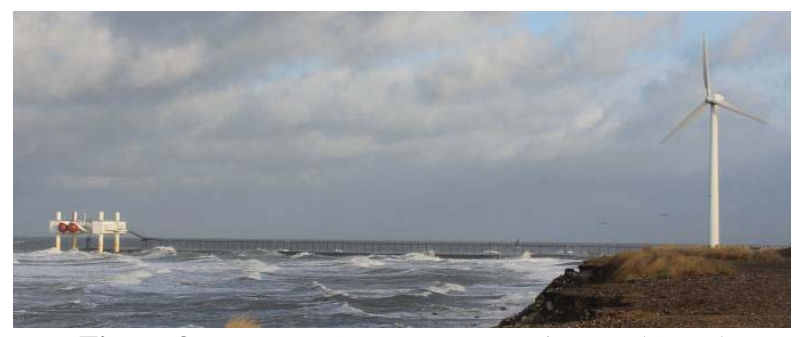

Figure 3. Wavestar (on storm protection mode) and Folkecenter wind turbine, Hanstholm.

In each scenario 'wave' denotes power production from Wavestar and 'wind' denotes power production from the Folkecenter wind turbine. The 75\%:25\% portfolio looks into the inclusion of one unit of wind turbines over a site utilising three units of wave converters, and vice-versa. The 50\%:50\% scenario indicates the same amount of wave and wind rated power.

Since the technologies have different mean power outputs, peak productions and rated power, nondimensional power productions are used throughout the study. These are expressed as a percentage of maximum system power output.

Then, the relationship between Wavestar's production and the wind turbine's production is evaluated by the correlation factor, where the variables $x$ and $y$ correspond to the non-dimensional power outputs of the two technologies. The standard deviation $\sigma$ is used to measure the variability.

\section{Results}

\subsection{Waves and winds characteristics}

Table 2 presents the mean and maximum values of the wave parameters $H_{m 0}, H_{\max }, T_{02}$ and $P_{\text {wave }}$ and the wind parameters $u_{\text {wind }}, M W D_{\text {wind }}$ and $P_{\text {wind }}$ at Hanstholm throughout the study period [15].

Wave data indicate less-energetic sea-states in the study period compared to the long-term wave climate. This is induced by the strong seasonal variability of Hanstholm. In this period prevailing wind direction is South-West, which coincides with the direction of the strongest winds (15 to $20 \mathrm{~m} / \mathrm{s}$ ) along with North-West and West directions.

\begin{tabular}{lccccccc}
\hline & $\begin{array}{c}\mathbf{H}_{\mathbf{m} 0} \\
(\mathrm{~m})\end{array}$ & $\begin{array}{c}\mathbf{H}_{\max } \\
(\mathrm{m})\end{array}$ & $\begin{array}{c}\mathbf{T}_{\mathbf{0 2}} \\
(\mathrm{s})\end{array}$ & $\begin{array}{c}\mathbf{P}_{\text {wave }} \\
(\mathrm{kW} / \mathrm{m})\end{array}$ & $\begin{array}{c}\mathbf{u}_{\text {wind }} \\
(\mathrm{m} / \mathrm{s})\end{array}$ & $\begin{array}{c}\mathbf{M W D} \\
\left({ }^{\circ}\right)\end{array}$ & $\begin{array}{c}\mathbf{P}_{\text {wind }} \\
\left(\mathrm{W} / \mathrm{m}^{2}\right)\end{array}$ \\
\hline $\boldsymbol{\mu}$ & 1.1 & 1.9 & 4.5 & 5.4 & 7.8 & 240 & 465 \\
Max. & 4.3 & 7.6 & 8.5 & 92 & 21.5 & 358 & 6140 \\
\hline
\end{tabular}

Table 2. Wave and wind conditions at Hanstholm from January to May 2011 characterized by mean and max. values.

The comparison of Tables 1 and 2 reveals the design condition of the wind turbine is above the typical conditions in the study period. This will derive into low mean power productions. It will also happen for Wavestar; although the power-output has been downrated the conditions near-shore and close to the pier are lower than those shown in Table .

Likewise, Table 3 depicts the percentages of time (from January to May 2011) the environmental 
conditions are too low and too high for the technologies operation. The theoretical time the wave and wind converter working alone would be out of operation is $16 \%$ and $19 \%$ of the total time, respectively. In contrast, when the technologies are working combined this value drops to $6 \%$.

\begin{tabular}{lcc}
\hline & $\begin{array}{c}\text { Below Cut-in } \\
\text { (\% of time) }\end{array}$ & $\begin{array}{c}\text { Above Cut-off } \\
\text { (\% of time) }\end{array}$ \\
\hline $\mathbf{H}_{\mathbf{m} 0}(\mathrm{~m})$ & $12 \%$ & $4 \%$ \\
$\mathbf{u}_{\mathbf{w i n d}}(\mathrm{m} / \mathrm{s})$ & $19 \%$ & $0 \%$ \\
$\mathbf{H}_{\mathbf{m} 0} \& \mathbf{u}_{\text {wind }}$ & $6 \%$ & $0 \%$ \\
\hline
\end{tabular}

Table 3. Percentage of time wave and/or wind conditions are below and above the cut-in and cut-out limits, respectively.

\section{Correlation of waves and winds}

The relationship of the wave and the wind resource is evaluated by comparing the significant wave height and the wind speed.

Figure 4 indicates there is high correlation between waves and winds $(C C(0)=0.8)$, which is explained by the wind-seas that dominate Hanstholm. The point in time when $C C(t)$ is maximum indicates the average time delay between winds and waves. This occurs for $t$ between 2 to 3 hours, where $C C=0.83$. For a delay up to 5 hours the correlation is high $(C C=0.8)$ and up to 9 hours there is a correlation above 0.7 .

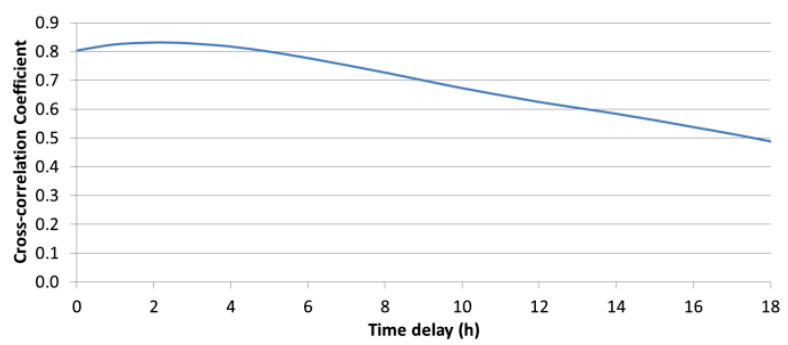

Figure 4. Cross-correlation (CC) coefficient between waves and winds for different time delays.

In fact, the cross-correlation coefficient between waves and winds also indicates a relationship between the power outputs of the corresponding technologies. When combining them it is convenient that the resources are uncorrelated so that the power outputs vary differently. This happens in swell dominated locations (i.e. $C C=0.4$ [2]), where the percentage of time the wave height and the wind speed are outside the operating limits (as shown in Table 3) would decrease further.

\section{Variability of waves and winds}

Figure 5 presents the evolution of the significant wave height and the wind speed during a 10-day period in January 2011 (note the different scales in the axes). It illustrates faster changes in the wind speed than in the wave height. The comparison also shows the wave height takes about twice the time the wind speed takes to increase or reduce from an average value to its double or half. The wind speed decreases from $16 \mathrm{~m} / \mathrm{s}$ to $10 \mathrm{~m} / \mathrm{s}$ in 5 hours (on 16/01) and increases from $1 \mathrm{~m} / \mathrm{s}$ to $10 \mathrm{~m} / \mathrm{s}$ in 6 hours (on 22/01). By contrast, the significant wave height takes twice this time (12 hours) to increase from $1.2 \mathrm{~m}$ to $2.6 \mathrm{~m}$.

\subsection{Wave and wind power production}

Table 4 shows the performance of the wave converter and the wind turbine in five different scenarios, where either they work alone or combined, from January to May 2011. The performance is evaluated in terms of percentage of time the power production falls within seven intervals of maximum power output. The following sections analyse each scenario.

\section{$100 \%$ wave scenario}

The first raw of Table 4 presents the performance of Wavestar in the study period. It is characterised by a high percentage of time (36\%) with zero-power output, which can be explained by the experimental stage of the device (i.e. repair and transition periods) and the presence of calm seas and high sea-states (occurring $12 \%$ and $4 \%$ of the time, respectively, according to Table 3). This result in an average production of $30 \%$, despite the production is well-distributed in the different production intervals, and into a high standard deviation and variability. Production goes over $80 \%$ of maximum production about $10 \%$ of the time.

\section{$100 \%$ wind scenario}

Table 4 indicates the performance of the wind turbine. Most of the production is concentrated in the interval 0 to $80 \%$ of maximum production and $13 \%$ of the time there is no production. The difference in the zero-production times derives into a higher average production and a lower variability than Wavestar. As in the wave device, the power output goes over $80 \%$ of maximum production about $10 \%$ of the time.

\begin{tabular}{|c|c|c|c|c|c|c|c|c|c|c|}
\hline & \multirow[b]{2}{*}{$\begin{array}{c}\mu \\
(\%)\end{array}$} & \multirow[b]{2}{*}{$\begin{array}{c}\sigma \\
(\%)\end{array}$} & \multirow[b]{2}{*}{$\sigma / \mu$} & \multicolumn{7}{|c|}{ Percentage of time $x$ falls in the indicated intervals of production } \\
\hline & & & & $\mathrm{x}=\mathbf{0}$ & $\begin{array}{r}\mathbf{0}<\mathbf{x}<\mathbf{2 0} \\
\text { (where }\end{array}$ & $\begin{array}{l}\mathbf{2 0}<\mathbf{x}<\mathbf{4 0} \\
\text { represents }\end{array}$ & $\begin{array}{l}\mathbf{4 0}<\mathbf{x}<\mathbf{6 0} \\
\text { rcentage of n }\end{array}$ & $\begin{array}{l}\mathbf{6 0}<\mathrm{x}<\mathbf{8 0} \\
\text { aximum pov }\end{array}$ & $\begin{array}{c}\quad \mathbf{8 0}<\mathbf{x}<\mathbf{1 0 0} \\
\text { er production) }\end{array}$ & $x=100$ \\
\hline $100 \%$ Wavestar & 30 & 32 & 1.06 & 36 & 11 & 22 & 13 & 8 & 5 & 6 \\
\hline $75 \%$ Wave - $25 \%$ Wind & 31 & 26 & 0.84 & 6 & 38 & 26 & 14 & 8 & 8 & 0 \\
\hline $50 \%$ Wave - $50 \%$ Wind & 32 & 23 & 0.73 & 6 & 31 & 30 & 19 & 10 & 5 & 0 \\
\hline $25 \%$ Wave - $75 \%$ Wind & 34 & 24 & 0.73 & 6 & 32 & 23 & 20 & 16 & 3 & 0 \\
\hline $100 \%$ Wind turbine & 35 & 29 & 0.82 & 13 & 26 & 20 & 17 & 15 & 9 & 0 \\
\hline
\end{tabular}

Table 4. Mean production, standard deviation and percentages of time the wind turbine and/or Wavestar productions falls in different intervals of maximum system power output, from January to May 2011. 


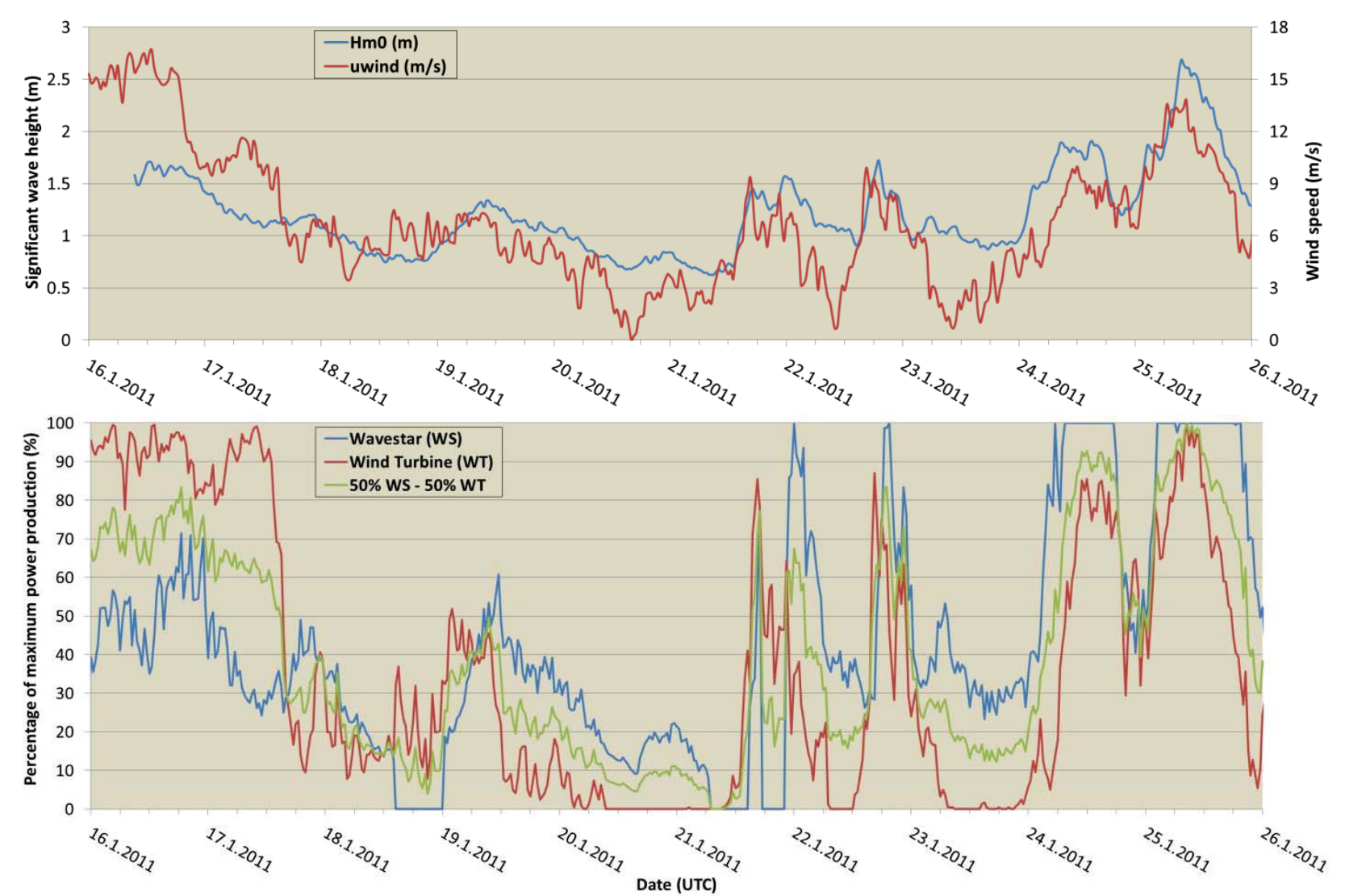

Figure 5. Significant wave height (blue), wind speed (red), and real power productions of Wavestar (blue), of the wind turbine (red) and a combination of both (green), expressed as a percentage of maximum power output, during 10 days of January 2011.

Combined wave and wind scenario

Provided Wavestar and the wind turbine exhibit different production patterns, this section characterizes the power output of a mix of technologies. It is investigated if co-located wave and wind converters in different ratios (25:75, 50:50 and 75:25 scenarios) provide more stable power outputs than increasing the installed capacity of only one technology (i.e. 100\% scenarios).

Figure 5 shows the power production of the two technologies, working alone and combined in the same ratio (50:50 scenario), during a 10-day period of January 2011. It illustrates typical operating conditions of Hanstholm, where the wave height and the wind speed are concentrated around the mean values (max. $H_{m 0}=2.6 \mathrm{~m}$, max. $u_{\text {wind }}=17 \mathrm{~m} / \mathrm{s}$ ). Hence, it is interesting to study the evolution of the wind turbine and the wave converter.

First, there are time-points where there is no production from the wind turbine, and others where there is no production from Wavestar. However, there are no periods where both power outputs drop to zero. It can be seen the power production of Wavestar follows that of the turbine with some delay.

Then, there are very fast changes in the wind turbine and in Wavestar's production (the fast changes in wind turbines' production is considered a main problem in the integration into the grid). In the 50:50 scenario the changes from maximum to zero values disappear, providing a less-fluctuating power output.
These characteristics can also be realized from Table 4 looking into the 50:50 scenario. Both the percentage of time with no production and the variability reduce. Variability is $10 \%$ smaller than the variability of the wind turbine and $30 \%$ smaller than for Wavestar.

Table 4 and Figure 5 also indicate the combined production does not often reach peak values. Rather than a disadvantage this can be of economic benefit for the cable ratings, for example.

The comparison of the 25:75 and 75:25 scenarios to the 50:50 shows similar patterns in the power productions (Table 4). Average power productions and the percentage of time with zero-production are similar.

As a result, independently of the combination ratio, the potential benefit of combining the two sources of power is that the percentage of time with no production reduces to a minimum $(6 \%)$ and that the variability in the power output reduces $(\sigma=23 \%)$. These ultimately provide a more continuous and smoother power output.

\section{Discussion}

The most interesting finding is that the pattern of the power production of any of the combined scenarios brings more benefits than the pattern of a single technology. The advantages of combining wave and wind technologies are the following:

\section{Providing a more continuous power output:}

i) Minimum zero-production: The three scenarios combining wave and wind (25:75, 50:50 and 75:25) 
reduce to a minimum the percentage of time the combined production drops to zero. From a 36\% (100\% wave) or a $13 \%$ ( $100 \%$ wind) to a $6 \%$ (combined scenarios). Similarly, metocean conditions indicate that, theoretically, 94\% of the time there are suitable conditions for the combined operation of the devices compared to a $65 \%$ of the time if the technologies are working individually.

ii) Waves are delayed to winds: There is a proven delay of waves to the corresponding winds; whenever winds stop waves continue flowing for some time. Hanstholm conditions show waves have an average delay of 2 to 3 hours to winds, and this delay can go up to 9 hours. Thus, the power output from wave converters continue several hours from the time wind turbines stop producing.

iii) Waves prolong the production: The comparison of winds and waves shows that at particular times the wave height takes twice the time (up to 12 hours) the wind speed take to reduce from a maximum value to its half. Thus, when winds drop to average values the corresponding waves remain at high values for a longer time.

> Providing a smoother power output:

iv) Less-variable power production: The three scenarios combining wave and wind (25:75, 50:50 and $75: 25$ ) have lower variability (10\% to $30 \%$ lower) than the one-technology scenario. This is proven by the fact that waves are more constant than winds

v) Reduce peaks in the production: the percentage of time the power production is above $80 \%$ of maximum power output is reduced in all of the combined scenarios. This provides an economic benefit on cable ratings. The low average and the infrequent peaks (down to $3 \%$ of the time) allow limiting the power output of the cable at a certain percentage (i.e. $80 \%$ of maximum power).

vi) Un-correlated power outputs: in this study the high correlation between winds and waves $(C C=0.8)$ indicate that the variation in the former is highly reflected in the variation of the latter. Nevertheless, the peaks in the power output are shifted. With this the spare capacity of the transmission lines would be reduced.

Beyond these findings, there are further identified advantages when combining wave and wind converters:

- They share common synergies in relation to marine policies, marine stakeholders, spatial constraints and environmental impact assessments. There are also synergies within offshore grids and the lack of available strong grid connection points onshore [16].

- They can share the costs for the cable laying, the infrastructure and maritime facilities, the installation and the maintenance activities. In hybrid solutions the structure cost may be shared too.
- The shielding effect of wave converters on wind turbines is useful for wind turbines' access.

- Waves are more predictable than winds. This is useful in the planning of operation and maintenance activities, storm periods, testing of control strategies and bids in electricity markets. Day-ahead electricity markets are related to the balancing costs. [17] shows wave power can be of the benefit to reducing the regulating costs of wind power, since waves are $23 \%$ more predictable than winds.

To finalise the discussion, there are three relevant limitations to this study. First, the findings are very dependent on the metocean conditions of the chosen location and on the study period. A wave climate dominated by swells will derive into uncorrelated waves and winds and into higher delays, which will result into less-correlated power outputs from the wind turbine and the wave converter.

The second limitation is that the analysis examines the power production of only one wave converter, whereas the sector is expected to be comprised by different wave technologies based on various principles. Moreover, although the wave converter is a full-scale device it is still a demonstrator. Indeed, the prototype of Wavestar cuts-off production at lower seastates than the commercial device or than other devices. On the other hand, wind turbines generally stop at 25 $\mathrm{m} / \mathrm{s}$, at the same wind speed considered in the study.

The third limitation relates to the scale of the investigation. If the analyses covered various wave and wind technologies, placed further offshore and spread over a wider area, the combined power output would be more constant, less-fluctuating and with a higher average. These are the result of reduced variability through regional diversification [16], of the different response of devices to metocean conditions and of the higher energy potentials available offshore.

\section{Conclusion}

This analysis is the first approach towards the study of real power productions of a full-scale wave converter and a full-scale wind turbine. The benefits of combining wave and wind power outputs have been examined.

The paper is based on real power productions from a wave converter (Wavestar) and a wind turbine (from the Nordic Folkecenter for Renewable Energy) located at Hanstholm, off the Northwest coast of Jutland, Denmark. Simultaneous production data from both technologies are available during a 5-month period.

Three main conclusions derive from the analyses of the metocean conditions at Hanstholm:

- $\quad$ There is high correlation between waves and winds.

- Waves have 2 to 3 hours average delay to winds, which can go up to 9 hours.

- Waves are less-variable than winds. 
Regarding power productions, results from this study are in line with the findings of the previous works and conclude the potential benefits of combining wave and wind technologies are:

- $\quad$ Providing a continuous power production by minimizing the zero-production and prolonging the power output.

- $\quad$ Providing a stable and smooth power output by reducing the peaks.

These findings ultimately suggest that combinations of wave and wind power spread over a wide area may be suitable for base-load generation provided the very low percentage of time the combined production drops to zero.

As a last remark it is important to note that this study evaluates wind turbines' production with the same assumptions and limitations wave power production's is analysed. Results are indicative to allow comparison and should not be read as the current level on wind turbine's performance.

Complementary work to this subject includes the study of the response of combinations of various wave converters and wind turbines. In [18] the benefits of combining different wave technologies were examined. Those results, along with the findings of this paper, suggest a number of technical and economic benefits when co-producing wind and wave power.

Beyond the scope of this investigation it has been largely agreed that harnessing different marine renewable energy sources works towards energy diversification and increasing security of supply [19].

\section{Nomenclature}

$\begin{array}{ll}C C & \text { cross-correlation coefficient [-] } \\ H_{m 0} & \text { significant wave height spectral estimate [m] } \\ H_{\text {max }} & \text { maximum individual wave height [m] } \\ \mu & \text { sample mean } \\ M W D_{\text {wind }} & \text { mean wind direction [deg] } \\ N & \text { number of samples } \\ \sigma & \text { standard deviation } \\ P_{\text {wave }} & \text { wave power per unit of crest width [kW/m] } \\ P_{\text {wind }} & \left.\text { wind power per unit of area [W/m }{ }^{2}\right] \\ t & \text { time lag [h] } \\ T_{02} & \text { zero crossing-period estimate [s] } \\ u_{\text {wind }} & \text { wind speed [m/s] } \\ U T C & \text { Coordinated Universal Time [date] } \\ U T M & \text { Universal Transverse Mercator [E, N] } \\ W S & \text { Wavestar } \\ W T & \text { wind turbine }\end{array}$

\section{Acknowledgements}

The authors are very grateful to the Nordic Folkecenter for Renewable Energy, Wave Star and Energinet Denmark (PSO project 10791) whose inputs and help to the study have been crucial. Environmental measurements at Hanstholm are courtesy of Kystdirektoratet, Denmark.

\section{References}

1. D. Vanucci, (2012) "Technologies state of the art". Technical report, Orecca Project.

2. F. Fusco, G. Nolan and J.V. Ringwood, (2010) "Variability reduction through optimal combination of wind/wave resources - An Irish case study", Energy 35,pg. 314-325.

3. E.D. Stoutenburg, N. Jenkins and M.Z. Jacobson, (2010), "Power Output Variability of Co-located offshore wind turbines and wave energy converters in California". Renewable Energy, 2010.

4. H.C Soerensen et.al. (2005) "Bølgekraftanlæg ved Horns Rev - Screening (Wave energy deployment at Horns Rev Wind Farm. Copenhagen" pg. 62 pp +2 appendixes, (partly in Danish). Technical report, Rambøll.

5. L. Cradden, et al., (2011) "Joint Exploitation of Wave and Offshore Wind Power". EWTEC 2011, Southampton, UK.

6. L. Marquis, M. Kramer, J.Kringelum, J.Fernández-Chozas, N.E. Helstrup Jensen, (2012), "Introduction of Wavestar wave energy converters at the Danish offshore wind power plant Horns Rev 2", ICOE 2012, Dublin, Ireland.

7. Ramboll, (1999). "Kortlægning af Bølgeenergiforhold i den Danske del af Nordsøen". Ramboll, Danish Hydraulic Institute and Danish Meteorological Insitute.

8. J. Cappelen and B. Jørgensen, 1999, "Observed Wind Speed and Direction in Denmark - with Climatological Standard Normals, 1961-90", Danish Meteorological Insitute. ISSN 1399-1388.

9. L. Margheritini (2012) "Review on available information on waves in the DanWEC area", Technical report, Dep. Civil Engineering Aalborg University.

10. krak [Online] www.map.krak.dk.

11. M. M. Kramer, L. Marquis and P. Frigaard, (2011) "Performance Evaluation of the Wavestar Prototype", EWTEC 2011 Proceedings, Southampton, UK.

12. Nordic Folkecenter for Renewable Energy. [Online] www.folkecenter.net.

13. R.H. Hansen and M.M. Kramer, (2011) "Modelling and Control of the Wavestar Prototype", EWTEC 2011 Proceedings, Southampton, UK.

14. E. Vidal Sanchez et. al., (2012) "Early performance assessment of the electrical output of Wavestar's prototype". ICOE 2012 Proceedings, Dublin, Ireland.

15. J. Fernández-Chozas, (2012), "Progress Report WP 7 Wave resource and forecast. Case study: "Predictability of wave parameters at Hanstholm, Denmark". Technical report. Wavetrain2 Project.

16. J. Fernandez-Chozas, H.C. Sørensen and M. Korpås, (2010) "Integration of wave and offshore wind energy in a European offshore grid". ISOPE 2010, Beijing, China.

17. J. Fernandez-Chozas, H.C. Sørensen and N.E. Helstrup Jensen (2012) "Economic benefit of Combining Wave and Wind Power Production in Electricity Markets". ICOE 2012 Proceedings, Dublin, Ireland.

18. J. Fernández-Chozas, et al, (2011) "Predictability of the Power Output of Three Wave Energy Technologies in the Danish North Sea", EWTEC 2011, Southampton, UK.

19. ECI (2005) "Variability of UK Marine Resources" Environmental Change Institute (ECI), University of Oxford, The Carbon Trust. 

Paper G: Predictability of the Power Output of Three Wave Energy Technologies in the Danish North Sea

\section{Published in}

Proceedings of the 9th European Wave and Tidal Energy Conference (EWTEC), 2011. 



\title{
Predictability of the Power Output of Three Wave Energy Technologies in the Danish North Sea
}

\author{
J. Fernández-Chozas ${ }^{1,2}$, N.E. Helstrup Jensen ${ }^{3}$, H.C. Sørensen ${ }^{1}$, J.P. Kofoed ${ }^{2}$ and A. Kabuth ${ }^{4}$ \\ ${ }^{1}$ Spok ApS \\ Blegdamsvej 4, 2200 Copenhagen (Denmark) \\ julia@spok.dk; consult@spok.dk \\ ${ }^{2}$ Aalborg University, Department of Civil Engineering \\ Sohngaardholmsvej 57, 9000 Aalborg (Denmark) \\ jfch@civil.aau.dk; jpk@civil.aau.dk \\ ${ }^{3}$ Energinet.dk \\ Fredericia (Denmark) \\ neh@energinet.dk \\ ${ }^{4}$ University of Copenhagen, Department of Geography and Geology \\ Copenhagen (Denmark) \\ akk@geo.ku.dk
}

\begin{abstract}
The paper addresses an important challenge ahead the integration of the electricity generated by wave energy conversion technologies into the electric grid. Particularly, it looks into the role of wave energy within day-ahead electricity markets. For that the predictability of the theoretical power outputs of three wave energy technologies in the Danish North Sea are examined. The simultaneous and co-located forecast and buoy-measured wave parameters at Hanstholm, Denmark, during a non-consecutive autumn and winter 3-month period form the basis of the investigation.

The objective of the study is to provide an indication on the accuracy of the forecast of i) wave parameters, ii) the normalised theoretical power productions from each of the selected technologies (Pelamis, Wave Dragon and Wavestar), and iii) the normalised theoretical power production of a combination of the three devices, during a very energetic time period.

Results show that for the $\mathbf{1 2}$ to $\mathbf{3 6}$ hours forecast horizon, the accuracy in the predictions (in terms of scatter index) of the significant wave height, zero crossing period and wave power are $22 \%, 11 \%$ and $74 \%$, respectively; and the accuracy in the predictions of the normalised theoretical power outputs of Pelamis, Wave Dragon and Wavestar are $37 \%$, 39\% and 54\%, respectively. The best compromise between forecast accuracy and mean power production results when considering the combined production of the three devices.
\end{abstract}

Keywords - Pelamis, Wave Dragon, Wavestar, Denmark, North Sea, Hanstholm, electricity markets, grid integration, power output, predictability, wave energy.

\section{INTRODUCTION}

As wave conversion technologies approach the commercial stage, it is necessary to investigate some of the issues ahead the integration of wave power into the electric grid. Above all, the paper focuses on the role of wave energy predictability within current electricity markets and their established rules [1].

Transmission System Operators (TSOs) have a major role in the functioning of electricity markets. They are the national bodies responsible for operating the grid and assuring the electricity demand is fulfilled. TSOs also publish the dayahead load forecast and plan grid operation before real-time, generally one-day in advance.

In the case of Denmark, the day-ahead electricity market closes at 12 noon. Thus, Energinet.dk as the Danish TSO requires the prediction of the following 12 to 36 hours electricity generation.

Electricity markets were first designed to accommodate conventional power generation. Besides hydropower, the contribution from renewable energy sources was scarce. Nowadays, as the percentage of renewable generation within the electricity mix increases [2], the uncertainty on the planned generation has also risen. The reason is that some of the most promising renewable energy sources such as wave power or wind power are not entirely predictable. This partial unpredictability is causing TSOs, producers and/or electricity users large expenditures to cope with the costs of the electric system balancing mechanisms [3].

Consequently, the paper examines waves predictability. It investigates the correlation of forecast and buoy-measured wave data as well as the correlation of forecast based and buoy-measured based theoretical power productions of three wave energy converters (WECs). 
The objective of this study is to provide some initial indication on the extent the power productions from WECs can be predicted 12 to 36 hours ahead for day-ahead markets. Moreover, waves forecasts play also a major role in the operation of WECs. It allows estimating and evaluating future power productions of a WEC, planning periods of tests and maintenance activities, and defining the storm protection strategy, if needed.

The study is based on available simultaneous and colocated forecast and buoy-measured wave data from Hanstholm site, Denmark, during a 5-month period. Also the power matrices of the selected devices form the basis of the study. The WECs chosen are Pelamis [4], an offshore floating heaving and pitching articulated converter, Wave Dragon [5], an offshore floating overtopping technology and Wavestar [6], a near-shore multi-point absorber.

This paper presents the first approach of the Danish TSO towards the study of predictability of WECs' power output. The novelties of this paper are first, examining wave parameters predictability; second, comparing forecast based and buoy-measured based theoretical power productions; third, considering the separated as well as the combined power outputs of three different WECs, and fourth, locating the study in the North Sea waters, an area of increased interest for wave energy [7].

The content of the paper is as follows:

i) Methodology of the study;

ii) Results of the study in terms of forecast accuracy of wave parameters and of forecast accuracy of theoretical power productions of the devices;

iii) Discussion of results and limitations of the study;

iv) Conclusions and further recommended work.

\section{MEthodOlOGY}

\section{A. Time period}

The analysis embraces three complete and non-consecutive months of wave measurements. The overall period covers from end of October 2010 to middle of February 2011; valid data is from $26 / 10$ to $20 / 11 / 2010$, from $11 / 12 / 2010$ to $13 / 01 / 2011$ and from 16/01 to 09/02/2011. All times and dates are expressed in the Coordinated Universal Time (UTC) system.

Generally at Hanstholm, January is the month with the most energetic wave climate, about 6 times more in terms of monthly mean wave power than the less energetic months, April, May, June and July [8]. Therefore, the time period considered in this study represents the most energetic season.

\section{B. Wave parameters}

Different environmental parameters such as wave height, wave period, wave direction, wind speed, wind direction, water depth or current speed fully characterize the environmental conditions at a particular location. However, as a first analysis, it is suitable to define the wave resource by the significant wave height $H_{s}$ and the zero crossing period $T_{z}$. These parameters have been approximated by $H_{m 0}$ and $T_{02}$, respectively [9].
The power output of a device is also influenced by some of these environmental features, the degree of influence depending on the working principle. An accurate performance evaluation requires the inclusion of several parameters although a WEC is also well defined by $H_{m 0}$ and $T_{02}$.

As a result, this study is based on records of $H_{m 0}$ and $T_{02}$. The maximum wave height $H_{\max }$ has also been included, since its evaluation can lead to useful results on buoy measurement errors and WECs' operation and survivability conditions.

\section{Study Location - Hanstholm}

The selected research site is Hanstholm, at the west coast of Jutland, Denmark, in the Danish part of the North Sea. The long term mean energy flux is estimated at $7 \mathrm{~kW} / \mathrm{m}$ at water depths of 17 meters coming primarily from West-North-West and West direction, and the 10 -year significant wave height is 6.6 meters [10-11]. The wave climate is characterized by a wind sea on top of a non-constant swell arriving from the northern part of the Atlantic Ocean.

The study refers to a point approx. $1.3 \mathrm{~km}$ offshore and at $17 \mathrm{~m}$ water depths (coordinates $8.5821^{\circ} \mathrm{E}, 57.1315^{\circ} \mathrm{N}$ ).

Fig. 1 depicts the wave conditions at this site throughout the study period, in terms of $H_{m 0}, T_{02}$ and the contribution of each sea state, in percentage, to the mean wave power in the study period. The scatter diagram is based on buoymeasurements of $H_{m 0}$ and $T_{02}$ over 4 months. It shows a dominant wind sea with a peak at $H_{m 0}=2.2 \mathrm{~m}$ and $T_{02}=5.3 \mathrm{~s}$ and a secondary peak at $H_{m 0}=4 \mathrm{~m}$ and $T_{02}=6.5 \mathrm{~s}$.

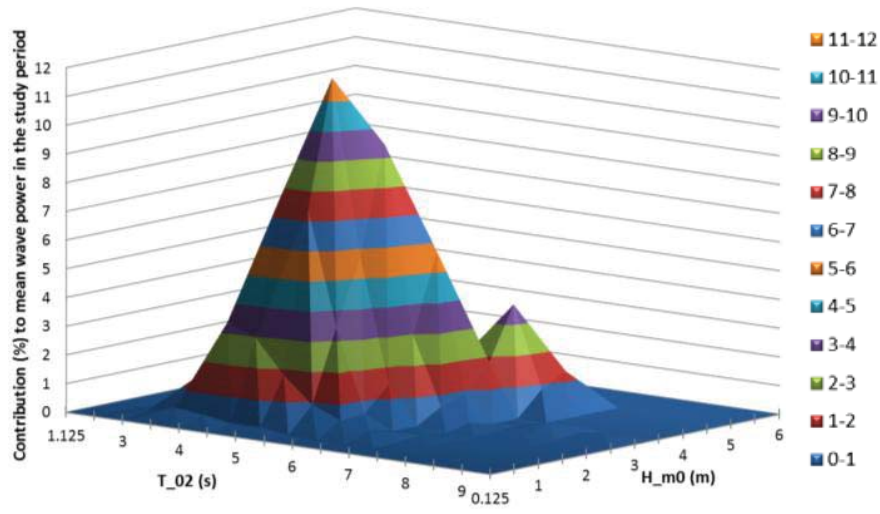

Fig. 1. Scatter Diagram of Hanstholm throughout the study period in terms of $H_{m 0}, T_{02}$ and contribution in percentage of each sea state to the mean wave power in the study period.

The wave conditions of the study period provide a valid representation of the long-term wave climate at Hanstholm. However, the mean wave power in this period, $8.9 \mathrm{~kW} / \mathrm{m}$, is higher than the mean annual wave power, $7 \mathrm{~kW} / \mathrm{m}$, due to the strong seasonal variability of the wave conditions at Hanstholm. Table I presents the probability of occurrence of the different wave parameters $H_{m 0}, H_{\max }, T_{02}$ and wave power $P_{\text {wave }}$ at Hanstholm in this period.

$P_{\text {wave }}$ (power per unit of crest width) has been calculated according to the wave power density formula: 


$$
P_{\text {wave }}(W / m)=\frac{1}{16} \cdot \rho \cdot g \cdot H_{m 0}^{2} \cdot C_{g}
$$

where $C_{g}$ is the group velocity, defined by:

$$
C_{g}(m / s)=\frac{1}{2} \cdot\left[1+\frac{2 k d}{\sinh (2 k d)}\right] \cdot \frac{g T_{e}}{2 \pi} \cdot \tanh (k d)
$$

$k\left(\mathrm{~m}^{-1}\right)=2 \pi / L$ is the wave number.

$L(\mathrm{~m})=g * T_{e}^{2} /(2 \pi) * \tanh (k d)$ is the wave length.

For Hanstholm the following values have been considered:

- $\rho_{\text {salt water }}=1027 \mathrm{~kg} / \mathrm{m}^{3}$ represents the water density considering an average water salinity concentration of 33 ppm and an average water temperature of $7^{\circ} \mathrm{C}$.

- $g=9.82 \mathrm{~m} / \mathrm{s}^{2}$ represents the gravity acceleration.

- $d=17.5 \mathrm{~m}$ represents the water depth.

- $T_{e}=1.2 T_{02}$, represents the energy period. The equality is true assuming a Pierson-Moskowitz spectral shape [10].

Hanstholm location has been selected due to several positive reasons, although it also brings some limitations.

On one hand, there are comprehensive data sets of simultaneous and co-located half-hourly forecast and buoymeasured wave data. Moreover, there is an increasing interest on the characteristics at this particular location. A new wave energy test site named DanWEC, the Danish Wave Energy Centre [12] has been established, where a 1:2 scale model of Wavestar and a 1:5 scale model of Dexa Wave [13] are currently deployed. These prototype tests can complement the present study by providing actual power production data.

On the other hand, the wave potential at Hanstholm is limited compared to other interesting deployment sites. In addition, the three WECs selected have not been optimized for the wave climate of the North Sea, characterised by shorter period waves than the Atlantic Ocean longer period swells.

\section{Forecast and Buoy-Measured Data}

Wave forecasts have been calculated by the spectral wave module of MIKE 21 from the Danish Hydraulic Institute, a model based on the wave action conservation equation. The service is part of The Water Forecast program [14]. The forecast reaches 5 days into the future, is calculated every 12 hours and provides half-hour records of the main wave parameters with 2 decimals resolution.

Environmental measurements have been provided by a Datawell Waverider buoy from The Danish Coastal Authority (i.e. Kystdirektoratet). Data consists of half-hour records of $H_{m 0}, T_{02}$ and $H_{\max }$ with 2 decimals resolution.

The data sets of forecast $H_{m 0}$ and $T_{02}$, and buoy-measured $H_{m 0}$ and $T_{02}$ have been used to develop time series of forecast $P_{\text {wave }}$ and buoy-measured $P_{\text {wave }}$, respectively.

A variable has been introduced into the study to compare the forecasts to the measured data. T-hour represents the forecast hour or the time horizon, in hours, before real time. In other words, it is the time-span, in hours, between the forecast is calculated and the buoy measures the corresponding parameters.

\section{E. Quality indices}

Verification of forecast data against buoy-measured data can be quantified by the quality indices described below, where $M O D$ corresponds to modeled, calculated or forecast data and $O B S$ to observed or buoy-measured data.

The Mean value of observations is defined as:

$$
\text { Mean }=\frac{1}{N} \sum_{i=1}^{N} O B S_{i}
$$

where $N$ corresponds to the number of valid observations.

The mean of difference or Bias represents an error that remains primarily constant in magnitude for all forecasts. It is defined as:

$$
\text { Bias }=\frac{1}{N} \sum_{i=1}^{N}(M O D-O B S)_{i}
$$

The mean of absolute difference or $M A E$ is defined as:

$$
M A E=\frac{1}{N} \sum_{i=1}^{N}(|M O D-O B S|)_{i}
$$

The root mean square of difference or RMSE is calculated assuming a normal distribution and represents the standard deviation of the mean (confidence level of $68.27 \%$ ). It is defined as:

$$
R M S E=\sqrt{\frac{1}{N} \sum_{i=1}^{N}(M O D-O B S)_{i}^{2}}
$$

The unbiased scatter index or $S I_{\text {unbiased }}$ is also calculated assuming a normal distribution. It provides a non-dimensional measure of the error and is defined as:

$$
S I_{\text {unbiased }}=\frac{\sqrt{\frac{1}{N} \sum_{i=1}^{N}(M O D-O B S-\text { Bias })_{i}^{2}}}{\text { Mean }}
$$

The correlation coefficient or $C C$ indicates the degree to which the variation in one parameter is reflected in the variation of the other parameter. It is a non-dimensional variable ranging from 0 to 1 , the former indicating no correlation between the two data sets and the latter perfect correlation. It is defined as:

$$
C C=\frac{\sum_{i=1}^{N}\left(M O D_{i}-\overline{M O D}\right)\left(O B S_{i}-\text { Mean }\right)}{\sqrt{\sum_{i=1}^{N}\left(M O D_{i}-\overline{M O D}\right)^{2} \sum_{i=1}^{N}\left(O B S_{i}-\text { Mean }\right)^{2}}}
$$




\section{F. Wave converters - Pelamis, Wave Dragon and Wavestar}

To take advantage of the variability of the wave resource along the coasts it is generally expected that several wave conversion solutions remain attractive for the market. Moreover, to extend the scope of this study towards different WECs responses to the wave climate as well as to consider the differences in the operating conditions among the existing WECs, three different technologies have been selected for the study. These are:

1) Pelamis, a floating heaving and pitching converter.

2) Wave Dragon, an offshore floating overtopping device.

3) Wavestar, a near-shore multi-point absorber.

Power productions $\left(P_{\text {prod }}\right)$ of the three WECs have been modeled from forecast and buoy-measured wave data. This process has required the application of a transfer function, i.e. a power matrix that represents the performance of the WEC at Hanstholm.

In this way, the records of forecast $H_{m 0}$ and $T_{02}$, and buoymeasured $H_{m 0}$ and $T_{02}$ along with the power matrices have been used to model time series of forecast $P_{\text {prod }}$ and buoymeasured $P_{\text {prod }}$, respectively.
Whereas Wavestar provided a power matrix particularly developed for Hanstholm wave climate, those for Pelamis and Wave Dragon have been down-scaled from [15] to match the predominant sea states (Table I) and to optimize their $P_{\text {prod }}$ in the study period.

Table II presents the scale factor, main dimensions and the peak power of the three devices, as well as the design sea states i.e. $H_{m 0}$ and $T_{02}$ where they reach full production, and the operating limits of each device (minimum and maximum $H_{m 0}$ and $T_{02}$ ). Table II shows Wavestar cuts-off production in lower sea states than Pelamis or Wave Dragon.

Fig. 2 presents a comparison between the probability of occurrence of different sea conditions (defined by the contribution in percentage of $H_{m 0}$ and $T_{02}$ to the mean wave power) and power production's dependency on these conditions. Fig. 2 shows that Wavestar has the best correlation between maximum $P_{\text {prod }}$ and probability of occurrence of the wave parameter $T_{02}$.

Throughout the study the power productions of the three WECs are given as percentages of peak power, i.e. as normalized or non-dimensional values.

TABLE I

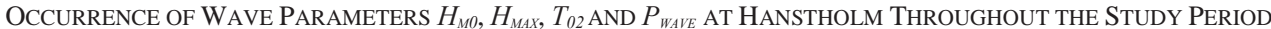

\begin{tabular}{|l|cc|cccc|cc|}
\hline & Mean & Max & $<\mathbf{1 \%}$ time & $<\mathbf{1 0} \%$ time & $<\mathbf{1 0} \%$ time & $<\mathbf{1 \%}$ time & Days & $\mathbf{N}$ \\
\hline $\boldsymbol{H}_{\boldsymbol{m} 0}(\mathrm{~m})$ & 1.4 & 4.7 & $\leq 0.4$ & $\leq 0.7$ & $\geq 2.3$ & $\geq 3.7$ & 87 & 4157 \\
$\boldsymbol{H}_{\text {max }}(\mathrm{m})$ & 2.4 & 8.5 & $\leq 0.7$ & $\leq 1.1$ & $\geq 3.8$ & $\geq 6.0$ & 87 & 4157 \\
$\boldsymbol{T}_{\mathbf{0 2}}(\mathrm{s})$ & 4.7 & 8.8 & $\leq 3.1$ & $\leq 3.8$ & $\geq 5.7$ & $\geq 6.7$ & 87 & 4157 \\
$\boldsymbol{P}_{\text {wave }}(\mathrm{kW} / \mathrm{m})$ & 8.9 & 98.6 & $\leq 0.4$ & $\leq 1.3$ & $\geq 19.6$ & $\geq 58.4$ & 87 & 4157 \\
\hline
\end{tabular}

TABLE II

Scaling RAtio, Dimensions, Peak Power and Design And Operating SEA States for Pelamis, WaVe Dragon and WaVestar at Hanstholm

\begin{tabular}{|c|c|c|c|c|c|c|c|c|c|}
\hline & $\begin{array}{c}\text { Ratio* }^{*} \\
(\lambda)\end{array}$ & $\begin{array}{l}\text { Main dimensions* } \\
\text { (m) }\end{array}$ & $\begin{array}{c}\text { Peak power } \\
(\mathrm{kW})\end{array}$ & $\begin{array}{c}\text { Design } \\
\mathrm{H}_{\mathrm{m} 0}(\mathrm{~m})\end{array}$ & $\begin{array}{l}\text { Design } \\
T_{02}(\mathrm{~s})\end{array}$ & $\begin{array}{c}\mathbf{H}_{\mathrm{m0}} \mathbf{m i n} \\
(\mathrm{m})\end{array}$ & $\begin{array}{c}\mathbf{H}_{\mathrm{m} 0} \mathbf{m a x} \\
(\mathrm{m})\end{array}$ & $\begin{array}{l}\mathbf{T}_{02} \min \\
(\mathrm{s})\end{array}$ & $\begin{array}{c}\mathbf{T}_{\mathbf{0 2}} \max \\
\text { (s) }\end{array}$ \\
\hline Pelamis & $1: 1.76$ & $\varnothing=2.3$ & 100 & 3.1 & 4.6 & 0.4 & 5 & 2.5 & 10 \\
\hline Wave Dragon & $1: 1.76$ & $w=170$ & 1000 & 3 & 5 & 0.4 & 5 & 2.6 & 10 \\
\hline Wavestar & $1: 2$ & $\varnothing=5$ & 600 & 2.5 & 3.4 & 0.5 & 3 & 2 & 13 \\
\hline
\end{tabular}

* Pelamis and Wave Dragon scaling ratios are relative to the Atlantic Ocean and Wavestar's to the North Sea. $l$ represents length, $w$ width and $\varnothing$ diameter.

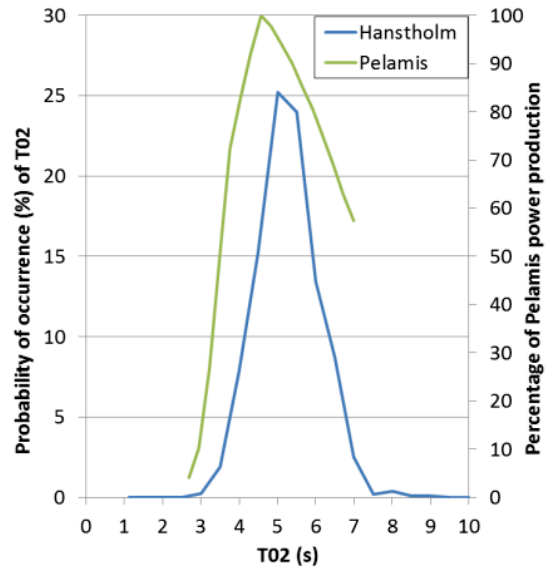

(a)

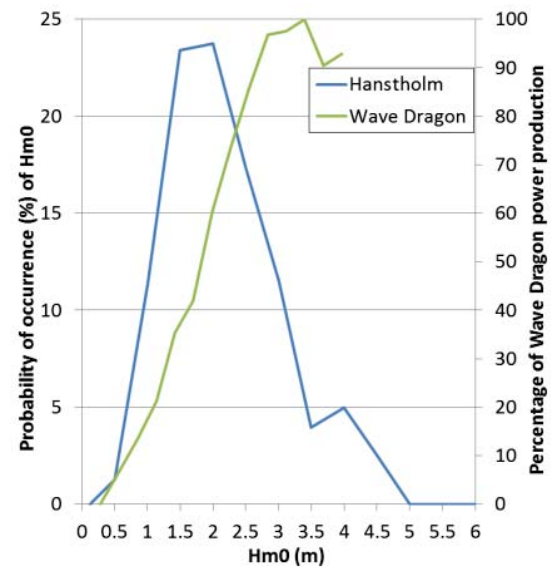

(b)

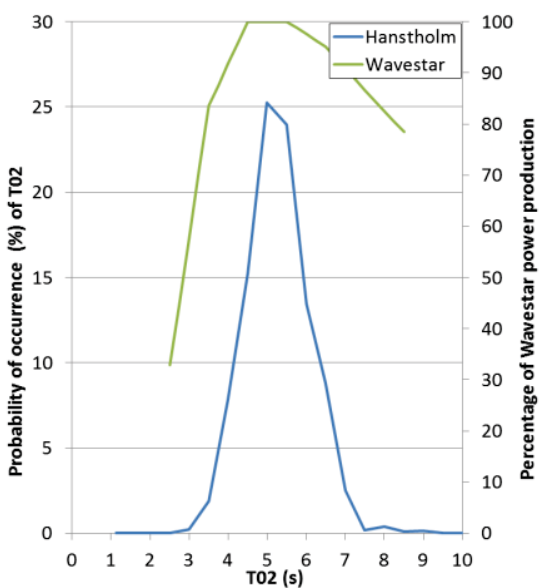

(c)

Fig. 2. Contribution, in percentage, of $T_{02}$ and $H_{m 0}$ to the mean wave power at Hanstholm throughout the study period and normalised power productions of Pelamis (a), Wave Dragon (b) and Wavestar (c) in terms of $T_{02}$ (a)-(c) and $H_{m 0}$ (b). Wave Dragon performance is more dependent on the variations of the wave height whereas Pelamis and Wavestar performances are more dependent on the period. 


\section{G. Further Assumptions}

- The current delay in the forecast has been disregarded. At present, due to the research purpose of this study, the model delivers the forecast with 19-hour delay. In real implementation of forecast data this delay can be reduced.

- Errors in the buoy acquisition system have been disregarded.

- WECs' power production dependency on wave directionality has been neglected.

- Real power production data from the half scale Wavestar operating at Hanstholm have not been used in the study. All stated power productions are theoretical and derived from the power matrices.

\section{RESULTS}

To investigate forecast accuracy of WECs' theoretical power productions the predictability of the typical wave parameters is examined first.

Consequently, this section presents two sets of results. First, the error statistics obtained from the comparison of forecast $H_{m 0}, H_{\max }, T_{02}$ and $P_{\text {wave }}$ and buoy-measured $H_{m 0}$, $H_{\max }, T_{02}$ and $P_{\text {wave }}$. Second, the error statistics obtained from the comparison of $P_{\text {prod }}$ based on forecast data and $P_{\text {prod }}$ based on buoy-measurements of each WEC and of a combination of them.

\section{A. Predictability of Wave Parameters}

Table III to Table VI show the quality indices, as defined in section II-D, for $H_{m 0}, H_{\max }, T_{02}$ and $P_{\text {wave }}$, respectively. Forecast accuracy is evaluated for T-hours embracing 0 to 1 hour, 12 to 24 hours, 24 to 36 hours, 84 to 96 hours and 0 to 144 hours.

TABLE III

$H_{M 0}$ QuAlity Indices Throughout THE STUdy PERIOD

\begin{tabular}{|lc|cccccc|c|}
\hline \multicolumn{2}{|c|}{$\begin{array}{c}\text { T } \text { hour } \\
(\mathrm{h})\end{array}$} & $\begin{array}{c}\text { Mean } \\
(\mathrm{m})\end{array}$ & $\begin{array}{c}\text { Bias } \\
(\mathrm{m})\end{array}$ & $\begin{array}{c}\text { MAE } \\
(\mathrm{m})\end{array}$ & $\begin{array}{c}\text { RMSE } \\
(\mathrm{m})\end{array}$ & SI $_{\text {unbiased }}$ & CC & N \\
\hline$\geq 0$ & $<12$ & 1.5 & 0.19 & 0.25 & 0.32 & $18 \%$ & 0.94 & 4015 \\
$\geq 12$ & $<24$ & 1.5 & 0.19 & 0.27 & 0.34 & $20 \%$ & 0.91 & 3991 \\
$\geq 24$ & $<36$ & 1.5 & 0.17 & 0.29 & 0.37 & $22 \%$ & 0.89 & 3967 \\
$\geq 36$ & $<48$ & 1.5 & 0.18 & 0.30 & 0.40 & $25 \%$ & 0.86 & 3943 \\
$\geq 84$ & $<96$ & 1.5 & 0.18 & 0.40 & 0.54 & $35 \%$ & 0.72 & 3847 \\
\hline$\geq \mathbf{0}$ & $<\mathbf{1 4 4}$ & $\mathbf{1 . 5}$ & $\mathbf{0 . 2 0}$ & $\mathbf{0 . 3 6}$ & $\mathbf{0 . 4 8}$ & $\mathbf{3 0 \%}$ & $\mathbf{0 . 7 9}$ & 41527 \\
\hline
\end{tabular}

TABLE IV

$H_{\text {MAX }}$ QUALITY INDICES THROUGHOUT THE STUDY PERIOD

\begin{tabular}{|c|c|c|c|c|c|c|c|}
\hline $\begin{array}{c}\text { T - hour } \\
\text { (h) }\end{array}$ & $\begin{array}{c}\text { Mean } \\
(\mathrm{m})\end{array}$ & $\begin{array}{c}\text { Bias } \\
(\mathrm{m})\end{array}$ & $\begin{array}{c}\text { MAE } \\
(\mathrm{m})\end{array}$ & $\begin{array}{c}\text { RMSE } \\
\text { (m) }\end{array}$ & SI unbiased & $\mathrm{CC}$ & $\mathrm{N}$ \\
\hline$\geq 0<12$ & 2.4 & 0.82 & 0.85 & 0.99 & $23 \%$ & 0.92 & 4015 \\
\hline$\geq 12<24$ & 2.4 & 0.82 & 0.87 & 1.02 & $25 \%$ & 0.90 & 3991 \\
\hline$\geq 24<36$ & 2.4 & 0.80 & 0.86 & 1.04 & $28 \%$ & 0.87 & 3967 \\
\hline$\geq 36<48$ & 2.4 & 0.82 & 0.89 & 1.08 & $30 \%$ & 0.85 & 3943 \\
\hline$\geq 84<96$ & 2.4 & 0.80 & 1.00 & 1.25 & $40 \%$ & 0.69 & 3847 \\
\hline$\geq 0<144$ & 2.4 & 0.85 & 0.97 & 1.20 & $36 \%$ & 0.77 & 41527 \\
\hline
\end{tabular}

TABLE V

$T_{02}$ QuAlity Indices Throughout THE STUdy PERIOD

\begin{tabular}{|c|c|c|c|c|c|c|c|}
\hline $\begin{array}{c}\text { T - hour } \\
\text { (h) }\end{array}$ & $\begin{array}{c}\text { Mean } \\
\text { (s) }\end{array}$ & $\begin{array}{c}\text { Bias } \\
\text { (s) }\end{array}$ & $\begin{array}{c}\text { MAE } \\
\text { (s) }\end{array}$ & $\begin{array}{c}\text { RMSE } \\
\text { (s) }\end{array}$ & SI unbiased & CC & $\mathrm{N}$ \\
\hline$\geq 0<12$ & 4.7 & -0.17 & 0.36 & 0.49 & $10 \%$ & 0.81 & 4015 \\
\hline$\geq 12<24$ & 4.7 & -0.16 & 0.38 & 0.51 & $10 \%$ & 0.80 & 3991 \\
\hline$\geq 24<36$ & 4.7 & -0.17 & 0.42 & 0.55 & $11 \%$ & 0.77 & 3967 \\
\hline$\geq 36<48$ & 4.7 & -0.17 & 0.43 & 0.56 & $11 \%$ & 0.75 & 3943 \\
\hline$\geq 84<96$ & 4.7 & -0.20 & 0.51 & 0.68 & $14 \%$ & 0.62 & 3847 \\
\hline$\geq 0<144$ & 4.7 & -0.18 & 0.47 & 0.62 & $13 \%$ & 0.68 & 41527 \\
\hline
\end{tabular}

TABLE VI

$P_{\text {WAVE }}$ QuAlity Indices Throughout THE STUdy PERIOD

\begin{tabular}{|cc|cccccc|}
\hline $\begin{array}{c}\text { T - hour } \\
(\mathrm{h})\end{array}$ & $\begin{array}{c}\text { Mean } \\
(\mathrm{kW} / \mathrm{m})\end{array}$ & $\begin{array}{c}\text { Bias } \\
(\mathrm{kW} / \mathrm{m})\end{array}$ & $\begin{array}{c}\text { MAE } \\
(\mathrm{kW} / \mathrm{m})\end{array}$ & $\begin{array}{c}\text { RMSE } \\
(\mathrm{kW} / \mathrm{m})\end{array}$ & SI $_{\text {unbiased }}$ & $\mathbf{C C}$ \\
\hline$\geq 0$ & $<12$ & 8.8 & 1.96 & 3.15 & 6.42 & $69 \%$ & 0.91 \\
$\geq 12$ & $<24$ & 8.8 & 1.94 & 3.33 & 6.28 & $68 \%$ & 0.90 \\
$\geq 24$ & $<36$ & 8.9 & 1.62 & 3.59 & 6.70 & $73 \%$ & 0.86 \\
$\geq 36$ & $<48$ & 8.9 & 1.58 & 3.88 & 7.26 & $80 \%$ & 0.82 \\
$\geq 84$ & $<96$ & 8.9 & 1.16 & 5.13 & 9.68 & $108 \%$ & 0.64 \\
\hline$\geq \mathbf{0}<\mathbf{1 4 4}$ & $\mathbf{8 . 9}$ & $\mathbf{1 . 8 1}$ & $\mathbf{4 . 6 2}$ & $\mathbf{8 . 8 2}$ & $\mathbf{9 7 \%}$ & $\mathbf{0 . 7 5}$ \\
\hline
\end{tabular}

The following figures present a comparison between forecast $H_{m 0}$ and buoy-measured $H_{m 0}$ during the most energetic month (11/12/2010 to 11/01/2011). Fig. 3 illustrates the forecast for a T-hour of 12 hours, Fig. 4 for a T-hour of 36 hours and Fig. 5 for a T-hour of 108 hours. Note the big waves passing Hanstholm on 12/12/2010 and on New Year's Eve.

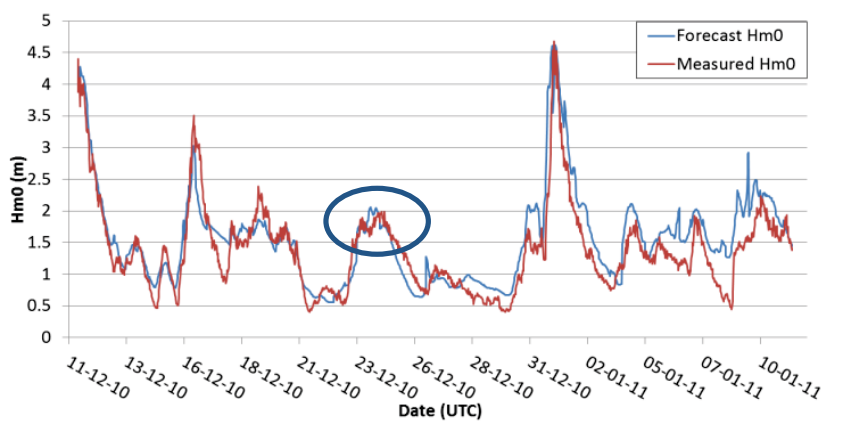

Fig. 3. $H_{m 0}$ comparison of measured (in red) and 12-hour forecast (in blue)

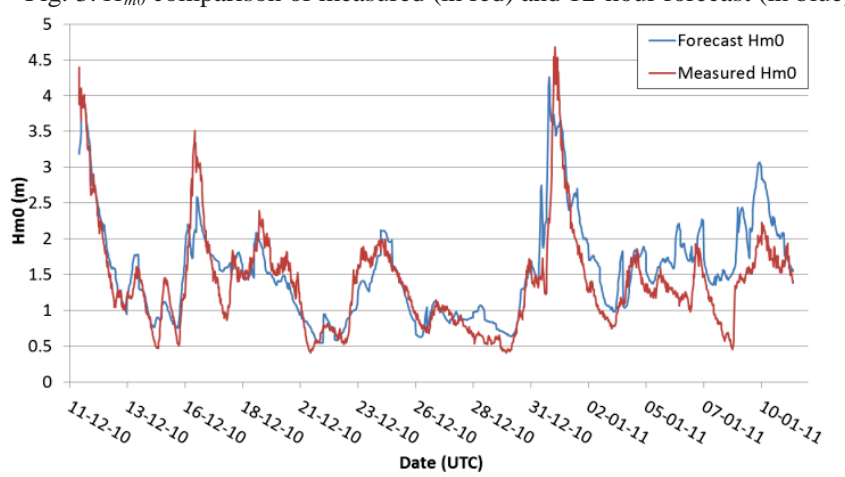

Fig. 4. $H_{m 0}$ comparison of measured (in red) and 36-hour forecast (in blue) 


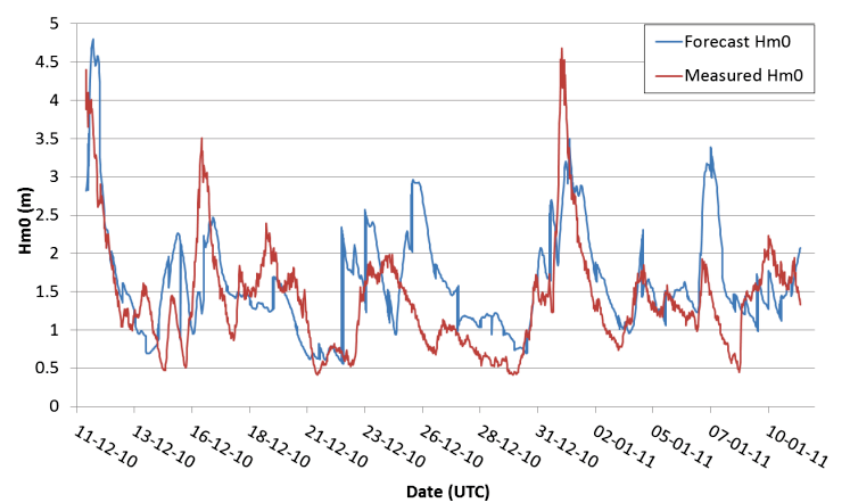

Fig. 5. $H_{m 0}$ comparison of measured (in red) and 108-hour forecast (in blue)

Fig. 6 presents a comparison between forecast $T_{02}$ and buoy-measured $T_{02}$ and Fig. 7 between forecast based $P_{\text {wave }}$ and buoy-measured based $P_{\text {wave }}$, during the same month (11/12/2010 to 14/01/2011) for a T-hour of 12 hours.

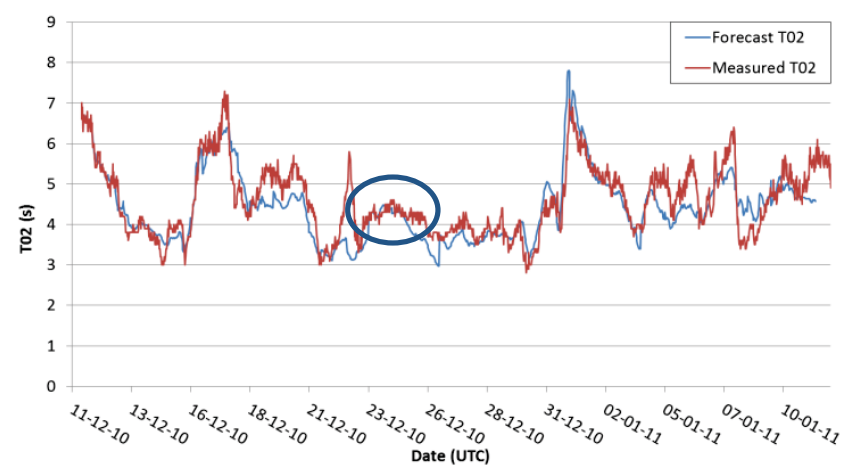

Fig. 6. $T_{02}$ comparison of measured (in red) and 12-hour forecast (in blue)

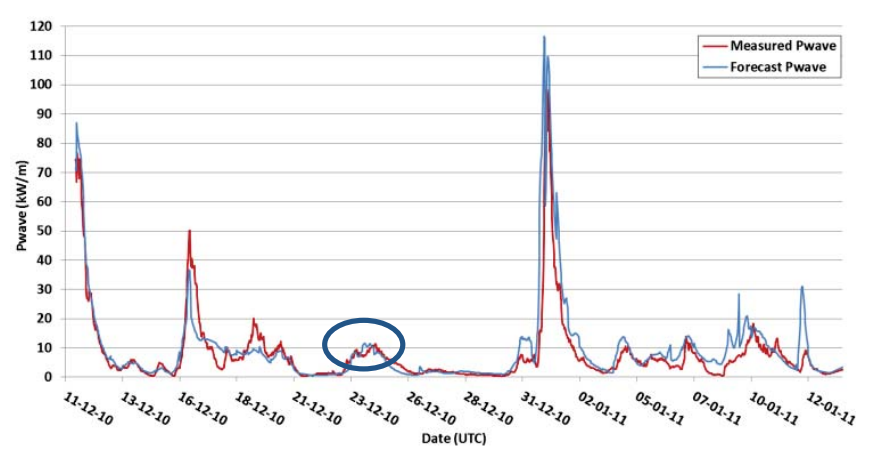

Fig. 7. $P_{\text {wave }}$ comparison of measured (in red) and 12-hour forecast (in blue)

The circles in Fig. 3, Fig. 6 and Fig. 7 show the 3-day period selected in the next section to illustrate the evolution of the power productions for the three devices. These days provide a good representation of the typical operating conditions at the research site.

\section{B. Predictability of WECS' Power Production}

To evaluate power productions predictability normalized quality indices are used, which are normalized in terms of peak power (Table II). They are indicated by an " $N$ " at the beginning of the parameter (i.e. NBias, NMAE, NRMSE).

Table VII presents the quality indices evaluating $P_{\text {prod }}$ based on forecast data and $P_{\text {prod }}$ based on buoy-measurements for each of the selected WECs and for the combination of the three of them. The 12 to 36 hours forecast has been considered. The 'combined' option reflects the contribution of one normalised unit of each technology.

TABLE VII

Pelamis, Wave Dragon, WAVESTAR ANd Combined Normalised $P_{P R O D}$ Quality Indices Throughout the Study Period

\begin{tabular}{|l|ccccc|c|}
\hline & NMean & NBias & NMAE & NRMSE & SI $_{\text {unbiased }}$ & $\mathrm{N}$ \\
\hline Pelamis & 0.33 & 0.08 & 0.11 & 0.14 & 0.37 & 11901 \\
Wave & 0.33 & 0.04 & 0.09 & 0.13 & 0.39 & 11901 \\
Dragon & & 0.04 & 0.15 & 0.24 & 0.54 & 11901 \\
Wavestar & 0.44 & 0.04 & 0.11 & 0.14 & 0.36 & 11901 \\
\hline Combined & 0.37 & 0.05 & 0.11 & & &
\end{tabular}

Fig. 8 to Fig. 10 give a graphical representation of the differences between forecast $P_{\text {prod }}$ and theoretical $P_{\text {prod }}$ of Pelamis, Wave Dragon, Wavestar and the combination of the three devices. The graphs cover a 3-day period (23/12 to 25/12/2010). Fig. 8 depicts the 12 hours forecast and Fig. 9 the 36 hours forecast for the power production of Pelamis, Wave Dragon and Wavestar.

Fig. 10 illustrates the differences of the 12, 24 and 36 hours $P_{\text {prod }}$ forecast to the theoretical $P_{\text {prod }}$ for the combination of the three devices.

For comparison Fig. 11 shows the variation of the 12 hours forecast $H_{m 0}, T_{02}$ and $P_{\text {wave }}$ and buoy-measured $H_{m 0}, T_{02}$ and $P_{\text {wave }}$ over this 3-day period. Note that buoy-measured $H_{m 0}, T_{02}$ and $P_{\text {wave }}$ vary around their mean values, as shown in Table I.

\section{DISCUSSION}

Due to the scope of the paper only the results for a $T$-hour varying from 12 to 36 hours are discussed.

\section{A. Location}

The results presented in the study on predictability of wave parameters and power productions are dependent on the wave climate of the chosen location. A wave climate characterized by swells will significantly improve the accuracy in the predictions, since swells are more regular compared to wind seas. In a wind sea, where the correspondence between waves and wind patterns reveals to be high [16], the short-term forecast errors in wind are more reflected in wave predictions.

\section{B. Predictability of Wave Parameters}

1) Significant wave height spectral estimate $H_{m 0}$ : Table III shows the error statistics obtained from the comparison of forecast $H_{m 0}$ and buoy-measured $H_{m 0}$ for different T-hours.

The positive Bias indicates a prevalent trend where the forecast overestimates the buoy-measured values. Then, an $M A E$ larger in magnitude than the Bias denotes that also the opposite trend is found, i.e. the forecast also underestimates the buoy-measured values, particularly as T-hour increases (Fig. 3 to Fig. 5).

$R M S E$ points out that $68 \%$ of the forecasts are within \pm 0.35 meters of the Mean measured value of $H_{m 0}$, i.e. 1.5 meters. 


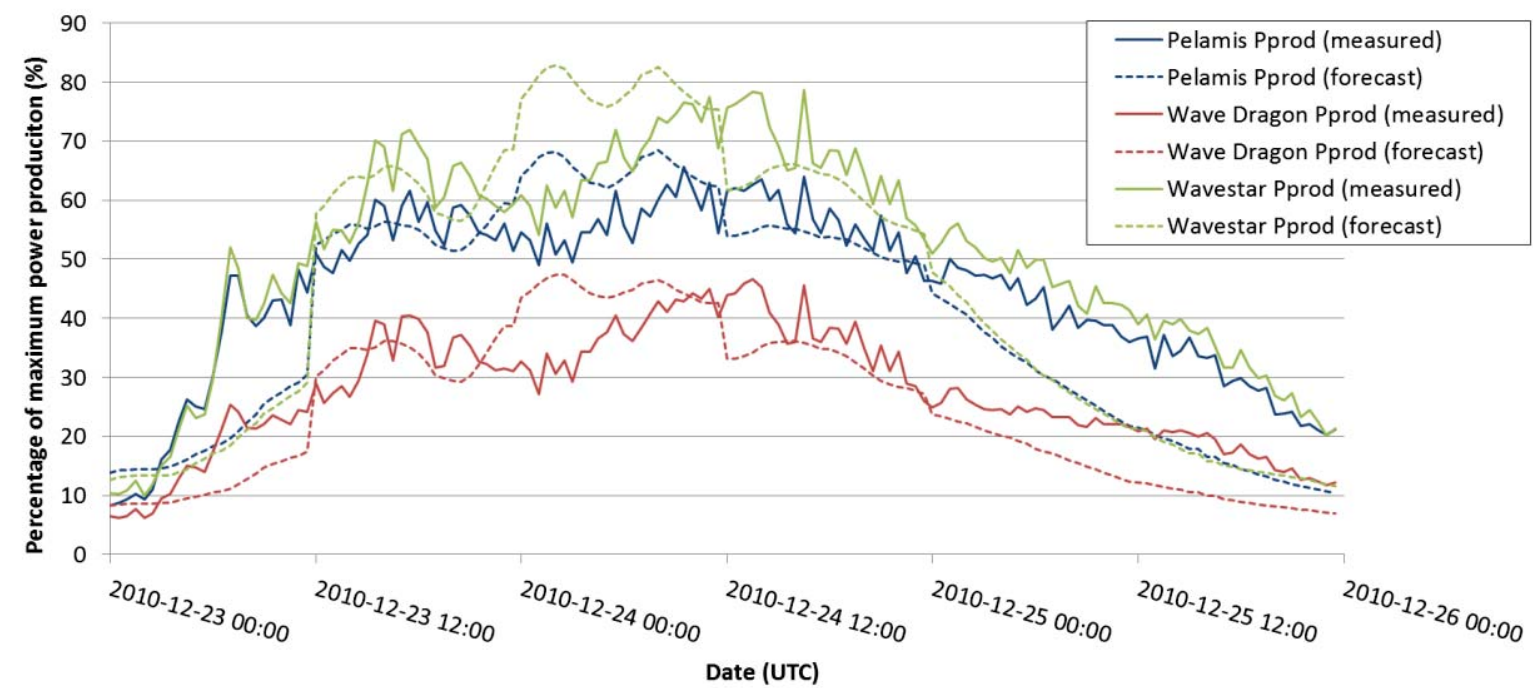

Fig. 8. $P_{\text {prod }}$ based on buoy-measurements (solid lines) and $P_{\text {prod }}$ based on forecast data (dashed lines), in terms of percentage of peak power of Pelamis (in blue), Wave Dragon (in red) and Wavestar (in green) for a T-hour of 12 hours over a 3-day period (23/12 to 25/12/2010).

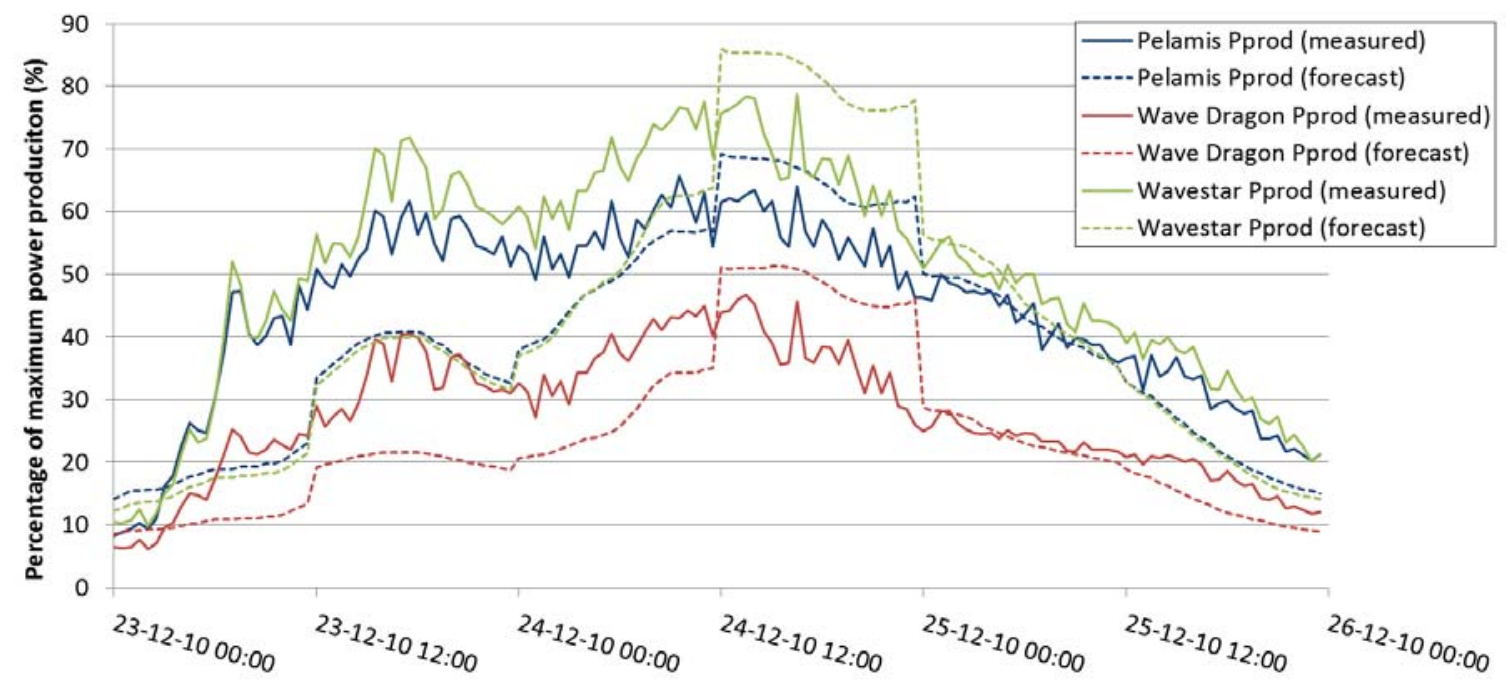

Fig. 9. $P_{\text {prod }}$ based on buoy-measurements (solid lines) and $P_{\text {prod }}$ based on forecast data (dashed lines), in terms of percentage of peak power of Pelamis (in blue), Wave Dragon (in red) and Wavestar (in green) for $T$-hour of 36 hours over a 3-day period (23/12 to 25/12/2010).

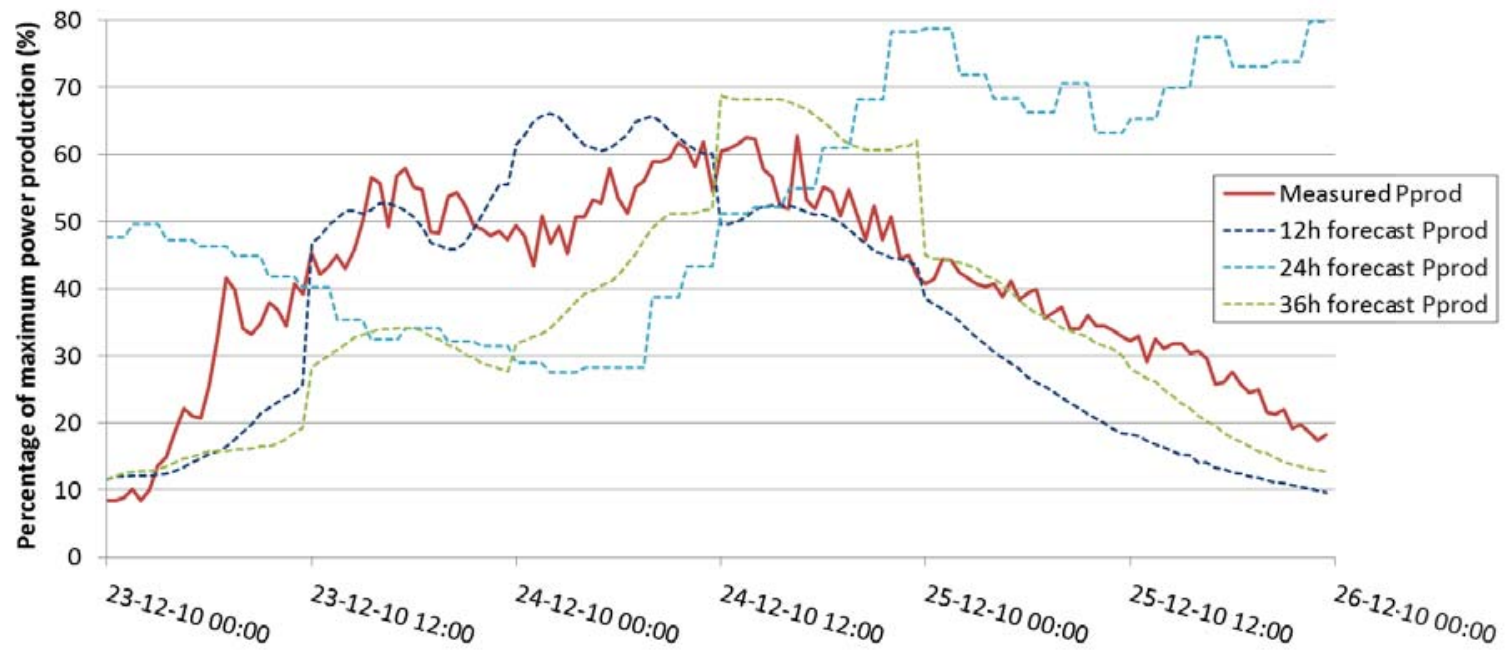

Fig 10. $P_{\text {prod }}$ based on buoy-measurements (solid line) and $P_{\text {prod }}$ based on forecast data (dashed lines), in terms of percentage of peak power of the combination of the three WECs, for a T-hour of 12 hours (dark blue), 24 hours (light blue) and 36 hours (green) over a 3-day period (23/12 to 25/12/2010). 
A 22\% SI $I_{\text {unbiased }}$ illustrates an acceptable dispersion of the distribution. Then, a CC of 0.89 suggests a high correlation between the two sets of compared values.

In brief, results show that the agreement between $H_{m 0}$ forecasts and $H_{m 0}$ buoy-measured data is good.

2) Maximum wave height spectral estimate $H_{\max }$ : Table IV shows the error statistics obtained from the comparison of forecast $H_{\max }$ and buoy-measured $H_{\max }$ for different T-hours.

Errors for $H_{\max }$ forecasting are always higher than for $H_{m 0}$, although the quality indices follow the same trend. These errors may be provided by the buoy-measured data. A known disadvantage of the spherical buoys (e.g. Datawell Waverider buoy) is that due to the single line mooring, it circles around the crests of steep waves and thus, does not reach the maxima in the surface elevation [17].

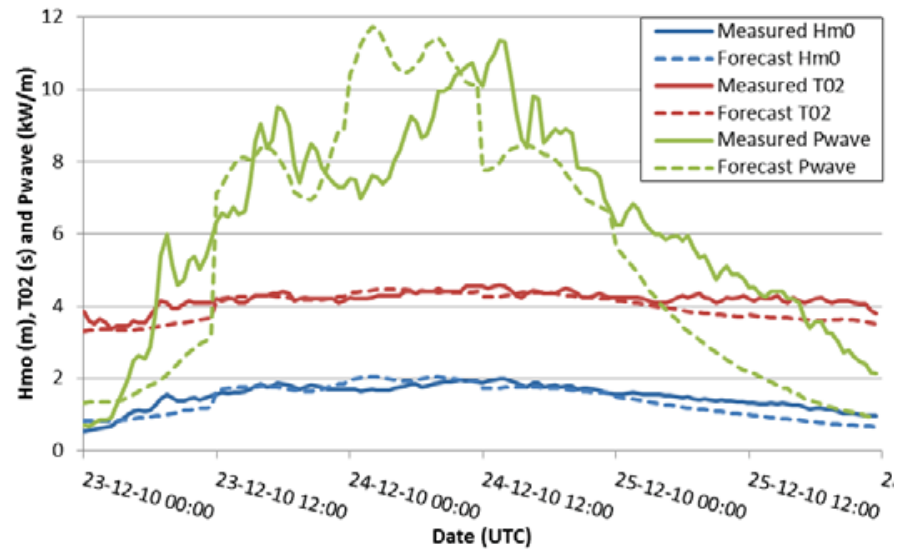

Fig. 11 Evolution of buoy-measured (solid line) and 12-hour forecast (dashed line) of $H_{m 0}$ (blue), $T_{02}$ (red) and $P_{\text {wave }}$ (green) over 23/12 to 25/12/2010.

3) Zero crossing period spectral estimate $T_{02}$ : Table $\mathrm{V}$ shows the error statistics obtained from the comparison of forecast $T_{02}$ and buoy-measured $T_{02}$ for different T-hours.

The negative Bias indicates a prevalent trend where the forecast underestimates the buoy-measured value. A $M A E$ more than twice the Bias denotes that the forecast also overestimates the measured values. However, both the Bias and the $M A E$ are small in magnitude compared to the Mean.

$R M S E$ indicates that $68 \%$ of the forecasts are within \pm 0.55 seconds of the Mean measured value of $T_{02}$, i.e. 4.7 seconds.

The graphical comparison (Fig. 6) illustrates the small and very acceptable dispersion of the distribution, which lies within small bounds ( $S I_{\text {unbiased }}$ of $\left.11 \%\right)$.

The correlation between forecast and buoy-measured values $(C C=0.77)$ is lower than for $H_{m 0}$. This can be clearly seen in Fig. 6, where the pattern tendencies of the buoymeasured values are not strictly followed by the forecasts.

In summary, results show that $T_{02}$ forecast and $T_{02}$ buoymeasurements are in very good agreement except for CC.

4) Wave Power $P_{\text {wave }}$ : Table VI shows the error statistics obtained from the comparison of forecast $P_{\text {wave }}$ and buoymeasured $P_{\text {wave }}$ for different T-hours.
In this case, it is important to note the relation of $P_{\text {wave }}$ with $H_{m 0}$ and $T_{02}$. The errors in $H_{m 0}$ get raised to the power of two and in $T_{02}$ to the power of one.

The positive Bias reveals the strongest influence of $H_{m 0}$. It indicates that the forecast overestimates the derived buoymeasured value. As happens also in the case of $H_{m 0}$ and $T_{02}$, $M A E$ is larger than the Bias, so the forecast also underestimates the buoy-measured values. Both Bias and $M A E$ are quite large in magnitude compared to the Mean.

$R M S E$ indicates that $68 \%$ of the forecasts are within \pm 6.8 $\mathrm{kW} / \mathrm{m}$ of the Mean measured value of $P_{\text {wave }}$, i.e. $8.9 \mathrm{~kW} / \mathrm{m}$. This value suggests an inaccurate forecast; however, it is due to the peaks in $P_{\text {wave }}$, which can reach up to $99 \mathrm{~kW} / \mathrm{m}$ at certain periods (Table I and Fig. 7). Similarly, the $S I_{\text {unbiased }}$ shows a $75 \%$ dispersion of the distribution.

On the contrary, the correlation $(C C=0.86)$ between forecast and buoy-measured values is high, induced by the high $C C$ of $H_{m 0}$.

Fig. 7 illustrates the peaks in $P_{\text {wave }}$ in comparison to the Mean value of $8.9 \mathrm{~kW} / \mathrm{m}$. This difference explains the high value of $R M S E$ and $S I_{\text {unbiased }}$.

In short, results show that $P_{\text {wave }}$ forecast derived and $P_{\text {wave }}$ buoy-measured derived are in good agreement for small $P_{\text {wave }}$ values but not for larger ones.

As a summary, wave parameters predictability can be considered accurate for $H_{m 0}$ and $T_{02}$, acceptable for $H_{\max }$ and for values of $P_{\text {wave }}$ close to the mean, and not very accurate for larger $P_{\text {wave }}$ values.

\section{Predictability of WECs' Power Production}

1) Pelamis, Wave Dragon and Wavestar: Table VII shows the error statistics obtained from the comparison of normalised $P_{\text {prod }}$ based on forecast data and normalised $P_{\text {prod }}$ based on buoy-measurements for the three devices.

The figures illustrate similar trends in the quality indices of each device. However, for comparison note the normalised mean production of Wavestar is approx. 7\% larger than that of Pelamis and Wave Dragon.

Forecast accuracy of Pelamis and Wave Dragon production are comparable. The main difference is that whereas the $S I_{\text {unbiased }}$ of Pelamis (37\%) is better than for Wave Dragon (39\%), the NMAE favours Wave Dragon (9\% versus 11\% for Pelamis).

Then, Wavestar presents larger standard deviation $(N R M S E=24 \%)$ and dispersion $\left(S I_{\text {unbiased }}=54 \%\right)$, although the normalised mean production reaches $44 \%$ of peak power. Hence, NMAE (15\%) is comparable to the others.

In the three cases, the positive NBias suggests an influence of $H_{m 0}$ forecast errors on the power production calculations. The $N M A E$ also indicates the influence from $T_{02}$ forecast errors, particularly for Wavestar.

For the three devices, NRMSE reveals to be high, especially compared to the other error statistics. The explanation is similar as for $P_{\text {wave }}$, it is due to the influence of the peaks in the power production during fast changing wave conditions and more extreme events (Table I and Fig. 7). 
Above all, figures show that predictions of Pelamis, Wave Dragon and Wavestar power productions are acceptable.

2) Combined $P_{\text {prod: }}$ : the last row of Table VII reveals the best forecast occurs when considering the combined production of the three devices. The NBias, NRMSE and SI unbiased $_{\text {improve }}$ compared to those of each single device.

Moreover, not only the quality indices show a more accurate forecast but also a high combined mean production.

Above all, the combined production provides the best compromise between forecast accuracy, as for Pelamis and Wave Dragon, and high mean production, as for Wavestar.

A good overview of forecast accuracy of the WECs' $P_{\text {prod }}$ can be found in Fig. 8 to Fig. 10 .

To compare these, Fig. 11 shows the evolution of the 12 hours forecast $H_{m 0}, T_{02}$ and $P_{\text {wave }}$ and buoy-measured $H_{m 0}, T_{02}$ and $P_{\text {wave }}$ over the same 3 -day period. The three wave parameters oscillate around their mean values, providing a real representation of the typical sea states at Hanstholm during a winter month.

Fig. 8 and Fig. 9 illustrate the differences between forecast $P_{\text {prod }}$ and theoretical $P_{\text {prod }}$ of Pelamis, Wave Dragon and Wavestar, for a T-hour of 12 hours and 36 hours, respectively. The comparison of both figures shows that the best forecast occurs for a T-hour of 12 hours. Here there are some periods where the predictions coincide with the theoretical production. Then, although the errors for the 36-hour forecast are higher, they do not exceed $30 \%$ of inaccuracy.

Wave Dragon shows the lowest errors among the three devices and Wavestar the largest. This can be explained due to the more limited working conditions of Wavestar compared to Pelamis and Wave Dragon (Table II).

Fig. 10 depicts the 12, 24 and 36 hours $P_{\text {prod }}$ forecast and the theoretical $P_{\text {prod }}$ for the combination of the three devices. For most samples the 12 hour forecast is the most accurate.

Then, comparing Fig. 8 to the 12-hour forecast combined $P_{\text {prod }}$ (Fig. 10, dashed dark blue line) and similarly, Fig. 9 to the 36-hour forecast combined $P_{\text {prod }}$ (Fig. 10, dashed green line), it can be concluded that Fig. 10 generally provides smaller errors than Fig. 8 and Fig. 9. In other words, the combined power production results in an overall better forecast accuracy.

The global improvement of the error statistics by the combined power output confirms that the response of each WEC to the wave climate is different.

Moreover, a relevant finding is that the errors in the forecast of wave parameters $H_{m 0}$ and $T_{02}$ do not accumulate but instead cancel-out when calculating the power production of each device. This is a major advantage to take into account in the short future, where the different solutions proposed for wave energy extraction should be considered attractive for the electricity market.

To finalize the discussion, there are three important limitations to this study. First, the selected WECs have been designed for more energetic wave climates than at Hanstholm. Therefore, the performances of the devices at this location are different than from those expected at more powerful sites, and thus, their predictability might be compromised. Moreover, comparisons among the performances of the devices should be avoided and cannot be conclusively drawn from these results, as the power productions shown are merely theoretical.

The second limitation is that the use of three WECs reflects the power production by those devices, which embraces different working principles, but not all existing wave conversion technologies.

The third limitation is that this study is not a resource assessment of Hanstholm site nor of the North Sea. Note the analysed data comprise of a 3-month period.

\section{CONCLUSIONS}

Examining the accuracy of wave energy forecasts plays a major role in the integration of wave energy into the electric grid. Waves predictability is related to the electricity market. Current rules of the Danish day-ahead market require the prediction of the following 12 to 36 hours electricity generation.

According to this, the paper has analysed the correlation of:

i) Forecast and buoy-measured wave parameters;

ii) Forecast based and buoy-measured based normalised power productions of three WECs;

iii) Forecast based and buoy-measured based normalised power productions of a combination of the three WECs.

The simultaneous and co-located forecast and measured wave parameters at Hanstholm site, Denmark, during a noncontinuous autumn and winter 3-month period, along with the power matrices of the devices, have formed the basis of the study.

The selected WECs have been Pelamis, an offshore floating heaving and pitching articulated device, Wave Dragon, an offshore floating overtopping technology, and Wavestar, a near-shore multi-point absorber. They have been chosen due to their differences in their working principles.

Results indicate accuracies (in terms of unbiased scatter index) in the 12 to 36 hours forecast horizon of:

i) $22 \%, 11 \%$ and $74 \%$ for the wave parameters $H_{m 0}, T_{02}$ and $P_{\text {wave }}$, respectively;

ii) $37 \%, 39 \%$ and $54 \%$ for the normalised theoretical power productions of Pelamis, Wave Dragon and Wavestar, respectively; with normalised mean power productions of $0.33,0.33$ and 0.44 .

iii) $36 \%$ for the combined normalised theoretical power production of the three devices, with a normalised mean power production of 0.37 .

The novelties of this study have been first, examining wave parameters predictability; second, comparing forecast based and buoy-measured based power productions; third, considering the individual as well as the combined power output of three different WECs, and fourth, locating the study in the North Sea waters, an area with increasing interest on wave energy. 
Two main conclusions can be drawn from the results: firstly, wave parameters such as $H_{m 0}$ and $T_{02}$ can be predicted accurately in the given energetic sea conditions, and secondly, the combined power production from different wave energy technologies provides the best compromise between forecast accuracy and high mean power production.

The latter finding is particularly important at this stage of development of the wave energy sector: it reveals there will probably be more than one established technology for wave energy utilization, it suggests to diversify R\&D grants among the different technologies, it indicates the strategy to follow within energy planning processes and it provides a good overview on the parameters to be improved to increase predictability of WECs' production.

These conclusions of the paper suggest two further studies. First, the examination of the predictability of combinations of co-located WECs and wind energy turbines. This will address the delay between wave and wind energy and the comparison of the predictability of both sources. The second study will examine the error statistics of the short-term (0-6 hours) forecast, in comparison to the analysed day-ahead forecast. This topic is also of great importance to TSOs' electric grid operation.

Furthermore, the on-going prototype tests at Hanstholm can be used to complement the studies by providing actual power production data.

Last but not least, further improvement is expected on the knowledge of device developers about the power production of their devices. This will ultimately decrease the uncertainty on the power matrices and thus, on the predictability of the actual power to be produced by the devices.

Nevertheless, current rules of the electricity market may have to change to accommodate larger amounts of renewable sources without increasing balancing costs.

\section{ACKNOWLEDGMENT}

The first author gratefully acknowledges the financial support from the European Commission through the 7th Framework Programme (the Marie Curie Initial Training Network WaveTrain2 project, grant agreement number 215414) which made this work possible.

The authors are also very grateful to Pelamis, Wave Dragon and Wavestar, whose inputs to the study have been crucial. Measurements at Hanstholm have been made available courtesy of Kystdirektoratet, Denmark.

\section{REFERENCES}

[1] Nord Pool Spot, "The Nordic Electricity Exchange and the Nordic Model for a Liberalised Electricity Market," Nord Pool Spot, Denmark, 2009.

[2] EREC, "Mapping Renewable Energy Pathways towards 2020," European Renewable Energy Council (EREC), 2011.
[3] IEA, "Innovative Electricity Markets to Incorporate Variable Production," IEA - Renewable Energy Technology Deployment, 2008.

[4] (2011) Pelamis website [Online]. Available: http://www.pelamiswave.com/.

[5] (2011) Wave Dragon website [Online]. Available: http://www.wavedragon.net.

[6] (2011) Wavestar website [Online]. Available: http://www.wavestarenergy.com/.

[7] H.C. Soerensen and J. Fernandez-Chozas, "The Potential for Wave Energy in the North Sea," International Conference on Ocean Energy (ICOE), Spain, 2010.

[8] Ramboll, "Kortloegning af Bølgeenergiforhold $i$ den Danske del af Nordsøen," Ramboll, Dansk Hydraulisk Institut, Danamrsk Meteorologiske Institut, 1999.

[9] Ramboll, "Bølgekraft - forslag til forsoeg og rapportering," Ramboll, 1999.

[10] K. Nielsen and T. Pontes, "Generic and Site-related Wave Energy Data," Final technical report, OES-IEA Document No: T02-1.1., 2010.

[11]L. Margheritini, "Review on available information on waves in the DanWEC area, (DanWEC Vakstforum 2011)," DCE Technical Report No. 135, Aalborg University, 2012.

[12](2011) Danish Wave Energy Centre website. [Online]. Available: http://www.danwec.com/.

[13](2011) DEXA website. [Online]. Available: http://www.dexa.dk/

[14] J. Kirkegaard et al., "Metocean forecasting for ports and terminals," Port Infraestructure Seminar, The Netherlands, 2010.

[15]ECI, "Variability of UK Marine Resources," Environmental Change Institute, University of Oxford, The Carbon Trust, 2005.

[16]F. Fusco, G. Nolan and J.V. Ringwood, "Variability reduction through optimal combination of wind/wave resources - An Irish case study," Energy 35, pp. 314-325, 2010.

[17]L.H. Holthuijsen, "Waves in Oceanic and Coastal Waters, " Cambridge, 2007.

[18] H. C. Soerensen et al., "Bølgekraftanlaeg ved Horns RevScreening (Wave energy deployment at Horns Rev Wind Farm," (partly in Danish), Copenhagen, 2005.

[19] M. Rugbjerg, O.R. Sørensen and V. Jacobsen, "Wave forecasting for offshore wind farms," 9th International Workshop on Wave Hindcasting and Forecasting, Canada, 2006.

[20]E.D. Stoutenburg, N. Jenkins, M.Z. Jacobson, "Power Output Variability of Co-located offshore wind turbines and wave energy converters in California," Renewable Energy, 2010.

[21] R. Gross, et al., "Renewables and the grid: understanding intermittency," Energy 160, pp. 31-41. Proceedings of the Institution of Civil Engineers, 2007. 
Paper H: Economic Benefit of Combining Wave and Wind Power Productions in Day-Ahead Electricity Markets

\author{
Published in \\ Proceedings of the 4th International Conference on Ocean Energy (ICOE), 2012.
}





\title{
Economic Benefit of Combining Wave and Wind Power Productions in Day-Ahead Electricity Markets
}

\author{
J. Fernández-Chozas ${ }^{1}$, H.C. Sørensen ${ }^{2}$ and N. E. Helstrup Jensen ${ }^{3}$ \\ ${ }^{1}$ Department of Civil Engineering, Aalborg University \\ Sohngaardholmsvej 57, 9000 Aalborg, Denmark \\ E-mail:.jfch@civil.aau.dk \\ ${ }^{2}$ SPOK ApS \\ Blegdamsvej 4, 2200 Copenhagen, Denmark \\ E-mail: consult@spok.dk \\ ${ }^{3}$ Energinet Denmark \\ Tonne Kjærsvej 65, 7000 Fredericia, Denmark \\ E-mail: neh@energinet.dk
}

\begin{abstract}
There is usually a cost associated to the integration of non-fully predictable renewables in electricity markets. This cost, named balancing cost, covers the difference between the bid to the dayahead electricity market and the actual power produced.

The objective of the paper is comparing the balancing costs of a diversified system including wind and wave power productions with a system based only on wind power. As a result, the paper estimates the balancing costs of wave converters, which are compared with the current balancing costs of wind turbines. The opportunities of a combined wave and wind scenario compared to the wind-only scenario are examined.

The study is based on day-ahead forecasts and on real-time theoretical power productions from wave converters and wind turbines, throughout a 5month autumn and winter period, at Hanstholm, Denmark.

Results show balancing costs of wave converters are 30 to $45 \%$ smaller than those brought by wind turbines. When wave converters are combined balancing costs keep low, $40 \%$ lower than for wind turbines. Finally, a diversified scenario of wind and wave technologies brings balancing costs 30 to $35 \%$ down compared to the wind-only scenario.

Beyond the technical benefits of diversified scenarios, the paper identifies an economic benefit of combining wind and wave power productions.
\end{abstract}

Keywords: Balancing costs, combined wind and wave, electricity markets, forecast, wind energy, wave energy.

\section{Introduction}

The paper addresses the integration of wave energy into electricity markets, particularly into the day-ahead and the regulating market. It evaluates the associated cost of including non-fully predictable energies in electricity markets and examines the economic benefits of combining wave and wind power productions.

In general terms, the difference between the bids to the day-ahead market and the actual power produced brings extra costs. These costs receive the name of balancing costs and are borne for the following reasons.

Electricity markets were first designed to accommodate predictable conventional generation. Besides hydropower, the contribution from renewable energies was scarce. As the percentage of not-entirelypredictable renewable generation (such as wind or wave power) increases [1], the uncertainty on the planned generation is also rising. This partial unpredictability causes grid operators, producers and/or electricity consumers to cope with the costs of balancing the power, which generally implies large expenditures [2].

Transmission System Operators (TSOs) are the national bodies responsible for operating the grid and assuring the electricity demand is fulfilled. TSOs publish the day-ahead load forecast and plan grid operation before real time, generally one day in advance. In the case of Denmark, the day-ahead electricity market closes at 12 am. Thus, Energinet Denmark as the Danish TSO requires the prediction of the following 12 to 36 hours electricity generation [3]. 
In the regulating market, which starts one hour ahead the actual generation time, the last corrections of imbalances between supply and demand take place. In this market, the actors contributing to the imbalances (i.e. over-producing or under-producing the estimated power) have to cover the costs for balancing the system. In Denmark, these balancing costs are ultimately passed on to Danish electricity consumers.

Consequently, the objective of this paper is to compare current balancing costs of wind production in the Danish electricity market with the balancing costs of a system including wave power production.

A research project by the same authors has evaluated the extent to which wave and wind conditions can be predicted, as well as the accuracy in the predictions of the theoretical power outputs of wave and wind technologies [4]. These results and estimates provide the background data for the present analysis.

The study looks into i) forecast accuracy of the power production of wave and wind technologies, working alone and combined, ii) balancing costs of wave power with respect to balancing costs of wind power, and iii) comparison of average regulation costs of wave power with the average balancing costs of wind power.

Balancing costs of wave power have only been investigated in a study that assesses the reduction of balancing costs in a diversified system including tidal, wave and wind power compared to a system dominated by wind power [5]. By contrast, extensive and recent research has been done on balancing costs of wind power [6-7], a topic highly related to current research on wind forecast [8].

As a result, the novelty of this study is examining the economic benefits of combining wave and wind generating technologies from the point of view of electricity markets.

\section{Methodology}

\subsection{Study period and study location}

The analysis embraces three complete and nonconsecutive months. The overall period covers from end of October 2010 to middle of February 2011. Valid data are from $26 / 10$ to $20 / 11 / 2010$, from $11 / 12 / 2010$ to $13 / 01 / 2011$, and from $16 / 01$ to $09 / 02 / 2011$. Times and dates are expressed in the Coordinated Universal Time (UTC [dd/mm/yyyy]) system.

The research site is Hanstholm, on the West coast of Jutland, Denmark, in the Danish part of the North Sea. The wave climate is dominated by wind seas (mean wave power of $7 \mathrm{~kW} / \mathrm{m}$ ) and wind speeds of $8 \mathrm{~m} / \mathrm{s}$ in average. It is an area with increasing interest on wave and wind energy development.

There is high seasonal variability at Hanstholm. Autumn and winter are the most energetic seasons and spring and summer the least [9-10]. Hence, the selected study period provides a good representation of typical operating conditions for the technologies.

\subsection{Measured and forecast data}

Environmental measurements have been provided by a non-directional Waverider buoy from The Danish Coastal Authority (i.e. Kystdirektoratet), positioned at 474700 East and 6332100 North in the UTM32 system. Data consists of half-hour records of recording time and of the spectral estimates of the significant wave height $\left(H_{m 0}\right)$, the zero-crossing period $\left(T_{02}\right)$ and the maximum wave height. Data have 2 decimals resolution.

Wind measurements are provided by a weather station from Kystdirektoratet. Data consists of tenminute records of recording time, wind speed $\left(u_{\text {wind }}\right)$ and mean wind direction, with 2 decimals resolution. The station is located $20 \mathrm{~m}$ above ground, positioned in the UTM32 system at 475467 East, 6331036 North.

Wave forecasts have been calculated by the spectral wave module of MIKE 21 from the Danish Hydraulic Institute (DHI), a model based on the wave action conservation equation. The forecast reaches 5 days into the future, is calculated every 12 hours and provides half-hour records of the main wave parameters with 2 decimals resolution. Weather forecasts from DHI are also available, providing half-hour records of wind parameters, air temperature and air pressure conditions. Only the 12 to 36 hours ahead forecasts are used for the study.

Buoy measurements and wave and weather forecasts are from the same location, which is about $2 \mathrm{~km}$ Northwest off the harbour, whereas weather data are obtained at the harbour (Figure 1). It is assumed that weather data are recorded at the buoy location, since there is a limited distance between the weather station and the forecast location, and data are in half-hour resolution.

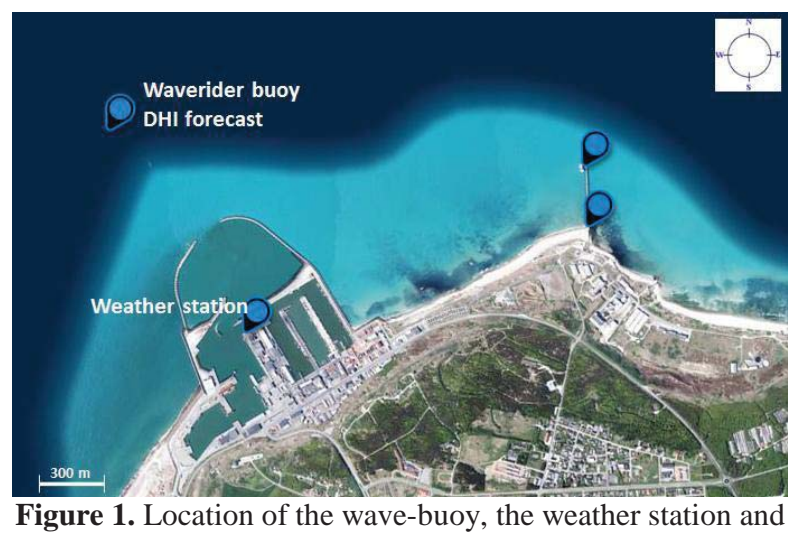

Figure 1. Location of the wave-buoy, the weather station and DHI forecast at Hanstholm, Denmark.

To match weather-station data to forecast wind data, the 10-minute records are expressed as half-hour time series through a weighted average.

\subsection{Wave and wind technologies}

The wave converters selected for the study are Pelamis, a floating heaving and pitching wave converter [11], Wave Dragon, an offshore floating overtopping converter [12], and Wavestar, a near-shore multi-point wave absorber [13]. 
Power productions of the three wave technologies have been modelled with a power matrix that represents the performance of the converter at the study location. The power matrices express the power production as a function of $H_{m 0}$ and $T_{02}$.

The data sets of forecast $H_{m 0}$ and $T_{02}$, and the data sets of buoy-measured $H_{m 0}$ and $T_{02}$, along with the power matrices have been used to develop theoretical time series of forecast power productions $\left(P_{M O D}\right)$ and real-time power productions $\left(P_{O B S}\right)$ for the three wave converters. (Throughout the paper MOD corresponds to modelled or forecast data and OBS to observed data).

Similarly, time series of offshore wind turbine (OWT) productions have been modelled with an offshore wind turbine power curve that represents the power production of a farm of wind turbines as a function of the wind speed [14]. The data sets of forecast $u_{\text {wind }}$ and weather-station $u_{\text {wind }}$ have been used to model forecast and real-time theoretical power productions for the offshore wind turbine $\left(P_{M O D}\right.$ and $P_{O B S}$, respectively).

To allow comparison among power productions, these are expressed as percentages of peak power, i.e. power productions are given as normalized or nondimensional values.

For the combined power production, one normalized unit of the indicated technologies is considered.

\subsection{Danish Electricity Market}

The Danish electricity market is part of the Nord Pool market. There are two markets in Denmark, WestDK (2400 MW) and East-DK (585 MW). Hanstholm belongs to West-DK.

Market data for West and East-DK can be retrieved from Energinet.dk [15]. Data include hourly values of net consumption, system imbalances (deficit and surplus of power), regulating power (upward and downward regulation) and price for balancing power (upward and downward regulation prices).

To match production data from wave and wind technologies to electricity market data, the half-hour records of the former are expressed as hourly time series through a weighted average.

\subsection{Balancing costs calculation}

Balancing costs are calculated by a two-price model that takes into account the direction of the imbalances of the traded power production and the direction of the imbalances of the general power system. Day-ahead forecasts can under-predict or over-predict the real amount of power that is produced. Accordingly, a developer buys or sells the difference between predicted power and real power. Power system imbalances can cause the system to be in excess or in deficit of power. When there is deficit of power upward regulation is needed, whereas excess of power requests downward regulation. The type of system imbalance influences the amount that is charged or paid to the developer.
Therefore, four cases can happen:

if $\left(P_{M O D}-P_{O B S}\right)>0=>$ Developer buys deficit of power If the system is in deficit of power:

$\Rightarrow \mid$ Buying Cost $|=|$ Up. RegPrice $\left.\right|^{*}\left|P_{M O D}-P_{O B S}\right|$

If the system is in excess of power:

$\Rightarrow \mid$ Buying Cost $|=|$ Market Price $\left|{ }^{*}\right| P_{M O D}-P_{O B S} \mid$

if $\left(P_{M O D}-P_{O B S}\right)<0=>$ Developer sells excess of power If the system is in deficit of power:

$\Rightarrow \mid$ Selling Price $|=|$ Market Price $\left|{ }^{*}\right| P_{M O D}-P_{O B S} \mid$

If the system is in excess of power:

$\Rightarrow \mid$ Selling Price $|=|$ Down. Reg. Price $\left|{ }^{*}\right| P_{M O D}-$ $P_{O B S} \mid$

The hourly upward and downward regulation price and the market price are known from [15]. Generally, downward regulation price is lower than market price, and upward regulation price is higher. The hourly errors in the production estimates have also been calculated.

Hence, hourly balancing costs per unit of energy generated are calculated for the entire study period as the sum of the costs for buying deficit of power and the loss of income when selling excess of power generally at a lower price than the market price.

$$
\begin{aligned}
& \text { Balancing Costs }= \\
& =\sum \frac{\mid \text { Up. Reg Price }|*| P_{M O D}-P_{O B S} \mid}{P_{O B S}} \\
& +\sum \frac{\mid \text { Market Price }|*| P_{M O D}-P_{O B S} \mid}{P_{O B S}} \\
& +\sum \frac{\mid \text { Market Price }- \text { Down.Reg Price }|*| P_{M O D}-P_{O B S} \mid}{P_{O B S}} \\
& +\sum \frac{\mid \text { Up.Reg Price }- \text { Market Price }|*| P_{M O D}-P_{O B S} \mid}{P_{O B S}}
\end{aligned}
$$

The corresponding units are:

$$
\begin{aligned}
& \mid \text { Up }- \text { Down }- \text { Market Price } \mid \text { in }[\mathrm{DKK} / \mathrm{MWh}] \\
& \left|P_{M O D}-P_{O B S}\right| \text { in }\left[\mathrm{MWh} / \mathrm{h} * P_{r a t e d}\right] \\
& P_{O B S} \text { in }\left[\mathrm{MWh} / \mathrm{h} * P_{\text {rated }}\right] \\
& \mid \text { Buying Cost }- \text { Selling Price } \mid \text { in }\left[\mathrm{DKK} / \mathrm{h} * P_{\text {rated }}\right] \\
& \text { Balancing costs in }[\mathrm{DKK} / \mathrm{MWh}]
\end{aligned}
$$

An exchange rate of $1 €=7.5 \mathrm{DKK}$ is assumed throughout the study.

\subsection{Balancing costs of wind and wave power}

According to Danish rules (onshore) wind turbines receive a premium on top of the feed-in tariff to balance the power. The premium equals $3 € / \mathrm{MWh}$. In line with this value, [16] shows the average costs of integrating wind in Denmark are 3-4 $€$ /MWh of wind power generated, at a $20 \%$ level of system penetration. Then, the average regulation costs for wind power in West-DK were $3.2 € / \mathrm{MWh}$, with a penetration level in all Denmark of 26\% [17], throughout the study period.

In order to compare balancing costs of wave power to balancing costs of wind power the former can be inferred from the balancing costs of wind. 
It has been assessed wave energy can provide $15 \%$ of Danish electricity demand [18], which can be compared to the current penetration level of wind power. It can also be assumed the transmission and market conditions of wave and wind production are the same, since wind generation is mostly concentrated in West-DK and the potential wave resource is also located in the Danish North Sea.

As a result, if balancing costs of wind power are taken as a reference value, balancing costs of wave power can be calculated. Reference value is chosen at 3 $€ / \mathrm{MWh}$, which coincides with the current balancing premium for wind turbines and is accepted as the average balancing costs for wind power in Denmark.

Therefore, the following calculations assume the upper balancing cost of wind power in West-DK are 3 $€ / M W h$. This assumption allows calculating the balancing costs of any diversified scenario compared to the wind-only scenario.

\subsection{Quality indices}

Verification of forecast data against measured data is quantified by the index Normalised Mean Absolute Error or $N M A E$. It is a non-statistical parameter that provides an absolute measurement of the error. This parameter is normally used by TSOs and grid regulators, in comparison to its counterpart statistical parameter used by academia RMSE, the Root Mean Square of Difference. The reason of using NMAE is that it can be linearly related to a cost per unit of energy generated (i.e. liner relation to EUR/MWh).

The following equation defines $N M A E$. $N$ represents the number of samples and $P_{\text {rated }}$ the rated power of the technology:

$$
N M A E=\frac{1}{P_{\text {rated }} \cdot N} \sum_{i=1}^{N}\left(\left|P_{M O D}-P_{O B S}\right|\right)
$$

\section{Results}

\subsection{Day-ahead forecasts of power productions}

Table 1 shows the errors in the forecast of wave converters and wind turbines power productions. They have been calculated by comparing day-ahead forecasts to real-time theoretical power productions. Errors are evaluated by the quality index $N M A E$ and are given as normalized values. To compare the results among the different technologies the figure NMAE/NMean is also given.

The errors in the predictions are calculated for each technology working alone and combined. The combination of technologies characterizes a diversified energy system. The combined scenarios include: the three wave converters working together, the three converters and the wind turbine, Wavestar and the wind turbine and Wave Dragon and the wind turbine.

\begin{tabular}{lccc}
\hline & NMean & NMAE & $\frac{\underline{\text { NMAE }}}{\text { NMean }}$ \\
\hline Technologies alone & & & \\
\hline Pelamis $(P)$ & $33 \%$ & $11 \%$ & 0.33 \\
Wave Dragon $(W D)$ & $33 \%$ & $9 \%$ & 0.27 \\
Wavestar $(W S)$ & $44 \%$ & $15 \%$ & 0.34 \\
Off. Wind Turbine $(O W T)$ & $32 \%$ & $17 \%$ & 0.53 \\
\hline Technologies Combined & & & \\
\hline $\boldsymbol{P + W D + W S}$ & $37 \%$ & $11 \%$ & 0.29 \\
$\boldsymbol{P + W D + W S + O W T}$ & $36 \%$ & $11 \%$ & 0.30 \\
WS+OWT & $38 \%$ & $14 \%$ & 0.37 \\
WD+OWT & $33 \%$ & $11 \%$ & 0.33 \\
\hline
\end{tabular}

Table 1. Day-ahead power productions predictabilities of wave and wind technologies, working alone and combined, from 26/10/2010 to 09/02/2011 at Hanstholm, Denmark.

Table 1 shows comparable and acceptable forecast accuracies for the three wave converters working alone (despite Wavestar has bigger NMAE value than Pelamis and Wave Dragon its mean power production is also 11 points higher). The error in the forecast for the offshore wind turbine is significantly higher, since its NMean is comparable to that of Wave Dragon or Pelamis.

Hence, day-ahead predictability of wave converters is 35 to $50 \%$ more accurate than day-ahead predictability of wind turbine's production.

In addition, Table 1 suggests that any combination of wave converters power productions (with or without including wind turbine's production) also provides improved day-ahead forecast than the wind-only scenario. Forecast errors get reduced from 30 to $45 \%$.

\subsection{Balancing costs of wind and wave power}

Table 2 presents the average balancing costs for the same technologies and combinations investigated in Table 1. Balancing costs are given as a percentage of the balancing costs of the wind-only scenario and as an absolute value, calculated from the reference value for wind turbines.

\begin{tabular}{lcc}
\hline & \multicolumn{2}{c}{ Balancing costs } \\
$(\%)^{1}$ & $(€ / \mathrm{MWh})^{2}$ \\
\hline Technologies alone & & \\
\hline Pelamis $(P)$ & $72 \%$ & 2.2 \\
Wave Dragon (WD) & $55 \%$ & 1.6 \\
Wavestar (WS) & $71 \%$ & 2.1 \\
Wind Turbine (OWT) & $100 \%$ & 3.0 \\
\hline Technologies Combined & & \\
\hline P+WD+WS & $63 \%$ & 1.9 \\
P+WD+WS+OWT & $64 \%$ & 1.9 \\
WS+OWT & $74 \%$ & 2.2 \\
WD+OWT & $69 \%$ & 2.1
\end{tabular}

${ }^{1}$ Balancing costs as a percentage of the wind-only scenario

${ }^{2}$ Balancing costs assuming a reference cost for wind of $3 € / \mathrm{MWh}$

Table 2. Balancing costs of different systems working at Hanstholm, Denmark, calculated for the period 26/10/2010 to 09/02/2011 
Table 2 reveals the average balancing costs for wave converters working alone are 35 to $45 \%$ lower than for the wind turbine. It also indicates that any combination of wave converters with and without wind turbines reduces balancing costs by a 35 to a $45 \%$ compared to the wind-only scenario.

\section{Discussion}

The most interesting finding is that the inclusion of any wave converter in a scenario dominated by wind significantly reduces the balancing costs. The economic benefit depends on the wave technology and on the considered mix. Overall, costs reduction varies from 30 to $35 \%$ compared to a wind-only scenario.

The reason is that day-ahead forecasts of wave power productions are 35 to $50 \%$ more accurate than for wind turbines (in terms of $N M A E$ ); which in turn depends on that waves are $23 \%$ more predictable than winds, in terms of MAE/Mean [4, 19].

The difference in NMAE for the wave technologies (11\% for Pelamis, 9\% for Wave Dragon and 15\% for Wavestar) depends on their mean power productions (NMean) and on the dependency of the converters to variations of the sea conditions, which has been represented by the power matrices.

The findings of this paper are in line with the results of [5], which conclude that in a diversified scenario comprised of $43 \%$ wind, $52 \%$ wave and $5 \%$ tidal, balancing costs reduce by $37 \%$ compared to the windonly scenario.

It is important to bear in mind two facts about balancing costs. Firstly, balancing costs correspond to $5-7 \%$ of the costs of wind generated electricity and secondly, balancing costs of wind power are low in comparison with the overall balancing costs of the power system, which also deal with un-fulfillment of demand or power plants break-down [6].

However, annual balancing costs represent large expenditures for TSOs, which are passed on to final electricity users. Moreover, penetration level of wind generation is increasing steadily in West-DK. This is the main motivation for the study and the reason why the Danish TSO Energinet Denmark has interest on it.

Lastly, results presented in the paper should be read by taking into consideration the assumptions and limitations behind the study:

First, the study is entirely based on theoretical data. Power productions derive from three power matrices and one power curve, which can represent only to a certain extent the productions from wave arrays or wind farms distributed over a wide area (such as within a $15 \%$ and $20 \%$ penetration level of wave and wind power, respectively).

Second, the study illustrates wind power predictability with the theoretical power production of an offshore wind turbine. This allows the comparison of wind production forecast to wave production forecast, but it does not coincide with the current accuracy level on wind forecasting (e.g. the offshore wind power plant Horns Rev1 located off the West coast of Denmark has a $N M A E=11 \%$ for the period Jan-Feb 2011 [15]). In addition, the errors on offshore wind forecasting are higher than for onshore wind, and currently Denmark is dominated by onshore wind production. And what is more, forecast accuracy also depends on the metocean conditions at the study location and during the study period.

Third, there are constant corrections in power production's estimates from the day-ahead to the regulating market, which have not been considered in the calculations. TSOs are developing complex algorithms for these [7].

Fourth, balancing costs of a generation technology depend both on the type of other generating equipment (to provide the balancing power) available on the grid and on the predictability of the variation in electricity demand (to schedule the use of the least expensive units). Balancing costs also depend on the penetration levels of the technologies, the extent of the balancing area and the system interconnection.

\section{Conclusion}

The paper has investigated the economic benefit that brings a diversified system including wind and wave technologies. It has been demonstrated that combined power productions are more predictable than when wind and wave technologies are working individually; and hence, balancing costs reduce.

Results indicate the costs of balancing wave power are 30 to $45 \%$ smaller than those faced currently by wind power. Results also suggest that any combination of wave technologies have $40 \%$ lower balancing costs than wind power. Then, the combination of wave and wind technologies also reduces balancing costs by a 30 to a $35 \%$, compared to a wind-only scenario.

The study is part of a collaborative project that has investigated the predictability of wave and wind parameters and technologies [4] and the advantages in combining the two power outputs [20]. Project results reveal that every diversified scenario brings economic and technical benefits.

This paper has identified the economic benefit of a diversified system compared to a wave-only or windonly system. In combined scenarios there are also cost reductions by common infrastructures and facilities.

The technical advantages are a less-fluctuating (lesspeaks in the production) and more continuous (reduced periods of zero power output and smooth changes) power output; increased predictability and reduced reserve capacity needed.

To conclude, reduced balancing costs can also be achieved by better knowledge on technologies performance and operation, (which for wave converters will happen through gained operational experience), by more accurate prediction tools, and most importantly, by reducing gate-closure times (i.e. bids based on 4 to 6 hours ahead forecasts instead of on day-ahead forecasts). 


\section{Nomenclature}

$\begin{array}{ll}\text { DKK } & \text { Danish krone } \\ € & \text { Euro } \\ H_{m 0} & \text { significant wave height spectral estimate [m] } \\ N & \text { number of data points } \\ \text { NMAE } & \text { normalized mean absolute error [\% of } P_{\text {rated }} \text { ] } \\ \text { NMean } & \left.\text { normalized mean production [\% of } P_{\text {rated }}\right] \\ \text { OWT } & \text { offshore wind turbine } \\ P & \text { Pelamis } \\ P_{M O D} & \text { forecast power production [MWh/h* } P_{\text {rated }} \text { ] } \\ P_{O B S} & \left.\text { real-time power production [MWh/h* } P_{\text {rated }}\right] \\ P_{\text {rated }} & \text { rated power [MW] } \\ T_{02} & \text { zero crossing-period spectral estimate }[\mathrm{s}] \\ T S O & \text { Transmission System Operator } \\ u_{\text {wind }} & \text { wind speed [m/s] } \\ U T C & \text { Coordinated Universal Time }[\mathrm{dd} / \mathrm{mm} / \mathrm{yyyy}] \\ U T M & \text { Universal Transverse Mercator }[\mathrm{E}, \mathrm{N}] \\ W D & \text { Wave Dragon } \\ W S & \text { Wavestar }\end{array}$

\section{Acknowledgements}

The authors are very grateful to Pelamis, Wave Dragon and Wavestar, whose inputs to the study have been crucial. The authors also gratefully acknowledge the support from Energinet Denmark (PSO project 10791) and the Nord Pool data which made this work possible. Measurements at Hanstholm have been made available courtesy of Kystdirektoratet, Denmark.

\section{References}

[1] EREC (2011). "Mapping Renewable Energy Pathways towards 2020". European Renewable Energy Council (EREC).

[2] IEA (2008). "Innovative Electricity Markets to Incorporate Variable Production" IEA - Renewable Energy Technology Deployment.

[3] Nord Pool Spot (2009). "The Nordic electricity Exchange and the Nordic Model for a Liberalised Electricity Market". Denmark. Nord Pool Spot.

[4] Fernández-Chozas, J., et al. (2011). "Predictability of the Power Output of Three Wave Energy Technologies in the Danish North Sea". Southampton. EWTEC 2011 Proceedings.

[5] ECI (2006). "Diversified renewable energy sources" Carbon Trust, Environmental Change Institute.
[6] Morthorst, P. E., (2007). "Detailed investigation of electricity market rules" Deliverable 4.1 of the TradeWind project.

[7] Litong-Palima, M., et al. (2012). "Wind-induced DayAhead and Hour-Ahead Imbalances in a Power System with a Significant Wind Mix: The Danish Experience". Copenhagen, Denmark. EWEC 2012 Proceedings.

[8] Madsen, H., (2004). "A Protocol for Standardizing the performance evaluation of short-term wind power prediction models" ANEMOS Project, Deliverable 2.3.

[9] Ramboll (1999). "Kortlægning af Bølgeenergiforhold i den Danske del af Nordsøen". Ramboll, Danish Hydraulic Institute, Danish Meteorological Institute.

[10] Cappelen, J. and Jørgensen, B. (1999) "Observed Wind Speed and Direction in Denmark - with Climatological Standard Normals, 1961-90". Danish Meteorological Institute of Transport. ISSN 1399-1388.

[11] Pelamis. [Online] www.pelamiswave.com.

[12] Wave Dragon. [Online] www.wavedragon.net.

[13] Wave Star. [Online] www.wavestarenergy.com.

[14] Soerensen, H.C., et al. (2005). "Bølgekraftanlæg ved Horns Rev - Screening (Wave energy deployment at Horns Rev Wind Farm)”. PSO project 2004: 5705.

[15] Energinet.dk. [Online] www.energinet.dk.

[16] Holttinen, H., (2008). "Estimating the impacts of wind power on power systems - summary of IEA Wind collaboration". Environmental Research Letters, vol. 3.

[17] Vind Energi Danmark. [Online] www.vindenergi.dk.

[18] Kofoed, J.P., (2009)."Ressourceopgørelse for bølgekraft i Danmark". Report 59 for the Klimakommissionen.

[19] Fernández-Chozas, J., (2012) "Progress Report WP 7 Wave resource and forecast. Case study: Predictability of wave parameters at Hanstholm, Denmark". Deliverable 26 to the Wavetrain2 Project.

[20] Fernández-Chozas, J, et al. (2012). “Combined Production of a full-scale Wave Converter and a fullscale Wind Turbine - a Real Case Study". Dublin, ICOE 2012 Proceedings. 